\author{
Universidade de São Paulo \\ Instituto de Física
}

\title{
A formação de aerossóis orgânicos secundários através da interação físico-química de emissões urbanas de Manaus com emissões biogênicas da Floresta Amazônica
}

\author{
Bruno Backes Meller
}

Orientador: Prof. Paulo Eduardo Artaxo Netto

Dissertação de mestrado apresentada ao Instituto de Física como requisito parcial para a obtenção do título de Mestre em Ciências.

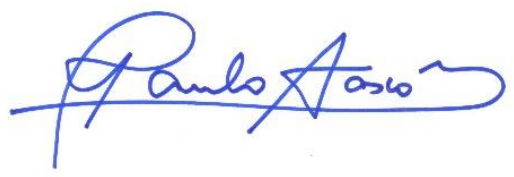

Banca Examinadora:

Prof. Dr. Paulo Eduardo Artaxo Netto (Instituto de Física da USP)

Profa. Dra. Maria de Fatima Andrade (Instituto de Astronomia, Geofísica e Ciências Atmosféricas da USP)

Profa. Dra. Luciana Varanda Rizzo (Universidade Federal de São Paulo) 


\section{FICHA CATALOGRÁFICA \\ Preparada pelo Serviço de Biblioteca e Informação do Instituto de Física da Universidade de São Paulo}

\section{Meller, Bruno Backes}

A formação de aerossóis orgânicos secundários através da interação físicoquímica de emissões urbanas de Manaus com emissões biogênicas da Floresta Amazônica. São Paulo, 2021.

Dissertação (Mestrado) - Universidade de São Paulo, Instituto de Física, Depto. de Física Aplicada.

Orientador: Prof. Dr. Paulo Eduardo Artaxo Netto

Área de Concentração: Física Atmosférica

Unitermos: 1. Espectrometria de massas; 2. Aerossol; 3. Poluição atmosférica; 4. Florestas tropicais. 


\title{
University of São Paulo \\ Institute of Physics
}

\section{The formation of secondary organic aerosols through physical-chemical interaction of urban emissions from Manaus with biogenic emissions from the Amazon Forest}

\author{
Bruno Backes Meller
}

Supervisor: Prof. Paulo Eduardo Artaxo Netto

M.Sc. dissertation submitted to the Physics Institute of the University of São Paulo in partial fulfillment of the requirements for the degree of Master of Science.

Examining Committee:

Prof. Dr. Paulo Eduardo Artaxo Netto (IF-USP)

Profa. Dra. Maria de Fatima Andrade (IAG-USP)

Profa. Dra. Luciana Varanda Rizzo (UNIFESP) 


\section{AGRADECIMENTOS}

Ao Prof. Paulo Artaxo pelo cuidado, tempo e esforço despendidos na orientação e, em especial, pelo trabalho em defesa da ciência de qualidade que certamente me influenciou a continuar na vida científica apesar do período difícil.

À Prof. Samara Carbone pelo incansável apoio em longas reuniões durante estes dois anos de mestrado que me ajudaram muito a desenvolver e interpretar o estudo de espectrometria de massa.

À equipe do LFA que trabalhou arduamente para idealizar, implantar e operar os equipamentos do experimento GoAmazon, dentre eles Fábio Jorge, Fernando G. Morais, Rodrigo A. F. de Souza, Rosa M. Nascimento, Delano Campos, Bruno Takeshi, Samara Carbone, Joel Brito, Luciana V. Rizzo, Henrique M. J. Barbosa e Paulo Artaxo.

Aos amigos e colegas de pesquisa do Laboratório de Física Atmosférica, que tanto contribuíram para todas as fases deste trabalho direta ou indiretamente e sempre animaram as reuniões semanais.

Aos amigos que passaram e que ficaram na minha equipe esportiva do coração, Demônios de Maxwell Rugby, por serem os melhores companheiros que eu poderia ter durante esta fase da minha vida, em especial ao Gabriel e ao Roger, que estiveram pessoalmente ao meu lado durante todo meu caminho na universidade.

À Maria Paula pelos sorrisos, sua força, pela construção de tantos anos e por sempre me fazer acreditar que eu era capaz.

À minha mãe Mônica e irmã Priscila pelo amor incondicional e por todo o esforço e sacrifício para que eu possa ter chegado aqui.

Ao CNPq pela bolsa de estudos 133393/2019-4 durante os dois anos de mestrado.

À FAPESP pelo financiamento aos projetos temáticos 2013/05015-0 e 2017/17047-0. 


\section{RESUMO}

Os impactos de emissões antrópicas na Floresta Amazônica vêm sendo objetos de estudo de campanhas de medidas nas últimas décadas, como o Experimento GoAmazon2014/15, que utilizou dados de múltiplos sítios experimentais para estudar a interação dos compostos emitidos pela área urbana de Manaus com as condições atmosféricas e compostos existentes naturalmente na atmosfera amazônica. Este trabalho focou em observar a abundância e características de poluentes atmosféricos da cidade de Manaus (UEA, sítio T1) e sua evolução vento abaixo, focando condições de pluma pouco envelhecida (Hotel Tiwa, sítio T2), cerca de $14 \mathrm{~km}$ vento abaixo de $\mathrm{T} 1$, fora da cidade, durante a temporada chuvosa dos anos de $2014 \mathrm{e}$ 2016. O estudo abrangeu medidas de concentração de gases traço, de compostos orgânicos voláteis (COVs) medidas por um PTR-MS, além de composição química de partículas medida por dois espectrômetros de massa (ToF-ACSM e Q-ACSM). Também determinamos propriedades físicas como distribuição de tamanho de partículas e propriedades ópticas de aerossóis. Observamos no centro de Manaus que grande parte dos poluentes medidos como CO, $\mathrm{SO}_{2}$, black carbon (BC), benzeno, tolueno e COVs aromáticos $\mathrm{C}_{8}$ estão fortemente associadas a emissões de tráfego. Foi observada baixa produção fotoquímica de ozônio em comparação a outras metrópoles, com níveis de $12 \mathrm{ppb}$ ao meio do dia. $\mathrm{Na}$ análise química do material particulado fino $\left(\mathrm{PM}_{1}\right)$ observado no centro da cidade, de $5.3 \mu \mathrm{g} / \mathrm{m}^{3}$, temos a maior parte composta por material orgânico (59\%), BC (33\%), com uma baixa fração de compostos inorgânicos secundários $(<10 \%)$ como sulfato e nitrato. Na componente orgânica, cerca de dois terços da massa foi relacionada a fontes primárias, sendo estas emissões de tráfego (21\%), de cozinha (22\%) e de queima de biomassa (22\%), enquanto 35\% são de origem secundária oxidada (OOA). Nas propriedades óticas, observamos um baixo albedo de espalhamento único (SSA) em $637 \mathrm{~nm}$ de 0.58 e índice de refração efetivo calculado de $\mathrm{m}=1.65-\mathrm{i}^{*} 0.18$. Estes resultados mostram um baixo nível de compostos secundários na atmosfera, com poluentes recém emitidos e com forte características de absorção de radiação. Observamos uma grande diferença entre poluentes medidos nos dois sítios (T1 e T2), distantes somente 14 km entre si. Significativo processo de diluição e deposição foi observado em T2 para poluentes primários, com concentrações de 2 a 3 vezes menores do que no centro de Manaus, e diminuição de COVs por fatores de até 8 vezes menor, mostrando forte e rápido consumo destas espécies. Para alguns poluentes secundários como ozônio observou-se rápida produção fotoquímica, com aumento de 10 ppb entre os dois sítios. Quanto ao $\mathrm{PM}_{1}$, importantes mudanças foram observadas: maior concentração relativa de espécies secundárias como sulfato, de 4\% para 12\% do total, e OOA, de $35 \%$ para $45 \%$ da fração dos orgânicos; intensa oxidação da fração orgânica, com razão de oxigênio para carbono aumentando cerca de $70 \%$, e aumento do diâmetro geométrico médio de 25nm. Também se observou no sítio T2 significativa frequência de eventos de formação de nanopartículas, em 19\% dos dias medidos. Quanto às propriedades ópticas, observamos aumento da componente espalhadora, com SSA medido em $637 \mathrm{~nm}$ aumentando de 0.58 no sítio T1 para 0.67 no sítio T2. Estas mudanças rápidas na composição do aerossol, na produção de ozônio e demais mudanças atmosféricas devem estar ocorrendo em várias áreas urbanas da África e Ásia, com impactos importantes na poluição do ar e nos ecossistemas.

Palavras-chave: partículas de aerossóis; Amazônia; Poluição do ar urbana; Espectrometria de massa; Aerossol orgânico secundário. 


\begin{abstract}
Several measurement campaigns in recent decades have studied the impacts of anthropic emissions in the Amazon Forest. The GoAmazon2014/15 experiment used data from multiple experimental sites to study the interaction of compounds emitted by the urban area of Manaus with atmospheric conditions and compounds naturally occurring in the Amazonian atmosphere. This work focused on observing the abundance and other characteristics of air pollutants emitted by the city of Manaus (UEA, site T1) and its evolution downwind, focusing on conditions of fast plume aging (Hotel Tiwa, site T2), about 14km downwind of T1, outside the city, during the Amazon wet season of the years 2014 and 2016. The study covered measurements of trace gas concentrations, volatile organic compounds (VOCs) measured by a PTR-MS, as well as the chemical composition of particles measured by two mass spectrometers (ToF-ACSM and Q-ACSM). We also determine physical properties like particle size distribution and optical properties of aerosols. In the center of Manaus, we observed that many of the pollutants measured as $\mathrm{CO}, \mathrm{SO} 2$, black carbon (BC), benzene, toluene, and $\mathrm{C} 8$ aromatic VOCs are strongly associated with traffic emissions. Low photochemical ozone production was observed compared to other cities, with levels of $12 \mathrm{ppb}$ at midday. In the chemical analysis of the fine particulate material (PM1) observed in the city center, of $5.3 \mu \mathrm{g} / \mathrm{m} 3$, we have the majority composed of organic material (59\%), BC (33\%), with a low fraction of secondary inorganic compounds $(<10 \%)$ as sulfate and nitrate. Traffic emissions $(21 \%)$, cooking $(22 \%)$, and biomass burning (22\%) were identified in the organic component, representing primary sources, while $35 \%$ are secondary and highly oxidized (OOA). In optical properties, we observed a low single scattering albedo (SSA) at $637 \mathrm{~nm}$ of 0.58 and calculated an effective refractive index of $m=1.65-i^{*} 0.18$. These results show a low level of secondary compounds in the atmosphere, with newly emitted pollutants and strong radiation absorption characteristics. We observed a significant difference between pollutants measured at the two sites (T1 and T2), only $14 \mathrm{~km}$ apart. A significant dilution and deposition process was observed in $\mathrm{T} 2$ for primary pollutants, with concentrations 2 to 3 times lower than in the center of Manaus, and a decrease in VOCs by a factor as high as 8, showing fast and robust consumption of these species. For some secondary pollutants such as ozone, rapid photochemical production was observed, with an increase of $10 \mathrm{ppb}$ between the two sites. As for $\mathrm{PM}_{1}$, significant changes were observed: higher relative concentration of secondary species such as sulfate, from $4 \%$ to $12 \%$ of the total, and OOA, from $35 \%$ to $45 \%$ of the organic fraction; intense oxidation of the organic fraction, with some oxygen to carbon ratio increasing by about $70 \%$, and an increase in the mean geometric diameter of $25 \mathrm{~nm}$. A significant frequency of nanoparticle formation events was observed at the T2 site in 19\% of the measured days. As for the optical properties, we observed an increase in the scattering component, with SSA measured at $637 \mathrm{~nm}$ increasing from 0.58 at the $\mathrm{T} 1$ site to 0.67 at the $\mathrm{T} 2$ site. These rapid changes in aerosol composition, ozone production and other atmospheric changes are likely to be occurring in various urban areas in Africa and Asia, with major impacts on air pollution and ecosystems.
\end{abstract}

Keywords: aerosol particles; Amazonia; urban air pollution; mass spectrometry; secondary organic aerosol. 


\section{Lista de figuras}

Figura 1.1 - Diagrama da forçante radiativa global em $\mathrm{W} / \mathrm{m}^{2}$ associada a cada espécie química, contendo gases e partículas, além de mudanças do uso do solo e da irradiância solar natural. A forçante é relativa a mudanças em 2010 relativas a 1750. Observamos também na coluna à direita a mediana, os intervalos de confiança e o nível de confiabilidade da estimativa (Fonte: IPCC 2013).

Figura 1.2 - Esquema mostrando a complexidade dos processos que regulam a composição atmosférica e sua relação com o clima da Amazônia. As emissões de gases biogênicos pela floresta (tais como monoterpenos, isopreno e outros) produzem partículas secundárias que tem o potencial de alterar processos hidrológicos e o balanço de radiação atmosférica. As partículas de aerossóis biogênicas são também emitidas diretamente sob a forma de grãos de pólen, bactérias, fragmentos de folhas, excrementos e fragmentos de insetos. Fonte: Barth et al., 2005 .

Figura 1.3 - Série temporal da taxa anual de desmatamento na Amazônia desde a 1977 até 2020 em km² por ano (extraído de INPE PRODES, 2020).

Figura 1.4 - Série temporal do número de focos de incêndio na Amazônia de 1998 a 2020, de acordo com dados do programa queimadas do INPE (extraído de http://queimadas.dgi.inpe.br/queimadas/portal), .................................................................... Figura 1.5 - Interações entre o clima global, uso da terra, fogo, hidrologia, ecologia e dimensões humanas. As forçantes estão indicadas nos ovais vermelhos; os processos abordados estão indicados nas caixas verdes e flechas; e as consequências socioeconômicas são indicadas nas caixas azuis (extraído de Davidson et al., 2012.)

Figura 1.6 - Ilustração do ciclo de vida interrelacionado de aerossóis, nuvens e precipitação na atmosfera terrestre, que mostra os processos atmosféricos sofridos pelas partículas atmosféricas e suas influências (extraído de ASR 2019).

Figura 1.7 - Processos que ligam as emissões de COVs na Amazônia e a produção de novas partículas na alta troposfera. Figura de Andreae et al., (2017).

Figura 3.1 - Imagem de satélite da localização dos sítios de amostragem utilizados no experimento GoAmazon, em especial os sítios T1 (Manaus) e T2 (margem oposta do Rio Negro), que serão os focos deste projeto de mestrado. Em azul está a direção média do vento na estação meteorológica do INMET durante o período amostrado, que mostra direção preferencial do vento vindo de nordeste e leste. 
Figura 3.2 - Foto do sítio experimental T2 do experimento GoAmazon 2014/15, na margem no Rio Negro, oposta à cidade de Manaus.

Figura 3.3 - (a) Precipitação acumulada mensal para o sítio meteorológico do INMET em Manaus, para os anos de 2014 (barras vermelhas), 2016 (barras azuis), e a média climatológica durante o período de 1961 a 1990 (pontos pretos). (b) Distribuição acumulada de precipitação diária nos dois anos.

Figura 3.4 - Esquema do contador de partículas por condensação (CPC), que mostra o mecanismo pelo qual as partículas entram em contato com um meio supersaturado e crescem. Então, são contadas opticamente por um sistema de laser e sensor de luz (extraído de http://www.cas.manchester.ac.uk/restools/instruments/aerosol/cpc/).

Figura 3.5 - Esquema do SMPS, instrumento que mede a distribuição de tamanho de partículas, por meio da seleção de mobilidade elétrica do DMA.

Figura 3.6 - Esquema de um nefelômetro, em que os aerossóis ao atravessar a câmara principal são iluminados por uma lâmpada em uma faixa de quase $180^{\circ}$ e espalham radiação, que é focada por uma lente e passa por filtros dicroicos antes de ser detectada (extraído de TSI Inc.).

Figura 3.7 - Esquema do PTR-MS, espectrômetro de massa com detector do tipo quadrupolo que mede concentrações de COVs, gases orgânicos precursores de partículas, através da ionização por transferência protônica ao COV e subsequente detecção em um detector quadrupolo (extraído de YERETZIAN et al., 2002).

Figura 3.8 - Esquema do ACSM-Q, espectrômetro de massa com detector do tipo quadrupolo, com lentes aerodinâmicas que focam o feixe de partículas que entram pelo inlet e são vaporizados e ionizados para permitir a detecção eletromagnética por meio de um detector quadrupolo (extraído de NG et al., 2011).

Figura 3.9 - Esquema do espectrômetro de massa ToF-ACSM, mostrando projeto semelhante ao espectrômetro quadrupolo e um detector do tipo tempo de voo que garante uma diminuição significativa da incerteza, reduzindo limites de detecção e aumentando a resolução do espectro de massa (extraído de FRÖHLICH et al., 2013).

Figura 3.10 - Menu principal do workflow 1. À esquerda, em cinza as etapas opcionais e em amarelo as etapas obrigatórias. À direita, os usuários podem selecionar uma lista de arquivos com dados diários na aba "Files" ou outras máscaras temporais determinadas pelo usuário na aba "Ranges \& masks (to-do)".

Figura 3.11 - Menu da calibração de massa. É possível refinar a calibração padrão dos arquivos e aplicar esta nova configuração dia a dia ou em maiores resoluções de tempo.......35 
Figura 3.12 - Menu para refinar a linha de base, em azul, que atua como zero do detector, já que este apresenta saturação próximo a fragmentos com sinal intenso. O principal parâmetro a ser determinado é o 'Width', a largura da janela em que será aplicado o algoritmo descrito abaixo.

Figura 3.13 - Menu para refinar o formato e a largura dos picos que servirão para a integração.

Figura 3.14 - Menu do workflow 2, que permite fazer as correções e diagnósticos finais para gerar as séries temporais das componentes do particulado fino.

Figura 3.15 - Menu de correção de airbeam, diagnósticos e conversão para concentração em massa.

Figura 3.16 - Menu de exportação da matriz de sinal e incerteza dos fragmentos orgânicos utilizados para algoritmos de PMF

Figura 3.17 - Menu de estimativa de ruído eletrônico.

Figura 3.18 - Comparação entre medidas de NR-PM1 do ACSM e estimativa de NR-PM1 a partir de dados dos SMPS/Aetalometro para o Q-ACSM.

Figura 3.19 - Menu principal do software de processamento e análise do ACSMQuadrupolo.

Figura 3.20 - Ajuste da dependência espectral da transmissão relativa de íons (RIT), que acontece somente para este tipo de detector.

Figura 3.21 - Comparação entre medidas de NR-PM1 do ACSM e estimativa de NR-PM1 a partir de dados dos SMPS/Aetalometro para o Q-ACSM.

Figura 4.1 - Perfil diário do $\mathrm{CO}$ (esquerda, em azul) e $\mathrm{SO}_{2}$ (direita, em laranja), com estatística a cada $30 \mathrm{~min}$, mostrando em linhas sólidas as medianas e em áreas semitransparentes mostram o intervalo interquartil (entre os percentis 0.25 e 0.75). Ambos os perfis diários acompanham os picos de transporte matutino e no início do período noturno de Manaus

Figura 4.2 - Gráfico de dispersão e ajuste linear entre Benzeno, Tolueno, Aromáticos de 8 carbonos e monóxido de carbono, um traçador de emissões veiculares.

Figura 4.3 - Distribuição de tamanho de número de partículas para cada moda no sítio T1. A moda de nucleação está exposta em verde, a moda de Aitken em azul, a moda de acumulação em vermelho e a mediana de toda a distribuição em preto. A mediana dos dados é indicada pela linha cheia, enquanto o IIQ é indicado pelas áreas semitransparentes 
Figura 4.4 - Mediana do ciclo diurno da concentração de número de partículas no T1 para cada moda, com estatística horária. A moda de nucleação está indicada em verde, a moda de Aitken em azul e a moda de acumulação em preto.

Figura 4.5 - No gráfico superior está a série temporal da composição do $\mathrm{PM}_{1}$ em médias a cada 30 minutos para o sítio no centro de Manaus, $\mathrm{T} 1$, em $\mu \mathrm{g} / \mathrm{m}^{3}$. No gráfico inferior está a mesma série temporal em sua forma fracionária, mostrando claramente a dominância dos orgânicos na composição química dos aerossóis, seguido do BC. A componente orgânica é mostrada em verde, sulfato em vermelho, nitrato em azul, amônio em amarelo, cloreto em rosa e na linha pontilhada cinza a comparação com o $\mathrm{PM}_{1}$ derivado das medidas de volume do SMPS

Figura 4.6 - À esquerda, ciclo diurno das diferentes componentes químicas do $\mathrm{PM}_{1}$, e à direita a composição fracionária do $\mathrm{PM}_{1}$ no centro de Manaus. Os aerossóis orgânicos estão indicados em verde, $\mathrm{BC}$ em preto, sulfato em vermelho, nitrato em azul, amônio em amarelo e cloreto em rosa.

Figura 4.7 - À esquerda, espectros de massa dos 4 fatores de aerossóis orgânicos da moda fina encontrados na análise PMF no sítio T1. O eixo horizontal representa os fragmentos com determinado $\mathrm{m} / \mathrm{z}$, enquanto o vertical mostra a fração da contribuição relativa de cada íon em relação ao fator. À direita, perfis diurnos da concentração associada aos fatores à esquerda, com a mediana representada pela linha sólida e a amplitude interquartil representada pela região semitransparente.

Figura 4.8 - Fração de contribuição de cada fator para a massa de aerossóis orgânicos da moda fina $\left(\mathrm{PM}_{1}\right)$ durante a temporada chuvosa em $\mathrm{T} 1$.

Figura 4.9 - Série temporal dos coeficientes ópticos de espalhamento, em laranja, e absorção, em azul, de particulado fino em $637 \mathrm{~nm}$.

Figura 4.10 - O gráfico superior mostra o resultado da regressão multilinear da composição química do $\mathrm{PM}_{1}$ aplicada no coeficiente de espalhamento óptico para cada componente: orgânicos em verde, sulfato em vermelho, nitrato em azul e uma constante em preto. $\mathrm{O}$ gráfico inferior mostra a comparação entre o total de espalhamento dado pela regressão, em verde, e as medidas diretas de espalhamento óptico, em preto.

Figura 4.11 - Resultado da qualidade das simulações utilizando a biblioteca libRadtran e a série temporal de distribuição de tamanho de partículas. A região mais escura é a que minimiza o resíduo entre o modelo e as observações. 
Figura 5.1 - Perfil diários das razões de mistura de $\mathrm{CO}$ e $\mathrm{SO}_{2}$ para o sítio T2, mostrando a mediana das concentrações para cada horário em linhas sólidas e o intervalo interquartil representados pelas faixas semitransparentes.

Figura 5.2 - Perfil diário do $\mathrm{O}_{3}$ nos sítios do centro de Manaus (T1; azul) e margem do Rio Negro (T2; laranja). A linha cheia indica a mediana de cada 30min e a faixa semitransparente o IIQ. Observa-se uma grande diferença na concentração de ozônio conforme a pluma urbana deixa a cidade, chegando a produção rápida de $\sim 10$ ppb no pico.. 79 Figura 5.3 - Distribuição espacial das concentrações médias de ozônio durante o período diurno (7h-18h), obtida através de simulação no modelo regional WRF-Chem mostrando o impacto da pluma vento abaixo de Manaus (extraído de NASCIMENTO et al., 2021).........80 Figura 5.4 - Distribuição de tamanho de número de partículas para o sítio T1 (em laranja) e T2 (em azul) e ATTO (em verde). A mediana dos dados é indicada pela linha cheia, enquanto a linha pontilhada são ajustes de distribuições lognormais para cada moda, e as referências são indicadas por sequências de linhas e pontos.

Figura 5.5 - Distribuição de tamanho de número de partículas para cada moda no sítio T2. A moda de nucleação está exposta em verde, a moda de Aitken em azul, a moda de acumulação em vermelho e a mediana de toda a distribuição em preto. A mediana dos dados é indicada pela linha cheia, enquanto o IIQ é indicado pelas áreas semitransparentes.

Figura 5.6 - Ciclo diurno da concentração de número de partículas no T2 para cada moda, com estatística horária. A moda de nucleação está indicada em verde, a moda de Aitken em azul e a moda de acumulação em preto.

Figura 5.7 - Distribuição de tamanho de aerossóis de alguns episódios de formação e crescimento de partículas durante o período da tarde com diferentes taxas de crescimento, partindo de tamanhos próximos a $10 \mathrm{~nm}$ a até $50 \mathrm{~nm}$

Figura 5.8 - Acima, a série temporal da composição do $\mathrm{PM}_{1}$ em médias a cada 30 minutos para o sítio T2. Abaixo, a série temporal da fração em massa das componentes do $\mathrm{PM}_{1}$, mostrando a dominância dos orgânicos na composição química dos aerossóis e a presença mais relevante do sulfato neste sítio.

Figura 5.9 - Composição química das frações do $\mathrm{PM}_{1}$, nos dois sítios amostrados, T1 e T2, com orgânicos em verde, $\mathrm{BC}$ em preto, sulfato em vermelho, nitrato em azul, amônio em amarelo e cloreto em rosa. A comparação mostra um aumento relativo no sulfato e diminuição de black carbon

Figura 5.10 - Análise da oxidação do aerossol no sítio T2. À esquerda o gráfico triangular da fração relacionada ao íon 43 e da fração relacionada ao íon 44, mostrando que as 
partículas entre T1 e T2 sofreram significativo processo de envelhecimento. À direita o boxplot da razão entre o conteúdo de oxigênio e carbono da fração fina do aerossol para a série temporal dos dois sítios.

Figura 5.11 - À esquerda, perfis dos 4 fatores de aerossóis orgânicos da moda fina encontrados na análise PMF no sítio T1. O eixo horizontal representa os fragmentos com determinado $\mathrm{m} / \mathrm{z}$, enquanto o vertical mostra a fração da contribuição relativa de cada íon em relação ao fator. À direita, perfis diurnos da concentração associada aos fatores à esquerda, com a mediana representada pela linha sólida e a amplitude interquartil representada pela região semitransparente.

Figura 5.12 - Fração de contribuição de cada fator para a massa de aerossóis orgânicos finos.

Figura 5.13 - Boxplots da série temporal de médias de 30 min das razões de enriquecimento (ER) com a comparação entre sítio T0a (ATTO), T1 e T2, mostrando em vermelho as medianas, nas caixas azuis o intervalo interquartil e entre as linhas tracejadas o intervalo de percentil $0.25-1.5^{*}$ IIQ e percentil $0.75+1.5^{*}$ IIQ, limite usado para outliers.

Figura 5.14 - Boxplots da série temporal de média de 30 min dos coeficientes de absorção e espalhamento com a comparação entre os sítios T1 e T2, mostrando em vermelho as medianas, nas caixas azuis o intervalo interquartil e entre as linhas tracejadas o intervalo de percentil $0.25-1.5^{*}$ IIQ e percentil $0.75+1.5^{*}$ IIQ, limites para outliers, e em vermelho os dados fora desses limites.

Figura 5.15 - Série temporal do albedo de espalhamento único (SSA) nos sítios T1 e T2 mostrando aerossóis com capacidade alta de absorver luz em ambos os sítios, e variações maiores no $\mathrm{T} 2$. 


\section{Lista de tabelas}

Tabela 1 - Comparação entre os dados meteorológicos diários para o período estudado (fevereiro a abril), mostrando os valores médios e entre parênteses o intervalo interquartil. Dados da estação meteorológica do INMET.

Tabela 2 - Instrumentação utilizada em cada sítio foco deste trabalho.

Tabela 3 - Estatística descritiva da média de 30 min da concentração de espécies químicas e propriedades físicas de partículas dos dois sítios de amostragem - T1, centro de Manaus, e T2, Hotel Tiwa - durante os meses de fevereiro a abril de 2016 e 2014, respectivamente. 52

Tabela 4 - Estatística descritiva da média de 30 min da razão de mistura de gases dos dois sítios de amostragem - T1, centro de Manaus, e T2, Hotel Tiwa - durante os meses de fevereiro a abril de 2016 e 2014, respectivamente, com unidades de ppbv

Tabela 5 - Estatística descritiva da média de $30 \mathrm{~min}$ de propriedades físicas de partículas dos dois sítios de amostragem, T1, centro de Manaus, e T2, Hotel Tiwa - durante os meses de fevereiro a abril de 2016 e 2014 , respectivamente.

Tabela 6 - Eficiências de espalhamento das espécies de particulado fino no sítio de Manaus (T1) 


\section{Lista de abreviaturas e siglas}

$\sigma_{\mathrm{e}}$

$\sigma_{\mathrm{a}}$

ACSM

ATTO

ати

$\mathrm{BC}$

$\mathrm{BCe}$

$\mathrm{CN}$

$\mathrm{CCN}$

COV

Dp

DGM

IES

IIQ

$\mathrm{MW}_{\mathrm{S}}$

NPF

$P M_{1}$

PMF

RIES $_{S}$

SSA

SOA
Coeficiente de espalhamento óptico

Coeficiente de absorção óptico

Aerosol Chemical Speciation Monitor

Amazon Tall Tower Observatory

Atomic Mass Unit

Black Carbon

Equivalente em Black Carbon

Concentração de número de partículas atmosféricas

Cloud Condensation Nuclei

Composto Orgânico Volátil

Diâmetro de partícula

Diâmetro Geométrico Médio

Ionization Efficiency of species $s$

Intervalo interquartil

Molecular Weight of species $s$

New Particle Formation

Material Particulado fino com diâmetro menor do que $1 \mu \mathrm{m}$

Positive Matrix Factorization

Relative Ionization Efficiency of species $s$

Single Scattering Albedo

Secondary Organic Aerosol 


\section{SUMÁRIO}

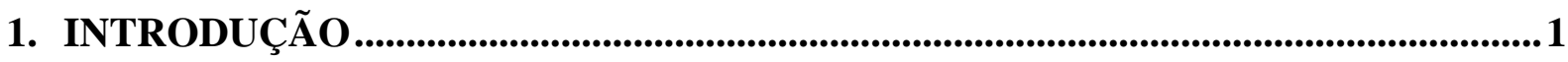

1.1 A BACIA AMAZÔNICA E SUAS INTERAÇÕES COM O CLIMA ..................................... 3

1.2 AEROSSÓIS ATMOSFÉRICOS E PROCESSOS QUE REGULAM SUA CONCENTRAÇÃO

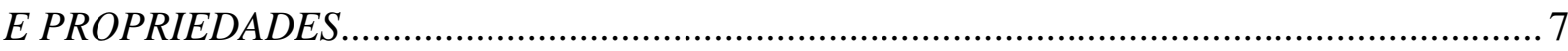

1.3 AEROSSÓIS ATMOSFÉRICOS NA AMAZÔNIA …...................................................... 9

1.4 INTERAÇÃO DA POLUIÇÃO DO AR URBANA COM EMISSÕES NATURAIS ............. 11

1.4.1 O Experimento GoAmazon 2014/15 ….......................................................................... 14

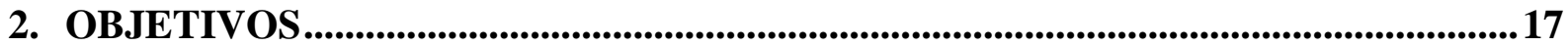

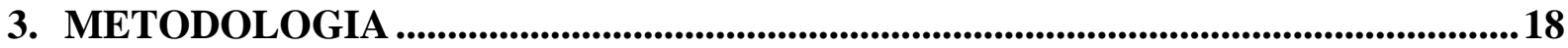

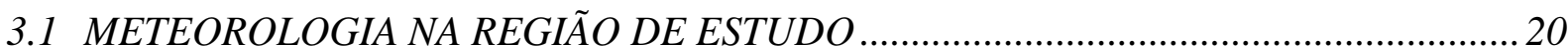

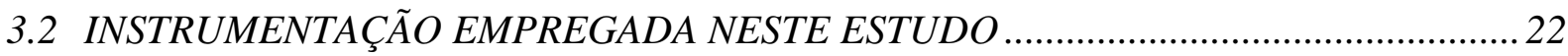

3.2.1 Medidas do número de partículas pelo contador de partículas por condensação

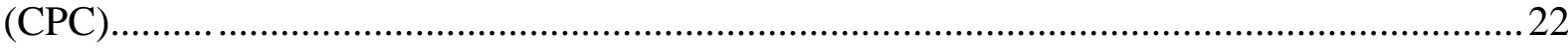

3.2.2 Medida da distribuição de tamanho de partículas por SMPS .......................................23

3.2.3 Medidas de espalhamento óptico de aerossóis pelo nefelômetro ..................................24

3.2.4 Medidas de absorção óptica de aerossóis pelo Aetalômetro .........................................25

3.2.5 Composição química de compostos orgânicos voláteis - COVs.....................................26

3.2.6 Composição química de aerossóis medida com espectrômetro de massa (ACSM)...... 27

3.3 PROCESSAMENTO DE DADOS DOS ESPECTRÔMETROS DE MASSA DE

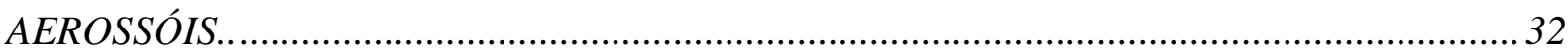

3.3.1 O espectrômetro de massa de aerossóis ToF-ACSM ....................................................33

3.3.1.1 Validação de dados do espectrômetro ToF-ACSM ................................................... 42

3.3.2 Processamento de dados pelo espectrômetro de aerossóis Q-ACSM ............................. 44

3.3.2.1 Validação de dados do espectrômetro Q-ACSM ....................................................... 48

3.4 ANÁLISE DE FATORAÇÃO DE MATRIZ POSITIVA (PMF) DO ESPECTRO DE

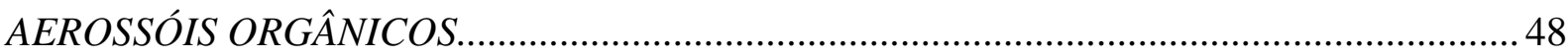

3.5 A BIBLIOTECA DE PROPRIEDADES ÓTICAS LIBRADTRAN ...................................... 50

4. PROPRIEDADES FÍSICO-QUÍMICAS DE AEROSSÓIS E GASES NO CENTRO DE MANAUS (SÍTIO T1) .............................................................................................51

4.1 AS CONCENTRAÇÕES DE GASES ATMOSFÉRICOS NO CENTRO DE MANAUS.... 54 


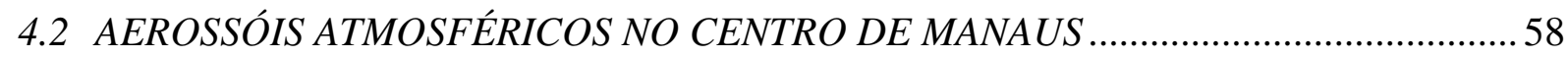

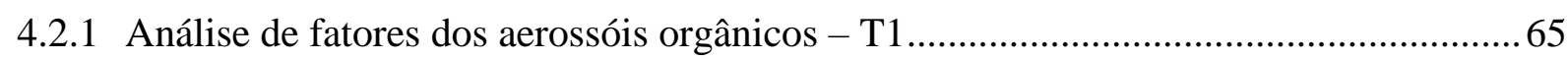

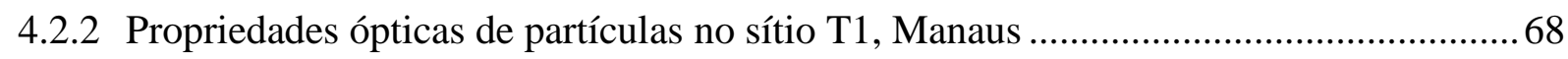

4.2.2.1 Regressão do coeficiente de espalhamento aplicado à composição do $\mathrm{PM}_{1} \ldots \ldots \ldots \ldots . . . . .70$

4.2.2.2 Determinação do índice de refração dos aerossóis da moda fina de Manaus ..............72

5. ESTUDO DA PLUMA URBANA VENTO ABAIXO DE MANAUS (SÍTIOS T2 E

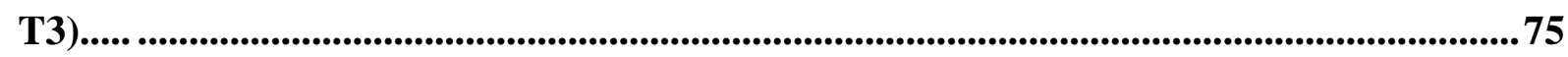

5.1 POLUENTES GASOSOS EM REGIÕES INFLUENCIADAS PELA PLUMA URBANA DE

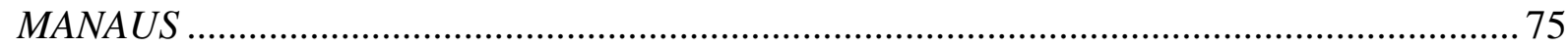

5.2 CONCENTRAÇÃO E PROPRIEDADES DE PARTÍCULAS ATMOSFÉRICAS NO

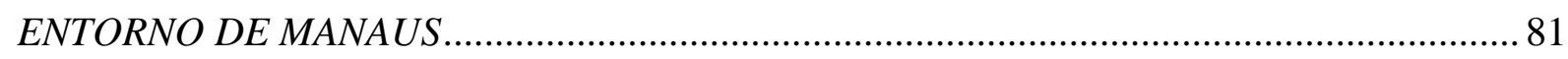

5.2.1 Análise de fatores dos aerossóis orgânicos - sítio T2 .............................................. 90

5.2.2 Comparação de razões de enriquecimento utilizando CO como traçador .....................92

5.2.3 Comparação das propriedades ópticas de aerossóis observadas vento abaixo de Manaus 95

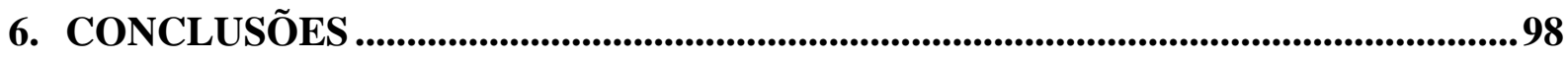

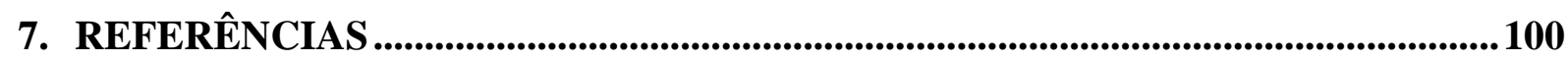

APÊNDICE A - ARTIGOS PUBLICADOS OU EM DESENVOLVIMENTO..............110

APÊNDICE B - TRABALHOS APRESENTADOS EM CONGRESSOS ......................110

APÊNDICE C - PAPER PUBLICADO_.......................................................................112 


\section{INTRODUÇÃO}

O sistema climático global interage fortemente com os oceanos e com os ecossistemas terrestres, e esta interação está sofrendo uma série de mudanças devido à atuação humana (IPCC AR5). As concentrações atmosféricas de gases de efeito estufa e de partículas de aerossóis estão aumentando significativamente desde a revolução industrial, e nosso planeta está em processo de forte aquecimento, e alterações na precipitação e na frequência e intensidade de eventos climáticos extremos.

As partículas de aerossóis têm efeitos diretos e indiretos no clima global e regional (BOUCHER et al., 2013). Os efeitos diretos são de interação da radiação solar com as partículas, resultando em espalhamento e absorção ópticos da radiação, cujo resultado líquido global é a redução da temperatura (resfriamento) na superfície. Os efeitos indiretos são devido às complexas interações aerossol-nuvem, onde os aerossóis são elementos necessários para a condensação da água, formação de gotículas de nuvens, seu desenvolvimento e formação de precipitação (IPCC, 2007, IPCC, 2013). Neste contexto, os aerossóis agem como núcleos de condensação de nuvem $(\mathrm{CCN})$ e alteram de maneira não linear a eficiência de precipitação, além de representarem efeitos complexos no clima (BOUCHER et al., 2013). O papel climático dos aerossóis, assim como sua capacidade de agir como um CCN por interações de nuvempartícula, dependem do seu tamanho, higroscopicidade e composição química (SWIETLICKI et al., 2008, SCHMALE et al., 2014), que são interdependentes (HONG et al., 2015).

O SSA é uma medida intrínseca da característica óptica da população de aerossóis, que não depende da quantidade de aerossóis e que representa quão espalhadora em relação à extinção total de luz (soma dos efeitos de absorção e espalhamento) é aquela matéria. Este coeficiente é calculado pela seguinte expressão:

$$
S S A=\frac{\sigma_{e s p}}{\sigma_{e s p}+\sigma_{a b s}}
$$

Esta é uma variável crucial para o balanço de energia do planeta, já que populações de aerossóis com maior efeito espalhador, de SSA mais próximo de 1, tendem a causar um efeito líquido de resfriamento na superfície, enquanto populações com SSA mais baixos tem efeito líquido de aquecimento.

A forçante radiativa dos aerossóis e gases, representada pela Figura 1, é uma medida da influência que uma espécie química tem em modificar o balanço do fluxo energético terrestre. Neste sentido, é um importante identificador do potencial deste particular fator para atuar no 
balanço de radiação planetária. No caso dos efeitos climáticos dos aerossóis, seu efeito direto é de resfriamento e estimado em $-0.27 \mathrm{w} / \mathrm{m}^{2}$, e o efeito indireto (através das nuvens) é de -0.55 $\mathrm{w} / \mathrm{m}^{2}$. A soma do efeito de resfriamento é de $-0.82 \mathrm{w} / \mathrm{m}^{2}$. Comparando este valor com o aquecimento pelo aumento das concentrações de $\mathrm{CO} 2$, que é de $+1.68 \mathrm{w} / \mathrm{m}^{2}$, observamos que os aerossóis mascaram cerca de 50\% do aquecimento global. Nota-se as grandes incertezas quanto aos efeitos diretos e indiretos de aerossóis, o que evidencia a importância de estudos como este trabalho.

Figura 1.1 - Diagrama da forçante radiativa global $\mathrm{em} \mathrm{W} / \mathrm{m}^{2}$ associada a cada espécie química, contendo gases e partículas, além de mudanças do uso do solo e da irradiância solar natural. A forçante é relativa a mudanças em 2010 relativas a 1750. Observamos também na coluna à direita a mediana, os intervalos de confiança e o nível de confiabilidade da estimativa (Fonte: IPCC 2013).

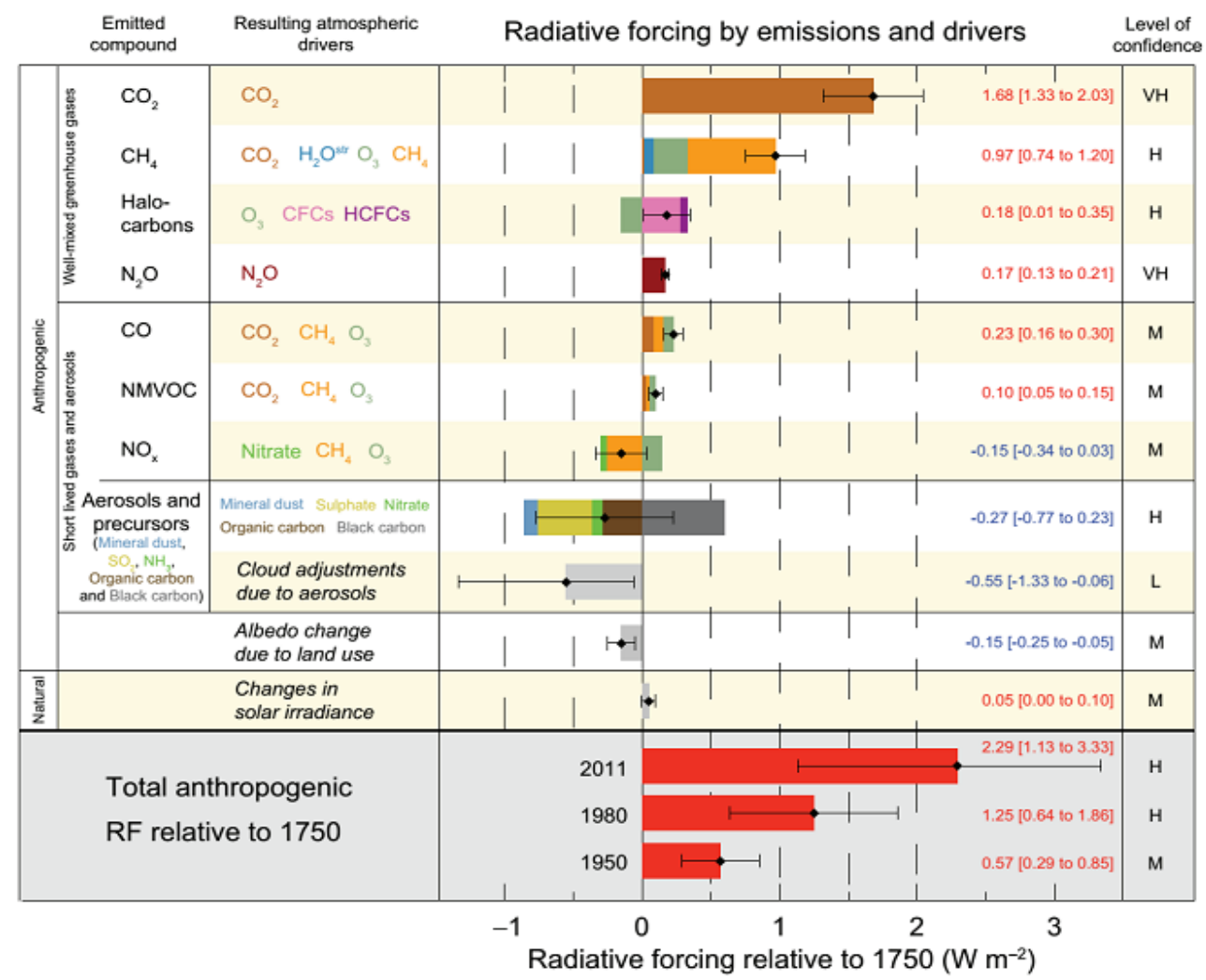

As florestas tropicais são componentes críticos para o clima do planeta (ARTAXO et al., 2021; IPCC, 2019), influenciando o ciclo hidrológico global e o balanço de radiação terrestre (IPCC, 2013). Florestas tropicais são três vezes mais efetivas em resfriar o clima em comparação com florestas boreais e temperadas (IPCC, 2019) e seus serviços ecossistêmicos são diversos e essenciais para a manutenção de nossa sociedade (IPBES, 2019, SWAMY et al., 2018). O estudo do papel da Amazônia no clima global é essencial para que possamos entender o impacto das mudanças que estão ocorrendo na Amazônia, com o desflorestamento e a urbanização (DAVIDSON et al., 2012). 


\subsection{A BACIA AMAZÔNICA E SUAS INTERAÇÕES COM O CLIMA}

A bacia amazônica é a maior bacia hidrográfica do planeta, que cobre cerca de 6.9 milhões de $\mathrm{km}^{2}$, e é a maior área de floresta tropical, que ocupa $80 \%$ da área dessa bacia (GOULDING et al., 2003) em 8 países: Brasil, Colômbia, Peru, Equador, Guiana Francesa, Suriname, Venezuela e Bolívia. A bacia amazônica tem papel fundamental como reguladora do clima regional já que, dentre outros fatores, esta mantém a umidade através da evapotranspiração e reciclagem de vapor de água e gera gases e partículas atmosféricas responsáveis pela manutenção do ciclo de vida das nuvens na região (LOVEJOY e NOBRE, 2019). A bacia amazônica também abriga um grande estoque de carbono de cerca de 110 Giga toneladas (Gton) (MALHI et al., 2008; PHILLIPS et al., 2009), o equivalente a cerca de 11 anos de queima de todos os combustíveis fósseis em 2020. Este estoque de carbono é sensível a processos que alteram a precipitação, temperatura e o fluxo de radiação (ARTAXO et al., 2013).

A Figura 1.2 mostra um esquema de alguns processos que mostram a interação entre a floresta amazônica e o clima.

Figura 1.2 - Esquema mostrando a complexidade dos processos que regulam a composição atmosférica e sua relação com o clima da Amazônia. As emissões de gases biogênicos pela floresta (tais como monoterpenos, isopreno e outros) produzem partículas secundárias que tem o potencial de alterar processos hidrológicos e o balanço de radiação atmosférica. As partículas de aerossóis biogênicas são também emitidas diretamente sob a forma de grãos de pólen, bactérias, fragmentos de folhas, excrementos e fragmentos de insetos. Fonte: Barth et al., 2005.

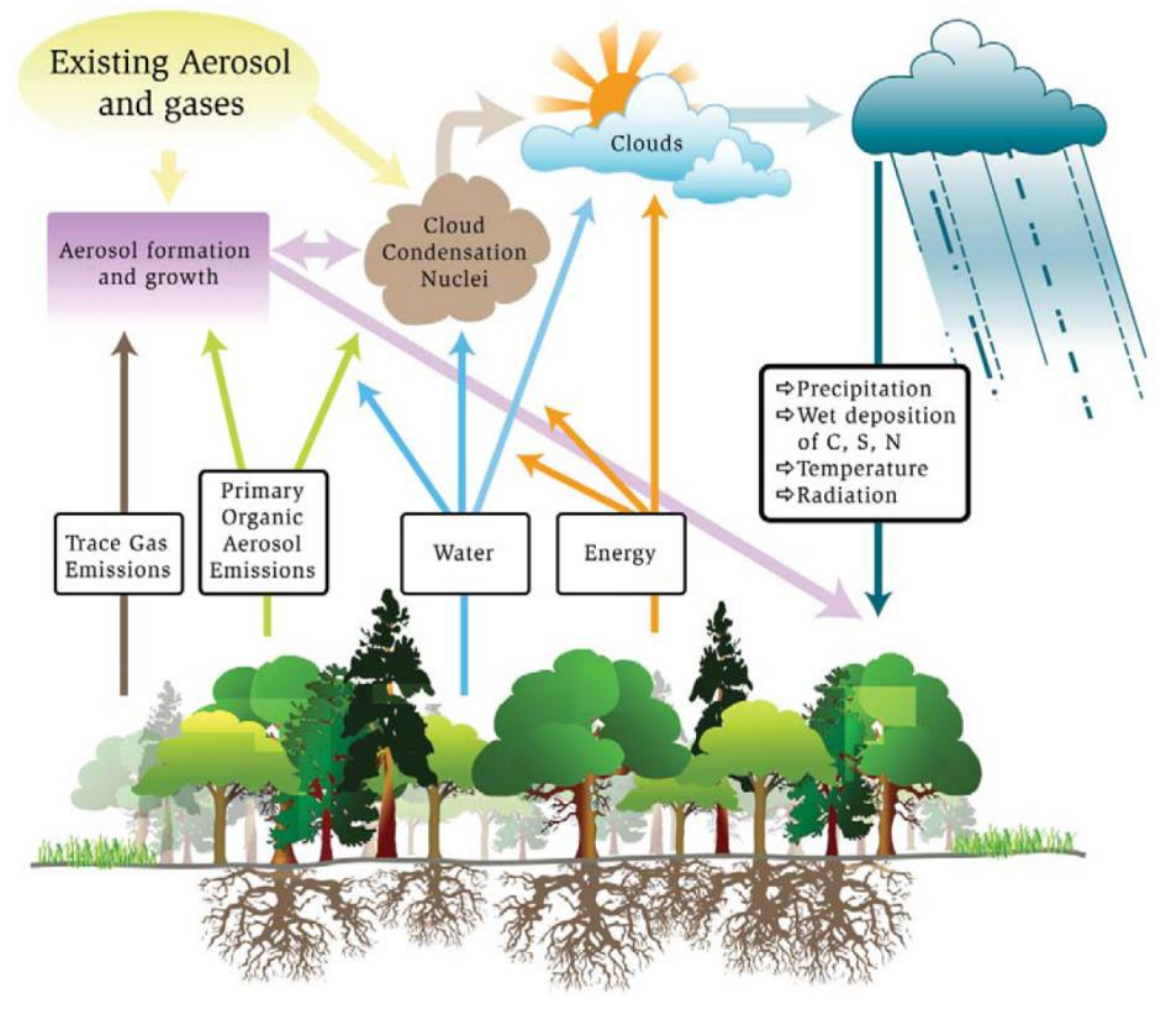


Embora na estação chuvosa possamos observar uma atmosfera com pouca perturbação antropogênica, na estação seca observamos o forte impacto que as emissões de queimadas na Amazônia têm nas propriedades físico-químicas da atmosfera (ARTAXO, 1985). As queimadas estão associadas à alta taxa de desmatamento da Amazônia (DE OLIVEIRA et al., 2020). A figura 1.3 abaixo mostra a série temporal da taxa anual de desmatamento na Amazônia desde a década de 80 até 2020 (INPE, 2020b). Observamos uma forte redução na taxa de desmatamento de 2003 a 2011, seguido por aumentos importantes na taxa de desmatamento no período mais recente, de 2011 a 2020. Em 2020 foram desmatados $11.088 \mathrm{~km}^{2}$ de florestas.

Figura 1.3 - Série temporal da taxa anual de desmatamento na Amazônia desde a 1977 até 2020 em $\mathrm{km}^{2}$ por ano, extraído de INPE, (2020b).

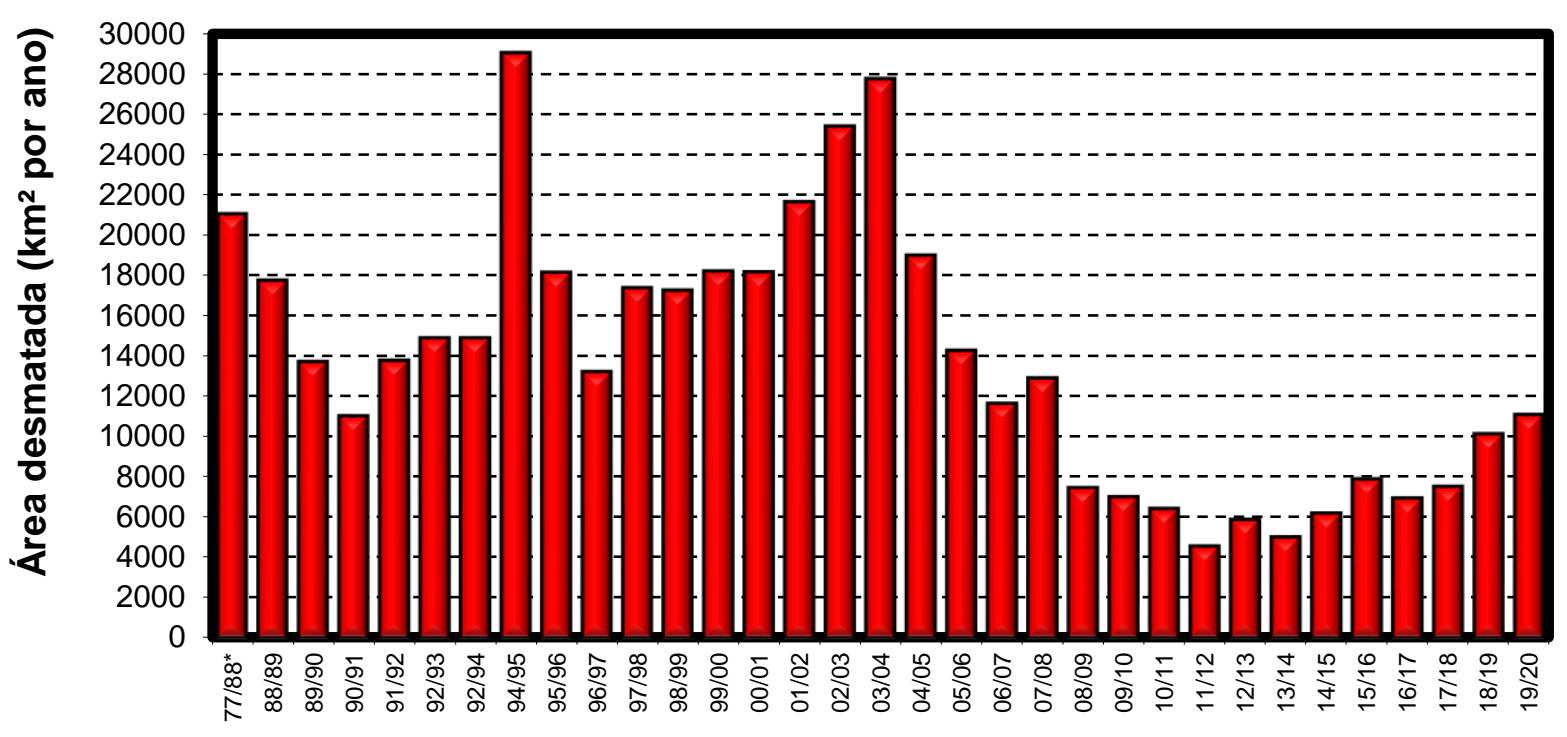

Outra importante consequência dos processos que estão alterando o bioma amazônico são as emissões das queimadas. Após o desmatamento, que em geral ocorre no final da estação chuvosa (maio-junho), a biomassa é queimada para possibilitar um uso à mudança de uso de solo, seja de novas áreas de pastagens ou de novas áreas agrícolas. 
Figura 1.4 - Série temporal do número de focos de incêndio na Amazônia de 1998 a 2020, de acordo com dados do programa queimadas do INPE (2020a) (extraído de http://queimadas.dgi.inpe.br/queimadas/portal).

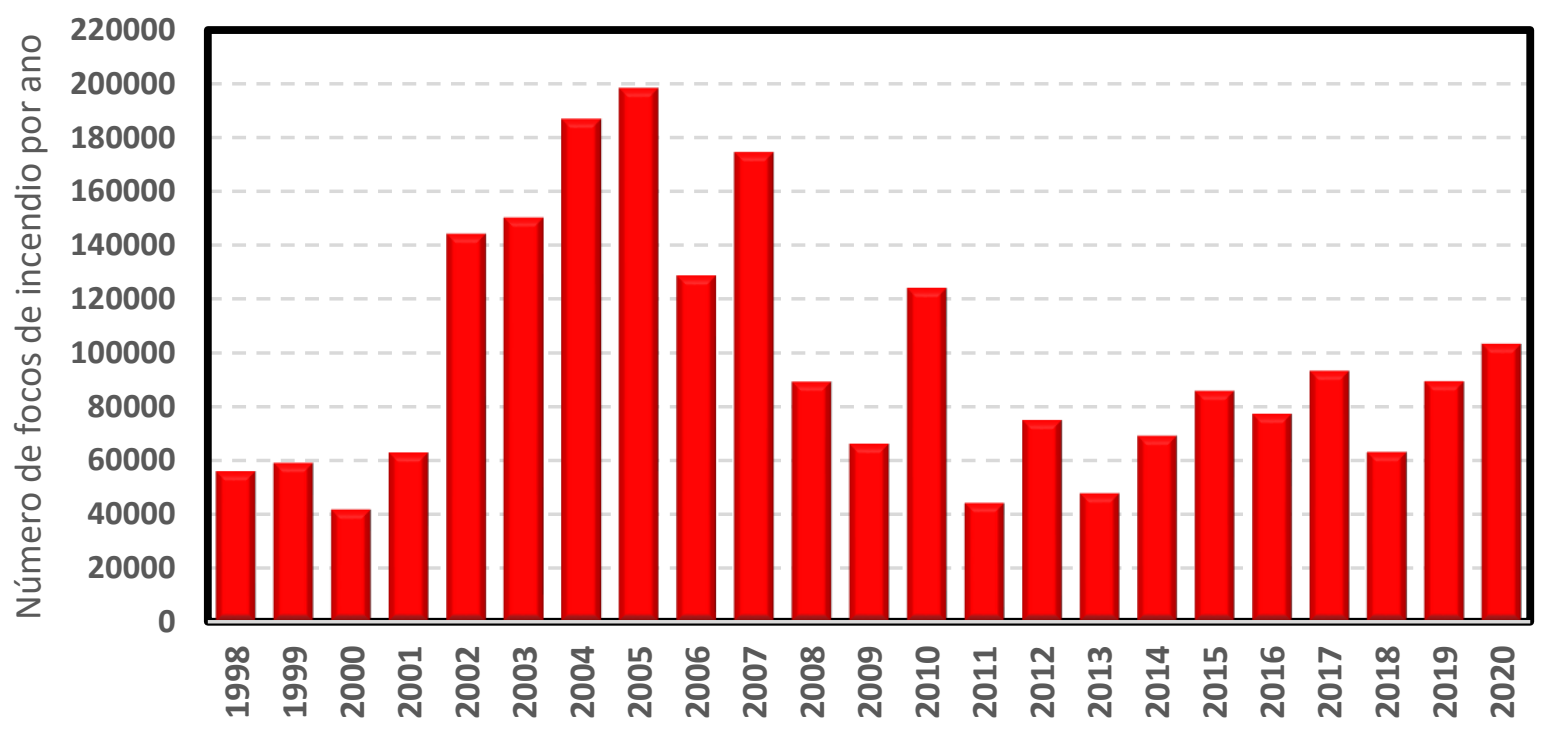

A figura 1.4 apresenta a série temporal do número de focos de incêndio na Amazônia de 1998 a 2020, de acordo com dados do projeto queimadas do INPE. Observamos um crescimento do número de focos de queimadas desde 2011, com aumento de $120 \%$ nos focos. Estes processos de desmatamento e queimadas está afetando significativamente a região amazônica, onde os principais vetores desta mudança de uso do solo são a expansão agrícola, a extração de madeira e as mudanças climáticas (DAVIDSON et al., 2012). A Figura 1.5 ilustra os impactos e as forçantes dos processos de mudanças que estão ocorrendo na região Amazônica. 
Figura 1.5 - Interações entre o clima global, uso da terra, fogo, hidrologia, ecologia e dimensões humanas. As forçantes estão indicadas nos ovais vermelhos; os processos abordados estão indicados nas caixas verdes e flechas; e as consequências socioeconômicas são indicadas nas caixas azuis. Extraído de Davidson et al., (2012).

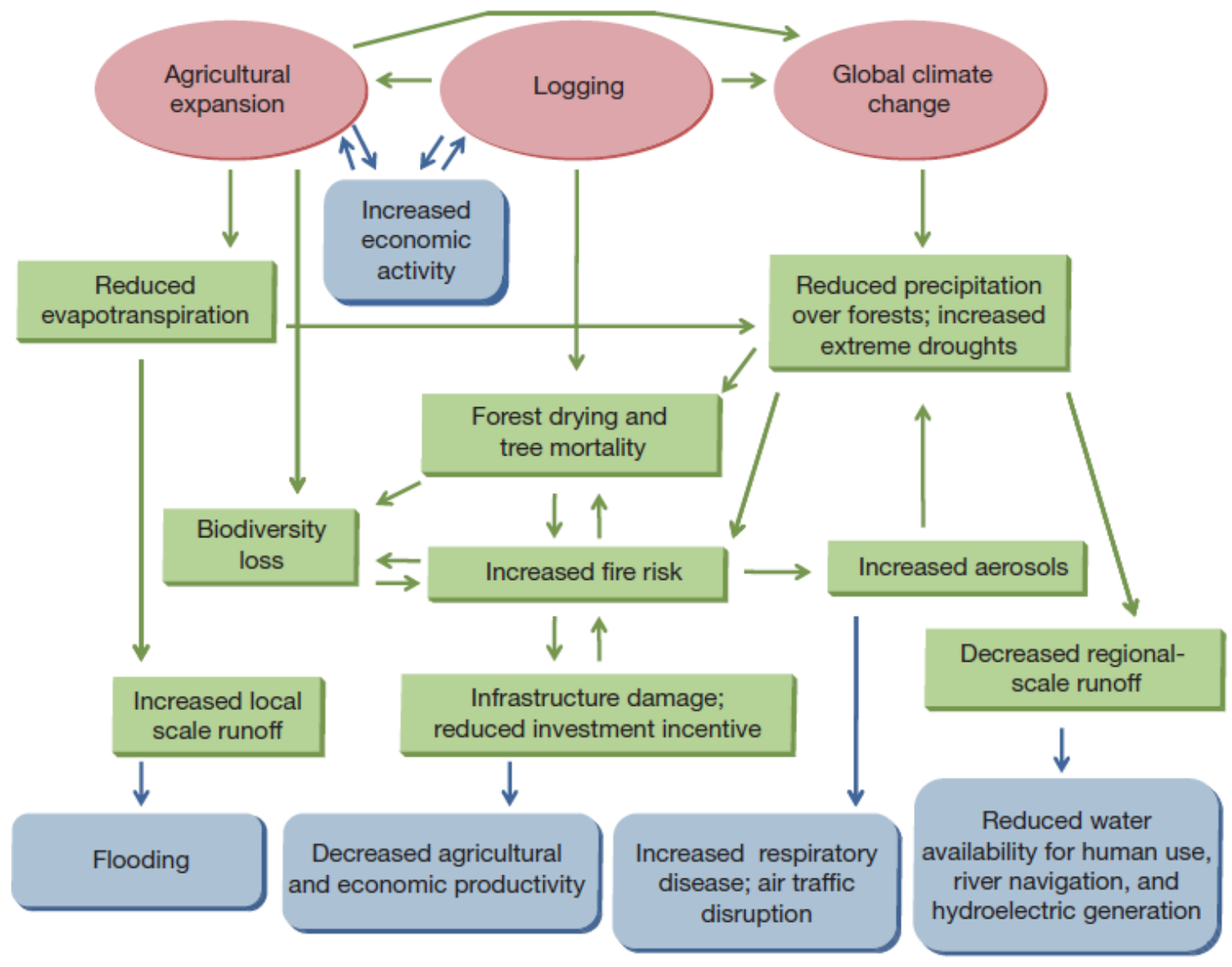

Parte destas mudanças está relacionada com emissões urbanas que também vêm modificando o ecossistema amazônico (MARTIN et al., 2017), e estão cada vez maiores. Dez das dezenove cidades brasileiras que dobraram a população na última década estão na Amazônia. Além disso, a população da região Norte cresceu $23 \%$ na primeira década do século, quase o dobro comparado ao total no Brasil, de 12\% (IBGE, 2012). As metrópoles Manaus e Belém são símbolos do processo de urbanização crescente da região amazônica que é motivada, dentre outras razões, por planos de integração nacional e desenvolvimento regional. A migração de força de trabalho depois de grandes obras acabadas na região, implementação de polo industrial e de zona de livre comércio foram fundamentais para a urbanização da região (SANTOS, 2017). 


\subsection{AEROSSÓIS ATMOSFÉRICOS E PROCESSOS QUE REGULAM SUA CONCENTRAÇÃO E PROPRIEDADES}

$\mathrm{Na}$ atmosfera amazônica podemos encontrar condições atmosféricas únicas em áreas continentais, na qual a maior parte das interações entre biosfera e atmosfera consistem em processos naturais, durante a estação chuvosa. Essas interações são fortemente influenciadas por partículas de aerossóis atmosféricos (MARTIN et al., 2010), e a causa se dá principalmente pelo ciclo de vida dos aerossóis estar associado com o balanço de radiação e a formação de nuvens e precipitação (BISCARO et al., 2021). A concentração de partículas atmosféricas durante a estação chuvosa na Amazônia é muito baixa, de cerca de 250 partículas por centímetro cúbico, que é similar à observada em regiões oceânicas remotas, e, como na atmosfera marinha, o sistema amazônico é particularmente suscetível a pequenas mudanças nas propriedades destas partículas, que podem resultar em grandes impactos nos mecanismos de formação e desenvolvimento de nuvens e no clima (ANDREAE et al., 2015).

Estes aerossóis atmosféricos são partículas sólidas ou líquidas em suspensão na atmosfera com tamanhos de poucos nanômetros a centenas de micrômetros (SEINFELD e PANDIS, 2006). Em termos de fontes de partículas, temos as emissões primárias ou diretas (poeira do solo, sal marinho, emissões industriais etc.), e a produção secundária de partículas proveniente da conversão gás-partícula. Os aerossóis primários são as partículas que têm origem em emissão direta da fonte para a atmosfera. Por exemplo, aerossóis biogênicos emitidos na bacia amazônica são pólen, bactérias, esporos de fungos, vírus e fragmentos de plantas e animais (ELBERT et al., 2007). A queima incompleta promovida por uso de combustível também é fonte de partículas primárias, como aerossóis orgânicos e fuligem, chamado de Black Carbon (BC) na literatura científica. Há também os aerossóis secundários, formados na atmosfera a partir de gases precursores. Estes gases podem ser compostos orgânicos voláteis (COVs), como o isopreno e terpenos, ou gases inorgânicos como o $\mathrm{NO}_{2} \mathrm{e}$ $\mathrm{SO}_{2}$. Na atmosfera, estes compostos sofrem reações de conversão gás-partícula ao reagirem com gases e radicais com alto potencial de oxidação como $\mathrm{O}_{3}$ e o radical hidroxila $(\mathrm{OH})$ e mudam de fase (de gás para sólido ou para líquido). Estes gases precursores podem condensar em outras partículas pré existentes, aumentando seu tamanho ou ainda formar uma nova partícula de aerossol.

Outra classificação importante é por tamanho da partícula, onde em geral as partículas são separadas em modas com faixas de tamanho aproximadas: a moda grossa, com diâmetros de partícula (Dp) maiores do que $1 \mu \mathrm{m}$, e moda fina, com Dp menor do que $1 \mu \mathrm{m}$. A moda fina 
ainda pode ser dividida em três outras modas: a de nucleação (menores que cerca de $30 \mathrm{~nm}$ ), a de Aitken (entre 30 e $80 \mathrm{~nm}$ ) e a de acumulação (entre 80 e $1000 \mathrm{~nm}$ ) (SEINFELD e PANDIS, 2006).

Figura 1.6 - Ilustração do ciclo de vida interrelacionado de aerossóis, nuvens e precipitação na atmosfera terrestre, que mostra os processos atmosféricos sofridos pelas partículas atmosféricas e suas influências (extraído de ASR 2019).

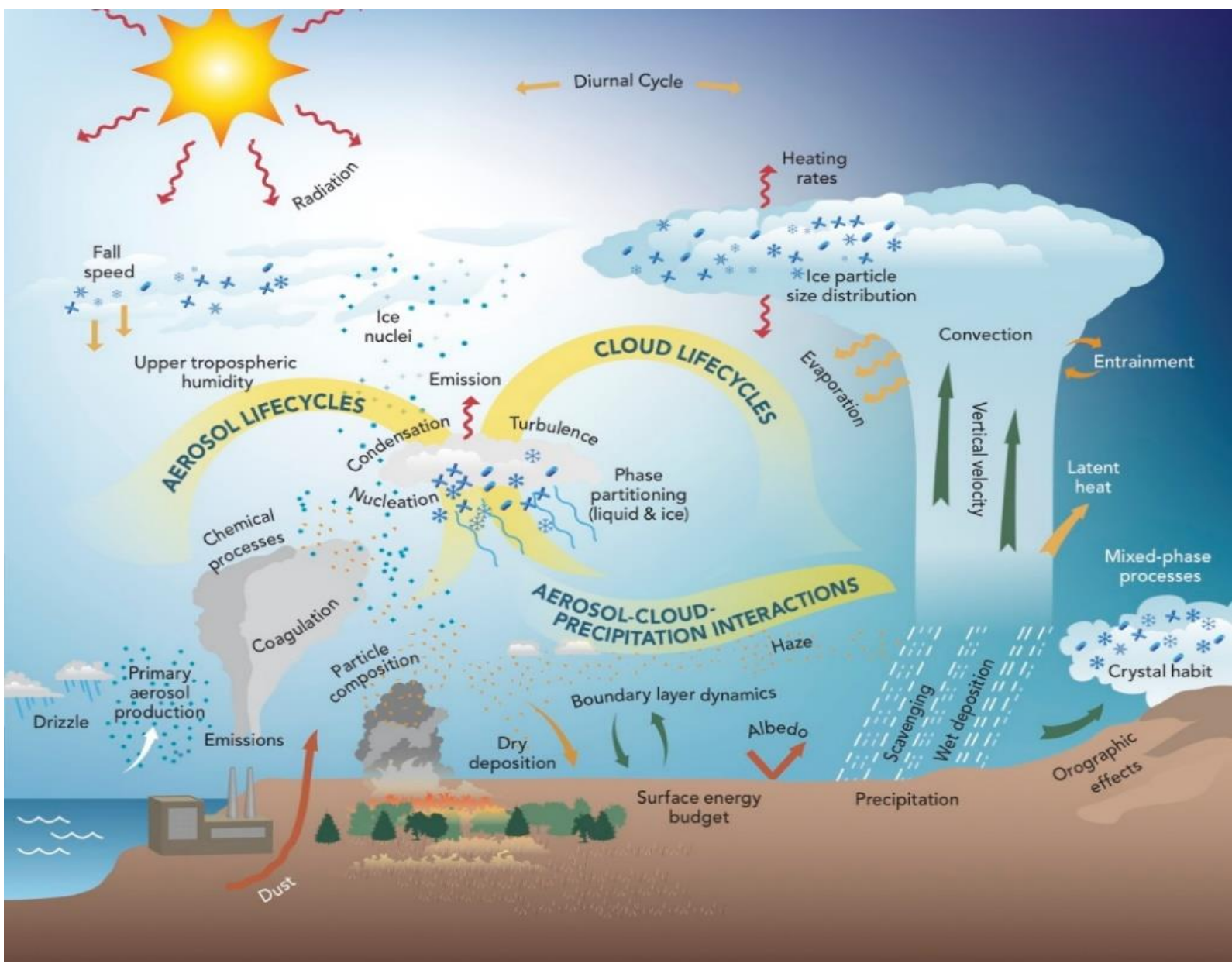

Os aerossóis têm um ciclo de vida na atmosfera da ordem de dias a semanas, até serem removidos da atmosfera e depositados em solo. Podem sofrer deposição úmida, pela qual são arrastados junto às gotas de chuva, ou deposição seca, na qual são levados a superfície por processos de difusão e sedimentação. Estes aerossóis, como mostrado na Figura 1.6, sofrem uma série de processos físico-químicos na atmosfera entre sua emissão e deposição, como crescimento por condensação de gases voláteis, por coagulação (colisão de duas ou mais partículas, formando uma maior) e oxidação dos seus compostos. Essas transformações são importantes pois são fatores determinantes para as propriedades ópticas e ativação de núcleos de condensação de nuvem, fundamental no ciclo de vida das nuvens. 


\subsection{AEROSSÓIS ATMOSFÉRICOS NA AMAZÔNIA}

A floresta amazônica interage fortemente com a atmosfera, através de uma série de processos físicos-químicos-biológicos (ARTAXO et al., 2013, 2021). Quanto à composição química, a matéria orgânica é o componente majoritário da fração fina das partículas na região natural da bacia amazônica, com uma contribuição tipicamente de 70 a $90 \%$ da massa de aerossóis (ARTAXO et al., 2021). Por consequência, este trabalho de mestrado se dedicou a estudar a composição química detalhada desta componente orgânica majoritária. Desta matéria orgânica fina, uma fração minoritária tem origem em emissão direta da biota amazônica, cujo limite superior de 20\% de massa foi proposto por SCHNEIDER et al. (2011). Portanto, a maior parte (limite inferior de $80 \%$ ) da matéria orgânica fina é composta por aerossóis orgânicos secundários (SOA).

Esta formação de aerossóis na Amazônia em áreas sem impactos antropogênicos é realizada a partir da oxidação de COVs biogênicos (BCOV) emitidos pela flora e presentes em grandes concentrações (YÁÑEZ-SERRANO et al., 2020) no ambiente natural. A contribuição de isopreno, um dos principais BCOV emitidos pela floresta amazônica gera um fluxo de carbono para a atmosfera global da ordem de $1.000 \mathrm{Tg}$ de carbono/ano (GUENTHER et al., 2012). Estas reações químicas de conversão gás partículas, portanto, dependem do equilíbrio químico de reações entre os BCOV e gases oxidantes como $\mathrm{NOx}, \mathrm{SOx}, \mathrm{OH}$ e O3. Próximo à superfície, a concentração de óxidos de nitrogênio e de enxofre é pequena (LIU et al., 2016), com emissões dominantes vindas do solo. Este ambiente gera concentrações bastante reduzidas de $\mathrm{O}_{3}$ que são dominadas por transportes convectivos e apresentam pouca produção fotoquímica líquida.

$\mathrm{Na}$ Amazônia, diferentemente de outras florestas, eventos de formação de novas partículas (NPF) são muito incomuns próximos a superfície (RIZZO et al., 2018). O mecanismo de NPF na Amazônia sugerido por Andreae et al. (2018) está descrito a seguir. Correntes ascendentes de nuvens de convecção profunda levam material emitido nas camadas mais baixas da troposfera, contendo partículas e BCOV, para camadas médias e altas da troposfera. Neste processo, as partículas são removidas da parcela de ar pois ficariam retidas nas gotas de nuvem e os COV sofrem processos oxidativos de forma a diminuir sua volatilidade. Esta remoção das partículas diminui a taxa de condensação de COVs em partículas pré-existentes. Ao mesmo tempo, há aumento das concentrações de oxidantes como $\mathrm{O}_{3}$ causado principalmente pela mistura da alta troposfera com a estratosfera e como $\mathrm{NO}_{\mathrm{x}}$ produzido por raios. Ao chegar na alta troposfera, portanto, os COVs encontram um ambiente muito mais frio (com temperaturas 
de até $-55^{\circ} \mathrm{C}$ ) com menos sumidouros por condensação em partículas pré-existentes e com mais oxidantes do que na camada limite, características que tornam muito mais provável a condensação de COVs de baixa volatilidade em novas partículas da moda de nucleação. Através de fortes correntes de convecção descendentes, estas partículas voltam a camadas mais baixas da troposfera e, neste caminho, aumentam seu diâmetro. A Figura 1.7 ilustra estes processos que são importantes na produção de novas partículas na Amazônia (ANDREAE et al., 2017).

Figura 1.7 - Processos que ligam as emissões de COVs na Amazônia e a produção de novas partículas na alta troposfera. Figura de Andreae et al., (2017).

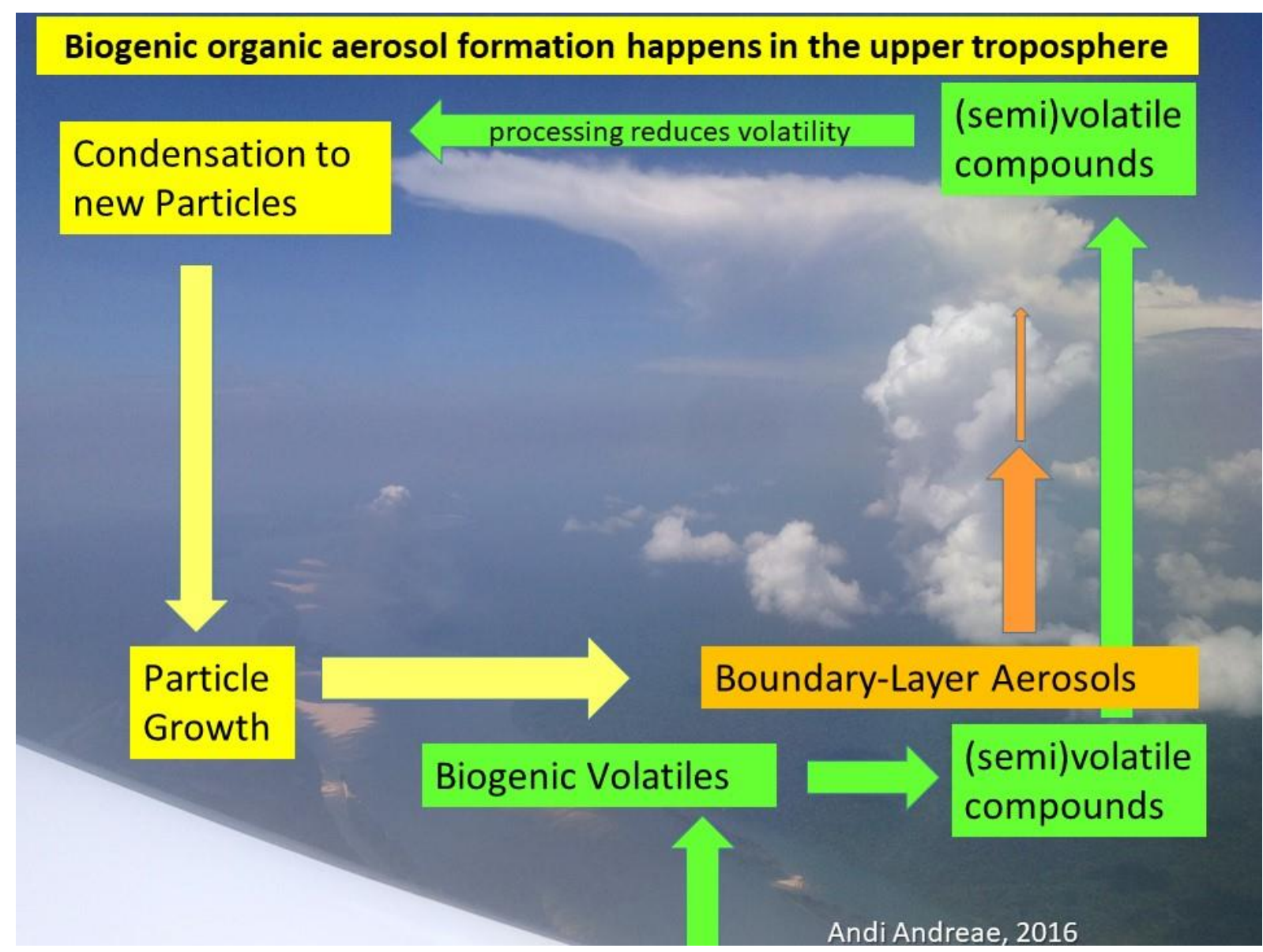

O equilíbrio deste ecossistema vem sofrendo significativas perturbações através de modificações causadas pela humanidade nas últimas 2 décadas, em especial em relação ao ciclo hidrológico, e suas causas não são completamente compreendidas (DAVIDSON et al., 2012; GLOOR et al., 2013; VAN MARLE et al., 2017).

Na parte brasileira da Amazônia, o desflorestamento das últimas 3 décadas devastou cerca de $19 \%$ da área florestal original (ARTAXO, 2019, SILVA et al., 2020) e é responsável por parte dessas modificações. As emissões das queimadas aumentam muito significativamente espécies atmosféricas como aerossóis e gases oxidantes, o que acaba por provocar redução da eficiência de precipitação, diferenças no balanço radiativo na superfície, corrosão da superfície 
das folhas, entre outras modificações na atmosfera amazônica (GONÇALVES et al., 2015; SCHROEDER et al., 2008; DE MENDONÇA et al., 2004).

Outra parte relevante do impacto antrópico no ecossistema amazônico está relacionada com a crescente urbanização deste ambiente. $\mathrm{Na}$ área central da Amazônia está a capital do estado do Amazonas e principal área metropolitana dentro da floresta, a cidade de Manaus, onde vivem mais de 2 milhões de habitantes, em alta taxa de crescimento e urbanização, envoltos de pelo menos $1500 \mathrm{~km}$ de floresta amazônica nativa, com exceções de pequena escala. A cidade é a capital dentre as metrópoles cuja população mais cresceu de 2010 até 2020, um aumento de mais de $23 \%$ (IBGE, 2020). Entre as causas para este crescimento estão os incentivos governamentais relacionados à Zona Franca de Manaus, atraindo trabalhadores à cidade, e também a mais alta taxa de natalidade no Brasil, de 2.4 filhos por mulher, em comparação com a taxa de 1.9 média para o Brasil (IBGE, 2012).

Os estudos da contribuição urbana para a poluição da floresta, como este projeto de mestrado, podem representar os efeitos e impactos associados ao processo de crescente urbanização de áreas em meio a florestas tropicais, como é o caso da Amazônia.

\subsection{INTERAÇÃO DA POLUIÇÃO DO AR URBANA COM EMISSÕES NATURAIS}

Uma das principais fontes de poluição da metrópole de Manaus é a frota de cerca de 600 mil veículos (DENATRAN, 2014), compostos 66.2\% por veículos leves (42.1\% flex, $21.6 \%$ a gasolina, $2.5 \%$ a etanol), $1.9 \%$ por ônibus a diesel, $3.2 \%$ por caminhões a diesel, $3.9 \%$ por picapes a diesel e $24.8 \%$ por motos a gasolina (MMA, 2014). Além das fontes móveis, algumas fontes fixas contribuem com emissões, como as usinas termoelétricas que queimam diesel ou gás natural e abastecem energeticamente a região, as refinarias locais, além de outras fontes urbanas como residenciais e de queima de lixo. Estas fontes urbanas emitem, dentre outros compostos, aerossóis, COVs antrópicos e óxidos de nitrogênio e de enxofre. Observar a abundância e características de poluentes atmosféricos da cidade e estudar o resultado das interações destes poluentes com os compostos atmosféricos naturais da floresta em diferentes níveis de processamento atmosférico são os principais objetivos deste trabalho. A Figura 1.8 ilustra a interação entre as emissões urbanas de Manaus e as emissões biogênicas naturais. 
Figura 1.8 - Esquema da influência das emissões urbanas na produção de aerossóis orgânicos secundários através da emissão de óxidos de nitrogênio e enxofre que oxidam os COVs biogênicos e impactam a produção de $\mathrm{O}_{3}$. Os processos naturais são indicados por flechas sólidas, enquanto os antrópicos por flechas pontilhadas (extraído de DE SÁ, et al. 2018).

(a)

\section{Real atmospheric chemistry}

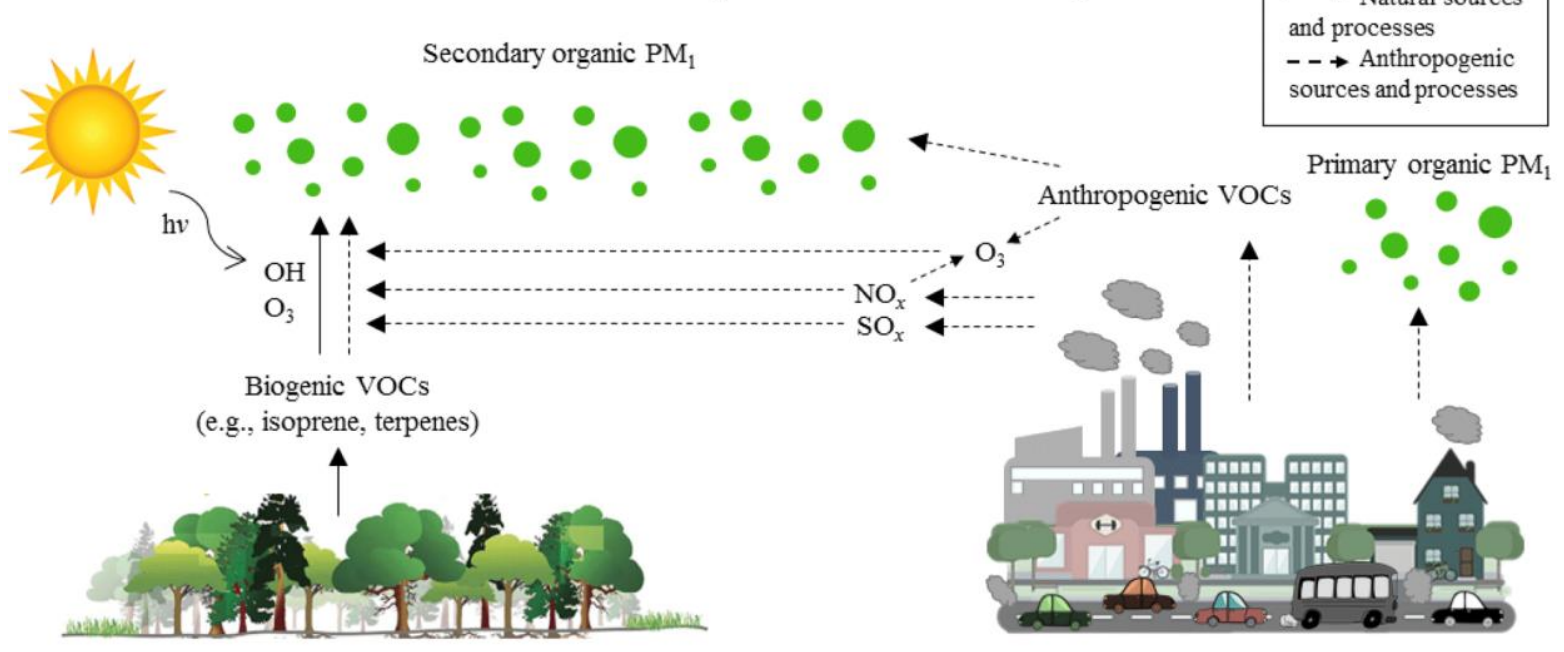

As concentrações atmosféricas destes poluentes em um dado local dependem de vários fatores, como a taxa de emissão de cada fonte medida em massa/tempo; a produção e consumo deste poluente na atmosfera; a deposição seca e a deposição úmida; transporte de massas de ar que carregam poluentes e a dispersão de poluentes. A dispersão de poluentes é fortemente controlada pelas características da camada limite, a parte mais baixa da atmosfera que tem comportamento diretamente influenciado pelo contato com a superfície. As altas taxas de radiação diurnas provocam uma camada limite turbulenta, com alta mistura e dispersão de poluentes, enquanto a ausência da radiação, durante o período noturno, provoca uma camada limite noturna mais estável e fina, que, em ambientes urbanos, limita a dispersão e pode acumular os poluentes emitidos após este estado estar estabelecido na atmosfera (SEINFELD e PANDIS, 2006).

Os poluentes emitidos em Manaus têm grande potencial de alterar as propriedades da atmosfera da floresta, e uma delas é quanto à produção de ozônio. As reações que dominam a produção e consumo de $\mathrm{O}_{3}$ na troposfera envolvem principalmente o equilíbrio entre dois compostos: NOx e COVs (LIU et al., 2016; SEINFELD e PANDIS, 2006). A rota de reações composta pelas reações R1 até R3 a seguir mostra um ciclo simplificado de equilíbrio de produção e consumo de ozônio na troposfera, em que as reações de dissociação e fotólise do $\mathrm{NO}_{2}$ levam a produção deste poluente e $\mathrm{NO}$, gerado nestas reações, acaba por consumir o ozônio: 
(R1)

(R2)

(R3)

$$
\begin{gathered}
\mathrm{NO}_{2}+h v(\lambda<420 \mathrm{~nm}) \rightarrow \mathrm{NO}+\mathrm{O} \\
\mathrm{O}+\mathrm{O}_{2}+\mathrm{M} \rightarrow \mathrm{O}_{3}+\mathrm{M} \\
\mathrm{NO}+\mathrm{O}_{3} \rightarrow \mathrm{NO}_{2}+\mathrm{O}_{2}
\end{gathered}
$$

em que hv é a radiação solar e M são moléculas inertes como $\mathrm{N}_{2}$.

Entretanto, espécies como COVs podem alterar este equilíbrio produzindo óxidos como o $\mathrm{HO}_{2}$ ou reagindo por si só com o $\mathrm{NO}$ e oxidando-o em $\mathrm{NO}_{2}$ sem consumir ozônio, como aconteceria pela reação R3.

O acréscimo de ozônio produzido a partir da adição de COVs ou NOx é determinado de forma não linear pela razão entre as concentrações destes compostos, definindo ou um regime de produção de $\mathrm{O}_{3}$ limitado por COVs, significando que a maior produção de ozônio se daria com a adição de COVs, ou um regime limitado por $\mathrm{NO}_{\mathrm{x}}$, onde a relação seria invertida. Pelas grandes concentrações de COVs biogênicos produzidos pela floresta e pequenas concentrações de $\mathrm{NO}_{\mathrm{x}}$ da atmosfera pristina, o regime natural de formação de ozônio é limitado por $\mathrm{NO}_{\mathrm{x}}, \mathrm{e}$, portanto, os óxidos de nitrogênio emitidos pelos veículos em Manaus têm grande potencial de produção fotoquímica de ozônio.

Outra propriedade da atmosfera potencialmente impactada é quanto às partículas de aerossóis. Além do transporte das partículas primárias emitidas diretamente na cidade, os compostos oxidantes co-emitidas, aliados aos gases precursores antrópicos e biogênicos, alta umidade relativa e taxas de radiação intensas são condições que contribuem para a formação intensificada de partículas secundárias na atmosfera, como mostrado no esquema da Figura 1.8. Características como propriedades microfísicas e de cobertura de nuvens, precipitação, e o clima regional sobre a bacia amazônica podem ser significativamente afetados por aerossóis (LIN et al., 2006; ROSENFELD et al., 2008, 2014; MARTINS et al., 2009; ALTARATZ et al., 2010; KOREN et al., 2012; GONÇALVES et al., 2015). Um aumento na massa de aerossóis irá modificar as propriedades ópticas das partículas. A produção de aerossóis secundários gera aerossóis particularmente espalhadores e a fração orgânica pode ter uma absorção não desprezível em comprimentos de onda menores, gerando impacto no balanço radiativo (LANGYONA et al., 2010; MAHILANG et al., 2020).

A resposta de sistemas naturais a emissões antrópicas permanece uma das maiores incertezas na influência antrópica sobre o clima (SEINFELD et al., 2016), e grande parte desta indeterminação está relacionada aos aerossóis, quanto a sua emissão e formação secundária na atmosfera. Para estudar a interação das emissões de Manaus com os compostos e condições atmosféricas naturais da bacia amazônica foi proposto um grande experimento que reúne 
simulações e observações em áreas estratégicas nas proximidades de Manaus, chamado de GoAmazon. O presente trabalho de mestrado faz parte deste experimento.

\subsubsection{O Experimento GoAmazon 2014/15}

O experimento GoAmazon 2014/15 (Observations and Modeling of the Green Ocean Amazon) foi desenvolvido visando estudar o impacto dos poluentes urbanos no ciclo de vida de aerossóis e nuvens em regiões da Floresta Amazônica. Em especial, este experimento buscou melhorar o entendimento de como os ciclos químicos, hidrológicos, energéticos e ecossistêmicos funcionam atualmente, suas suscetibilidades a mudanças e como podem evoluir em cenários possíveis de estresse e poluição (MARTIN et al., 2016, 2017). O ambiente ao entorno de Manaus é único e excelente para este tipo de experimento pois o estado da atmosfera na região nos garante um imenso laboratório natural para estudos atmosféricos, já que nos permite estudar a componente natural da geração de partículas junto a química da atmosfera pristina, sua relação com o ciclo de vida das nuvens e precipitação, e, ao mesmo tempo, nos possibilita compreender detalhadamente a influência da componente antrópica em cada aspecto deste sistema.

A localização dos principais sítios envolvidos no projeto está exposta na Figura 1.9. Vento acima de Manaus, cerca de $150 \mathrm{~km}$ distante da cidade, há uma torre científica de $325 \mathrm{~m}$ de altura, chamada de sítio ATTO (Amazon Tall Tower Observatory). Este sítio é a referência para entender a atmosfera pristina e seus processos naturais sobre a região central da Bacia Amazônica. No centro de Manaus, designada para medir a assinatura de poluição de Manaus, está o sítio T1. Recebendo a pluma que acabou de sair das fronteiras da cidade, o sítio T2 dista em torno de $14 \mathrm{~km}$ vento abaixo de T1, na margem do Rio Negro oposta a Manaus. O último sítio, T3, está cerca de 70km vento abaixo de T1, na direção preferencial do vento partindo da cidade, e sua atmosfera alterna entre períodos com mais e com menos impactos da pluma urbana com significativo processamento atmosférico. 
Figura 1.9 - Mapa com os principais sítios de medida do projeto GoAmazon, mostrando a torre ATTO de $325 \mathrm{~m}$ de altura, o sítio T1 no centro de Manaus, o sítio T2 $14 \mathrm{~km}$ vento abaixo da cidade, e o sítio T3 localizado $70 \mathrm{~km}$ vento abaixo da cidade.

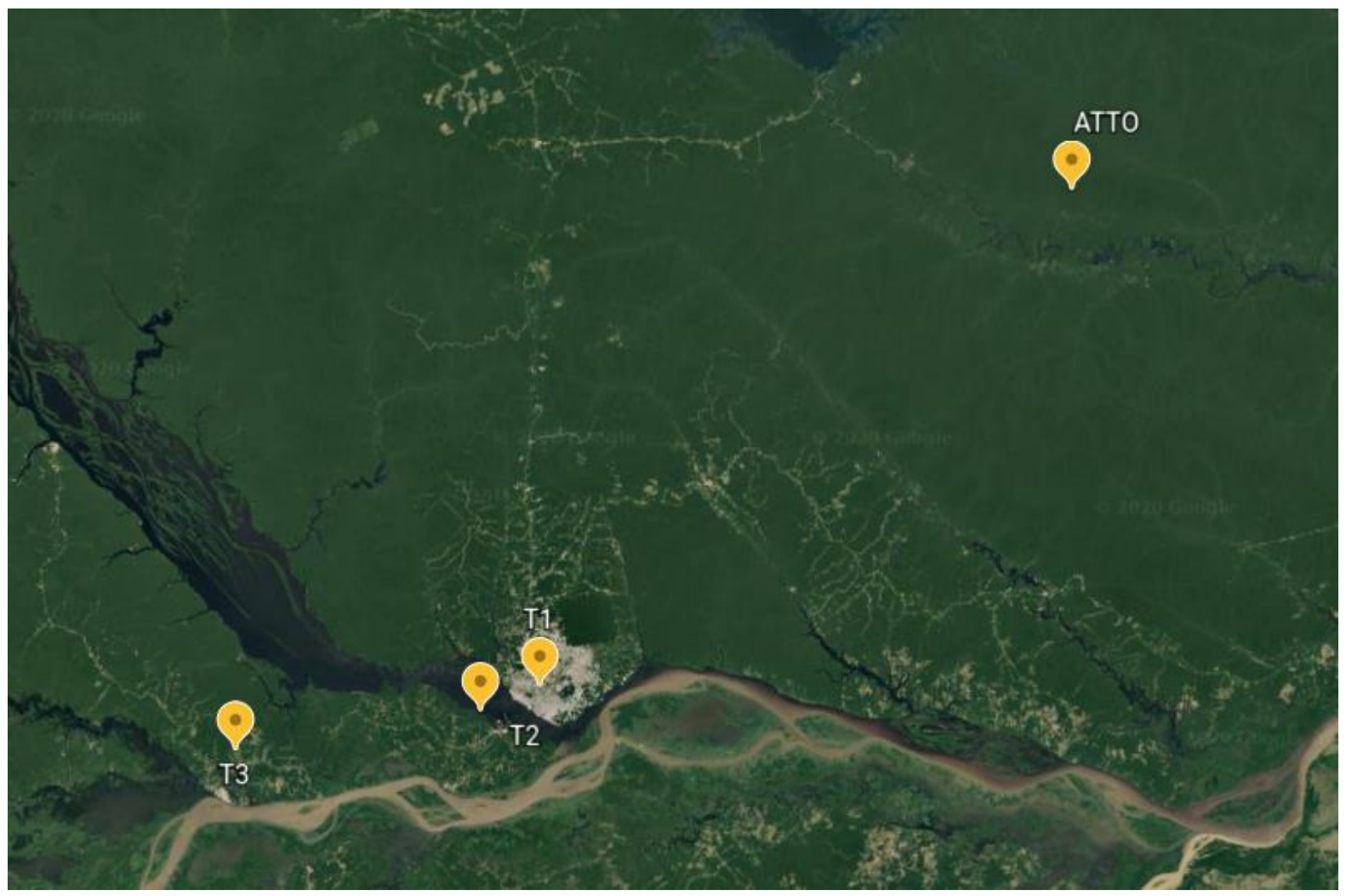

A partir deste experimento foi obtida uma ampla gama de resultados que elucidaram mecanismos até então não conhecidos de transporte, produção de SOA e fotoquímica que já foram publicados e são referências utilizadas no corpo deste documento. Foi observado a até $100 \mathrm{~km}$ vento abaixo da cidade que os compostos emitidos em Manaus aumentam a concentração de aerossóis, em especial quanto a formação de aerossol orgânico secundário e com composição com diferentes caminhos químicos de formação partículas em relação às condições naturais (DE SÁ, et al. 2017; DE SÁ, et al. 2018; SHILLING et al., 2018; SHRIVASTAVA et al., 2019). A composição química destas partículas mostra que os óxidos de nitrogênio da poluição urbana intensificam a oxidação dos COVs naturais, que, por reações de conversão gás-partícula, aumentam o impacto da poluição urbana na atmosfera na floresta.

Outro impacto significativo identificado por meio deste experimento foi quanto as propriedades ópticas dos aerossóis atmosféricos, com um aumento dos coeficientes ópticos de absorção e espalhamento de partícula em quase uma ordem de grandeza, e um maior efeito absorvedor em uma ampla região vento abaixo de Manaus, ultrapassando os sítios com medidas em solo do GoAmazon (CIRINO et al., 2018; NASCIMENTO et al., 2020). 
Foi observado que as nuvens que foram afetadas pela poluição têm uma quantidade maior de gotículas, estas apresentam menores diâmetros e menores taxas de crescimento, além de permitirem que partículas ultrafinas provenientes de Manaus de tamanhos menores do que o esperado atue como CCN (CECCHINI et al., 2016; FAN et al., 2018).

Estas interações entre a pluma de Manaus e os compostos e condições da atmosfera amazônica, porém, nunca foram estudadas em áreas tão próximas de Manaus, que é a principal componente original deste trabalho. Este estudo busca ampliar o conhecimento sobre o processamento atmosférico das emissões urbanas em contato com as emissões da bacia amazônica e sua velocidade.

Nossa contribuição neste experimento foi observar diretamente a abundância e características de poluentes atmosféricos em Manaus em termos de gases e partículas, no sítio experimental chamado de T1, e analisar no sítio T2, próximo a Manaus, no Rio Negro, como a população de partículas evoluiu e se modificou no curto espaço de tempo no transporte entre T1 e T2. Além disso, comparamos brevemente as propriedades de aerossóis destes dois sítios urbanos com a composição dos aerossóis biogênicos na torre ATTO, ZF2 e de aerossóis com origem mista do sítio de Manacapuru (T3). Isso nos permite uma análise da evolução da formação de aerossóis orgânicos secundários e das propriedades óticas dos aerossóis na Amazônia central, influenciada por emissões urbanas de Manaus. 


\section{OBJETIVOS}

Este trabalho visa o estudo da interação entre as emissões urbanas de Manaus e as emissões biogênicas naturais na Amazônia Central. Analisaremos a mudança na composição química e propriedades físicas das emissões atmosféricas de Manaus ao interagir com as emissões biogênicas naturais de uma floresta tropical. Em especial, busca-se entender como as características físico-químicas da atmosfera natural da Bacia Amazônica são modificados pela interação com emissões urbanas, em particular quanto à formação de aerossóis orgânicos secundários. Para isso, propõem-se os seguintes objetivos específicos:

1) Caracterizar a abundância e características de gases e partículas atmosféricas na região central de Manaus em termos de suas concentrações características, composição físicoquímica, razões entre concentrações de compostos co-emitidos, além das propriedades óticas das partículas.

2) Caracterizar as alterações que emissões urbanas de Manaus sofrem a $10 \mathrm{~km}$ vento abaixo da cidade em termos de sua composição físico-química e propriedades óticas.

3) Avaliar a produção de ozônio e aerossóis orgânicos secundários dos sítios T1 e T2 do experimento GoAmazon 2014/15.

4) Comparar os processos de envelhecimento observados pela pluma urbana em regiões próximas a cidade com resultados obtidos em demais sítios do GoAmazon 2014/15 km vento abaixo e vento acima de Manaus.

Estes objetivos complementam os mais de 70 artigos publicados com resultados do experimento GoAmazon 2014/15. Importante salientar que nenhum destes 70 trabalhos analisou detalhadamente medidas realizadas nos sítios T1 e T2 próximos ou dentro de Manaus. A abordagem experimental deste trabalho de mestrado é única e relevante para regiões tropicais. Seja em futuros novos centros urbanos que estão se desenvolvendo na região amazônica ou em regiões centrais da África e Sudoeste da Ásia que também apresentam emissões urbanas interagindo com emissões biogênicas da floresta no entorno de cidades em expansão rápida, como Manaus. 


\section{METODOLOGIA}

Neste capítulo detalharemos a metodologia utilizada na coleta e análise de dados neste trabalho. A base de dados analisada é muito extensa, e reflete a operação de instrumentação operada em condições difíceis e inéditas na região tropical brasileira. Nos baseamos em medidas intensivas realizadas pelo projeto GoAmazon2014/15 em dois principais sítios de amostragem nas proximidades de Manaus, mostrados na Figura 3.1, equipados com ampla gama de instrumentos. Estas medidas, assim como todas as realizadas pelo Experimento GoAmazon, estão disponíveis livremente para download por meio do servidor ftp público do grupo do Laboratório de Física Atmosférica da USP, no endereço http://lfa.if.usp.br/ftp/public/LFA_Processed_Data/. Importante salientar que o grupo tem uma política livre de disponibilidade de dados.

Figura 3.1 - Imagem de satélite da localização dos sítios de amostragem utilizados no experimento GoAmazon, em especial os sítios T1 (Manaus) e T2 (margem oposta do Rio Negro), que serão os focos deste projeto de mestrado. Em azul está a direção média do vento na estação meteorológica do INMET durante o período amostrado, que mostra direção preferencial do vento vindo de nordeste e leste.

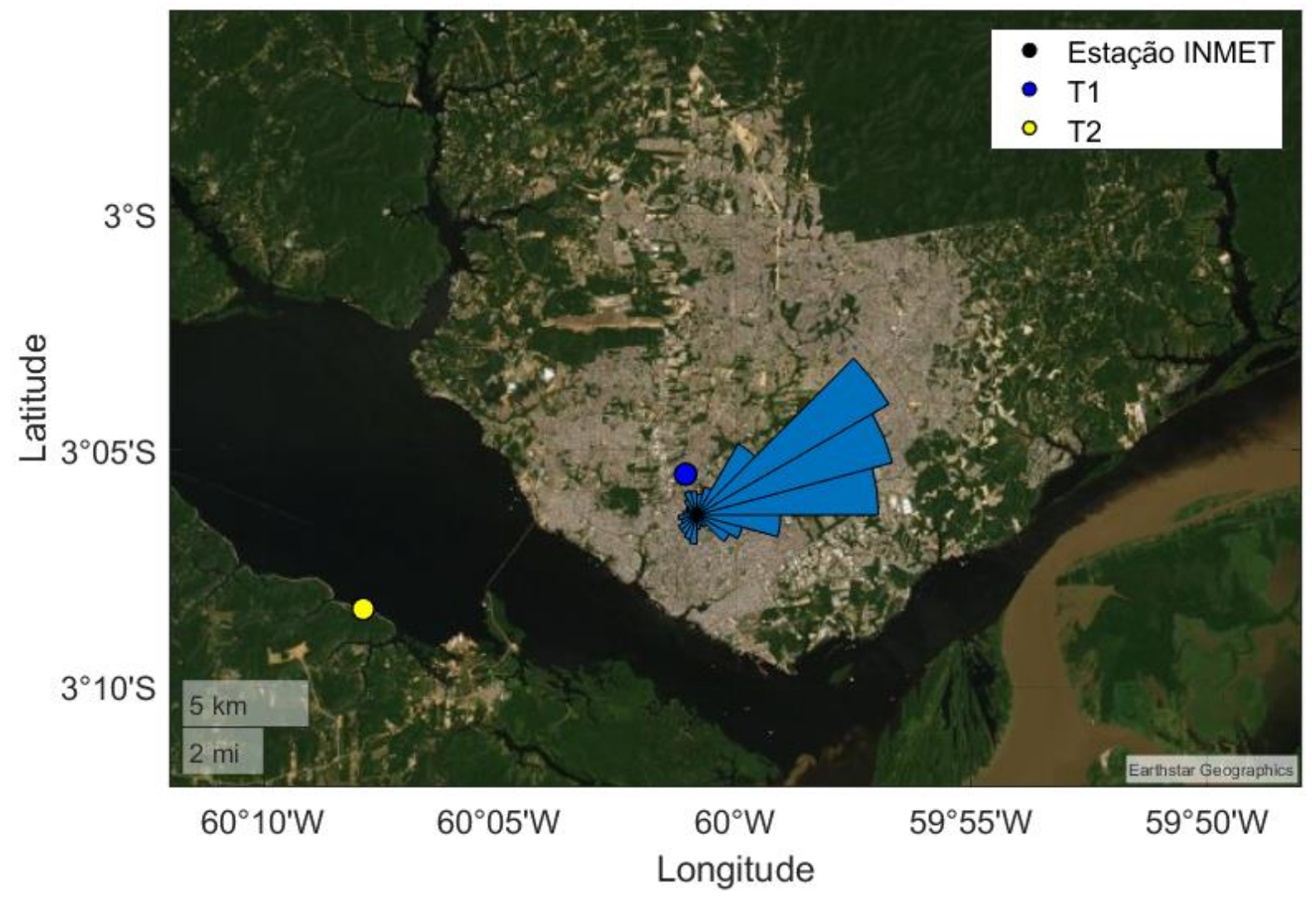

O primeiro sítio de medidas, denominado $\mathrm{T} 1\left(^{\circ} 05^{\prime} 49.9^{\prime \prime} \mathrm{S} 59^{\circ} 59^{\prime} 12.1^{\prime \prime} \mathrm{W}\right)$, ponto azul na figura 3.1, está localizado no centro de Manaus, na Escola Superior de Tecnologia da 
Universidade do Estado do Amazonas (UEA), em uma área ao lado de vias muito movimentadas na cidade, e é o sítio de referência para medir a o perfil da poluição urbana de Manaus. A análise da poluição urbana através de um único sítio, porém, está sujeita a dois vieses que representam limitações relevantes para este estudo: fontes locais que não atuam em toda a cidade podem influenciar mais fortemente as medidas; e fontes relevantes relacionadas às atividades urbanas que estão vento abaixo da região central da cidade podem influenciar menos as medidas em T1. As emissões de usinas termelétricas podem ser exemplos de contribuições à poluição atmosférica não significativamente amostradas em T1 pois uma fração significativa destas termelétricas está localizada próxima ao Rio Negro (MARTIN et al., 2016).

O segundo sítio experimental, denominado T2 ( $\left.3^{\circ} 8^{\prime} 21.12^{\prime \prime} \mathrm{S}, 60^{\circ} 7^{\prime} 53.40^{\prime \prime} \mathrm{W}\right)$, fica em um container nas proximidades do Hotel Tiwa, na margem do Rio Negro oposta a Manaus e pode ser visto na Figura 3.2. Este sítio experimental T2 está separado por uma distância de 13.7 $\mathrm{km}$ de $\mathrm{T} 1$ e foi posicionado na direção preferencial do vento vindo da cidade, de forma a capturar na maior parte do dia a pluma poluída da cidade (CIRINO et al., 2018). Dependendo desta direção, pode amostrar a pluma da metrópole depois de 8 a $12 \mathrm{~km}$ de passagem sobre o Rio Negro, com vento vindo de nordeste a leste).

As medidas foram realizadas durante os meses de fevereiro, março e abril de 2014 no sítio T2 e de 2016 no sítio T1, parte do período da estação chuvosa da Amazônia, com o objetivo de eliminar os efeitos de queimadas regionais que acontecem anualmente na região e focar o estudo na interação da poluição urbana com as emissões biogênicas naturais. 
Figura 3.2 - Foto do sítio experimental T2 do experimento GoAmazon 2014/15, na margem no Rio Negro, oposta à cidade de Manaus.

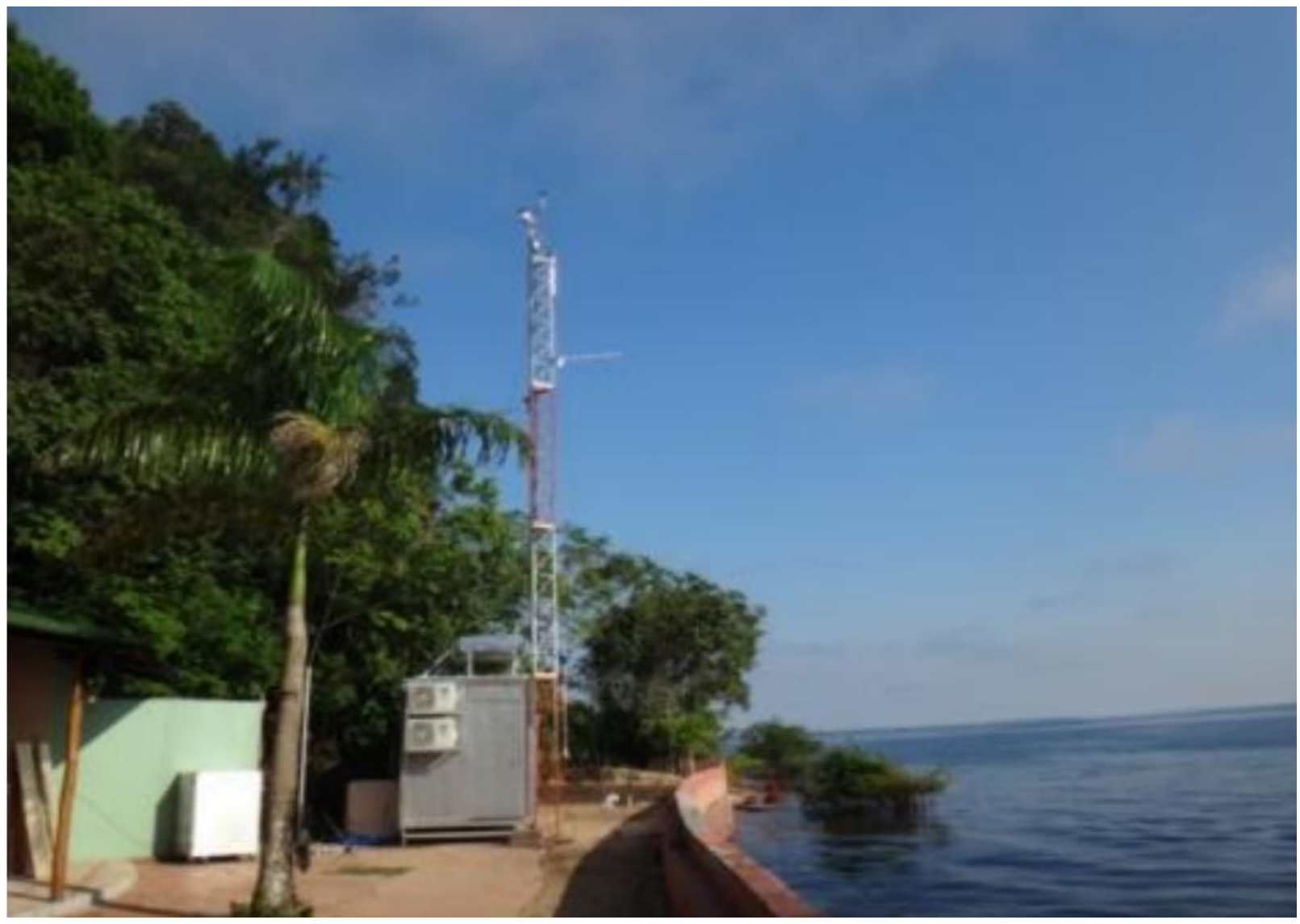

\subsection{METEOROLOGIA NA REGIÃO DE ESTUDO}

A Figura 3.1 contém um histograma que mostra a direção preferencial do vento medida na estação meteorológica de Manaus do Instituto Nacional de Meteorologia (INMET) durante a estação chuvosa de 2016, que mostra claramente a direção preferencial do vento vindo de nordeste e leste para oeste e sudeste. Apesar do sítio T2 contar com medidas meteorológicas, neste trabalho preferimos utilizar as medidas já validadas do INMET para mostrar a direção usual do vento por conta de uma particularidade da topografia deste sítio: o local onde se situa o sítio T2 está muito próximo de uma pequena elevação do terreno. Este fator afeta a circulação local e faz com que a direção do vento no local não seja um bom indicador de se a massa de ar veio ou não da região central da cidade de Manaus. Esta mesma direção preferencial do vento já foi analisada e demonstrada com dados dos dois aeroportos de Manaus que também possuem estações meteorológicas completas por DOS SANTOS et al. (2014) e por simulações de trajetórias por MARTIN et al. (2017). 
Durante o período noturno, outros fatores podem ser relevantes para a meteorologia local e para o transportes de massa de ar entre Manaus e o sítio T2: a brisa do Rio Negro pode provocar mudança na direção usual do vento, causando correntes de ar do continente para a direção do Rio Negro e trazendo massas de ar de sul e de oeste em relação a T2, direção contrária à cidade; e a camada limite noturna da cidade, que por ser mais fina e estável, deve limitar a dispersão e transporte da poluição emitida na cidade até o sítio T2. Apesar disso, para manter as hipóteses simples e manter um grande volume de dados de forma que estes representem de forma adequada as observações típicas da temporada chuvosa na região, optamos por comparar os períodos completos e considerar os vieses conhecidos nas conclusões.

Figura 3.3 - (a) Precipitação acumulada mensal para o sítio meteorológico do INMET em Manaus, para os anos de 2014 (barras vermelhas), 2016 (barras azuis), e a média climatológica durante o período de 1961 a 1990 (pontos pretos). (b) Distribuição acumulada de precipitação diária nos dois anos.
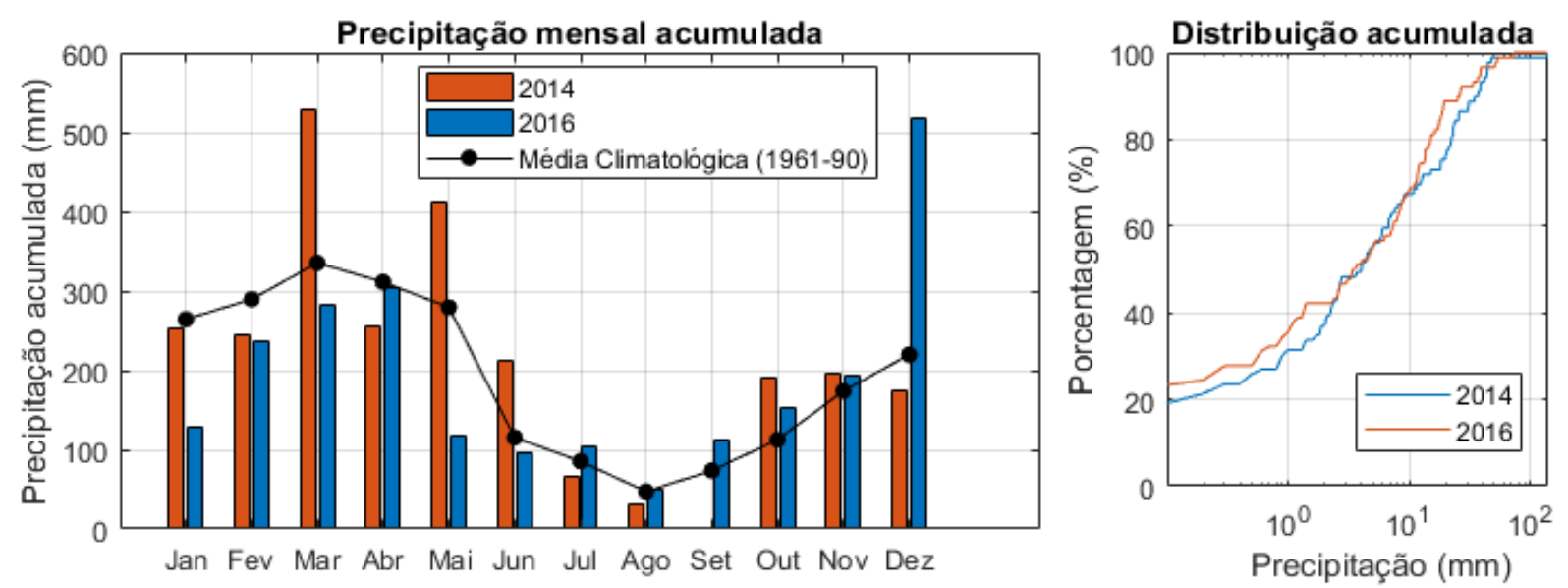

O período analisado teve, em geral, meteorologia semelhante entre os anos de 2014 e 2016, o que pode ser visto na Figura 3.3 (a) pela semelhança entre os valores de precipitação acumulada em fevereiro e abril, à exceção de março. Neste mês houve um dia em que a precipitação diária, de $137 \mathrm{~mm}$, foi responsável pela maior parte desta diferença e que, portanto, não representa um efeito de alteração de precipitação ao longo do mês. A Figura 3.3 (b) mostra uma distribuição acumulada de precipitação diária, ou seja, a porcentagem dos dias (eixo y) que tiveram precipitação acumulada diária menor ou igual a um dado limite (eixo x). Uma pequena diferença entre os dois anos de $\sim 4 \%$ na região de dias com baixa precipitação desta figura indica que em 2016 pode ter agido um efeito maior de remoção úmida de particulado atmosférico ou outros efeitos relativos à precipitação mais acentuados. A Tabela 1 mostra a mediana e intervalo interquartil (intervalo entre o percentil 0.25 até o percentil 0.75 ) relativos às variáveis meteorológicas entre os dois anos. 
Tabela 1 - Comparação entre os dados meteorológicos diários para o período estudado (fevereiro a abril), mostrando os valores médios e entre parênteses o intervalo interquartil. Dados da estação meteorológica do INMET.

Variável meteorológica

Temperatura compensada diária

Umidade média diária

Precipitação média diária
2014

$27.0(26.1-27.6){ }^{\circ} \mathrm{C}$
$84.5(80.9-88.7) \%$
$4.0(0.4-18.5) \mathrm{mm} / \mathrm{dia}$

$4.0(0.4-18.5) \mathrm{mm} / \mathrm{dia}$
2016

$28.1(26.9-28.9){ }^{\circ} \mathrm{C}$

$81.5(75.7-87) \%$

$3.5(0.2-13.3) \mathrm{mm} / \mathrm{dia}$

\subsection{INSTRUMENTAÇÃO EMPREGADA NESTE ESTUDO}

Para cumprir os objetivos deste projeto, foram utilizados múltiplos instrumentos para medidas de propriedades físico-químicas de aerossóis e de gases traço, cujos modelos e propriedades medidas estão listados na Tabela 2, abaixo.

Tabela 2 - Instrumentação utilizada em cada sítio foco deste trabalho.

\begin{tabular}{|l|l|l|}
\hline \multicolumn{1}{|c|}{ Propriedade medida } & \multicolumn{2}{c|}{ Instrumentos } \\
\cline { 2 - 3 } & \multicolumn{1}{c|}{ T1 } & \multicolumn{1}{c|}{ T2 } \\
\hline Número de partículas & CPC 3776 & CPC 3772 \\
\hline Distribuição de tamanho de partículas & SMPS TSI 3081 & SMPS TSI 3081 \\
\hline Composição química de partículas & ToF-ACSM & Q-ACSM \\
\hline Coeficiente de espalhamento & Aurora Ecotech 2000 & Aurora Ecotech 3000 \\
\hline Coeficiente de absorção & Magee AE-33 & MAAP 5012 \\
\hline Concentração de COVs & Q-PTRMS & Q-PTRMS \\
\hline Concentração de CO & LGR's CO Analyzer & LGR's CO Analyzer \\
\hline Concentração de O3 & 49i Ozone Analyzer & 49i Ozone Analyzer \\
\hline
\end{tabular}

Os principais instrumentos utilizados neste trabalho têm seus princípios de funcionamento resumidos abaixo.

\subsubsection{Medidas do número de partículas pelo contador de partículas por condensação (CPC)}

O Condensation Particle Counter (CPC) é um instrumento utilizado para obter a densidade de número de partículas que tem limite mínimo de diâmetro de partícula para detecção de 10nm nos modelos TSI 3772 (sítio T2) e 3776 (sítio T1). Seu esquema de 
funcionamento está exposto na Figura 3.4. O instrumento conta com uma bomba aspirando o ar por um inlet com um impactador para filtrar as partículas pelo diâmetro $\left(\mathrm{PM}_{2.5}\right.$ - aerossóis menores de $2.5 \mu \mathrm{m}$ ) que, entrando no equipamento, atravessam um bloco poroso aquecido. $\mathrm{O}$ bloco, em contato com butanol, faz com que o ar saindo deste meio esteja saturado por este composto orgânico. Em seguida, o fluxo de ar entra em contato com um bloco resfriado diminuindo a temperatura da amostra de ar e causando supersaturação. Este fenômeno causa um processo similar ao que acontece nas nuvens, de forma que as partículas se tornam núcleos de condensação e crescem rapidamente.

Figura 3.4 - Esquema do contador de partículas por condensação (CPC), que mostra o mecanismo pelo qual as partículas entram em contato com um meio supersaturado e crescem. Então, são contadas opticamente por um sistema de laser e sensor de luz (extraído de http://www.cas.manchester.ac.uk/restools/instruments/aerosol/cpc/).

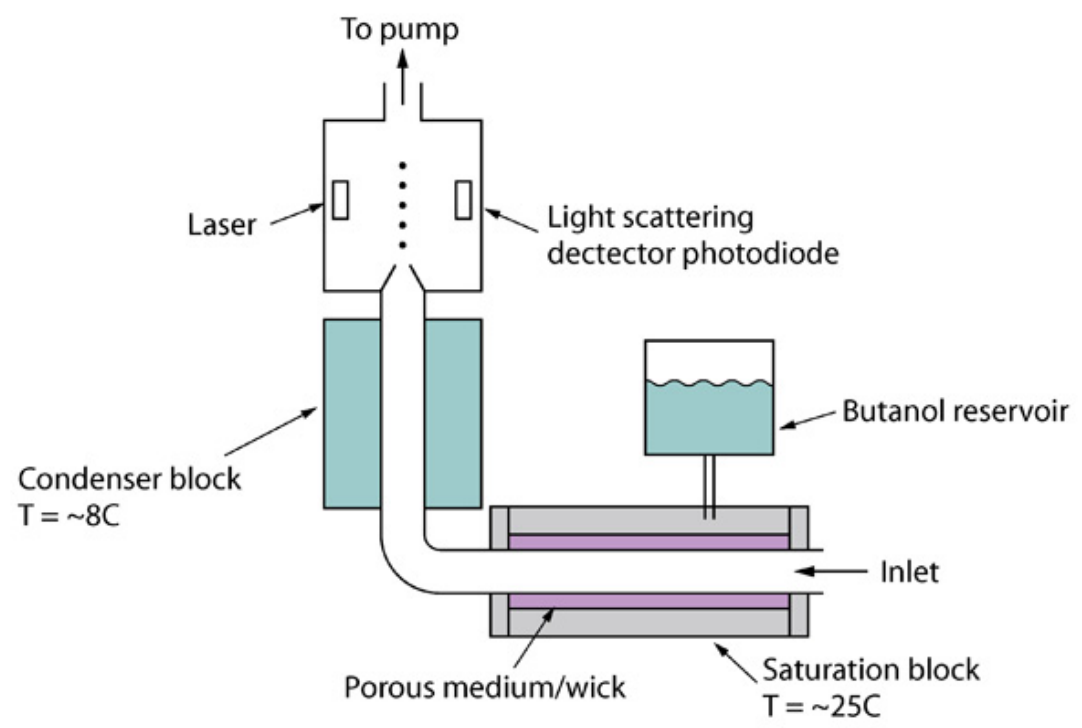

Ao crescerem, atingem tamanho suficiente para serem contadas por um detector óptico simples, e, com a vazão de ar de 1 litro por minuto, obtém-se a concentração de partículas por unidade de volume de ar em tempo real.

\subsubsection{Medida da distribuição de tamanho de partículas por SMPS}

O Scanning Mobility Particle Sizer (SMPS) é um instrumento utilizado para determinação da distribuição de tamanho das partículas finas e seu esquema está ilustrado pela Figura 3.5. As partículas aspiradas pelo instrumento passam por um neutralizador de cargas, que age alterando a carga elétrica destas partículas para uma distribuição de carga previsível. Estas partículas serão direcionadas por um fluxo de ar laminar (sem partículas, filtrado) dentro de um DMA (Differential Mobility Analyzer). Este dispositivo seleciona o aerossol baseado em 
sua mobilidade elétrica, que depende do seu diâmetro e de sua carga elétrica. O instrumento seleciona as partículas em 108 canais com faixas estreitas de diâmetros entre 9 e 445 nm, de forma que são dirigidas para dentro de um CPC e então são contadas, de forma a obter uma distribuição de tamanho de partículas em tempo real.

Figura 3.5 - Esquema do SMPS, instrumento que mede a distribuição de tamanho de partículas, por meio da seleção de mobilidade elétrica do DMA.

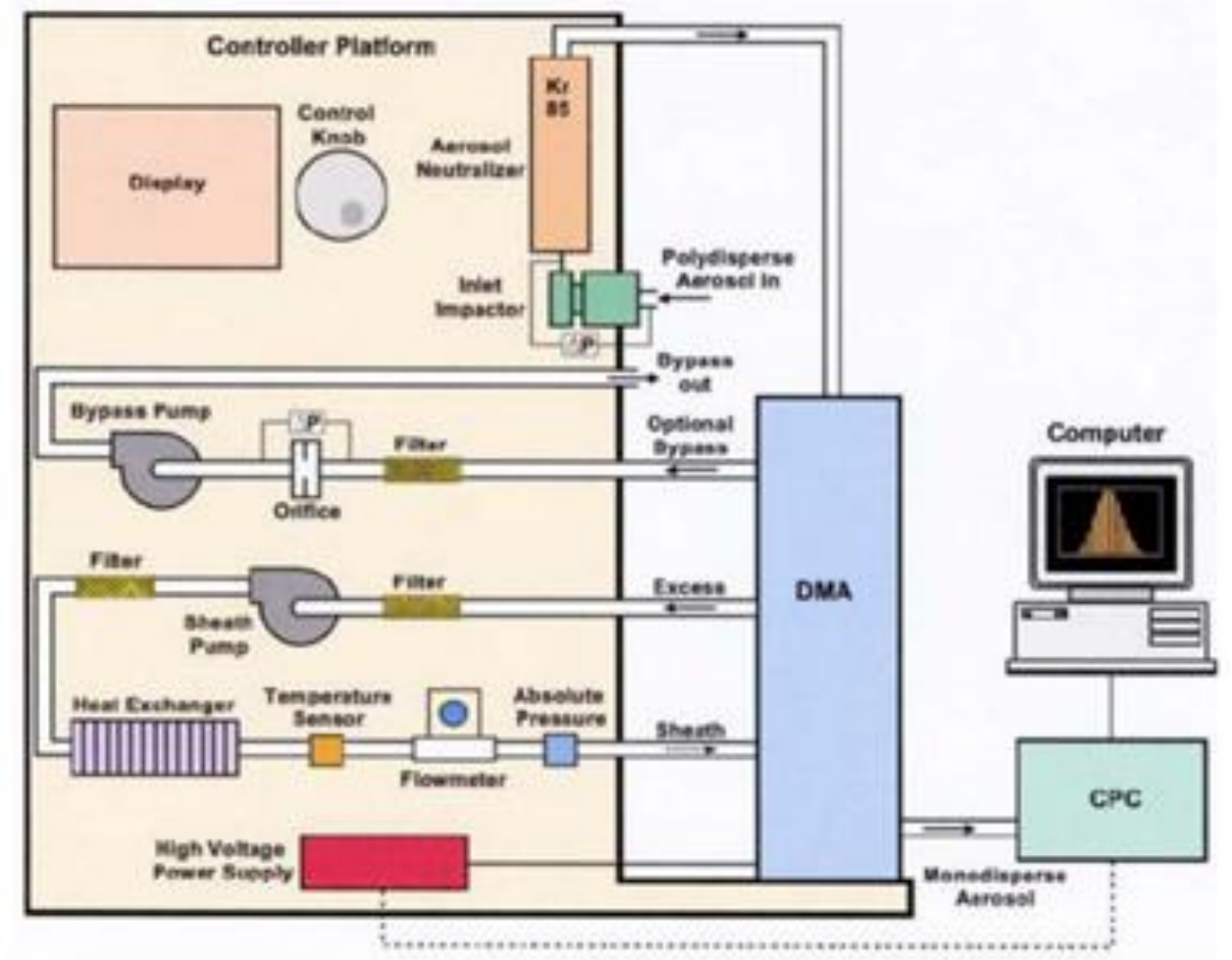

\subsubsection{Medidas de espalhamento óptico de aerossóis pelo nefelômetro}

O nefelômetro é um instrumento que mede o coeficiente de espalhamento e de retro espalhamento de aerossóis atmosféricos em tempo real. Os modelos utilizados neste trabalho foram o Aurora Ecotech 2000 e 3000, nos sítios T1 e T2, respectivamente. A Figura 3.6 representa o esquema do aparelho, cuja medida começa pela sucção da amostra ambiente feita por uma bomba para dentro do instrumento através de um inlet com um impactador que separa partículas de $\mathrm{PM}_{2.5}$. Estas partículas entram em uma câmara halogênica iluminada horizontalmente em uma faixa angular de $7^{\circ}$ a $170^{\circ}$, e esta luz atinge as partículas distribuídas no corpo do equipamento. No lado esquerdo da figura, é possível notar que o espalhamento é detectado pela radiação que atravessa a lente e, em seguida, atravessa filtros dicroicos que separam a luz em três comprimentos de onda (450nm, 550nm e 750nm). Esta luz chega a três fotomultiplicadores e este sinal é transmitido eletronicamente para um computador no contêiner 
do sítio. Deste sinal, se subtrai a luz espalhada pelo gás, pelas paredes do instrumento e pelo ruído de fundo, e se obtém o coeficiente de espalhamento óptico apenas gerado pelos aerossóis atmosféricos.

Figura 3.6 - Esquema de um nefelômetro, em que os aerossóis ao atravessar a câmara principal são iluminados por uma lâmpada em uma faixa de quase $180^{\circ}$ e espalham radiação, que é focada por uma lente e passa por filtros dicroicos antes de ser detectada (extraído de TSI Inc.).

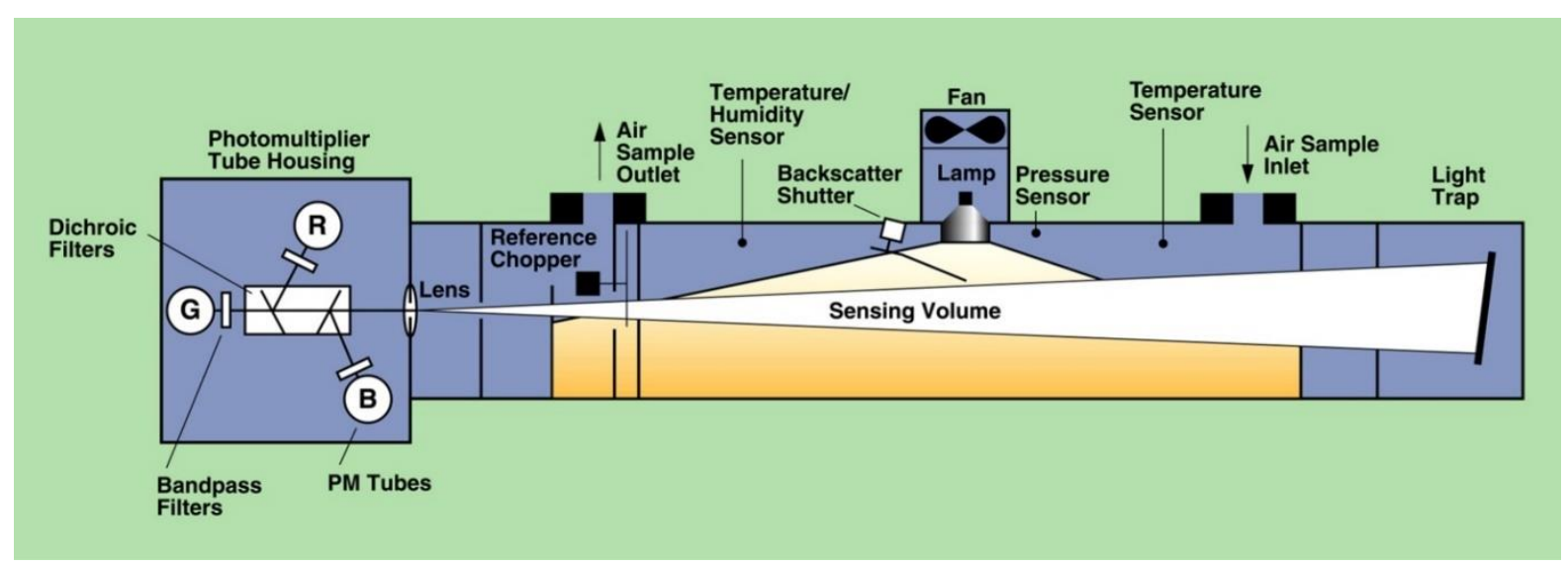

\subsubsection{Medidas de absorção óptica de aerossóis pelo Aetalômetro}

O Aetalômetro é um instrumento que mede absorção óptica de aerossóis em tempo real para diferentes comprimentos de onda e transforma em concentração de black carbon. No caso do AE-33, utilizado neste experimento, as medidas contam com resolução temporal de 1 minuto e são realizadas em sete comprimentos de onda, entre $370 \mathrm{~nm}$ e $950 \mathrm{~nm}$.

O mecanismo é baseado na medida da intensidade de radiação detectada após esta atravessar um filtro com partículas, obtendo-se assim a atenuação óptica a partir da lei de BeerLambert.

$$
\mathrm{ATN}=100 \ln \left(\frac{\mathrm{I}_{\mathrm{o}}}{\mathrm{I}}\right)
$$

em que $\mathrm{I}_{\mathrm{o}}$ é a radiação detectada após atravessar um filtro limpo de referência e é I a radiação detectada após atravessar o filtro com partículas.

A diferença na atenuação óptica $(\Delta \mathrm{ATN})$ entre um tempo e outro é atribuída a presença de aerossóis absorvedores do tipo black carbon, e a seguinte equação é utilizada para se obter indiretamente a concentração desta classe de partículas (HANSEN et al., 1984):

$$
\left[\mathrm{BC}_{e}\right]=\frac{\mathrm{A} \cdot \Delta \mathrm{ATN}}{\alpha_{\mathrm{ATN}} \cdot 100 \cdot \mathrm{Q} \cdot \Delta \mathrm{t}}
$$

sendo ' $\mathrm{A}$ ' a área do filtro, ' $\mathrm{Q}$ ' o fluxo de ar aspirado pela bomba, $\Delta$ t o intervalo de tempo entre as medidas de atenuação, $\propto_{\mathrm{ATN}} \mathrm{o}$ coeficiente de absorção de massa e $\mathrm{BC}_{\mathrm{e}}$ denominado de 
"equivalente de black carbon" para indicar que este foi mensurado a partir de uma medida ótica, e representa a massa de BC que causaria a atenuação medida.

Através da obtenção dos coeficientes de espalhamento e absorção ópticos de aerossóis, podemos estudar características intrínsecas da população de partículas amostrada, que não dependem de sua quantidade, mas de seu caráter físico-químico. Neste sentido, uma importante variável é o albedo de espalhamento único (SSA - single scattering albedo), dado pela razão entre o coeficiente de espalhamento e a soma dos coeficientes de espalhamento e absorção (denominada de coeficiente de extinção). Este coeficiente reflete o grau de espalhamento causado por uma determinada população de partículas.

\subsubsection{Composição química de compostos orgânicos voláteis - COVs}

Medidas em ambos os sítios da razão de mistura de COVs a cada 30 minutos foram realizadas pelo PTR-MS (Proton Transfer Reaction Mass Spectrometer). Por meio deste instrumento, as concentrações de $12 \mathrm{COVs}$ foram medidas, para os compostos: metanol, acetonitrila, acetaldeído, acetona, isopreno, metacroleína + metil-vinil-cetona, metil-etilcetona, benzeno, tolueno, aromáticos com 8 carbonos, aromáticos com 9 carbonos e monoterpenos.

Figura 3.7 - Esquema do PTR-MS, espectrômetro de massa com detector do tipo quadrupolo que mede concentrações de COVs, gases orgânicos precursores de partículas, através da ionização por transferência protônica ao COV e subsequente detecção em um detector quadrupolo (extraído de YERETZIAN et al., 2002).

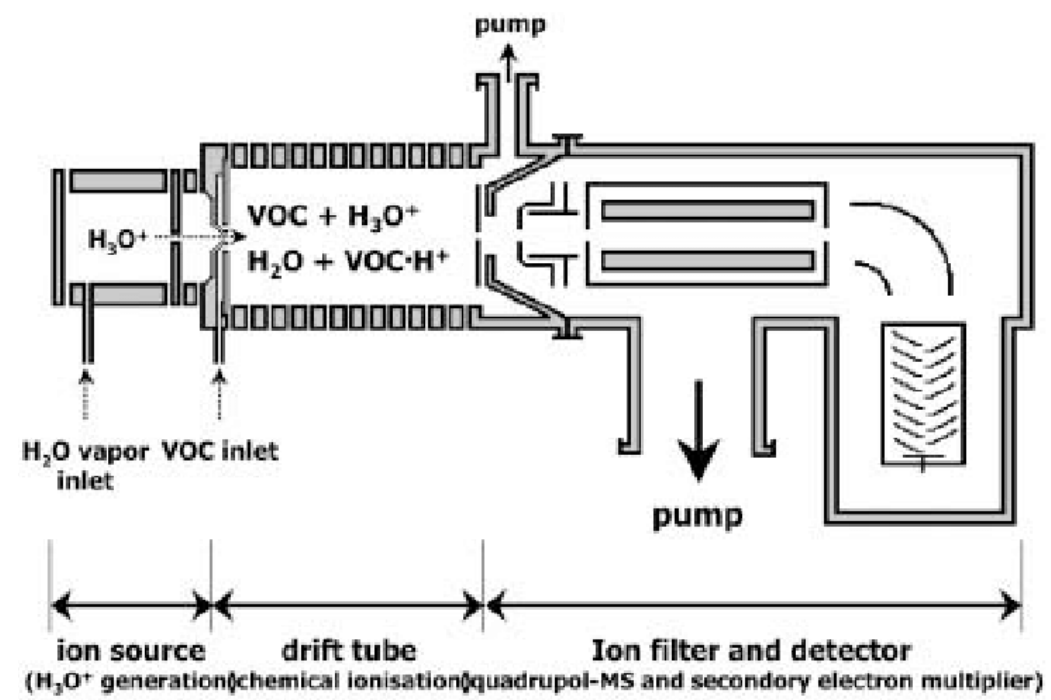

Como ilustrado pela Figura 3.7, o instrumento consiste em 3 câmaras. Na primeira, a água é volatilizada e ionizada, de forma a produzir $\mathrm{H}_{3} \mathrm{O}^{+}$, o íon hidrônio. Estes íons são dirigidos 
para a próxima câmara por diferença de pressão causada por uma bomba. Nesta câmara, COVs com afinidade protônica suficiente $(>166.5 \mathrm{kcal} / \mathrm{mol})$ entram através de um inlet e reagem com os íons hidrônios, resultando em uma transferência do íon $\mathrm{H}^{+}$para o $\mathrm{COV}$, uma reação de transferência protônica. Desta forma, os íons são acelerados para a próxima câmara, onde estes gases com uma razão entre massa e carga $(\mathrm{m} / \mathrm{z})$ específica são acelerados por meio de campos eletromagnéticos e a intensidade de fluxo de íons com esta razão $\mathrm{m} / \mathrm{z}$ é medida por um detector quadrupolo.

Como a reação predominante é a transferência protônica, os COVs originais podem ser identificados (a menos de isômeros como metacroleína e metil-vinil-cetona, ambos com 70 unidades de massa atômica (amu)) a partir das razões de $\mathrm{m} / \mathrm{z}$, considerando que sua massa original foi acrescida de 1 amu e sua carga é de uma unidade. Desta forma, através de calibrações com gases com composição e concentrações conhecidas, é possível obter a concentração absoluta destes COVs.

\subsubsection{Composição química de aerossóis medida com espectrômetro de massa (ACSM)}

Medidas de composição química das componentes inorgânicas de sulfato, nitrato, amônio, cloreto, e a componente orgânica do particulado fino (aerossóis com diâmetro menor do que $1 \mu \mathrm{m}-\mathrm{PM}_{1}$ ) foram realizadas por meio de dois espectrômetros de massa denominados ACSM (Aerosol Chemical Speciation Monitor) e foram essenciais para este trabalho. Os instrumentos fazem medições de composição química em tempo real (10 a 30 minutos de resolução) pela técnica de espectrometria de massa, uma poderosa ferramenta utilizada para caracterizar aerossóis e seu processamento atmosférico. Os dois espectrômetros utilizados neste trabalho foram equipados com dois detectores diferentes, um quadrupolo (ACSM-Quad), no T2, e outro por tempo de voo (ToF-ACSM), no T1.

A Figura 3.8 mostra um esquema do funcionamento do ACSM-Quadrupolo. As partículas entram no equipamento através de um inlet e são focadas por um conjunto de lentes aerodinâmicas, com eficiência de transmissão maior do que 50\% para partículas de $75-650 \mathrm{~nm}$ (LIU et al., 2007). O fluxo de partículas é controlado pela diferença de pressão entre três bombas turbo com pressão diferencial entre cada uma das três câmaras, que diminuem a quantidade de moléculas gasosas da amostra, chegando a valores de pressão de $\sim 10^{-7}$ mbar na última câmara.

As partículas atravessam duas câmaras e atingem um impactador de tungstênio que é mantido tipicamente a $600^{\circ} \mathrm{C}$, o que causará a vaporização quase instantânea de uma fração do material particulado coletado, chamada de não refratária (exclui componentes como poeira 
mineral e BC, que não são vaporizadas). Esta fração, agora em estado gasoso, sofre ionização por um feixe de elétrons emitidos com $75 \mathrm{eV}$, de forma que a contribuição em massa de íons com múltiplas cargas é negligível e, portanto, pode-se identificar o íon através de sua massa considerando sua carga como a unidade (NG et al., 2011).

O instrumento elimina o sinal dos gases da atmosfera através do princípio de uma '3way valve': alterna-se ciclos entre um modo onde o fluxo de ar passa por um filtro de partículas (filter), em que se mede apenas o sinal de gases, e um modo sem filtro (sample), em que se mede o sinal de contribuição de gases e partículas. Desta forma, calcula-se o sinal proveniente apenas das partículas por meio da diferença (diff) entre estes dois sinais (sample - filter).

Figura 3.8 - Esquema do ACSM-Q, espectrômetro de massa com detector do tipo quadrupolo, com lentes aerodinâmicas que focam o feixe de partículas que entram pelo inlet e são vaporizados e ionizados para permitir a detecção eletromagnética por meio de um detector quadrupolo (extraído de NG et al., 2011).

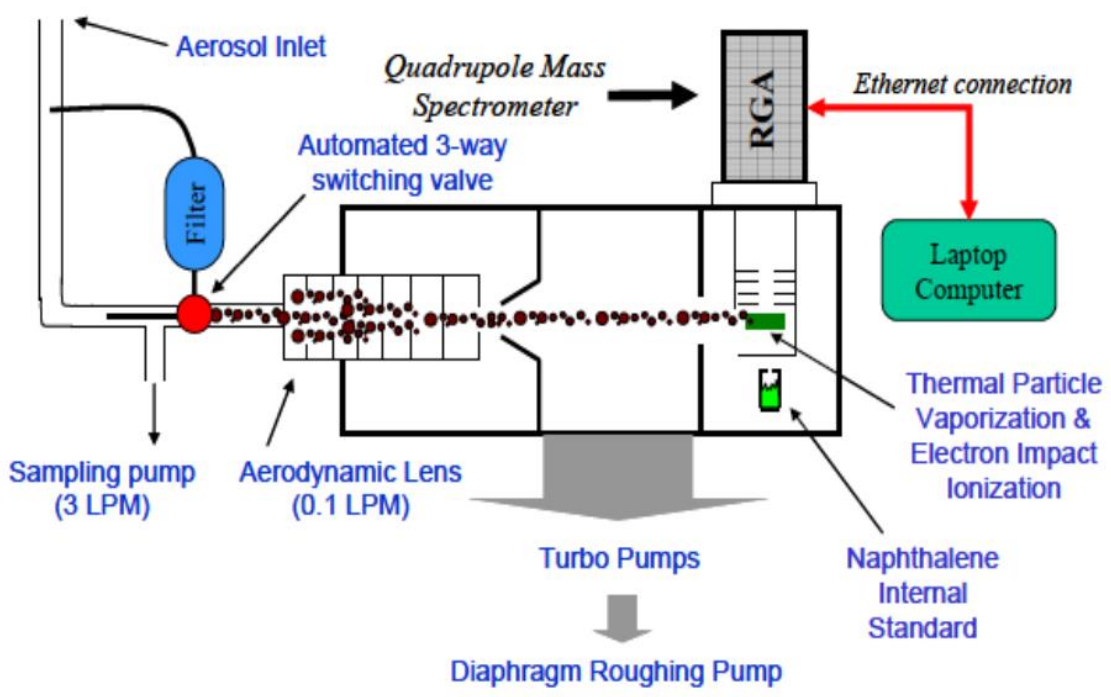

Neste processo de vaporização e ionização, as partículas atmosféricas sofrem fragmentação e dissociação térmica e os fragmentos ionizados das moléculas originais são transferidos para um detector do tipo quadrupolo, sendo então selecionados através de campos eletromagnéticos que selecionam fragmentos com diferentes razões entre massa e carga $(\mathrm{m} / \mathrm{z})$, uma de cada vez em uma taxa de $\sim 1 \mathrm{amu} / \mathrm{s}$. Depois de processamento detalhado na próxima sessão, é obtido um espectro de massa com intensidades em íons por segundo para fragmentos de m/z que variam entre 12 e 140 amu. Esse espectro de massa contínuo é convertido a valores unitários de m/z.

O outro espectrômetro de massa utilizado neste trabalho é o ToF-ACSM, que foi operado no sítio T1. A principal diferença deste instrumento é seu detector (Economy Time-ofFligh - EToF), baseado na dependência conhecida entre a razão $\mathrm{m} / \mathrm{z}$ e o tempo de voo de 
fragmentos acelerados através de campos eletromagnéticos pela mesma distância. À exceção do detector, a estrutura deste instrumento é muito semelhante à estrutura do ACSM-Q, como pode ser visto pela Figura 3.9. O impactador e ionizador apresentam a mesma temperatura e energia de elétrons ionizantes, respectivamente, de forma que a fragmentação é comparável entre os instrumentos. Uma vantagem deste tipo de detector de tempo de voo sobre o quadrupolo é que a intensidade de todo o espectro de massa é medida ao mesmo tempo, o que permite contagens (de íons por segundo) muito maiores para todos os fragmentos, levando a uma diminuição significativa da incerteza, reduzindo limites de detecção e aumentando a resolução do espectro de massa (FRÖHLICH et al., 2013).

Figura 3.9 - Esquema do espectrômetro de massa ToF-ACSM, mostrando projeto semelhante ao espectrômetro quadrupolo e um detector do tipo tempo de voo que garante uma diminuição significativa da incerteza, reduzindo limites de detecção e aumentando a resolução do espectro de massa (extraído de FRÖHLICH et al., 2013).

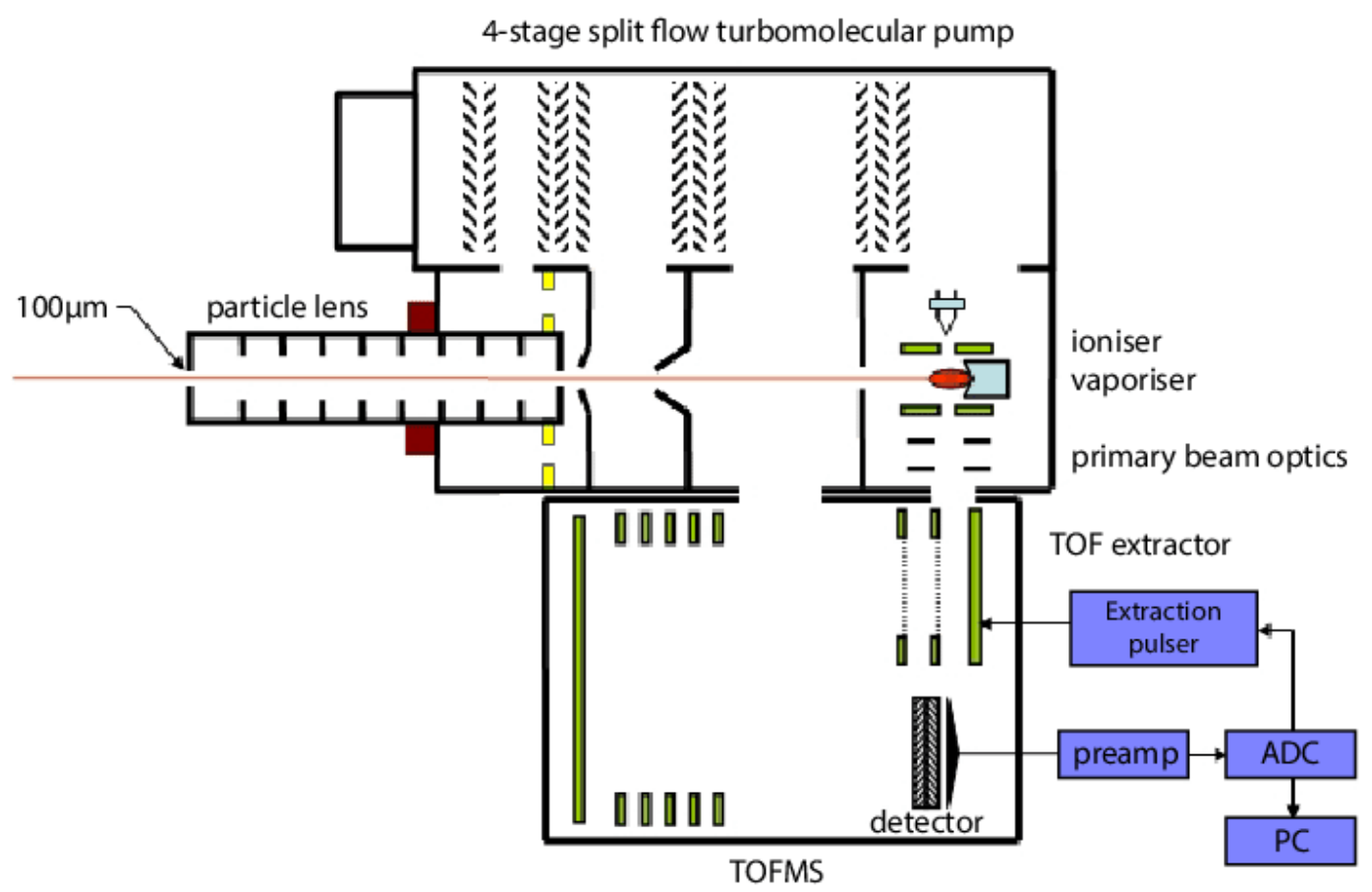

A partir dos fragmentos detectados pelos espectrômetros de massa de aerossol, é possível "remontar" o sinal devido aos compostos originais a partir de uma tabela de fragmentação (AIKEN et al., 2008; CANAGARATNA et al., 2015). Esta é responsável por atribuir contribuições de espécies químicas responsáveis por cada fragmento com $\mathrm{m} / \mathrm{z}$ diferentes. Assim, é possível converter as intensidades de íons $i$ por segundo provenientes de aerossóis da espécie química $s$, denominado de $I_{s, i}$ (íons/s), em concentração volumétrica de massa total da espécie $s, C_{s}\left(\mu \mathrm{g} / \mathrm{m}^{3}\right)$, por meio da seguinte relação (CANAGARATNA et al., 2007): 


$$
C_{S}=\frac{10^{12} * M W_{S}}{I E_{S} * Q * N a} * \sum_{i} I_{S, i}
$$

onde Q é o fluxo volumétrico em $\mathrm{cm}^{3} \mathrm{~s}^{-1}$, Na é a constante de Avogadro e IEs a eficiência de ionização da espécie s em íons/molécula.

A eficiência de ionização é determinada por uma calibração realizada com o auxílio de um gerador de aerossóis com solução de composição química conhecida (nitrato de amônio e/ou sulfato de amônio) acoplado em um DMA que seleciona um tamanho de partículas (300nm por padrão) e em um CPC para contar o número de partículas na mesma linha que o ACSM. Desta forma, o tamanho e número de partículas amostradas pelo ACSM são conhecidos e, portanto, é possível calcular a concentração em massa da amostra. Desta forma, é feito um ajuste linear entre a soma dos sinais dos fragmentos oriundos da espécie s detectada pelo ACSM (em íons/s) e a concentração em massa da espécie s calculada através desse sistema (em $\mu \mathrm{g} / \mathrm{m}^{3}$ ) para obter-se uma eficiência de ionização $\left(\mathrm{IE}_{\mathrm{s}}\right)$ relativa à espécie s.

A solução de nitrato de amônio é a principal solução utilizada na calibração pois é acessível, facilmente atomizada, vaporiza com 100\% de eficiência em íons de nitrato e amônio, é bem focada pelas lentes aerodinâmicas e não apresenta efeito elástico ao impactar o vaporizador (FRÖHLICH et al., 2013). Este efeito elástico acontece com partículas que atingem o impactador, mas não permanecem no material, e é corrigido através de uma eficiência de coleção (CE), que tem uma dependência conhecida com a composição química (MIDDLEBROOK et al., 2012).

Desta forma, para obter a concentração de uma outra espécie s de massa atômica $\mathrm{MW}_{\mathrm{S}}$, utilizamos eficiências de ionização relativas $\left(\mathrm{RIE}_{S}\right)$ à calibração com nitrato através da seguinte relação:

$$
\frac{I E_{S}}{M W_{S}}=R I E_{S} * \frac{I E_{N O 3}}{M W_{N O 3}}
$$

Porém, enquanto em sistemas de alta resolução temporal como no AMS é possível detectar partículas únicas, no ACSM isso não é possível. Por este motivo, ao invés de obter-se $\mathrm{IE}_{\mathrm{S}}$, obtém-se através do ajuste da calibração descrita um fator de resposta $\left(\mathrm{RF}_{\mathrm{S}}\right)$, com unidade de $\mathrm{A}\left(\mu \mathrm{g} \mathrm{m}^{-3}\right)^{-1}$ que está relacionado com a grandeza $\mathrm{IE}_{\mathrm{S}}$ a partir da seguinte expressão:

$$
I E_{N O 3} * \frac{N a}{M W_{N O 3}}=\frac{R F_{N O 3}}{Q_{c a l} G_{c a l}}
$$

com Q $\mathrm{CAL}$ sendo o fluxo volumétrico em $\mathrm{cm}^{3} \mathrm{~s}^{-1}$ durante a calibração e $\mathrm{G}_{\mathrm{CAL}}$ o ganho do detector durante a calibração. Desta forma, é possível aplicar as equações 5 e 6 na equação 4 para obter as concentrações em massa das componentes não refratárias do $\mathrm{PM}_{1}$. 
Enquanto a quantidade de fragmentos de razões $\mathrm{m} / \mathrm{z}$ diferentes que compõem cada uma das espécies inorgânicas é de poucas unidades, a quantidade de fragmentos diferentes provenientes dos aerossóis orgânicos é de cerca de uma centena, resultado da diversidade dos compostos orgânicos presentes na em aerossóis na atmosfera. Este espectro químico de fragmentos orgânicos nos garante uma ótima estatística de observações de aproximadamente 100 fragmentos distintos a cada 30 minutos, sendo um importante dataset que pode fornecer informações quanto a fontes e processamento atmosférico da componente orgânica, majoritária em relação a massa do particulado.

A estimativa da incerteza dos sinais é especialmente importante para a introdução em algoritmos de regressão linear e foi detalhada por Allan et al., (2003). Esta é calculada dinamicamente, e, portanto, é diferente para cada fragmento e tempo. Como o número de moléculas de ar/partículas é muito alto, mas a probabilidade de ionização e de detecção de uma molécula é baixa, a distribuição de probabilidade de detecções é modelada como uma distribuição de Poisson. Desta forma, a incerteza do sinal referente ao íon s (Is) medido em íons/s é calculada através da seguinte equação:

$$
\operatorname{Inc} c_{\text {cont }}\left(I_{S}\right)=\sqrt{I_{S}}
$$

Como o sinal das partículas é calculado pela diferença entre dois sinais, sample e filter, estas incertezas são combinadas quadraticamente. Uma correção é aplicada a esta distribuição de Poisson já que o sinal de um único íon é medido como um pulso gaussiano. Logo, a expressão utilizada para calcular a incerteza devido às contagens do sinal dos aerossóis da espécie s, $I_{\text {diff }, S}$, é a seguinte:

$$
I n c_{\text {cont }}\left(I_{\text {diff }, S}\right)=\alpha \sqrt{I_{\text {sample }, S}^{2}+I_{\text {filter }, S}^{2}}
$$

$\operatorname{com} \alpha=1.2$ sendo o termo de correção do pulso gaussiano, determinado por Allan et al., (2003).

Além da incerteza das contagens, outra fonte de incertezas é o ruído eletrônico. Como o sinal de partículas para fragmentos de razão $\mathrm{m} / \mathrm{z}$ muito alta ( 200) é negligível, estima-se empiricamente o ruído eletrônico pelo desvio padrão dentro de uma 'janela' de pontos, denominada $I n c_{\text {ruído }}$. Neste trabalho, o fragmento utilizado foi o de m/z 140 no ACSM-Q e 211 no ToF-ACSM. A incerteza final de um fragmento s é dada pela é combinação quadrática da incerteza de contagens com a incerteza do ruído eletrônico, que resulta na seguinte expressão:

$$
\operatorname{Inc}\left(I_{\text {diff }, S}\right)=\sqrt{\left(\operatorname{Inc} c_{\text {cont }}\left(I_{\text {diff }, S}\right)\right)^{2}+\left(\operatorname{Inc} c_{\text {ruído }}\right)^{2}}
$$


A partir deste dataset de sinal e incerteza do sinal de fragmentos orgânicos, foi possível a aplicação de um método estatístico de fatoração por análise multivariada (detalhado a seguir, na seção 3.4), a obtenção da concentração de traçadores de fontes e processos específicos e parâmetros quantitativos para a população de partículas analisada, como oxidação, enriquecendo assim a análise desenvolvida neste projeto.

\subsection{PROCESSAMENTO DE DADOS DOS ESPECTRÔMETROS DE MASSA DE AEROSSÓIS}

O dataset utilizado neste trabalho foi processado baseado em procedimentos padrões do laboratório LFA fundamentados na literatura instrumental de cada instrumento e que podem ser consultados em documento disponível no servidor $f t p$ (junto aos dados utilizados neste projeto de mestrado) do Laboratório de Física Atmosférica, no endereço FTP público http://lfa.if.usp.br/ftp/public/LFA_Processed_Data/GoAmazon_USP_Data_processing.pdf. O principal software de análise e processamento de dados utilizado neste trabalho foi o Matlab (MATrix LABoratory).

De forma geral, são atribuídos 3 níveis de validação das séries temporais medidas, com dois padrões de médias temporais: 5 e 30 minutos. Os dados nível 1 foram filtrados por períodos com problemas instrumentais ou de manutenção. No nível 2 ocorrem dois tipos de correção: a correção específica para cada instrumento, que pode incluir a correção de zero, de erro de truncamento, calibrações, dentre outras; e a correção STP (em inglês, Standard Temperature and Pressure), que significa a normalização de concentrações para temperatura $0^{\circ} \mathrm{C}$ e pressão 1013hPa. Por fim, as séries temporais dos dados de nível 3 são as que passaram pelos testes de intercomparações dentro de certo grau de acurácia. Os dados utilizados neste trabalho (salvo quando dito o contrário) foram médias de 30 minutos de nível 3, quando possível, ou nível 2.

O processamento de dados de espectrometria de massa medidos pelos ACSM, entretanto, foi um desafio a parte cujo processo está descrito nas próximas duas sessões. Para cada instrumento há uma biblioteca própria em desenvolvimento baseada no software proprietário Igor Pro (Wavemetrics). Licenças para cada versão do Igor Pro (6 e 8) foram adquiridas separadamente através do link https://www.wavemetrics.com/products/igorpro. Estas duas bibliotecas podem ser obtidas gratuitamente através do endereço https://support.aerodyne.com/knowledgebase/ após contato com o suporte, cujo endereço de email está disponível no mesmo website. 


\subsubsection{O espectrômetro de massa de aerossóis ToF-ACSM}

A teoria do processamento de dados do ToF-ACSM está apresentada e validada em FRÖHLICH et al. (2013). Este processamento foi realizado a princípio através do Tofware versão 2.5.13, baseado em Igor Pro 6.3x. Porém, as versões 2.x (utilizadas em diversas publicações na última década) apresentam um erro no cálculo da baseline (calibração de zero do espectro de massa) com magnitude ainda não determinada e foi recentemente descontinuada. Por este motivo, é essencial que futuros trabalhos baseados neste instrumento utilizem a versão mais atual do software. A versão utilizada neste trabalho foi a 3.2.40208, baseada em Igor Pro 8, e foi lançada em novembro de 2020. A versão 3.x ainda não conta com um manual até a data de depósito deste trabalho e seus princípios e práticas das etapas essenciais estão detalhados abaixo.

A partir da versão 3.x, o processamento foi dividido em duas rotinas, workflows 1 e 2 , com interface gráfica e etapas divididas em botões cinzas indicando as etapas opcionais e em botões amarelos as obrigatórias. O objetivo do workflow 1 é refinar algumas calibrações e parâmetros e obter o espectro de massa em resolução unitária de razão m/z do sinal dos aerossóis. O objetivo do workflow 2 é aplicar calibrações para transformar medidas de fluxo de íons em concentração de massa, reconstruir as concentrações das partículas através da tabela de fragmentação, fazer análises e diagnósticos padrões e por fim exportar as concentrações corrigidas de partículas.

Para abrir o workflow, deve-se acessar um template de experimento do Igor Pro na pasta principal do Tofware cujo nome é “Tofware_(versão)_ACSM_part1.pxt”. O primeiro passo do primeiro workflow 1 é carregar os arquivos gerados pelo instrumento no formato hdf5 (.h5) a partir da opção "Add file” ou "Add folder". Após serem carregados, é possível selecionar algum destes na aba "Files" ou criar uma série temporal na aba "Ranges \& masks (to-do)" composta por um conjunto pontos de um ou mais arquivos para fazer o processamento. Estas máscaras temporais (chamadas pelo software de 'to-do's) são utilizadas para, por exemplo, eliminar períodos de manutenção ou de mau funcionamento reportados e conhecidos previamente a análise. 
Figura 3.10 - Menu principal do workflow 1. À esquerda, em cinza as etapas opcionais e em amarelo as etapas obrigatórias. À direita, os usuários podem selecionar uma lista de arquivos com dados diários na aba "Files" ou outras máscaras temporais determinadas pelo usuário na aba "Ranges \& masks (to-do)".

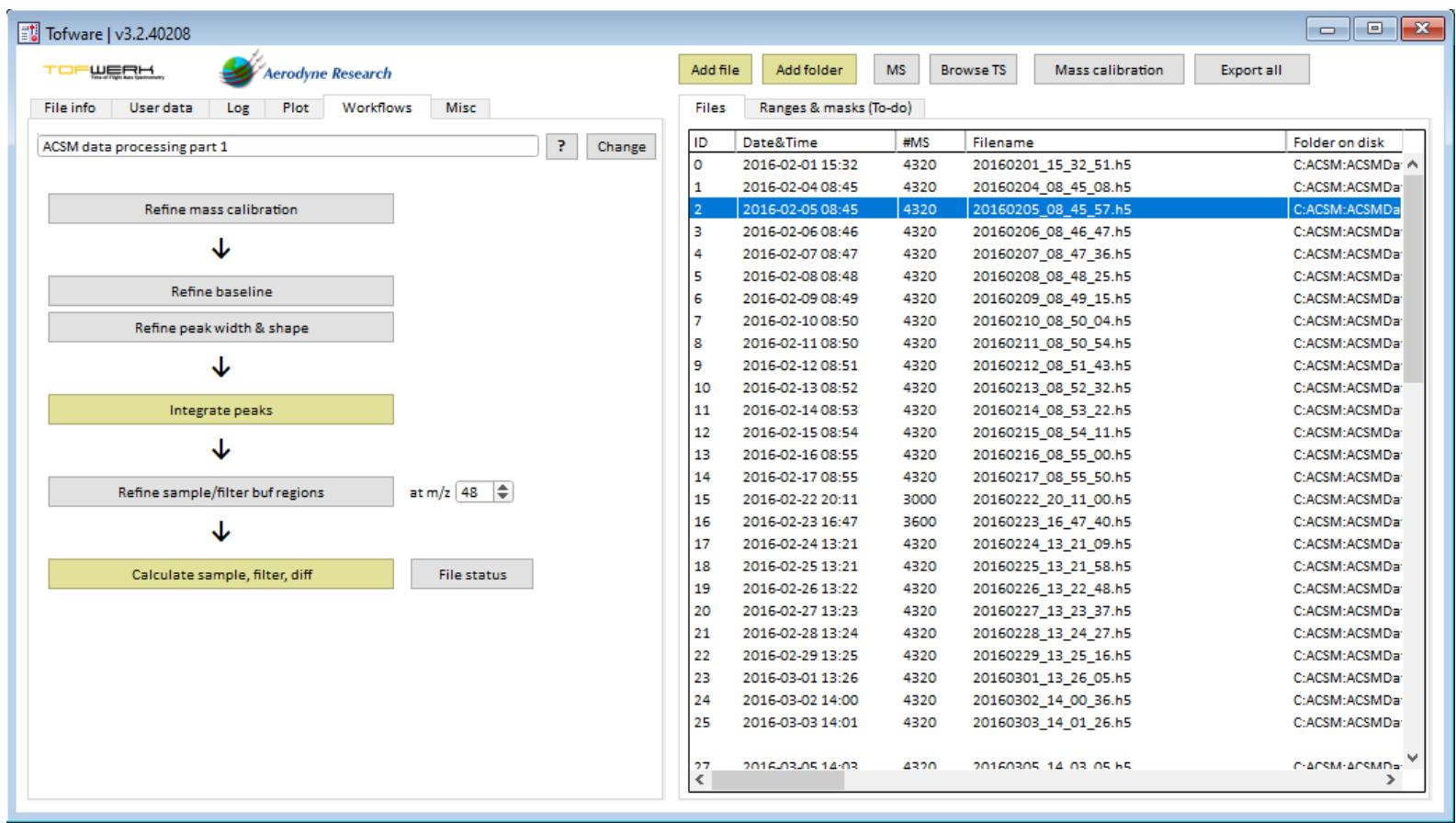

Com um arquivo selecionado no menu a direita, o primeiro botão cinza (cor que indica as etapas opcionais) abre o menu visto na Figura 3.10 e permite refinar a calibração de massa (“Refine mass calibration”), já que esta calibração pode apresentar pequenas variações temporais. É feito um ajuste entre tempo de voo e razão m/z, por meio da equação:

$$
t=k \sqrt{\frac{m}{z}}
$$

em que k é uma constante que representa fatores relacionados a características do instrumento. Esta relação é obtida com a hipótese de que a energia potencial imprimida nas cargas é convertida em energia cinética e este íon viaja livre de qualquer influência por um tubo com velocidade constante até acertar o detector, com tempo de voo t.

É realizado um ajuste de mínimos quadrados do coeficiente k por meio de alguns íons escolhidos cuja espécie química e massa atômica são conhecidas. Neste trabalho utilizamos os íons $\mathrm{OH}^{+}(\mathrm{m} / \mathrm{z}=17.002740), \mathrm{H}_{2} \mathrm{O}^{+}$(18.010565), $\mathrm{N}_{2}^{+}$(28.006148), $\mathrm{O}_{2}^{+}$(31.989829), $\mathrm{CO}_{2}^{+}$ (43.989829) e $\mathrm{C}_{7} \mathrm{H}_{7}{ }^{+}$(91.054775), que são sinais maiores do que a vizinhança e por isto representam fáceis referências. Para cada um destes íons o software ajusta uma curva gaussiana aos pontos ao redor de uma referência, e o centro é o ponto utilizado no ajuste da constante k.

Especialmente pela não linearidade, é importante que esta lista contenha íons com valores de grandes de razão $\mathrm{m} / \mathrm{z}$, como o $\mathrm{C}_{7} \mathrm{H}_{7}{ }^{+}$de $\mathrm{m} / \mathrm{z}$ aproximadamente $91 \mathrm{amu}$, próximo dos 
valores normalmente utilizados como limite máximo para sinal de partículas, de 120 a $140 \mathrm{amu}$, pois acima disso há uma fração muito pequena da massa. O íon $\mathrm{W}$ com razão m/z 184 (isótopo de tungstênio de massa atômica 184) é uma opção para calibrar o final do espectro de massa, mas não foi incluído na calibração de massa pois aumentou na ordem de 5 vezes o resíduo médio do ajuste quando incluído.

Figura 3.11 - Menu da calibração de massa. É possível refinar a calibração padrão dos arquivos e aplicar esta nova configuração dia a dia ou em maiores resoluções de tempo.

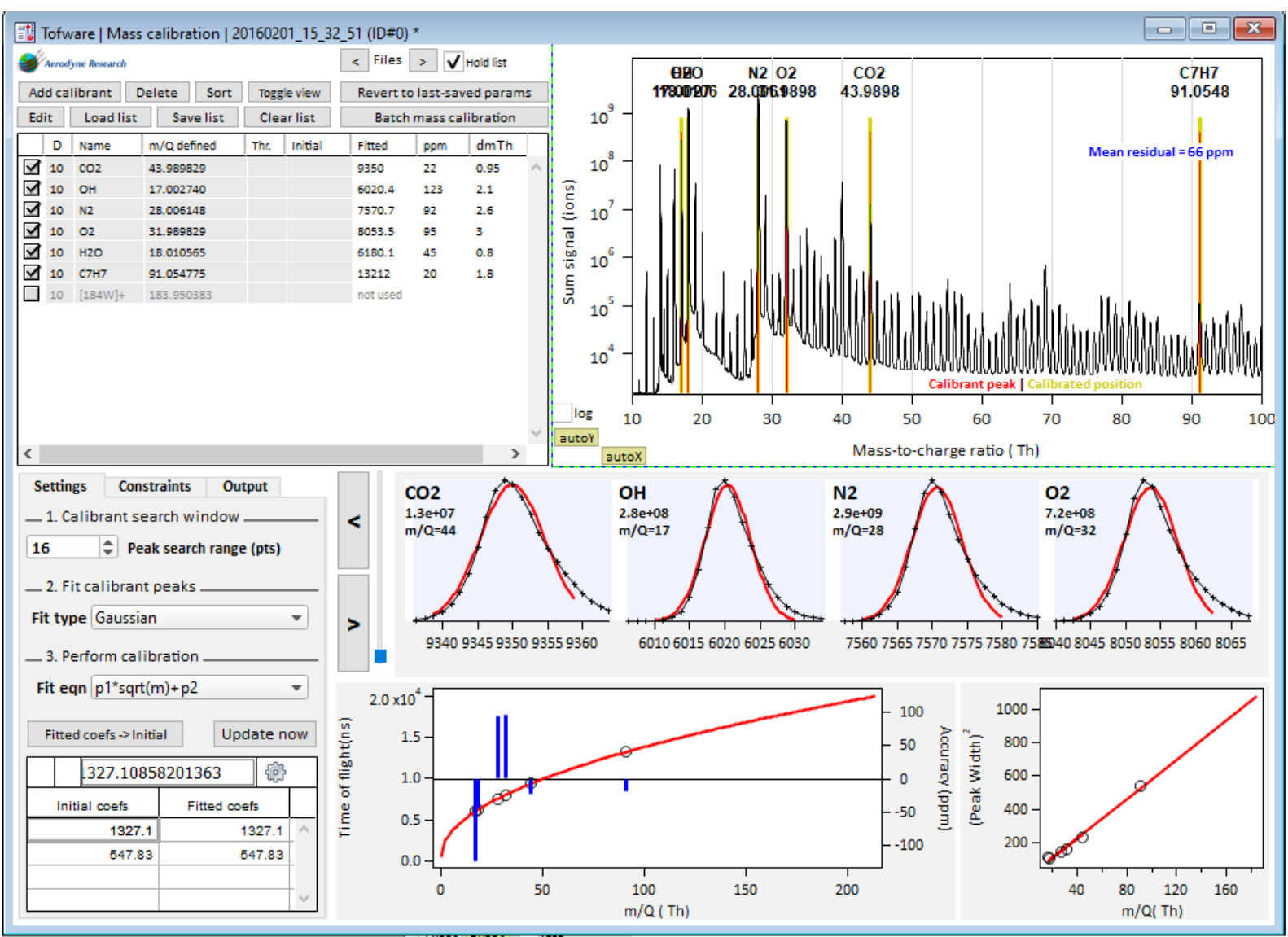

No quadro a direita da Figura 3.11, as linhas vermelhas são as referências salvas nos arquivos e podem ser deslocadas manualmente, enquanto as amarelas são os centros das gaussianas ajustadas. A largura da região ajustada, a massa e o tempo de voo de referência podem ser modificados clicando com o botão direito no nome do íon e novos íons podem ser adicionados clicando no botão "Add Calibrant".

Ao lado direito desta janela, há uma lista com os arquivos carregados e duas opções: aplicar a calibração estabelecida de arquivo em arquivo (dia a dia) ou ponto a ponto - temporal - com médias de um número escolhido de minutos. A calibração dia a dia costuma ser suficiente, já que mesmo entre vários dias esta calibração costuma apresentar pequena variação, por este motivo e foi a opção escolhida neste trabalho. 
O segundo passo opcional é refinar a linha de base, acessível através do segundo botão em cinza do menu principal ("Refine baseline"). Mostrada pela linha azul da Figura 3.12, a linha de base é composta de valores dinâmicos que determinam o zero para cada ponto do espectro de massa. Esta linha de base dinâmica é necessária pois além do detector apresentar ruído eletrônico e íons de fundo, este também apresenta certa saturação eletrônica em regiões do espectro de massa adjacentes a picos com alta intensidade.

Figura 3.12 - Menu para refinar a linha de base, em azul, que atua como zero do detector, já que este apresenta saturação próximo a fragmentos com sinal intenso. $\mathrm{O}$ principal parâmetro a ser determinado é o 'Width', a largura da janela em que será aplicado o algoritmo descrito abaixo.

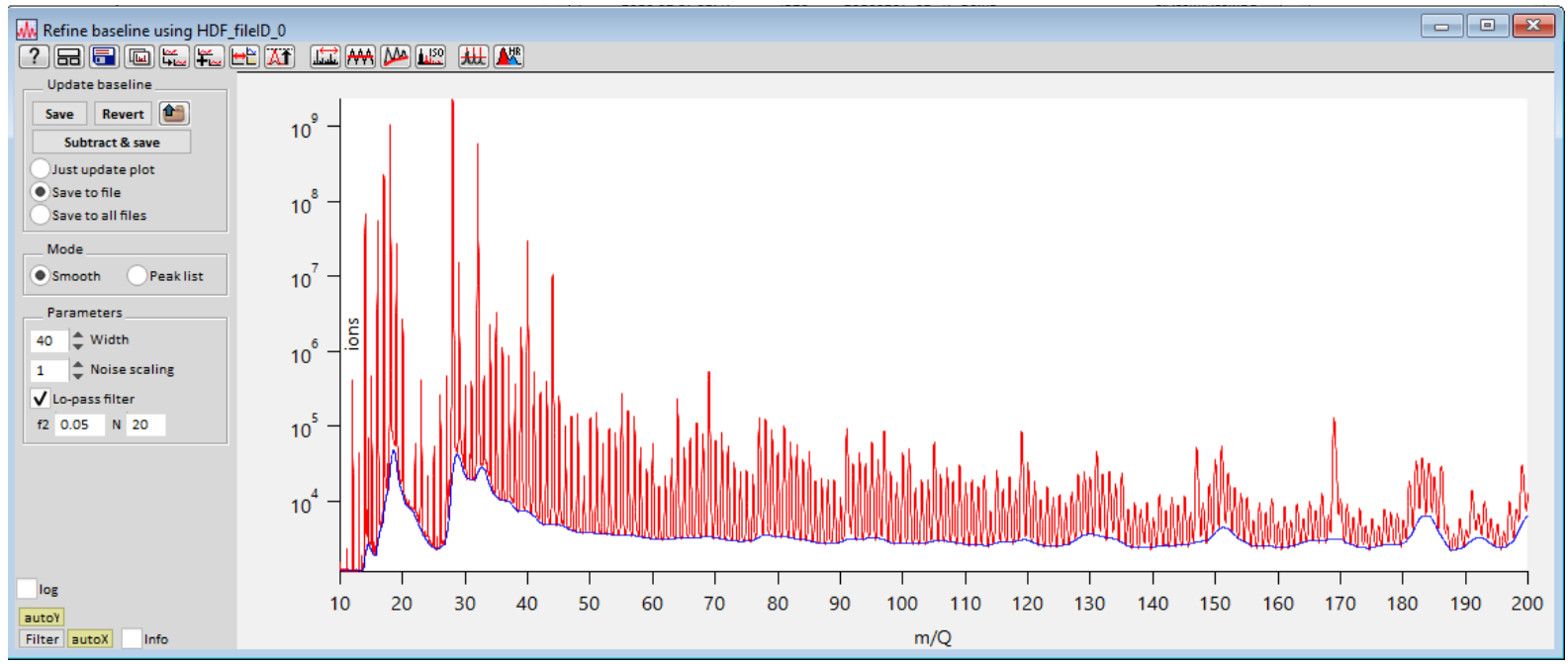

A opção recomendada para cálculo da linha de base é o modo suavizado ("Smooth"), cujo método está detalhado em TIMONEN et al. (2016). Basicamente, neste modo ocorre a aplicação de um filtro para eliminar o ruído de alta frequência e, a partir deste novo sinal, são identificados os mínimos ponto a ponto ao redor de uma largura (parâmetro 'Width') para que seja calculada uma média móvel destes mínimos dentro da largura determinada, cujo resultado é a linha de base.

O parâmetro Width deve ser determinado de forma que esta largura seja grande o bastante para superar a largura dos picos de todo o espectro de massa (de forma que nos pontos internos de um pico, a largura alcance os dois extremos) mas pequeno o suficiente para que esta linha de base não seja afetada pelos picos vizinhos. $\mathrm{O}$ valor padrão de largura para o detector ETOF do ToF-ACSM é de 40 (unidades arbitrárias) e o aplicado neste trabalho foi de 32 . O parâmetro de "noise scaling" pode ser utilizado para aumentar ou diminuir o efeito de eliminação do ruído. É indicado que não se modifique os outros parâmetros relativos ao filtro de ruído. A mesma configuração de baseline foi salva para toda a série temporal analisada para se evitar vieses e será aplicada uma baseline por arquivo diário. 
O terceiro botão cinza no menu principal habilita o refino da largura e formato dos picos ("Refine peak width \& shape"). Estas opções definem a curva que será ajustada para integrar o sinal de cada unidade da razão m/z. Através deste menu, irão ser carregadas duas janelas. Uma delas é sobre o formato de picos, que mostra um conjunto de picos individuais levemente não gaussianos em linhas serrilhadas, um ajuste gaussiano na área cinza, e a média das curvas na linha preta grossa. Aqui, deve-se ter certeza que os picos representam picos isolados e não apresentam picos adjacentes, como a linha tracejada vermelha na Figura 3.13 à direita. Neste caso, pode-se modificar o parâmetro Threshold para um valor menor, de forma que este limite inclua menos íons, ou ainda remover este $\mathrm{m} / \mathrm{z}$ do ajuste manualmente clicando na curva. A função a ser ajustada parte de uma gaussiana e pode ser consultada com detalhes em DECARLO et al., (2006). Com as opções setadas, deve-se calcular o novo peak shape ("Calculate") e salvar no botão amarelo acima.

A segunda janela, à esquerda da Figura 3.13, é sobre a largura dos picos. A largura dos picos em meia altura deve seguir uma relação linear com a razão m/z (STARK et al., 2015), como mostrado na figura. Esta é determinada por padrão por picos de maior intensidade, por padrão. Caso um pico não esteja acompanhando a relação linear, pode-se eliminá-lo diminuindo o valor do parâmetro Tolerance ou clicando manualmente no íon. Também deve-se salvar a configuração no botão amarelo superior.

Figura 3.13 - Menu para refinar o formato e a largura dos picos que servirão para a integração.

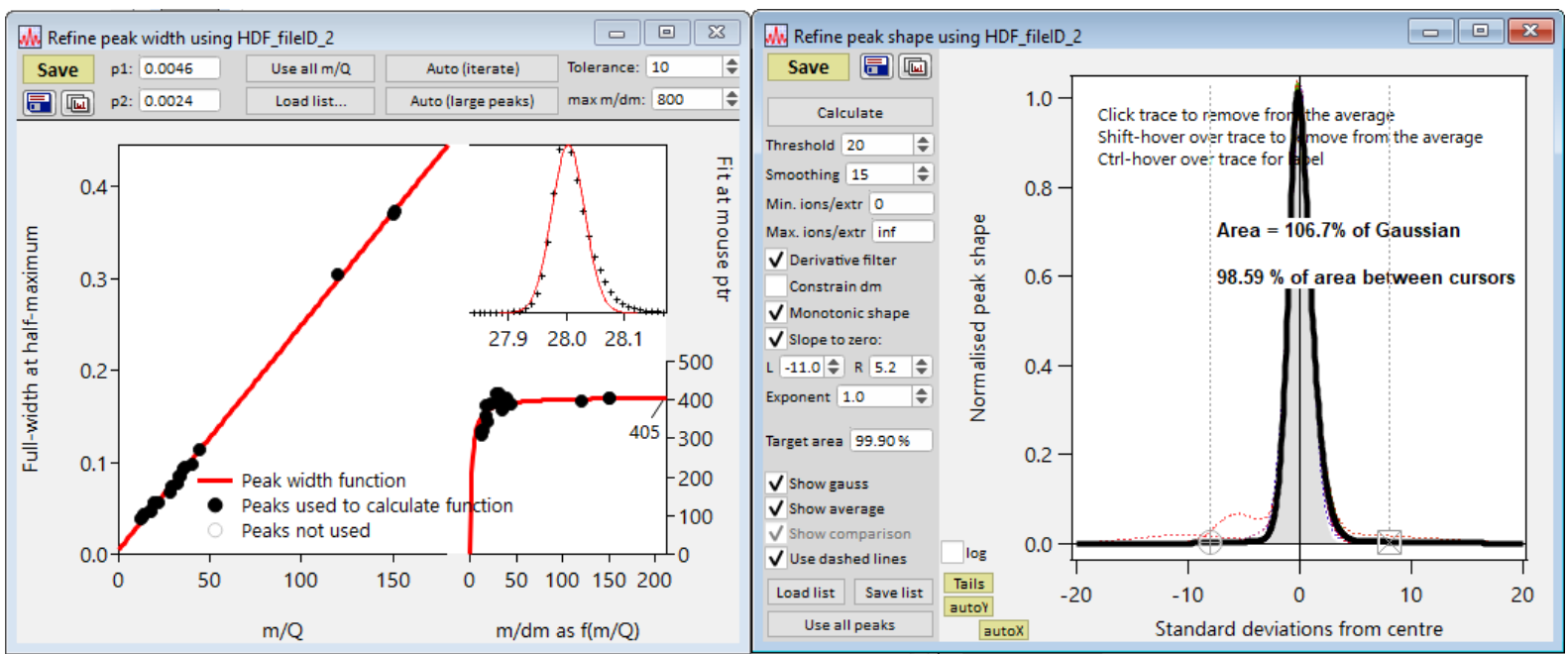

O próximo passo é obrigatório e realiza a integração dos picos (“Integrate peaks"). Esta etapa utiliza as configurações anteriores para somar o sinal de cada pico e transformar o espectro de massa em um espectro unitário de massa (UMR), ou seja, com uma intensidade por unidade de razão m/z. O próximo botão cinza não se aplica ao procedimento do ToF-ACSM. 
A próxima etapa também é obrigatória e termina este workflow realizando o cálculo dos valores de medida ambiente, do filtro e de sua diferença (“Calculate sample, filter, diff') do UMR. Nesta etapa, são calculados e gravados em novos arquivos as intensidades unitárias do espectro de massa da medida ambiente (com sinal de gases e aerossóis), do filtro (com sinal apenas de gases), e da diferença entre as duas medidas, que visa isolar o sinal dos aerossóis. Os arquivos contendo a diferença (referente ao sinal do particulado) serão gravados em uma subpasta chamada 'dif' dentro da pasta dos arquivos originais, com o mesmo nome e formato exceto pela terminação “_dif”.

Figura 3.14 - Menu do workflow 2, que permite fazer as correções e diagnósticos finais para gerar as séries temporais das componentes do particulado fino.
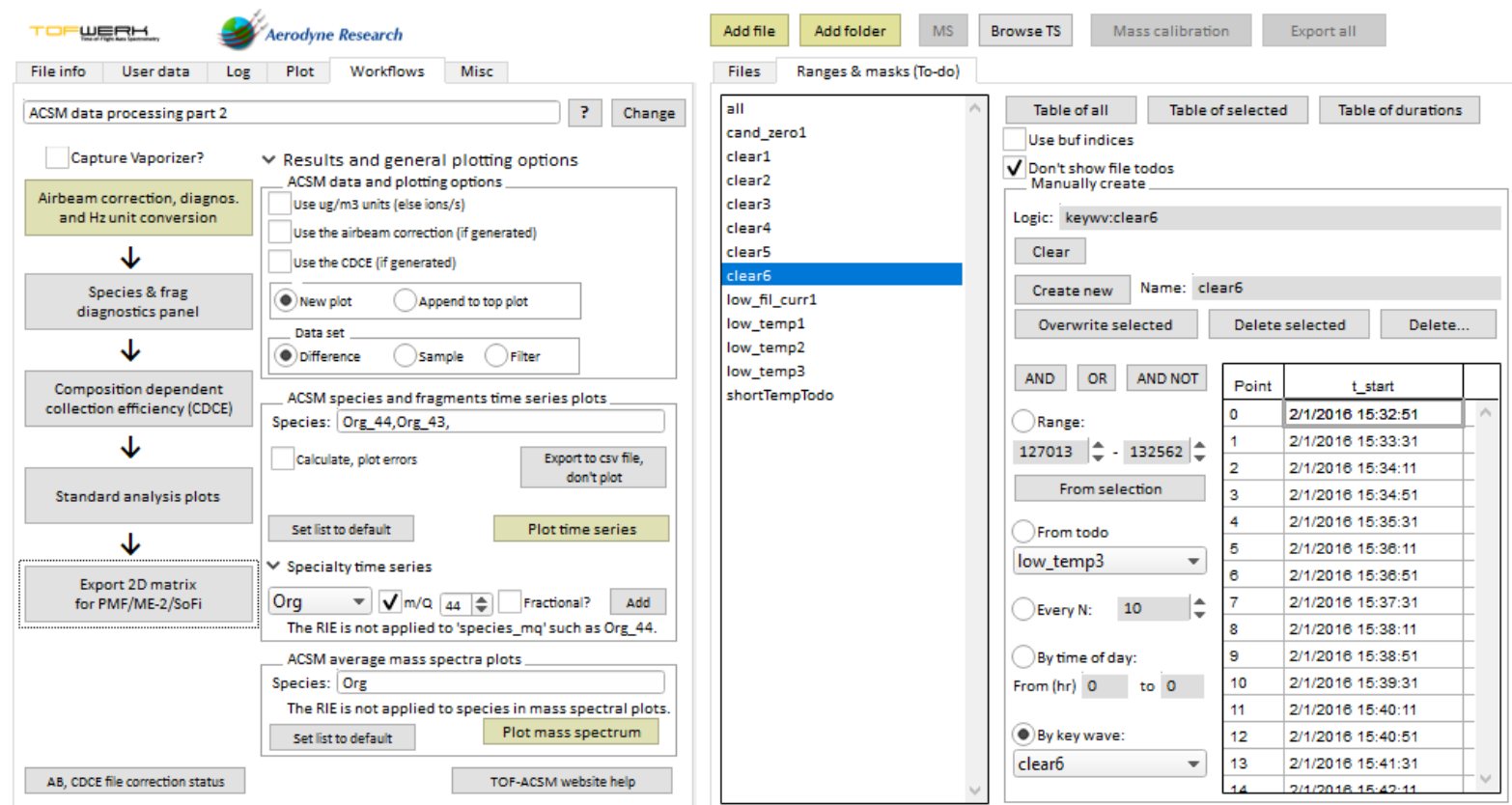

Dessa forma, podemos partir para a segunda de processamento. O workflow 2 é acessado abrindo o segundo template de experimento do Igor Pro da pasta principal deste software, e seu primeiro passo é carregar estes arquivos processados anteriormente com terminação "_dif". Nesta rotina, também é possível a criação de máscaras temporais assim como no menu da Figura 3.10 .

A única etapa obrigatória desta rotina exibida na Figura 3.14 é acessada pelo primeiro botão do menu principal, que realiza a correção de airbeam, diagnósticos e conversão de unidades. É possível alterar os valores de eficiência de ionização (Calibration factor) obtido com setup descrito na seção anterior. Os valores de fluxo volumétrico (flowrate) e intensidade do íon $\mathrm{N}_{2}{ }^{+}$(airbeam), anotados ao fazer uma calibração, podem ser introduzidos na parte amarela da janela exposta na Figura 3.15. Neste trabalho, utilizamos fator de calibração (equivalente ao RF do ACSM-Quadrupolo) $=98.8, \mathrm{Q}_{\mathrm{CAL}}=1.4 \mathrm{~cm}^{3} \mathrm{~s}^{-1}$ e Airbeam $\mathrm{CAL}=224059$. 
Figura 3.15 - Menu de correção de airbeam, diagnósticos e conversão para concentração em massa.

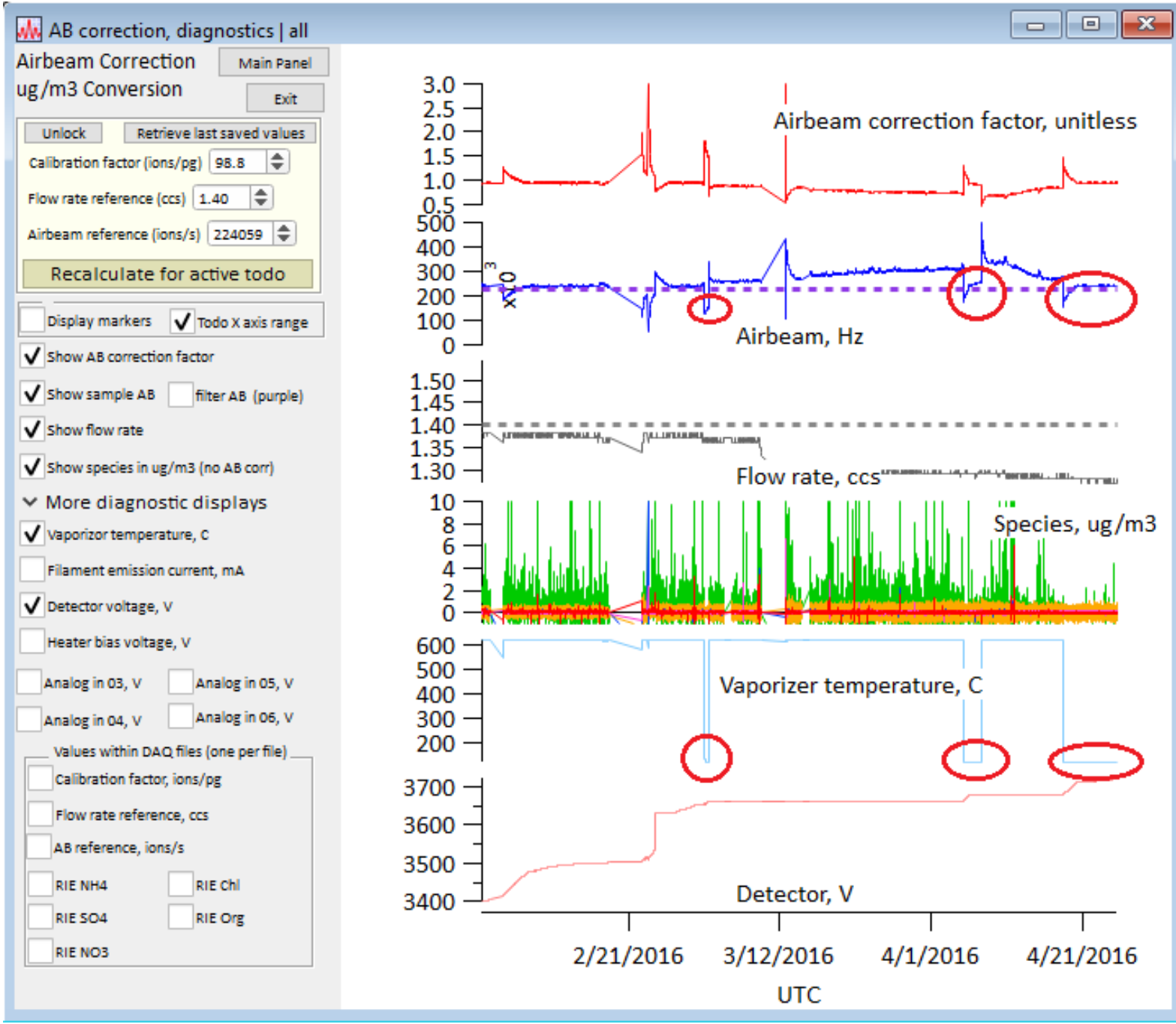

Para uma grande série temporal como a deste trabalho, a sensibilidade do instrumento pode variar devido a mudanças em variáveis do ambiente como temperatura e pressão. Para contabilizar essas mudanças no ganho do detector, utilizamos o sinal do íon $\mathrm{N}_{2}{ }^{+}$(chamado de airbeam) como proxy, proveniente do gás $\mathrm{N}_{2}$. A correção de airbeam gera um fator multiplicativo que é dado pela razão entre o sinal referência do íon de $\mathrm{m} / \mathrm{z}=28$, anotado durante a calibração, e a série temporal da intensidade deste íon.

O princípio desta correção é que assumindo que o instrumento está funcionando corretamente e um íon com concentração constante (como o $\mathrm{N}_{2}$ ) no ambiente tiver sua concentração aumentada ou diminuída em alguma porcentagem, esse efeito deve ser um artefato instrumental que levou a uma mudança no ganho do detector do instrumento. Desta forma, todos os íons terão sua concentração artificialmente aumentada ou diminuída na mesma porcentagem e, portanto, precisam de uma normalização. 
A partir deste menu, também é possível fazer um diagnóstico simples a partir de algumas variáveis fundamentais, como a voltagem do detector, a temperatura do vaporizador e o próprio sinal do íon $\mathrm{N}_{2}{ }^{+}$. Por exemplo, existem três episódios de súbitas quedas no airbeam na série temporal circulados em vermelho na Figura 3.15. Embora a correção de airbeam sirva justamente para corrigir períodos com mudanças nesta variável, eventos desse tipo sempre precisam ser investigados pois podem ser sinais de que algum dos processos necessários para o funcionamento do instrumento pode não estar acontecendo. Nestes casos, bastou observar a temperatura do vaporizador para perceber que durante estes eventos esta variável cai rapidamente a valores próximos de $100{ }^{\circ} \mathrm{C}$, temperatura muito mais baixa do que o suficiente para vaporizar as espécies estudadas. Este período, portanto, foi retirado da análise.

A etapa seguinte, finalmente, permite o uso de uma tabela de fragmentação para recuperar as concentrações das espécies químicas originais a partir das intensidades do espectro de massa unitário, através do botão "Species \& frag diagnostics panel". Neste trabalho, utilizamos a tabela de fragmentação descrita por Allan et al. (2004) e corrigida por Aiken et al. (2007) para recuperar as concentrações dos compostos inorgânicos sulfato, nitrato, amônio, cloreto e dos compostos orgânicos do $\mathrm{PM}_{1}$. Também nesta etapa são definidos a eficiência de coleção (CE) e as eficiências de ionização relativas (RIE). O valor de CE utilizado foi constante de 0.45 pela equação de Middlebrook et al. (2012) e a RIE para amônio utilizada neste trabalho foi de 3.46, obtida na calibração. Embora a literatura recomende calibração com sulfato de amônio para obter o RIE do sulfato específico para o instrumento utilizado, que apresenta valores típicos com uma dispersão alta na literatura, de 0.6 a 2.0, esta calibração não foi realizada e foi utilizado um valor padrão de 1.2, podendo estar sujeito a erros sistemáticos. Para os outros componentes, foram utilizadas RIEs tradicionais da literatura de 1.4 para orgânicos e 1.3 para cloreto.

As etapas de análise infelizmente não puderam ser realizadas no Tofware versão 3.x neste trabalho uma vez que o workflow 2 reconhece as séries temporais como um ponto por ciclo. O ciclo do sinal da diferença (referente ao sinal dos aerossóis) tem período de $40 \mathrm{~s}$, sendo 20 s de medidas ambientes e 20s de medidas de filtro. Esse período de medida apresenta poucas contagens e, portanto, incertezas e ruídos tão grandes que impedem uma análise de qualidade, uma vez que o instrumento trabalha normalmente com médias de 10 a 30 minutos. Por este motivo, toda a análise foi feita com rotinas próprias no Matlab. 
Figura 3.16 - Menu de exportação da matriz de sinal e incerteza dos fragmentos orgânicos utilizados para algoritmos de PMF.

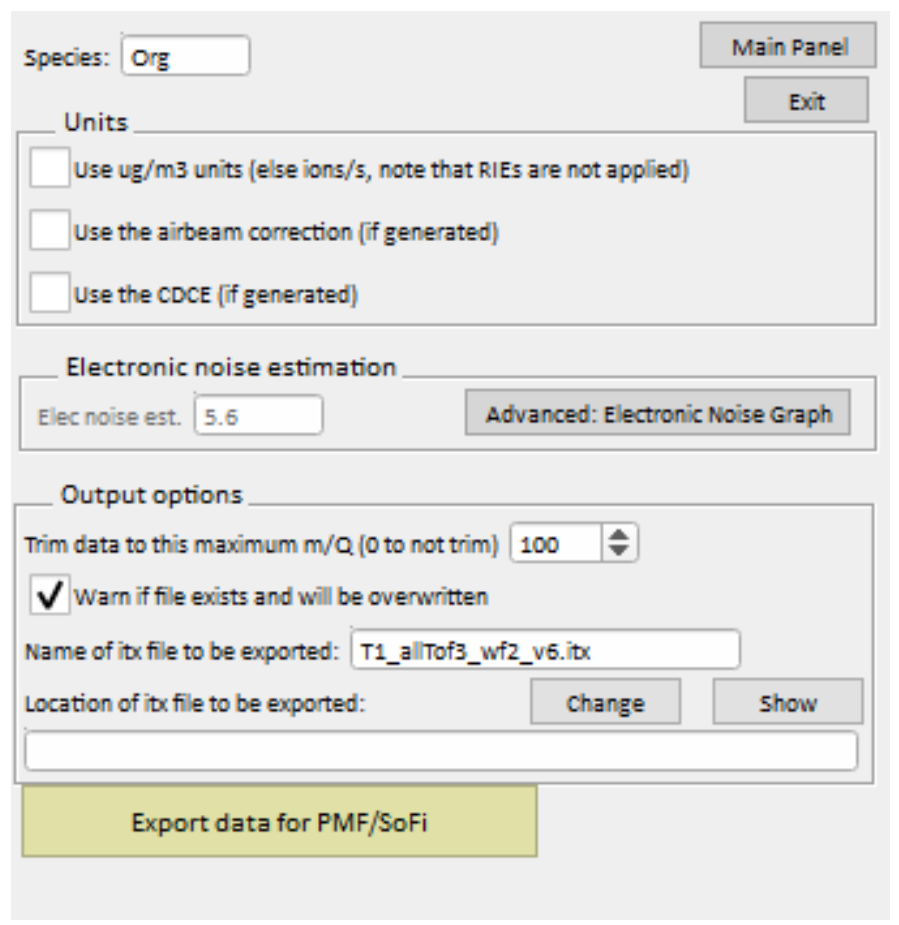

Para isto, no menu principal marca-se as opções "use $\mu g / m^{3}$ units (...)" e "use the airbeam correction (...)" para usar unidades de concentração em massa e a correção de airbeam. Depois, escreve-se o nome das espécies, tal como na tabela de fragmentação, no campo após "Species:”. Por fim, clica-se em “Export to csv file (...)” para exportar as séries temporais em um formato csv.

Por fim, é possível também exportar as matrizes de sinal e de incerteza de fragmentos provenientes de aerossóis orgânicos para análise fina da componente orgânica do $\mathrm{PM}_{1}$, em especial pelo algoritmo Fatoração de Matriz Positiva (PMF), como visto na Figura 3.16. Devese verificar se o nome da espécie no topo do menu é o nome correspondente aos fragmentos orgânicos da tabela de fragmentação. As mesmas opções de unidades e correção estão presentes neste menu, além de um painel específico para tratar o ruído eletrônico. 
Figura 3.17 - Menu de estimativa de ruído eletrônico.

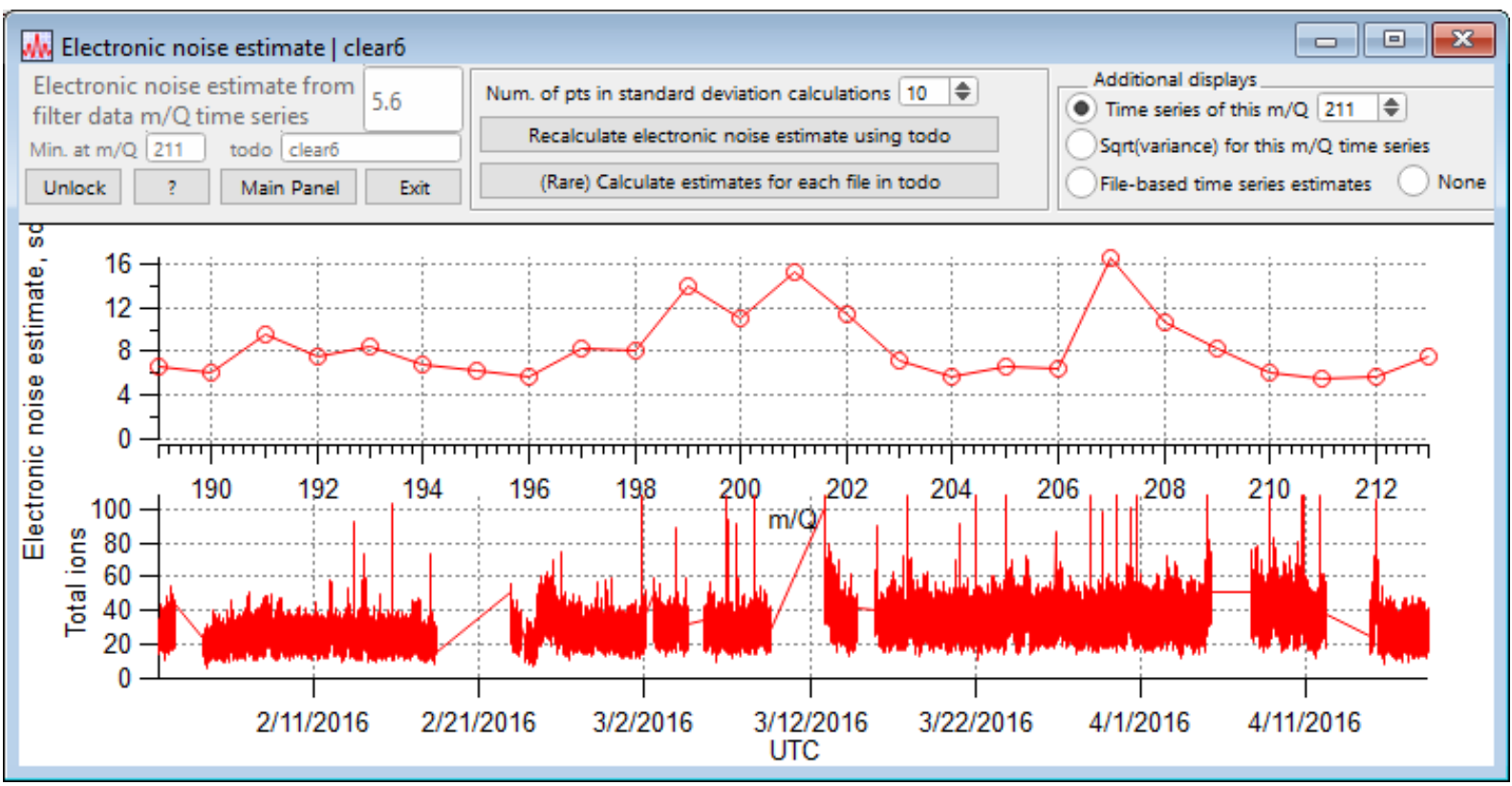

Este menu, visto na Figura 3.17, pode ser acessado pela opção “Advanced: Eletronic Noise Graph", e mostra uma série de estimativas de ruído eletrônico (raiz quadrada do sinal diff) para íons com os valores mais altos de $\mathrm{m} / \mathrm{z}$ do espectro de massa. Como espera-se apenas ruído do sinal deste íon e que, portanto, não haja um sinal de aerossol governando a detecção deste fragmento, a escolha deve ser de um íon com baixa estimativa de ruído eletrônico e que não apresente tendências significativas na série temporal. Desta forma, o software fez uma escolha satisfatória com o fragmento 211. Caso o usuário deseje modificar esta escolha, devese escolher a opção "Unlock" e modificar o campo preenchido por 211 na figura em questão.

Desta forma, foram obtidas séries temporais calibradas e processadas de $40 \mathrm{~s}$. Para a comparação e validação com o resto da base dados e minimização das incertezas, realizei por meio de rotinas no software Matlab médias temporais de 30 minutos das concentrações de componentes do $\mathrm{PM}_{1}$ e de sinais da matriz dos fragmentos orgânicos. A incerteza para as médias de 30 minutos foi obtida por propagação de incertezas obtidas no Tofware com pontos de 40s.

\subsubsection{Validação de dados do espectrômetro ToF-ACSM}

Os espectrômetros de massa são instrumentos complexos e por isso a validação de resultados é especialmente importante. Para a validação do NR-PM 1 medido pelo ACSM, comparamos com estimativas do NR-PM 1 a partir de medidas de volume de partículas pelo SMPS e de BCe pelo Aetalômetro. Espera-se que o BC seja a maior parte da massa refratária de $\mathrm{PM}_{1}$ (que não vaporiza a $\sim 600^{\circ} \mathrm{C}$ e, portanto, não é observada pelo $\mathrm{ACSM}$ ), e que 
contribuições de espécies como poeira mineral e sal marinho represente uma parcela desprezível do particulado fino. Dessa forma, a partir de hipóteses simplificadas como assumir um formato esférico e assumir alguma densidade de aerossol, podemos utilizar o volume total da distribuição de tamanho para estimar a massa de $\mathrm{PM}_{1}$ e subtrair a massa de $\mathrm{BCe}$ para obter o NR-PM

Figura 3.18 - Comparação entre medidas de NR-PM1 do ACSM e estimativa de NR-PM1 a partir de dados dos SMPS/Aetalometro para o Q-ACSM.

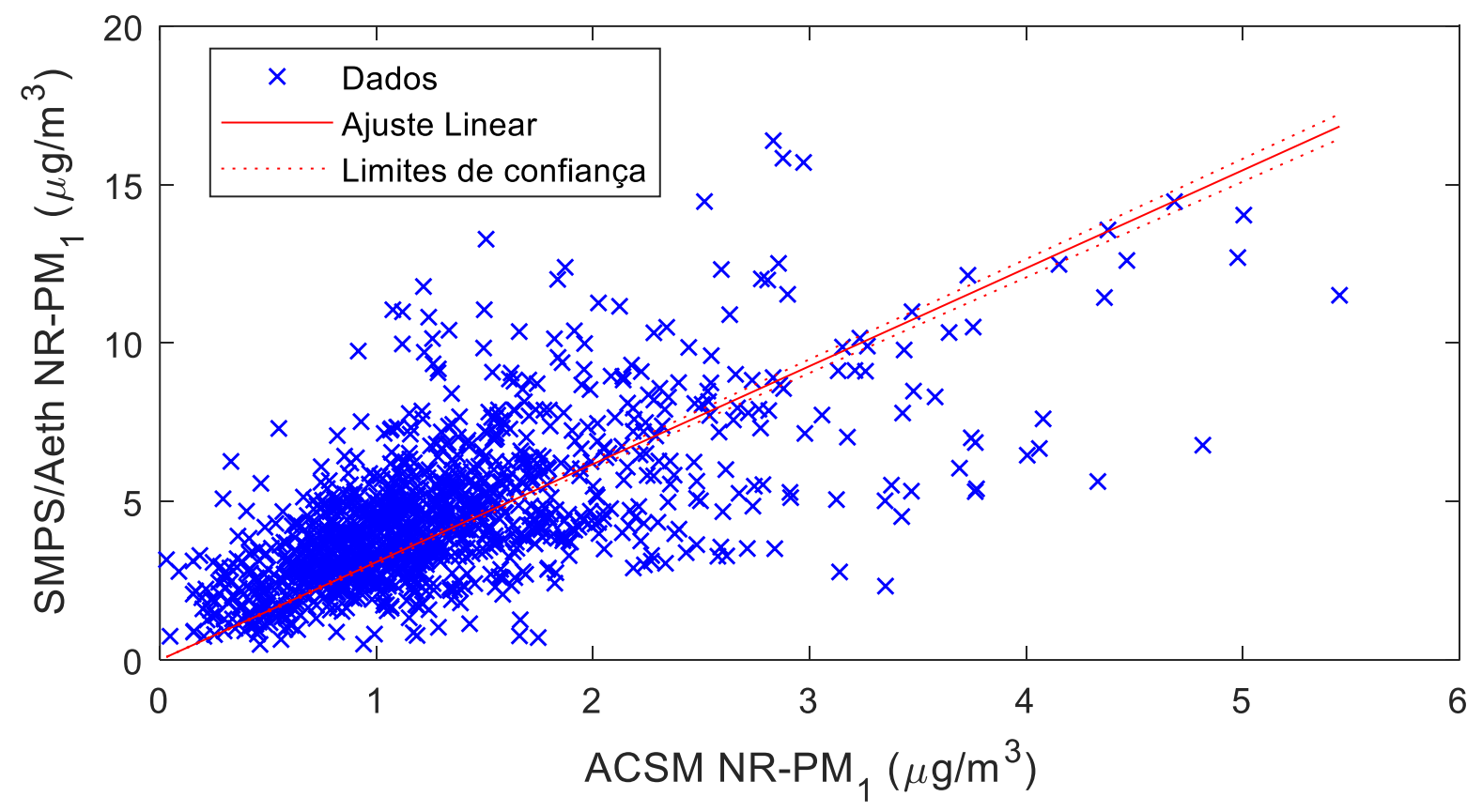

Essa comparação normalmente mostra-se de qualidade, como demonstrado em uma extensa intercomparação por Crenn et al., (2015), embora muitas simplificações podem alterar a qualidade deste ajuste. Dentre estes fatores, estão a medição indireta de partículas de BC, a suposição de uma densidade que pode não representar as partículas, a suposição de eficiências de ionização (RIE) gerais que podem não ser adequadas para o sítio ou apresentar dependências temporais e diferença de limites tamanho de partículas que são detectadas por cada um dos três instrumentos.

Neste trabalho, a densidade do aerossol foi calculada por uma média da expressão de Kuwata et al. (2012) aplicada na série temporal da composição, que apresentou variações menores do que $10 \%$ no intervalo interquartil, resultando em uma densidade média para o $\mathrm{PM}_{1}$ de $1.25 \mathrm{~g} / \mathrm{cm}^{3}$. Nosso ajuste entre a massa das espécies medidas pelo ACSM-ToF, chamadas de NR-PM 1 , e a estimativa esta quantidade a partir de medidas de SMPS e aetalômetro foi mostrado na Figura 3.18, com valor do coeficiente $\mathrm{R}^{2}$ de $0.57(\mathrm{p}<0.01)$ mostrando um nível de espalhamento maior do que o esperado, após as correções e diagnósticos detalhados na metodologia terem sido aplicados. 
As hipóteses levantadas para este maior nível de espalhamento observado são a diferença entre tamanhos de partículas amostradas entre SMPS e ACSM: o diâmetro das partículas medidas pelo SMPS vai de $\sim 9 \mathrm{~nm}$ a $\sim 500 \mathrm{~nm}$, enquanto as lentes aerodinâmicas do ACSM focam com eficiência $>50 \%$ partículas de tamanhos $70 \mathrm{~nm}$ a $\sim 700 \mathrm{~nm}$ (LIU et al., 2007). Enquanto a diferença no limite inferior não deve representar diferença significativa na massa (já que as partículas menores representam uma pequena fração do volume e massa total), a diferença do limite superior pode causar diferenças notáveis e pode ser responsável por parte da diferença na comparação entre NR-PM 1 medido pelo ACSM e estimado por medidas de SMPS e Aetalômetro.

A comparação entre as concentrações mostra também um coeficiente angular de 3.1, o que significa que as medidas entre o ACSM estavam amostrando valores $\sim 3$ vezes menores do que a estimativa. Como os instrumentos SMPS e BCe foram validados independentemente para as medidas ambiente (incluindo comparação com outros instrumentos), aplicamos este fator às medidas ambientes do ACSM, corrigindo sua calibração. As hipóteses para explicar a necessidade desta correção são o desalinhamento de lentes entre as medidas ambiente e a calibração, e possível diferença de valores de RIE calculados baseados em medidas do hemisfério norte com composição diferente, em especial dos orgânicos. Por esta correção ter sido realizada com um SMPS de tamanho de partícula detectada reduzida e por não incluir outras espécies não refratárias como poeira mineral, as concentrações aqui reportadas representam um limite inferior das concentrações reais de $\mathrm{PM}_{1}$.

\subsubsection{Processamento de dados pelo espectrômetro de aerossóis Q-ACSM}

O processamento de dados referente ao Q-ACSM é mais direto, apresenta semelhanças com o ToF-ACSM que não serão exploradas em detalhe novamente, mas também algumas peculiaridades causadas pela mudança no tipo de detector, que serão exploradas no texto. Por isto tem uma biblioteca dedicada própria, cujo software não permite tantas opções de refino das calibrações e formato de pico como o ToF-ACSM, apenas utiliza a referência da última calibração realizada. A versão do software relacionado ao ACSM-Quadrupolo utilizado neste trabalho foi a ACSM Local 1.6.1.5 lançada em abril de 2020 e utiliza a versão antiga 6.3x do Igor Pro. 
Figura 3.19 - Menu principal do software de processamento e análise do ACSM-Quadrupolo.

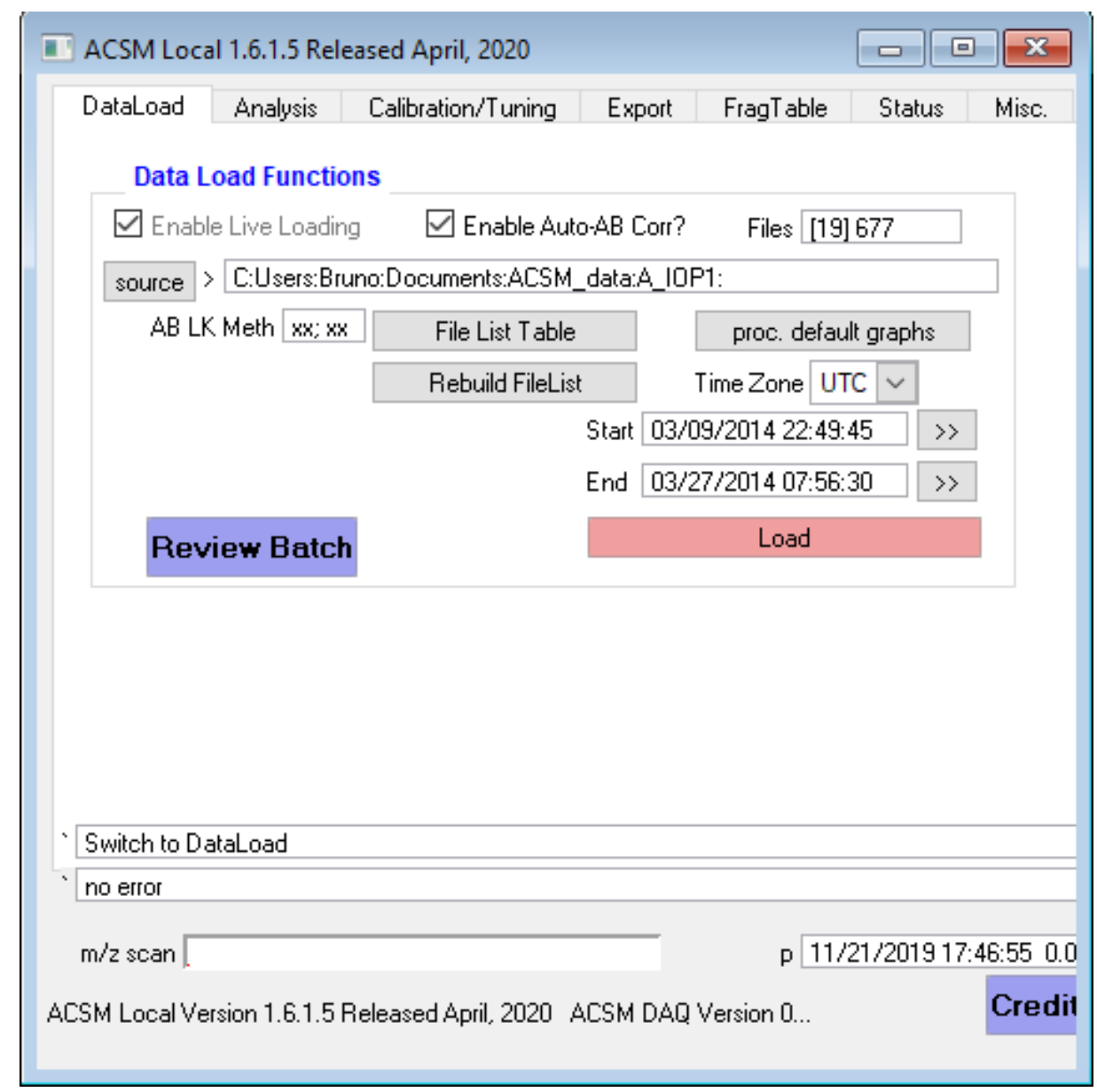

Deve-se abrir e compilar a rotina denominada "acsm_local_(versão).ipf", de forma a expor o menu da Figura 3.19. O primeiro passo para fazer o processamento dos dados é, na primeira aba ("DataLoad"), selecionar os arquivos clicando em "source", selecionar a pasta contendo os arquivos de formato hdf5 (.h5), definir o período em Start/End e carregar os arquivos clicando em Load. Após, deve-se inserir os valores de IE e RIE obtidos na calibração, além de valores de eficiência de coleção (CE). Este instrumento apresentou os coeficientes de $\mathrm{IE}=1.4 \mathrm{e}-10$ para a calibração de nitrato, $\mathrm{RIE}_{\mathrm{NH} 4}=5.5 \mathrm{e}$, para calibração de sulfato, $\mathrm{RIE}_{\mathrm{SO} 4}=0.8$.

É realizado o diagnóstico de variáveis como sinal do airbeam, temperatura do vaporizador, e pressão no inlet (proxy para fluxo de volume) assim como feito no software do ToF-ACSM. por meio da aba Analysis e menu Basic Diagnostics. Na aba "FragTable" é possível modificar a tabela de fragmentação e recalcular as espécies químicas. A tabela de fragmentação utilizada neste instrumento foi idêntica à utilizada no ToF-ACSM para a comparabilidade.

Para descartar pontos da análise que foram entendidos como problemáticos na fase de diagnóstico, utilizaremos uma lista acessível ao plotar a série temporal dos componentes do 
$\mathrm{PM}_{1}$ na aba Misc do menu principal e opção “Time Series - $\mu \mathrm{u} / \mathrm{m}^{3}$ ”. Neste gráfico, além da própria série temporal de cada componente ainda sem as correções aplicadas, temos a opção "blacklist", pela qual é possível inserir pontos que serão descartados da análise, além de sua justificativa.

Para aplicar as correções de ganho e fluxo de volume, dadas respectivamente pelo sinal do $\mathrm{N}_{2}$ e de pressão como proxys, deve-se escolher a opção "Time series Corr." no menu "Analysis". No painel seguinte, deve-se conferir se os valores de referência da calibração, em especial o $\mathrm{RF}_{\mathrm{CAL}}$, estão corretos. Desta forma, é possível seguir para a correção pela opção "Continue to Corrections Panel". Neste novo painel, é recomendado marcar as opções "Use pressure" e "Use this sensitivitv Marker" para que sejam aplicadas ambas as correções (fluxo de volume e ganho do detector). É possível suavizar a série temporal da correção (Re-Smooth), já que o sinal no $\mathrm{N}_{2}$ pode sofrer variações bruscas pontuais que não refletem diferença no ganho do detector.

Uma correção que ocorre apenas no ACSM-Q é devido a chamada transmissão relativa de íon (RIT - Relative Ion Transmission), e corrige a eficiência de detecção que decresce rapidamente em função da razão m/z. Esta correção pode ser acessada através da opção "Ion Transmission Corr.", que abrirá o painel da Figura 3.20.

A câmara de detecção contém um padrão de naftaleno que garante um sinal para calibração relativa $\left(\mathrm{C}_{10} \mathrm{H}_{8} ; \mathrm{m} / \mathrm{z}=128\right)$. A correção mais atual para este RIT é baseada no sinal de background dos fragmentos do naftaleno nas redondezas das razões m/z 51, 62, 76, 102 e 128. Estes sinais são comparados entre si e com a fragmentação de referência do naftaleno por impactação eletrônica (com a mesma energia da utilizada nos ACSM) da base de dados do Instituto Nacional de Padrões e Tecnologia (NIST - National Institute of Standards and Technology) dos Estados Unidos. Desta forma, deve-se assegurar que o ajuste indicado pela curva azul aos pontos pretos entre razões $\mathrm{m} / \mathrm{z} \sim 50$ a $\sim 140$ é razoável. O ajuste padrão é o exponencial, que foi mantido neste trabalho. Para valores de $\mathrm{m} / \mathrm{z}<50$ e $\mathrm{m} / \mathrm{z}>140$, a curva é considerada constante e igual a 1 e 0.05 , respectivamente. 
Figura 3.20 - Ajuste da dependência espectral da transmissão relativa de íons (RIT), que acontece somente para este tipo de detector.

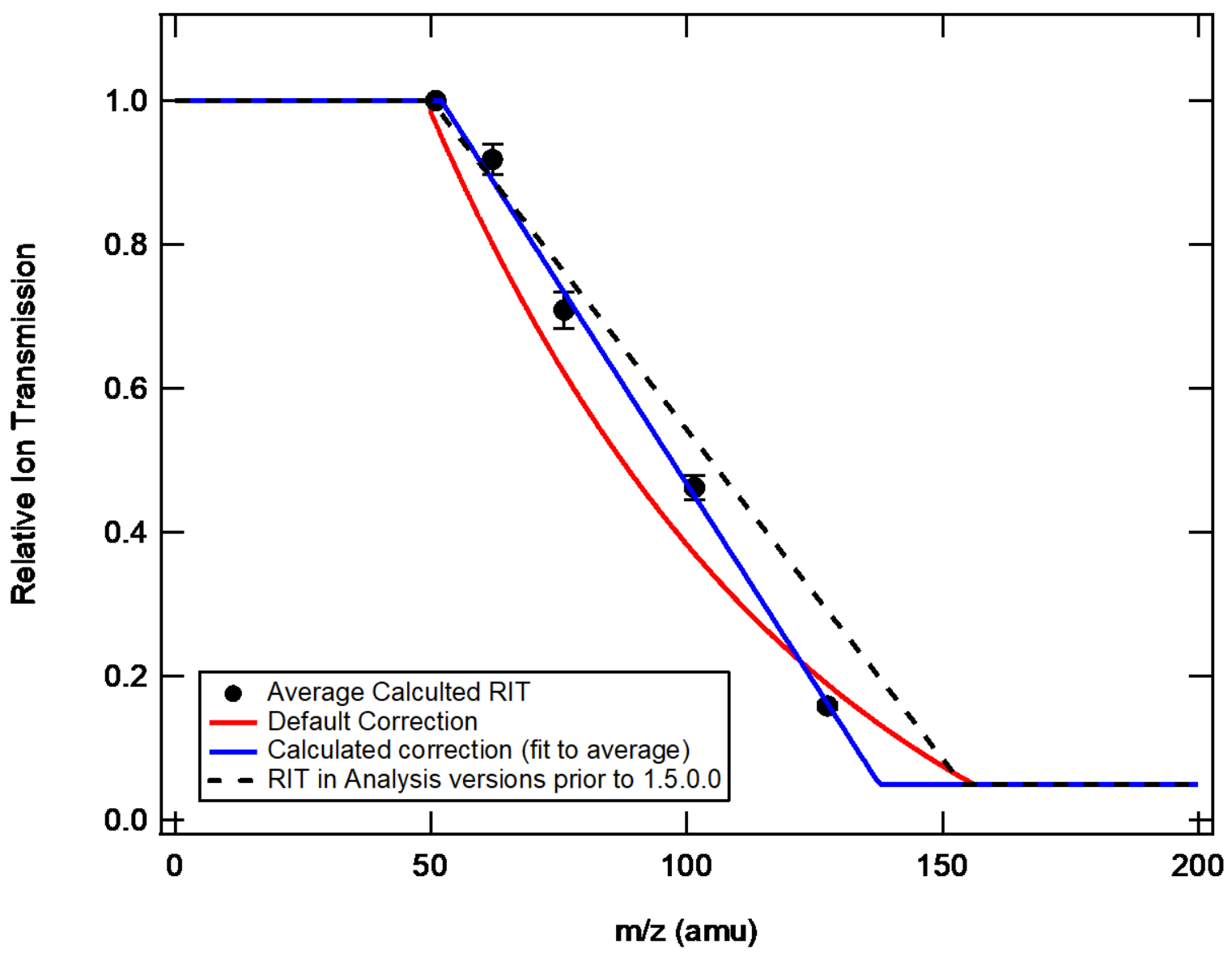

Com as duas correções prontas, deve-se marcar as duas caixas do menu Corrections na aba Analysis e aplicá-las clicando em Apply Corrections. Na aba Export, é possível exportar as séries temporais das componentes do $\mathrm{PM}_{1}$ por meio da opção "Save time Series". Na mesma aba, por fim, para exportar as matrizes de sinal e incerteza do sinal dos fragmentos orgânicos, existem seis opções no Menu PMF Exporting. Neste trabalho, utilizamos apenas a primeira opção para aplicar correções e a última para exportar.

A primeira opção aplica nos sinais e incertezas dos fragmentos a correção de ganho, com referência padrão de ganho de 20000, e calcula o erro com ruído eletrônico proveniente do fragmento de $\mathrm{m} / \mathrm{z}=140$. Esta é a escolha padrão, já que é o fragmento de maior $\mathrm{m} / \mathrm{z}$ detectado pelo quadrupolo. As etapas seguintes incluem diagnósticos de linearidade do erro em relação ao sinal, que foram realizados em rotina própria no Matlab, e incremento da incerteza de alguns fragmentos para aplicação no PMF, que foi aplicado pelo próprio software que performa a Fatoração de Matriz Positiva. 


\subsubsection{Validação de dados do espectrômetro Q-ACSM}

Para a validação do Q-ACSM que se encontra no sítio T2, a densidade do aerossol foi calculada por uma média da mesma expressão utilizada na sessão passada (KUWATA et al., 2012) e aplicada na série temporal da composição, que apresentou variações menores do que $5 \%$ no intervalo interquartil, resultando em uma densidade média para o $\mathrm{PM}_{1}$ de $1.37 \mathrm{~g} / \mathrm{cm}^{3}$. Nosso ajuste entre a massa das espécies medidas pelo Q-ACSM (NR-PM $)$ e a diferença entre massa total de $\mathrm{PM}_{1}$ calculado através das medidas do SMPS foi mostrado na Figura 3.21, o valor do coeficiente $\mathrm{R}^{2}$ foi de $0.81(\mathrm{p}<0.01)$ mostrando um ótimo acordo entre a massa estimada e a medida para o $\mathrm{PM}_{1}$. O coeficiente angular do ajuste foi de 1.01, de forma que não foi necessária nenhuma outra correção na série temporal.

Figura 3.21 - Comparação entre medidas de NR-PM1 do ACSM e estimativa de NR-PM1 a partir de dados dos SMPS/Aetalometro para o Q-ACSM.

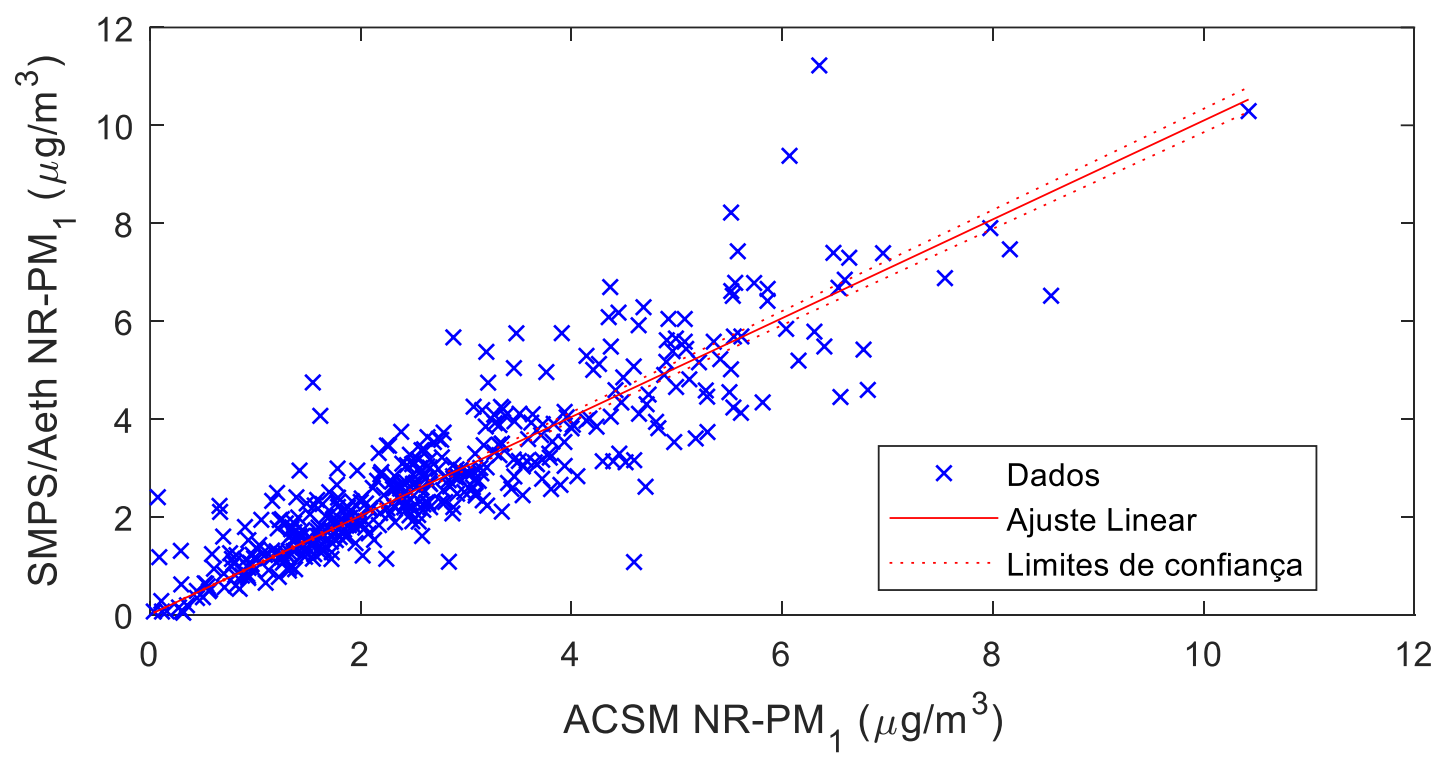

Esta validação possibilita o estudo quantitativo do espectro de massa medido pelo ACSM para a determinação de fatores, como pelo método descrito a seguir.

\subsection{ANÁLISE DE FATORAÇÃO DE MATRIZ POSITIVA (PMF) DO ESPECTRO DE AEROSSÓIS ORGÂNICOS}

Foi implementada uma análise da componente orgânica do particulado fino através do algoritmo de Fatoração de Matriz Positiva (PMF), um método robusto de análise multivariada que busca representar a matriz de fragmentos orgânicos por uma combinação linear de fatores com significado físico, cujos fatores representam classes químicas que de partículas que 
compartilham fontes e/ou processos meteorológicos que induzem transformações físicoquímicas. A partir deste método, cada fator conta com um espectro de massa fixo que indica a contribuição relativa de cada íon e com uma série temporal variável de concentração em massa.

As vantagens deste algoritmo são: restrição de fatores para concentrações positivas de cada íon do espectro de massa; fatores não são restritos a serem ortogonais entre si; as intensidades do espectro de massa têm peso dependente da sua incerteza, que é dinâmica; a massa é conservada, de forma que é possível quantificar a responsabilidade de cada fator para a massa total; é capaz de lidar com outliers e dados abaixo dos limites de detecção de forma apropriada (ULBRICH et al., 2009).

Desta forma, a concentração de cada fragmento é dada pela combinação linear da contribuição de cada um dos p fatores, que assumem diferentes intensidades a cada período de tempo, e que tem um perfil fixo para a contribuição relativa entre as variáveis inseridas no modelo. Esta relação pode ser representada a partir da seguinte combinação linear (FORELLO et al., 2019):

$$
x_{i j}=\sum_{k=1}^{P} g_{i k} f_{k j}+r_{i j}
$$

sendo $x_{i j}$ as concentrações do fragmento orgânico j no tempo i $\left(\mu \mathrm{g} / \mathrm{m}^{3}\right), f_{k j}$ a contribuição relativa do fator $\mathrm{k}$ em relação ao fragmento $\mathrm{j}$ (sem unidade), $g_{i k}$ a intensidade do fator k no tempo i $\left(\mu \mathrm{g} / \mathrm{m}^{3}\right)$ e $r_{i j}$ o resíduo, ou seja, a diferença entre a concentração medida e a modelada quanto ao fragmento $\mathrm{j}$ no tempo $\mathrm{i}$.

A equação é resolvida por método iterativo, minimizando a variável Q, a somatória dos resíduos $r_{i j}$ normalizados por suas incertezas $\alpha_{i j}$, sem informação a priori do perfil de massa dos fatores $\mathrm{f}$ e da concentração em massa $\mathrm{g}$ destes fatores, a partir da seguinte expressão:

$$
Q=\sum_{i=1}^{m} \sum_{j=1}^{n}\left(\frac{r_{i j}}{\alpha_{i j}}\right)^{2}
$$

Há uma extensa literatura para diferentes fatores encontrados em análise de PMF aplicada a espectrômetros de massa e seus processos/fontes relacionados. Estes processos e fontes podem ser identificados, por exemplo, pela análise do perfil dos fatores, que apresentam traçadores como o fragmento de m/z 60, característico de queima de biomassa (CUBISON et al., 2011) e o fragmento de $\mathrm{m} / \mathrm{z}$ 82, característico de produção secundária derivada da oxidação do COV isopreno por um caminho químico comum na atmosfera natural (ROBINSON et al., 2011). Também podem ser identificados através de altas correlações entre a série temporal dos fatores obtidos através do PMF com a série temporal de outros poluentes. 
Esta componente do trabalho foi desenvolvida através da versão gratuita da biblioteca SoFi versão 6.E (CANONACO et al., 2013) baseada no software Igor Pro, e se encontra disponível no endereço https://www.datalystica.com/sofi, embora seja necessário contato com o suporte (disponível no mesmo endereço) para receber as credenciais para realizar o download.

Esta análise representa uma importante componente original deste trabalho, que será o estudo das fontes e processos físicos relacionados a composição química do material particulado proveniente de emissões urbanas em meio a floresta tropical em diferentes tempos de envelhecimento na atmosfera.

\subsection{A BIBLIOTECA DE PROPRIEDADES ÓTICAS LIBRADTRAN}

Para ampliar a caracterização do particulado de Manaus, também utilizaremos o LibRadtran, uma biblioteca de funções em Fortran e $\mathrm{C}$ utilizada amplamente na comunidade científica para prever, analisar e modelar as propriedades ópticas da atmosfera.

Neste trabalho em especial, utilizaremos a função mie deste pacote, que recebe uma distribuição de tamanho de partículas e um índice de refração, suas saídas são SSA e coeficiente de extinção, pelos quais podemos obter os coeficientes de espalhamento e absorção de aerossóis.

Para calcular a interação óptica da matéria, o modelo irá resolver as equações de Maxwell para partículas de formato esférico e mistura homogênea. O tamanho das partículas que servirá de input no modelo será a série temporal medida pelo SMPS. A fim de conhecer um índice de refração que represente as emissões de Manaus, buscamos comparar os coeficientes ópticos medidos ao resultado do modelo de forma iterativa buscando minimizar o resíduo.

Este software pode ser baixado e tem instruções para instalação no seguinte endereço: http://www.libradtran.org/doku.php?id=start. A versão utilizada neste trabalho foi a 2.0.3. 


\section{PROPRIEDADES FÍSICO-QUÍMICAS DE AEROSSÓIS E GASES NO CENTRO DE MANAUS (SÍTIO T1)}

O experimento GoAmazon2014/15 reuniu condições únicas no mundo, de estudar o impacto de uma cidade completamente isolada cercada de florestas por todos os lados por milhares de quilômetros. É um laboratório perfeito para o estudo de interações de emissões urbanas com os compostos atmosféricos naturais de uma floresta tropical. Porém, até o momento da idealização deste trabalho os estudos em geral focaram em estudar a atmosfera amazônica sem perturbação antrópica e sua modificação por impactos da pluma urbana de Manaus com $\sim 4 \mathrm{~h}$ de envelhecimento, no sítio T3 do Experimento GoAmazon2014/15, considerando as concentrações de poluentes em T2, $10 \mathrm{~km}$ vento abaixo da cidade, como poluentes frescos e recém emitidos. Mostramos, porém, que existem diferenças marcantes entre as características da poluição em T1, centro de Manaus, e em T2 e que indicam diferentes evidências de processamento atmosférico muito rápido, além de efeitos de fontes diferentes.

Nos próximos dois capítulos apresentaremos os resultados obtidos neste trabalho quanto às propriedades físico-químicas das partículas e gases traço presentes na atmosfera de Manaus e arredores durante a temporada chuvosa. Estudamos em detalhe a composição química das partículas orgânicas da fração fina - $\mathrm{PM}_{1}$ - e como a composição química do particulado fino se relaciona com as propriedades ópticas. Estes são resultados originais que adicionarão ao entendimento da comunidade científica como uma referência para atmosferas urbanas em meio a grandes extensões de floresta tropical.

Neste capítulo iremos caracterizar e estudar as propriedades físico-químicas das partículas e gases atmosféricos de Manaus com medidas próximas à fonte e um detalhamento e amplitude ainda não existente na literatura.

Nas Tabelas 3, 4 e 5 encontram-se um resumo da estatística descritiva relativa a médias de 30 minutos da série temporal dos poluentes medidos em ambos os sítios utilizados neste estudo quanto a concentração de espécies químicas, propriedades ópticas e de tamanho de partículas, que serão exploradas em detalhes nas próximas subseções deste capítulo. Estas tabelas contém as medianas e percentis 0.25 e 0.75 pois esta descrição representa melhor uma distribuição não gaussiana, como é comum para séries temporais de concentração de poluentes.

Grandes diferenças podem ser observadas entre as propriedades e concentrações de poluentes amostrados nos dois sítios T1 e T2. Enquanto foi observada uma redução de mais de $50 \%$ para gases primários como $\mathrm{CO}$ e $\mathrm{SO}_{2}$ de $\mathrm{T} 1$ para $\mathrm{T} 2$, observou-se um aumento no ozônio, poluente secundário, como visto na Tabela 4. Foi observada em T2 uma grande diminuição na 
concentração de COVs para valores, dependendo do particular COV, até 8 vezes menores do sítio T1. Para os aerossóis, como pode ser notado na Tabela 3, foi observada uma forte redução nas concentrações entre T1 e T2 para valores 3 vezes menores e diminuição menos intensa para espécies com origem secundária ou mista, como orgânicos $\mathrm{OA}$, nitrato, amônio e número de partículas. Também foi observado diferentes diminuições de coeficientes de absorção e espalhamento entre os sítios, resultando em uma mudança na característica óptica intrínseca representada pelo $\mathrm{SSA}_{637 \mathrm{~nm}}$, de 0.58 (um aerossol altamente absorvedor) em T1 para 0.67 em T2, notado na Tabela 5. Houve também um notável aumento no diâmetro geométrico médio (DGM) de $44 \mathrm{~nm}$ em T1 para $69 \mathrm{~nm}$ em T2. As diferenças entre as características da poluição amostrada em cada um dos sítios e os processos que estão impulsionando essas diferenças serão discutidos em detalhe no Capítulo 5 deste trabalho.

Esta base de dados reúne condições únicas no mundo para trabalhos de modelagem atmosférica da interação de emissões naturais com emissões urbanas, razão pela qual esta base foi utilizada para o desenvolvimento do trabalho que está no Apêndice C, cujo aluno é coautor. Tabela 3 - Estatística descritiva da média de 30 min da concentração de espécies químicas e propriedades físicas de partículas dos dois sítios de amostragem - T1, centro de Manaus, e T2, Hotel Tiwa - durante os meses de fevereiro a abril de 2016 e 2014, respectivamente.

T1

\begin{tabular}{|c|c|c|c|c|c|c|}
\hline Aerossóis & Mediana & p. 0.25 & p. 0.75 & Mediana & p. 0.25 & p. 0.75 \\
\hline $\begin{array}{c}\mathrm{BCe} \\
\left(\mu \mathrm{g} / \mathrm{m}^{3}\right)\end{array}$ & 1.7 & 1.1 & 2.5 & 0.58 & 0.25 & 1.1 \\
\hline $\begin{array}{c}\mathrm{OA} \\
\left(\mu \mathrm{g} / \mathrm{m}^{3}\right)\end{array}$ & 2.9 & 2.1 & 4.3 & 1.9 & 1.1 & 3.0 \\
\hline $\begin{array}{l}\text { Sulfato } \\
\left(\mu \mathrm{g} / \mathrm{m}^{3}\right)\end{array}$ & 0.18 & 0.09 & 0.30 & 0.35 & 0.20 & 0.60 \\
\hline $\begin{array}{l}\text { Nitrato } \\
\left(\mu \mathrm{g} / \mathrm{m}^{3}\right)\end{array}$ & 0.13 & 0.08 & 0.20 & 0.09 & 0.05 & 0.15 \\
\hline $\begin{array}{l}\text { Amônio } \\
\left(\mu \mathrm{g} / \mathrm{m}^{3}\right)\end{array}$ & 0.14 & 0.02 & 0.32 & 0.09 & 0.02 & 0.17 \\
\hline $\begin{array}{l}\text { Cloreto } \\
\left(\mu \mathrm{g} / \mathrm{m}^{3}\right)\end{array}$ & \multicolumn{3}{|c|}{ < limite detecção } & \multicolumn{3}{|c|}{ < limite detecção } \\
\hline $\mathrm{CN}\left(\mathrm{cm}^{-3}\right)$ & $7.2 \mathrm{E}+03$ & $4.9 \mathrm{E}+03$ & $1.0 \mathrm{E}+04$ & $3.3 \mathrm{E}+03$ & $1.1 \mathrm{E}+03$ & $5.8 \mathrm{E}+03$ \\
\hline
\end{tabular}


Tabela 4 - Estatística descritiva da média de 30 min da razão de mistura de gases dos dois sítios de amostragem - T1, centro de Manaus, e T2, Hotel Tiwa - durante os meses de fevereiro a abril de 2016 e 2014, respectivamente, com unidades de ppbv.

T1

T2

\begin{tabular}{|c|c|c|c|c|c|c|}
\hline Gases & Mediana & p. 0.25 & p. 0.75 & Mediana & p. 0.25 & p. 0.75 \\
\hline $\mathrm{CO}$ & $3.0 \mathrm{E}+02$ & $2.2 \mathrm{E}+02$ & $4.1 \mathrm{E}+02$ & $1.3 \mathrm{E}+02$ & $1.2 \mathrm{E}+02$ & $1.6 \mathrm{E}+02$ \\
\hline $\mathrm{SO}_{2}$ & 0.40 & 0.24 & 0.59 & 0.13 & 0.04 & 0.34 \\
\hline $\mathrm{O}_{3}$ & 2.5 & 0.4 & 7.1 & 6.3 & 2.6 & 13 \\
\hline $\mathrm{N}_{2} \mathrm{O}$ & $3.8 \mathrm{E}+02$ & $3.7 \mathrm{E}+02$ & $3.9 \mathrm{E}+02$ & $3.1 \mathrm{E}+02$ & $3.1 \mathrm{E}+02$ & $3.2+02$ \\
\hline $\mathrm{NO}_{2}$ & 7.6 & 5.3 & 11 & - & - & - \\
\hline Metanol & 8.6 & 8.1 & 9.2 & 1.1 & 0.64 & 1.4 \\
\hline Acetonitrila & 0.40 & 0.32 & 0.51 & $9.7 \mathrm{E}-02$ & $7.1 \mathrm{E}-02$ & 11E-02 \\
\hline Acetaldeído & 3.0 & 2.5 & 3.7 & 0.45 & 0.21 & 0.87 \\
\hline Acetona & 1.8 & 1.4 & 2.4 & 0.72 & 0.54 & 0.92 \\
\hline Isopreno & 1.9 & 1.3 & 2.0 & 0.69 & 0.43 & 1.1 \\
\hline $\begin{array}{c}\mathrm{MVK}+\mathrm{MA} \\
\mathrm{CR}\end{array}$ & 1.0 & 0.65 & 1.1 & 0.58 & 0.27 & 1.1 \\
\hline MEK & 0.48 & 0.37 & 0.63 & $9.5 \mathrm{E}-02$ & $5.2 \mathrm{E}-02$ & 18E-02 \\
\hline Benzeno & 0.49 & 0.34 & 0.74 & 0.13 & $6.6 \mathrm{E}-02$ & 0.22 \\
\hline Tolueno & 0.64 & 0.45 & 0.91 & 0.29 & 0.11 & 0.54 \\
\hline $\begin{array}{c}\text { Aromáticos } \\
\mathrm{C}_{8}\end{array}$ & 0.72 & 0.49 & 1.1 & 0.14 & 6.0E-02 & 0.27 \\
\hline $\begin{array}{c}\text { Aromáticos } \\
\mathrm{C}_{9}\end{array}$ & 0.18 & 0.15 & 0.22 & $5.4 \mathrm{E}-02$ & 2.4E-02 & 8.7E-02 \\
\hline $\begin{array}{c}\text { Monoterpen } \\
\text { os }\end{array}$ & 0.28 & 0.23 & 0.38 & 0.12 & 7.5E-02 & 0.20 \\
\hline
\end{tabular}


Tabela 5 - Estatística descritiva da média de 30 min de propriedades físicas de partículas dos dois sítios de amostragem, T1, centro de Manaus, e T2, Hotel Tiwa - durante os meses de fevereiro a abril de 2016 e 2014, respectivamente.

T1

$\mathbf{T 2}$

\begin{tabular}{|c|ccc|ccc|}
\hline $\begin{array}{c}\text { Propriedad } \\
\text { es Físicas }\end{array}$ & Mediana & p. 0.25 & p. 0.75 & Mediana & p. 0.25 & p. 0.75 \\
DGM (nm) & 44 & 40 & 48 & 69 & 56 & 91 \\
$\begin{array}{c}\sigma_{\mathrm{a}} 637 \mathrm{~nm} \\
\left(\mathrm{Mm}^{-1}\right)\end{array}$ & 11 & 6.7 & 16 & 3.8 & 1.7 & 7.3 \\
$\begin{array}{c}\sigma_{\mathrm{e}} 637 \mathrm{~nm} \\
\left(\mathrm{Mm}^{-1}\right)\end{array}$ & 14 & 10 & 20 & 7.6 & 4.3 & 13 \\
\begin{tabular}{c} 
SSA $637 \mathrm{~nm}$ \\
\hline
\end{tabular} & 0.58 & 0.49 & 0.68 & 0.67 & 0.55 & 0.78 \\
\hline
\end{tabular}

\subsection{AS CONCENTRAÇÕES DE GASES ATMOSFÉRICOS NO CENTRO DE MANAUS}

Um importante traçador de atividade antrópica medido foi o monóxido de carbono (CO), um poluente - em geral - emitido conjuntamente a todas as outras emissões primárias ligadas a combustão, dado ser fruto da combustão incompleta. Em particular emissões veiculares e de termelétricas são importantes fontes de CO. Além disso, a espécie não é solúvel (portanto não é removida pela chuva), razoavelmente inerte na atmosfera e tem tempo médio de vida na atmosfera da ordem de várias semanas (HOLLOWAY et al. 2000). Já o poluente dióxido de enxofre $\left(\mathrm{SO}_{2}\right)$, que também é associado com atividade antrópica, oxida mais rapidamente na atmosfera, com tempo de vida menor que um dia (LEE et al. 2011).

As concentrações características de $\mathrm{CO}$ e $\mathrm{SO}_{2}$ na estação $\mathrm{T} 1$ para o período deste estudo e suas variações, indicadas pela mediana e intervalo interquartil (IIQ; intervalo entre os percentis 0.25 e 0.75 ) foram de 334 (225-409) ppbv para CO e $0.40(0.24-0.59)$ ppbv para $\mathrm{SO}_{2}$. Os valores característicos de $\mathrm{CO}$ são duas vezes menores do que os medidos na cidade do México, três vezes menores do que os medidos na Região Metropolitana de São Paulo, e são compatíveis com sítios em grandes cidades como Paris e Buenos Aires. (TÉ et al., 2012 e 2016; STREMME et al., 2013; ROZANTE et al., 2017). Já as concentrações de $\mathrm{SO}_{2}$ em Manaus são metade do que as medidas no sítio altamente impactado por emissões veiculares, na Marginal 
Tietê em São Paulo (NAKADA et al., 2020), mostrando altas emissões de $\mathrm{SO}_{2}$ na cidade de Manaus mesmo com uma frota significativamente menor do que a de São Paulo.

Figura 4.1 - Perfil diário do $\mathrm{CO}$ (esquerda, em azul) e $\mathrm{SO}_{2}$ (direita, em laranja), com estatística a cada 30 min, mostrando em linhas sólidas as medianas e em áreas semitransparentes mostram o intervalo interquartil (entre os percentis 0.25 e 0.75 ). Ambos os perfis diários acompanham os picos de transporte matutino e no início do período noturno de Manaus.

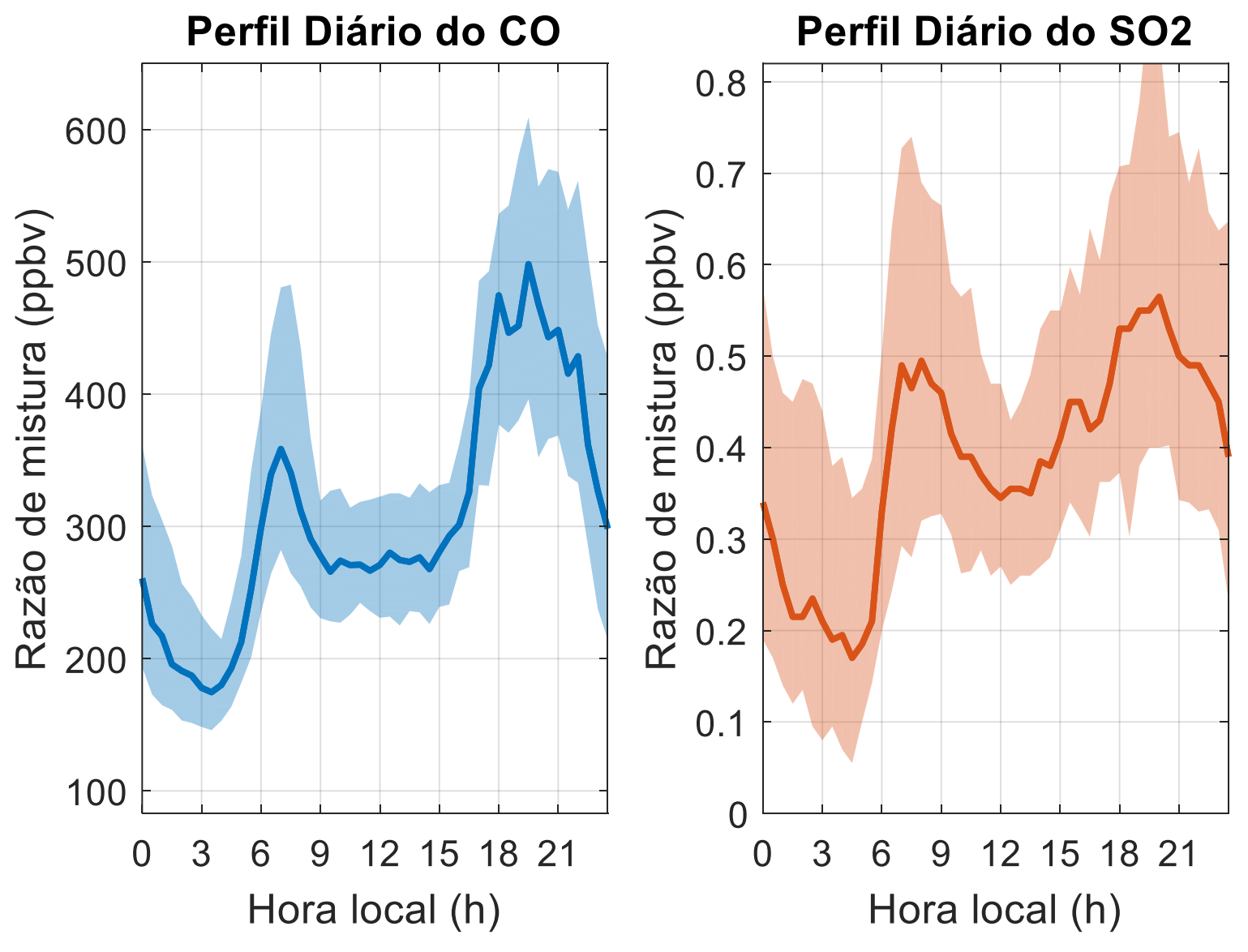

A Figura 4.1 exibe o ciclo diurno na hora local de concentração de $\mathrm{CO}$ e $\mathrm{SO}_{2}$, com a linha sólida indicando a mediana e a faixa semitransparente indicando a IIQ. Este perfil médio dado pelo ciclo diurno das concentrações de um poluente pode ser útil para avaliar suas fontes, produção e consumo fotoquímicos, dentre outros fatores. A concentração do $\mathrm{CO}$ (perfil à esquerda, em azul) tem valores máximos nos horários de pico de transporte da manhã (7h) e do final da tarde (19h30min). Ambos os picos de CO, portanto, devem acontecer devido às emissões veiculares. Nota-se também que o pico noturno é mais largo, fato que se deve à camada limite noturna, mais fina e estável, que se estabelece ao anoitecer e não propicia a dispersão dos poluentes. $\mathrm{O}$ pico matutino tem máxima intensidade às $7 \mathrm{~h}$, mas o perfil diurno começa a aumentar a partir das $4 \mathrm{~h}$ da manhã, que deve acompanhar o começo do aumento do tráfego de veículos. No meio do dia há menores concentrações deste poluente, que é explicado além de menores as emissões de veículos em relação ao horário de pico, pelo aumento dos 
processos de turbulência e do aumento da altura da camada limite, fazendo com que a mistura aconteça em uma camada maior da atmosfera. Os menores valores são medidos às 3:30 da manhã. Este ciclo diurno evidencia que no centro de Manaus as concentrações para este poluente são conduzidas pelas emissões de tráfego.

$\mathrm{O}$ ciclo diurno do $\mathrm{SO}_{2}$ (perfil à direita, em laranja) em $\mathrm{T} 1$ apresenta uma tendência semelhante ao CO no mesmo sítio, com picos durante a manhã e à noite acompanhando os picos do tráfego. Este perfil é uma evidência de que as fontes móveis são fontes importantes para compostos de enxofre no centro de Manaus. No diesel brasileiro temos enxofre a altos níveis de 500 a 2000 ppm.

Outros gases de importante quantificação em um ambiente urbano são os COVs, cujas concentrações podem causar significativos impactos na saúde, interferir na produção e consumo de ozônio, e na produção de SOA. Por isto, a quantificação de COVs é uma etapa fundamental para se determinar estratégias de mitigação e para prever seus impactos ambientais. Embora alguns estudos já tenham feito algum trabalho neste sentido para a região, ainda não há um inventário regional de emissões oficial para o Estado do Amazonas (DUTRA, 2018; ABOU RAFEE et al., 2017).

Uma vantagem deste trabalho é que o PTR-MS mede separadamente a massa de diversos COVs, de forma a quantificá-los separadamente. Esta especiação é importante pois estes gases apresentam reatividades e, portanto, potenciais de produção de espécies secundárias muito diferentes. Desta forma, foram determinados doze COVs por este espectrômetro de massa e sua descrição estatística está presente na Tabela 4. A razão de mistura destes COVs é razoavelmente diferente do observado em medidas em região central de São Paulo por Brito et al. $(2015$; 2018), e esta diferença não segue um padrão para todos os COVs: enquanto o isopreno e o metanol tem valores de 1.9 (1.3-2.0) ppbv e 8.6 (8.1-9.2) ppbv, ambos maiores por um fator de quase 2; tolueno e aromáticos de 8 carbonos, com valores de 0.64 (0.45-0.91) e 0.72 (0.491.1), tem valores característicos cerca de 2x menores. Em destaque, benzeno tem valores de 0.49 (0.34-0.74), comparáveis às medidas de São Paulo, mesmo com uma frota veicular de 600 mil veículos em Manaus em comparação com cerca de 7 milhões de veículos na cidade de São Paulo.

As concentrações de vários COVs antrópicos em ambientes urbanos foram identificadas com alta correlação com as concentrações de monóxido de carbono por alguns estudos (SCHNEIDEMESSER et al., 2008, BAKER et al., 2010), sugerindo que a concentração de ambos os poluentes nestes ambientes é controlada pelas emissões de fontes móveis, apesar de sofrerem influência de outras fontes como evaporação. Temos razões para acreditar que as 
razões de emissão entre COVs e CO em Manaus podem ser diferentes de outras metrópoles no mundo. Dentre os motivos estão o combustível diferente (com 23\% de álcool) em comparação aos estudos realizados na América do Norte, e da frota ser mais nova do que em cidades como São Paulo por estar crescendo mais recentemente que em outras metrópoles.

Figura 4.2 - Gráfico de dispersão e ajuste linear entre Benzeno, Tolueno, Aromáticos de 8 carbonos e monóxido de carbono, um traçador de emissões veiculares.

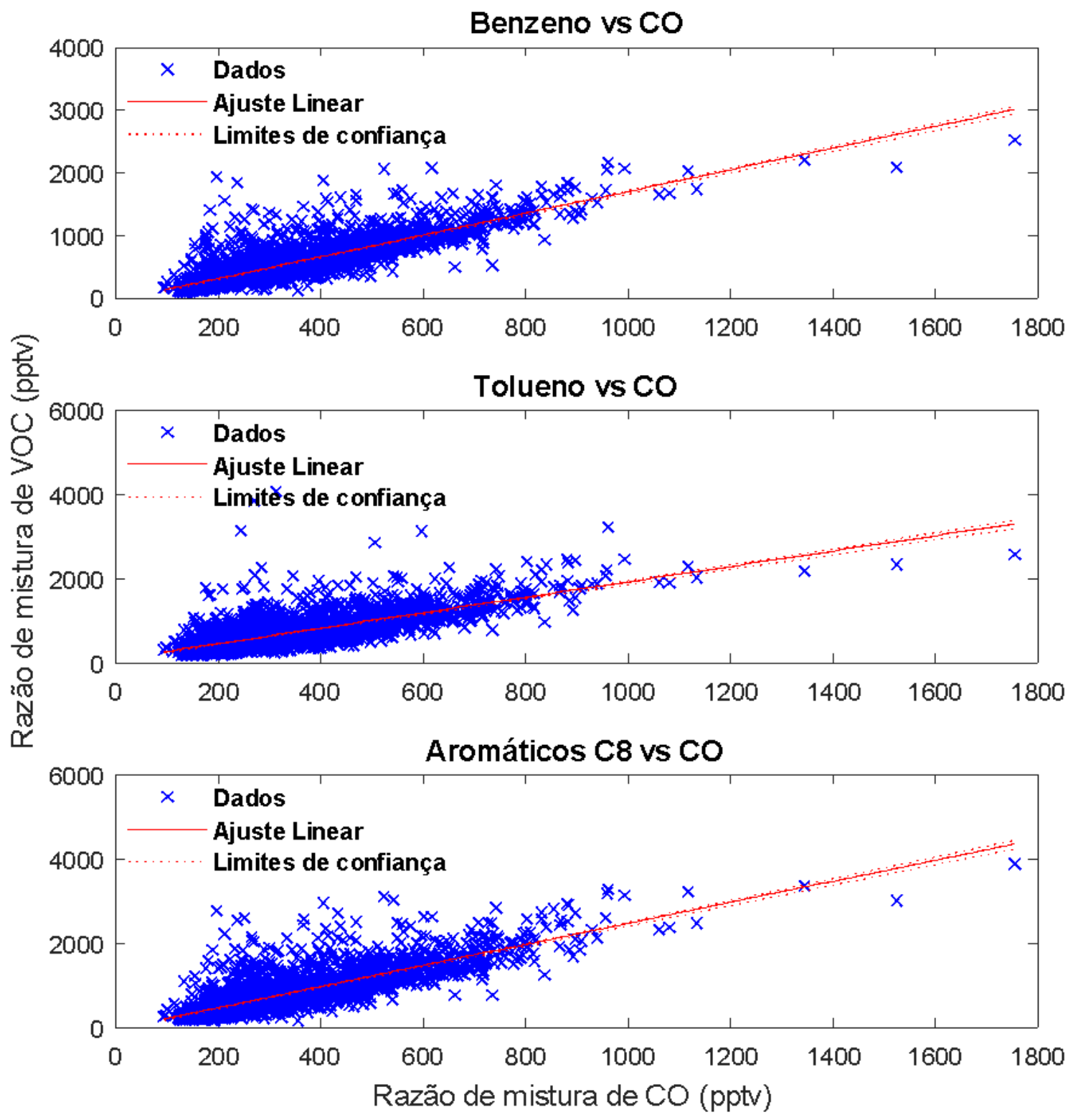

Uma estratégia para quantificar as emissões de COVs sugerida por Borbon et al., (2013) é realizar uma regressão linear entre estes gases e um traçador inerte como CO durante o período noturno. Desta forma, seriam descontados os efeitos de diluição na atmosfera (pois o mesmo efeito é sofrido pelo CO co-emitido e, portanto, o coeficiente angular ajustado não é alterado) e efeitos de processamento atmosféricos, que seriam negligíveis durante o período noturno. 
Assim, são apresentados na Figura 4.2 as regressões lineares entre CO e os COVs cujas regressões tiveram coeficiente $\mathrm{R}^{2}$ maior do que 0.5 e $\mathrm{p}<0.01$.

Os três COVs que obtiveram uma boa associação com $\mathrm{CO}$ são conhecidos como traçadores de emissões veiculares, tais como o benzeno, o tolueno e os aromáticos de 8 carbonos. Os coeficientes de ajuste $\mathrm{R}^{2}$ foram $0.70,0.55$ e 0.70 , respectivamente, enquanto as razões de emissão obtidas expressas por valor ajustado \pm desvio padrão foram de: $1.70 \pm 0.03$ pptv de benzeno/ppbv de CO, $1.78 \pm 0.05$ pptv de tolueno/ppbv de CO, $2.43 \pm 0.05$ pptv de aromáticos $\mathrm{C}_{8} / \mathrm{ppbv}$ de CO. Nenhuma tendência geral para todos os COVs foi observada na comparação com esta mesma determinação em outras cidades como São Paulo, Cidade do México, e cidades dos EUA (BRITO et al., 2015; BON et al., 2011; BAKER et al., 2008). A razão de emissão de benzeno é maior do que as observadas nestes locais (0.7-1.3), de tolueno é menor (2.7-4.2).

Um dos gases cuja produção fotoquímica depende da quantidade de COVs é o ozônio, que na troposfera é um importante poluente e oxidante atmosférico. Este composto tem sua formação e consumo governados pela radiação solar e pela concentração de duas espécies químicas precursoras em especial: os $\mathrm{NO}_{\mathrm{x}}$ e os COVs (NETTO et al., 2017).

Verificamos produção fotoquímica líquida de ozônio que acompanha o ciclo de radiação na cidade, com concentrações características no meio do dia de 12.0 (7.0-15.9) ppb e de $\sim 0.9$ ppb durante a noite, sem radiação solar para fazer a fotólise do $\mathrm{NO}_{2}$. Estas concentrações observadas foram muito mais baixas do que em outras metrópoles: as concentrações características do meio do dia observadas em metrópoles como São Paulo e cidade do México são uma ordem de grandeza maiores, da ordem de 60 a 160 ppb (SILVA JUNIOR et al., 2009; CARVALHO et al., 2015; VELASCO et al., 2017; ANDRADE et al., 2012). As hipóteses são de que as emissões seriam muito frescas de forma que ainda não houve tempo suficiente para formação fotoquímica de ozônio, e/ou os equilíbrios entre NOx e COVs na cidade não favoreceriam a formação de ozônio.

\subsection{AEROSSÓIS ATMOSFÉRICOS NO CENTRO DE MANAUS}

O número de partículas característico das medidas no centro da cidade, dado pela mediana e IQQ foi de 7.2 (4.9-10.3) E+03 partículas $\mathrm{cm}^{-3}$. Esta concentração de partículas é mais de 3 vezes menor do que valores observados na cidade do México, Pequim e São Paulo (KALAFUT-PETTIBONE et al., 2011; WU et al., 2008). 
Além da concentração total de partículas é importante determinar a distribuição de tamanho. Para isso, ajustamos a distribuição de tamanho com três distribuições log-normais com modas em regiões determinadas, como descrito em detalhe por RIZZO et al., (2018). As restrições para o ajuste foram de que o diâmetro geométrico médio (DGM) da moda de nucleação é menor do que 25nm, o DGM para moda de Aitken está entre 30nm e 90nm e o DGM para moda de acumulação é maior do que 90nm.

Desta forma, ajustou-se as distribuições de tamanho medidas e obteve-se a distribuição de intensidade de cada uma das modas no centro de Manaus, como mostrado na Figura 4.3. Nesta figura, as linhas sólidas mostram a mediana das curvas obtidas para cada moda e o intervalo interquartil indicado pelas faixas semitransparentes. O ajuste entre o número de partículas medidas e o número de partículas obtido através do ajuste das distribuições lognormais mostrou que o modelo representa bem a concentração total de partículas no sítio T1 já que apresentou valor de $\mathrm{R}^{2}$ de 0.98 e $\mathrm{p}<0.01$.

No centro da cidade, a moda de nucleação que estava centrada em $20 \mathrm{~nm}$ foi responsável por $42 \%$ das partículas em número, a moda de Aitken, centrada em 52nm, foi responsável por $40 \%$ e a moda de acumulação, centrada em 149nm, foi responsável por apenas $18 \%$ das partículas. A moda de nucleação é a moda com o menor tamanho de partícula, portanto, foi mais recentemente emitida ou foi formada recentemente na atmosfera. Para comparação, em uma cidade como Pequim, com altos níveis de poluição, a moda de nucleação é responsável por $28 \%$ do número de partículas atmosféricas (WU et al., 2008). Este resultado, com a modas de Aitken e, em especial, a modas de nucleação dominantes, indica que a maior parte do particulado amostrado é fresco, ou seja, foi emitido e/ou formado na atmosfera recentemente. 
Figura 4.3 - Distribuição de tamanho de número de partículas para cada moda no sítio T1. A moda de nucleação está exposta em verde, a moda de Aitken em azul, a moda de acumulação em vermelho e a mediana de toda a distribuição em preto. A mediana dos dados é indicada pela linha cheia, enquanto o IIQ é indicado pelas áreas semitransparentes.

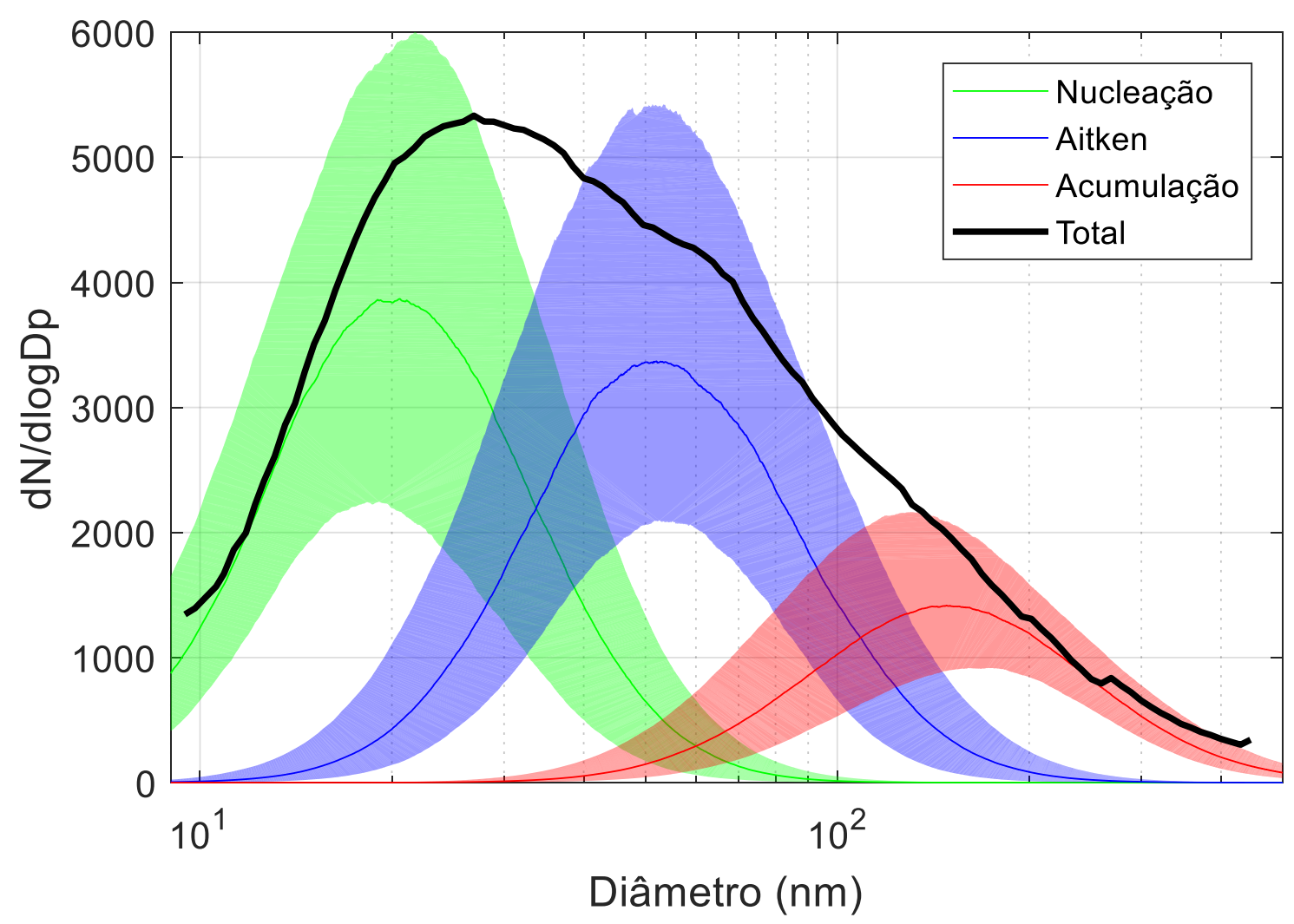

A Figura 4.4 mostra o ciclo diurno da concentração em número para cada moda. Podemos observar que para o sítio T1 quanto às modas de nucleação e Aitken, a concentração em número de partículas é semelhante ao perfil diurno das emissões de $\mathrm{CO}$ e $\mathrm{SO}_{2}$, e, portanto, sua fonte principal deve estar relacionada a emissão veicular. Embora a moda de acumulação mostra pequena variação durante o dia, a variação do perfil diurno acompanha bem o perfil da moda de Aitken, especialmente no período ensolarado, com concentrações durante o período da manhã com tendências semelhantes a gases primários. 
Figura 4.4 - Mediana do ciclo diurno da concentração de número de partículas no T1 para cada moda, com estatística horária. A moda de nucleação está indicada em verde, a moda de Aitken em azul e a moda de acumulação em preto.

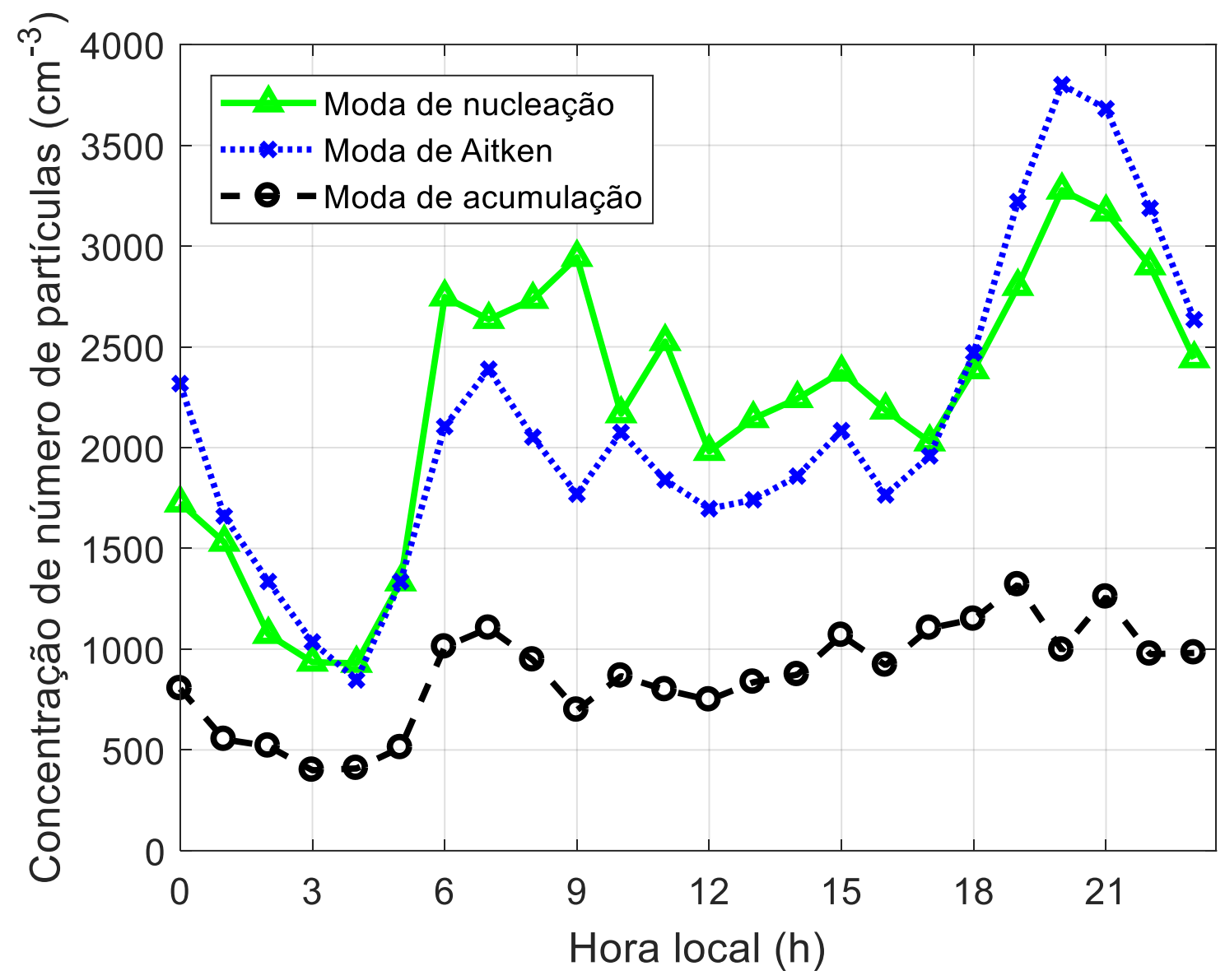

Respectivamente, as modas de nucleação e Aitken contam com concentrações características de 2.2 (1.3-3.3) E+03 e 2.0 (1.3-3.2) E+03 partículas/cm³ , mas a concentração durante o horário de pico noturno aumenta até 3800 e 3300 partículas $/ \mathrm{cm}^{3}$ durante o pico noturno das $20 \mathrm{~h}$, concentrações cerca de $50 \%$ e $90 \%$ maiores do que as características. Enquanto a dominância no período diurno é da moda de nucleação, a partir das $18 \mathrm{~h}$ esta dominância é assumida pela moda de Aitken. Este fato pode estar relacionado à dependência da radiação solar que mantém as altas concentrações de oxidantes como $\mathrm{OH}$ e $\mathrm{O}_{3}$, que devem participar das reações de conversão gás partícula sofrida por gases precursores.

As componentes químicas da massa de material particulado fino foram medidas pelo espectrômetro de massa ToF-ACSM, que mede aerossóis orgânicos e sulfato, nitrato, amônio e cloreto inorgânicos, além de medidas de BCe realizadas pelo Aetalômetro AE-33. Abaixo, na Figura 4.5, podemos observar a série temporal da composição do particulado em Manaus. 
Figura 4.5 - No gráfico superior está a série temporal da composição do $\mathrm{PM}_{1}$ em médias a cada 30 minutos para o sítio no centro de Manaus, T1, em $\mu \mathrm{g} / \mathrm{m}^{3}$. No gráfico inferior está a mesma série temporal em sua forma fracionária, mostrando claramente a dominância dos orgânicos na composição química dos aerossóis, seguido do BC. A componente orgânica é mostrada em verde, sulfato em vermelho, nitrato em azul, amônio em amarelo, cloreto em rosa e na linha pontilhada cinza a comparação com o PM 1 derivado das medidas de volume do SMPS
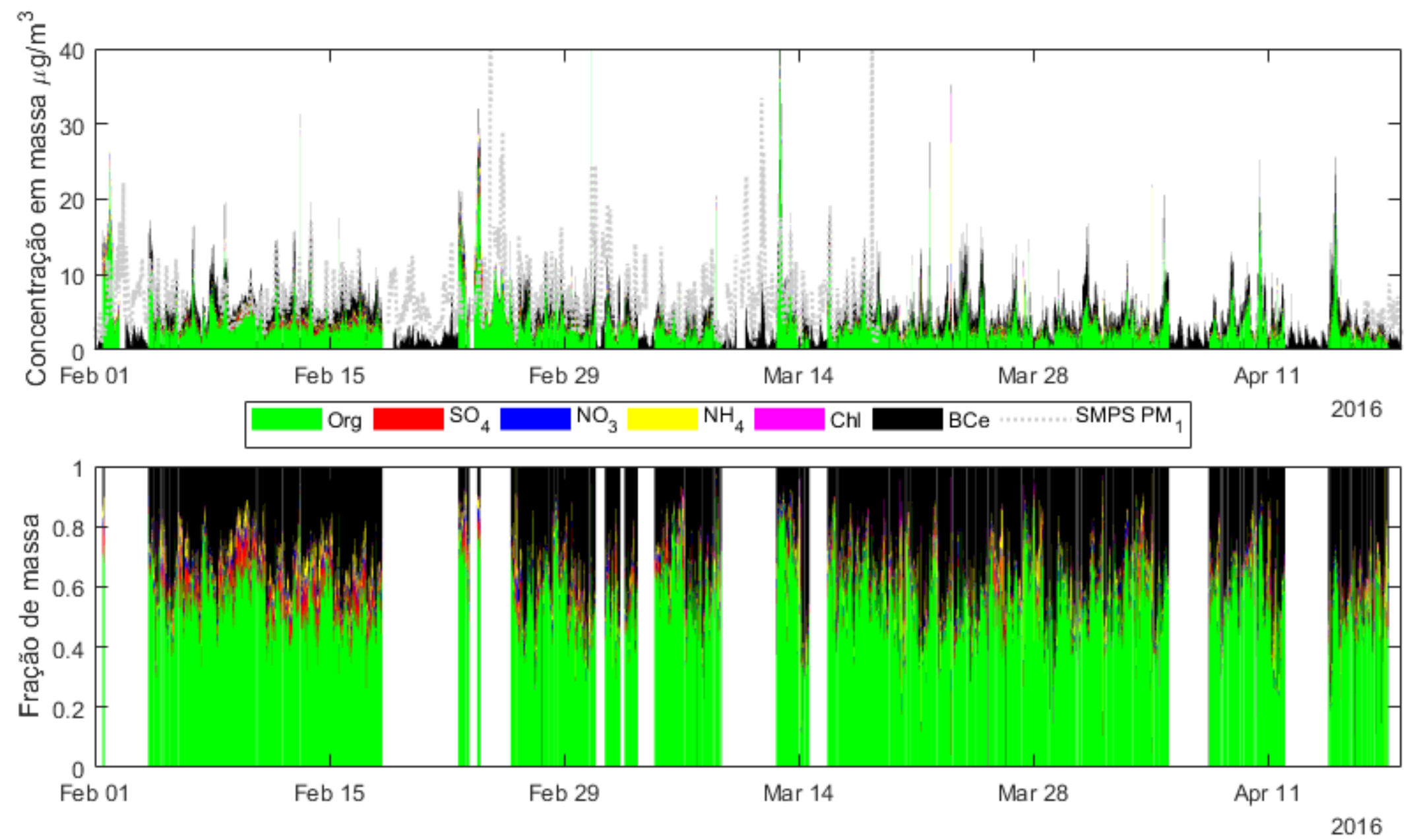
A Figura 4.5 mostra a série temporal da composição do particulado fino de fevereiro até abril, com concentrações típicas de massa total de PM1 expressos pela mediana e IIQ de 5.3 (3.8-7.2) $\mu \mathrm{g} / \mathrm{m}^{3}$. Observa-se concentrações razoavelmente constantes, dominadas pelos aerossóis orgânicos e pelo $\mathrm{BC}$, com episódios de curta duração mostrando efeitos locais que alcançam altas concentrações de até $40 \mu \mathrm{g} / \mathrm{m}^{3}$. Também é possível identificar alguns curtos episódios de maior duração, causados provavelmente por efeitos meteorológicos desfavoráveis à dispersão atmosférica. Em especial, nota-se nas primeiras duas semanas de fevereiro um aumento de sulfato de forma que sua fração em massa, no gráfico inferior da Figura 4.5, seja notável.

Medidas de filtros de $\mathrm{PM}_{2.5}$ - particulado fino com diâmetro menor do que $2.5 \mu \mathrm{m}$ coletadas no centro de Manaus durante anos anteriores à campanha deste presente trabalho e apresentadas por Barbosa (2014) resultaram em concentrações de $8.8 \pm(7.5) \mu \mathrm{g} / \mathrm{m}^{3}$ (média e desvio padrão) que concordam com a média de $6.3 \pm(4.2) \mu \mathrm{g} / \mathrm{m}^{3}$ de $\mathrm{PM}_{1}$ obtida neste estudo. Esta diferença de $30 \%$ entre concentrações de $\mathrm{PM}_{1}$ e $\mathrm{PM}_{2.5}$ está dentro do observado em ambientes urbanos impactados por fontes veiculares (LEE et al., 2006; JOHANNESSON et al., 2007; HUSSEIN et al., 2014).

A contribuição percentual de BC para o particulado fino representa uma fração de massa consideravelmente maior do que em outras metrópoles, de 33\% em média, em comparação com 6 a 9\% observados em sítios urbanos na China, 12\% em estações na cidade do México e 20 a 25\% em estações em São Paulo na última década (ZHANG et al., 2018; AIKEN et al., 2009; SANTOS JUNIOR, 2015). As concentrações relativas de BC em Manaus são semelhantes às observadas em estudos da década de 2000 para metrópoles brasileiras como São Paulo e Belo Horizonte, por volta de 30\% (ANDRADE et al., 2012; MIRANDA et al., 2012). As concentrações absolutas de BC no centro de Manaus apresentadas pela Tabela 3, de 1.7 (1.12.5) $\mu \mathrm{g} / \mathrm{m}^{3}$ são semelhantes às medidas de carbono elementar para sítios na região central de São Paulo de $\sim 2 \mu \mathrm{g} / \mathrm{m}^{3}$, mesmo com uma frota veicular muito menor do que nesta cidade (SANTOS JUNIOR et al., 2016). Este fato pode estar relacionado a legislações menos restritivas em comparação com outros estados quanto a emissões de veículos pesados circulando na cidade de Manaus. 
Figura 4.6 - À esquerda, ciclo diurno das diferentes componentes químicas do $\mathrm{PM}_{1}$, e à direita a composição fracionária do $\mathrm{PM}_{1}$ no centro de Manaus. Os aerossóis orgânicos estão indicados em verde, $\mathrm{BC}$ em preto, sulfato em vermelho, nitrato em azul, amônio em amarelo e cloreto em rosa.

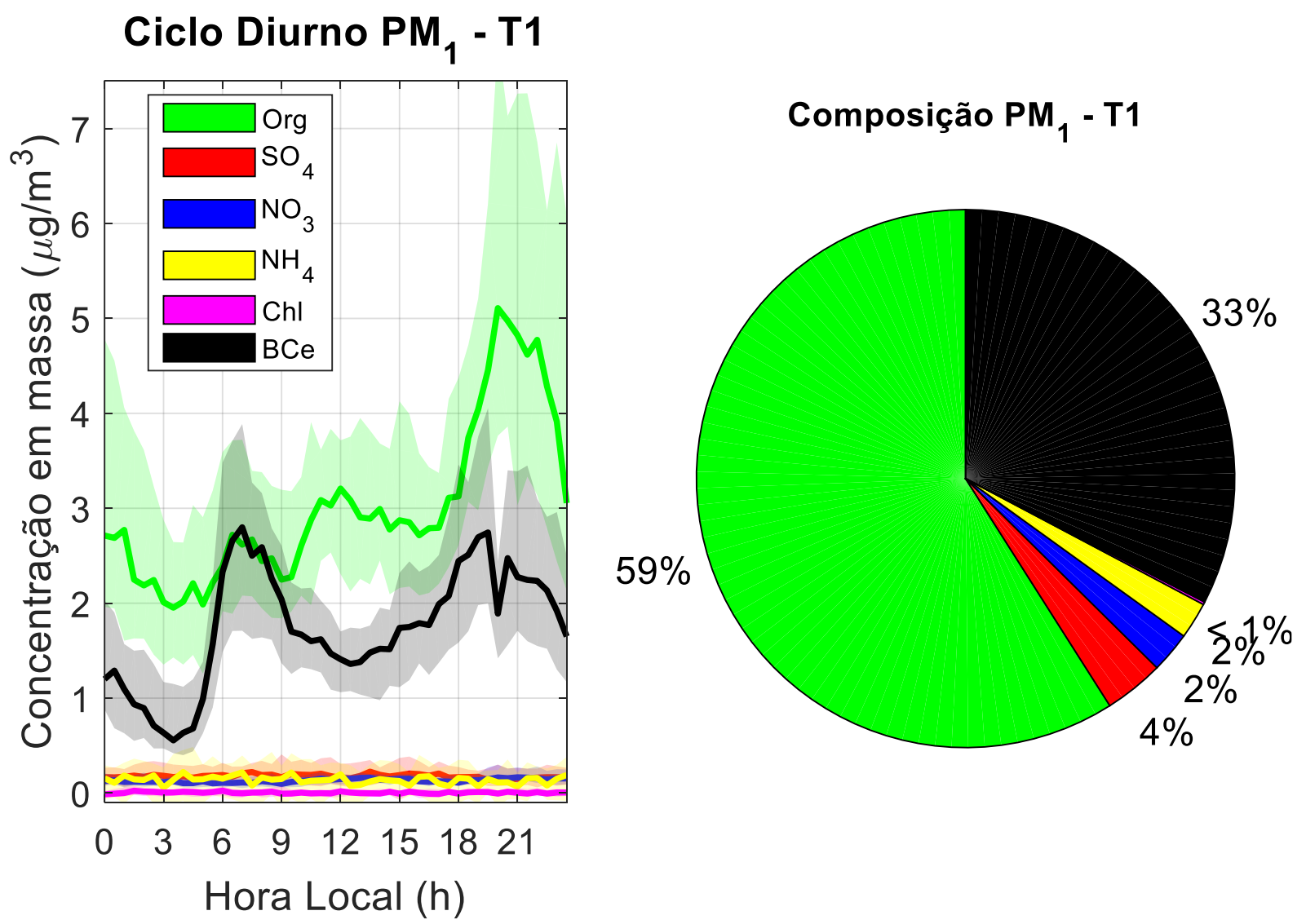

As concentrações de $\mathrm{BC}$ acompanham bem o ciclo diurno de $\mathrm{CO}$ e $\mathrm{SO}_{2}$ para este sítio, com picos matutino (às 7h) e noturno (às 19h30min) ambos com intensidade de $\sim 2.8 \mu \mathrm{g} / \mathrm{m}^{3} \mathrm{e}$ um vale durante o dia, acompanhando o aumento da altura da camada limite e dos processos turbulentos que aumentam a dispersão. Este resultado sugere que os veículos da cidade sejam importantes fontes para este poluente. Estas concentrações no perfil de BC mostram um vale no começo da manhã (antes do horário de pico de emissões veiculares) com concentrações muito baixas para um ambiente urbano, de $0.5 \mu \mathrm{g} / \mathrm{m}^{3}$.

Já as concentrações de aerossóis orgânicos apresentam algumas diferenças importantes em relação aos poluentes primários. Embora as concentrações durante o horário de rush da manhã apresentem um certo aumento, ao contrário da tendência de poluentes primários como $\mathrm{CO}$ e $\mathrm{BC}$, as concentrações do período seguinte não decrescem e sim aumentam até um pico às $12 \mathrm{~h}$ e permanecem razoavelmente constante até às $18 \mathrm{~h}$. Esta componente apresenta no final do dia (20h) um pico duas vezes maior que o da manhã, com grande dispersão. Estas diferenças sugerem que outras fontes de partículas sejam importantes para esta componente, como 
produção secundária devido a fotoquímica no meio do dia ou emissões de fontes fixas cujos perfis diários de intensidade de emissão não acompanhem o perfil horário da emissão veicular.

As concentrações observadas de aerossóis inorgânicos como sulfato, nitrato e amônio, tanto em números absolutos, que constam na Tabela 3, como em composição fracionária, à direita da Figura 4.6, foram consideravelmente mais baixas do que o usual para áreas urbanas. A hipótese para explicar estas concentrações baixas é de não houve tempo suficiente para que os gases precursores observados na cidade, como os óxidos de enxofre e de nitrogênio, sofram as reações de conversão de gás partícula.

Para explorar mais profundamente a composição química dos aerossóis urbanos, em especial a do componente majoritário do $\mathrm{PM}_{1}$, utilizamos o método de análise multivariada denominado de PMF aplicado no espectro de orgânicos medido pelo espectrômetro de massa ToF-ACSM

\subsubsection{Análise de fatores dos aerossóis orgânicos - T1}

O método de análise multivariada Fatoração de Matriz Positiva (PMF) para a determinação de fatores foi aplicado às médias de 30 min da matriz de dados (sinais e incertezas variáveis) de espectrometria de massa das partículas orgânicas coletadas na cidade de Manaus. Este modelo possibilita a determinação de espécies químicas em forma de particulado que tem seus sinais correlacionados e, portanto, compartilham fontes e/ou processos atmosféricos.

A seguir há uma descrição dos fatores normalmente observados em metrópoles. $\mathrm{O}$ fator OOA (oxygenated $O A$ ) tem a maior contribuição relativa de todos os fatores ao fragmento 44 (doravante a fração relacionada ao fragmento 44 será denominada de f44, e de forma semelhante com outros fragmentos), relacionado à detecção de $\mathrm{CO}_{2}{ }^{+}$. $\mathrm{O} \mathrm{f} 44$, pela sua alta contribuição de massa de oxigênio, é um indicador do nível de oxigenação das partículas e, portanto, está ligado a processos secundários de formação de partícula e/ou processamento na atmosfera.

O fator HOA (em inglês, hydrocarbon-like $O A$ ) tem como fragmentos característicos o f43 (majoritariamente $\mathrm{C}_{2} \mathrm{H}_{3} \mathrm{O}^{+}$para partículas mais processadas ou $\mathrm{C}_{3} \mathrm{H}_{7}^{+}$para partículas recentemente emitidas), f55 $\left(\mathrm{C}_{4} \mathrm{H}_{7}{ }^{+}\right)$e f57 $\left(\mathrm{C}_{4} \mathrm{H}_{9}{ }^{+}\right)$, pouco ou não oxigenados. Este fator é identificado na literatura como um conjunto de partículas orgânicas primárias relacionadas a emissão veicular fresca.

Há alguns outros fatores relacionados à emissão primária antrópica com espectros de massa semelhantes ao HOA como o COA (em inglês, cooking OA), fator associado com 
partículas emitidas no processo de cozimento de alimentos. Em estudo compilado por Mohr et al., (2012) este fator é estudado em alta resolução, através do espectrômetro de massa AMS. Foi observado que o sinal f55 é especialmente relevante para o fator COA e que este deve apresentar sinal f57 reduzido. Dessa forma, esses espectros podem ser diferenciados de emissões de tráfego através do perfil diurno, que costuma apresentar um máximo local durante o horário de almoço, e/ou por comparação entre sinais de fragmentos como f55 e f57 (MOHR et al., 2012).

O fator BBOA (em inglês, biomass burning $O A$ ) é ligado a queima de biomassa, e apresenta sinais de $\mathrm{f} 60\left(\mathrm{C}_{2} \mathrm{H}_{4} \mathrm{O}^{+}\right)$e $\mathrm{f} 73$ proeminentes, o que indica a presença de fragmentos de levoglucosan, composto orgânico resultado da pirólise de biomassa. O limite inferior sugerido para o sinal f60 necessário para representar sinal significativo de queima de biomassa é de f60>0.3\% (CAPES et al., 2008; CUBISON et al., 2011).

A solução mais razoável obtida é a que minimiza o coeficiente $\mathrm{Q}$, coeficiente que representa os resíduos normalizados entre as observações e o resultado modelado (calculado a partir da equação 12), e, ao mesmo tempo, fornece fatores que têm sentido físico. Este sentido físico limita o número de fatores, já que ao aumentar os graus de liberdade da regressão, a tendência sempre será de diminuição dos ruídos. No caso do sítio T1 a solução que equilibra a minimização de Q com fatores com sentido físico possui 4 fatores.

Os espectros de massa dos quatro fatores que explicam a componente orgânica do particulado fino no centro de Manaus estão expostos na Figura 4.7, ao lado do perfil diurno das concentrações associadas a cada fatores. Na Figura 4.8 está indicada a contribuição fracionária de cada fator para a massa total de aerossóis orgânicos da moda fina.

$\mathrm{O}$ primeiro fator, OOA, foi o maior responsável pela massa de $\mathrm{PM}_{1}$ no sítio $\mathrm{T} 1$ e foi identificado pelos intensos 444 e f28 $\left(\mathrm{CO}_{2}{ }^{+}\right.$e $\left.\mathrm{CO}^{+}\right)$, com altas razões de O:C. Suas maiores concentrações acontecem durante a luz do dia, o que indica que este é um fator importante para as reações de mudança de fase de gás para partícula.

$\mathrm{O}$ fator HOA tem um perfil classicamente encontrado para fatores do tipo: é dominado por f43, f55 e f57, íons pouco ou não oxigenados. Este fator está relacionado a emissões frescas veiculares, como evidencia seu perfil diurno, que é marcado por dois máximos nos horários de pico do trânsito. Sua contribuição para a massa é de $21 \%$. Este fator se correlaciona bem com Black Carbon (0.61 - coeficiente de correlação R de Pearson), concentração de número de partículas $(0.57)$ e CO (0.65), poluentes associados a emissões de tráfego no T1 e, portanto, seriam espécies co-emitidas ou com variabilidade similar. 
Figura 4.7 - À esquerda, espectros de massa dos 4 fatores de aerossóis orgânicos da moda fina encontrados na análise PMF no sítio T1. O eixo horizontal representa os fragmentos com determinado $\mathrm{m} / \mathrm{z}$, enquanto o vertical mostra a fração da contribuição relativa de cada íon em relação ao fator. À direita, perfis diurnos da concentração associada aos fatores à esquerda, com a mediana representada pela linha sólida e a amplitude interquartil representada pela região semitransparente.
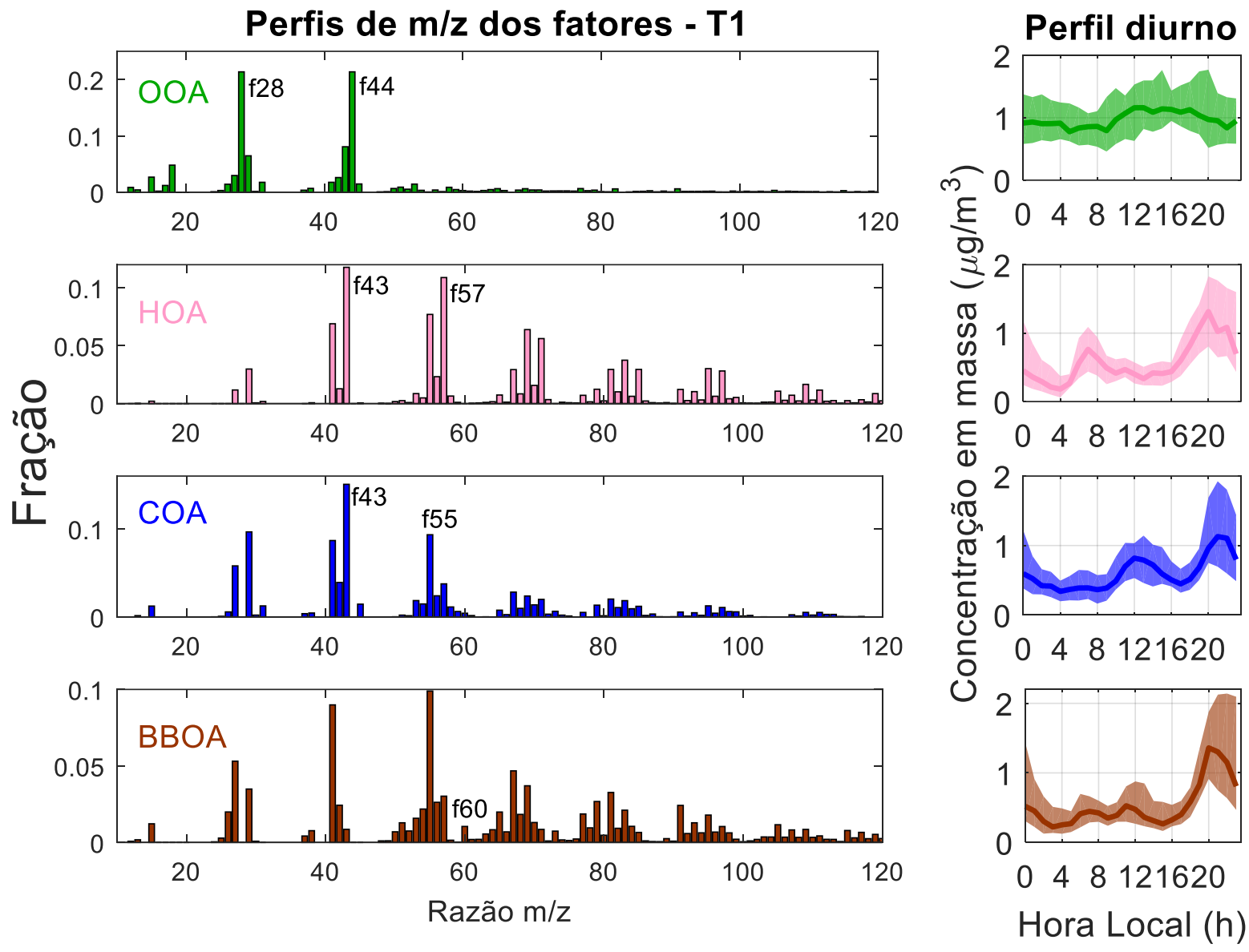

O fator COA é semelhante ao HOA quanto aos traçadores $\mathrm{f} 43$ e f55, mas apresenta um aumento do sinal de f29 e uma significativa redução de f57, de forma que a razão entre sinais f55 e f57 seja de 2.5, em comparação com 0.7 para o HOA. Este perfil é semelhante ao COA encontrado por Mohr et al., (2012). Outros sinais de que este fator está relacionado a emissões de cozinha são um máximo local às $12 \mathrm{~h}$, horário do almoço, e um sinal de f60 (traçador de queima de biomassa) de $0.4 \%$, levemente acima do limite de fundo. Este sinal de f60 pode estar relacionado à queima de lenha para o preparo de alimentos que vem sendo uma prática crescente no Brasil com o aumento do preço do gás de cozinha (GIODA et al., 2019). A contribuição média de massa para este fator foi alta, de $22 \%$, semelhante à contribuição veicular.

$\mathrm{O}$ último fator identificado em T1 é o BBOA, ligado à queima de biomassa, caracterizado pelos sinais de f60 e f73. O sinal de f60 é de $1.0 \%$, bem maior que o limite sugerido por Cubison et al. (2011) de $0.3 \%$. Este fator representa que $22 \%$ da massa de 
particulado fino no T1 está ligada a queima de biomassa, mesmo durante a temporada chuvosa da Amazônia, fração semelhante a observada para ambiente urbano em sítio em Santiago, no Chile (CARBONE, et al., 2013). As contribuições para este fator podem ser queima de lixo na cidade, uma vez que suas maiores concentrações são noturnas e não há um máximo local claro durante o dia, ou ainda queima de lenha para uso doméstico e para uso fabril.

Figura 4.8 - Fração de contribuição de cada fator para a massa de aerossóis orgânicos da moda fina $\left(\mathrm{PM}_{1}\right)$ durante a temporada chuvosa em $\mathrm{T} 1$.

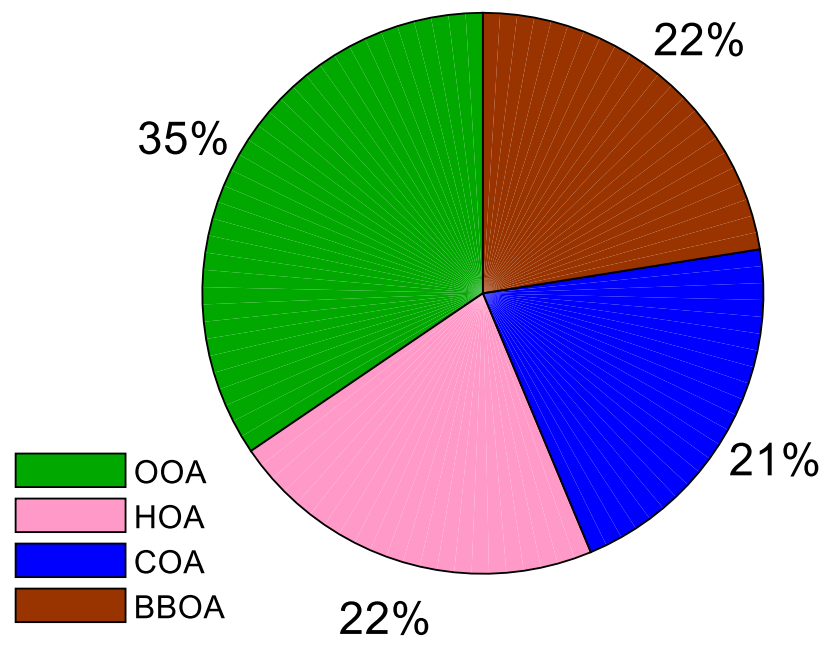

Foi observado, portanto, que a maior parte do material particulado observado é primária e de origem em emissões frescas, com reduzida formação de aerossóis secundários no centro da cidade, tanto para a componente orgânica quanto para a componente inorgânica do material particulado fino. Quanto a contribuição dos fatores à massa de orgânicos, observa-se frações excepcionalmente altas para emissões de cozinha (COA), que podem indicar contribuições locais, e de queima de biomassa (BBOA), que não estão relacionadas às queimadas regionais de floresta, mas sim a atividades urbanas de queima.

\subsubsection{Propriedades ópticas de partículas no sítio T1, Manaus}

A composição química do $\mathrm{PM}_{1}$ está diretamente relacionada às propriedades ópticas dos aerossóis da moda fina que também foram medidas e estudadas no sítio T1, no centro da cidade. O nefelômetro e o aetalômetro foram os instrumentos utilizados para medir, respectivamente, os coeficientes de espalhamento e absorção ópticos causados pelos aerossóis atmosféricos. O corte de tamanho de partícula pelo inlet dos instrumentos ópticos foi de diâmetro máximo $2.5 \mu \mathrm{m}$, de forma que o particulado fino amostrado foi de $\mathrm{PM}_{2.5}$, diferente da medida da composição de massa pelos espectrômetros de aerossóis, que corresponde a $\mathrm{PM}_{1}$. 
A série temporal de ambos os coeficientes ópticos está indicada na Figura 4.9 abaixo em $637 \mathrm{~nm}$, em laranja o espalhamento e em azul a absorção. O coeficiente de espalhamento em $637 \mathrm{~nm}$ característico para o centro da cidade de Manaus foi de 13.8 (10.4-20.3) $\mathrm{Mm}^{-1}$ com altos picos de até $70 \mathrm{Mm}^{-1}$. Em sua série temporal, um evento relativamente longo foi notado em um período de aproximadamente duas semanas durante o mês de fevereiro, que elevou as médias diárias de $\sigma_{\mathrm{e}}$ a valores maiores do que $20 \mathrm{Mm}^{-1}$ durante 8 dias. Este período é semelhante ao período em que se nota um aumento relativo nas concentrações de sulfato e sua responsabilidade no espalhamento óptico durante este evento será estudado em detalhe posteriormente neste trabalho.

O coeficiente de absorção característico para este sítio foi de 10.5 (6.7-15.6) $\mathrm{Mm}^{-1} \mathrm{e}$ foram identificados apenas eventos de curta duração (poucas horas) em que o valor de $\sigma_{a}$ foi tão alto quanto $65 \mathrm{Mm}^{-1}$. Os valores absolutos de ambos os coeficientes $\sigma_{\mathrm{a}}$ e $\sigma_{\mathrm{e}}$ em $637 \mathrm{~nm}$ são baixos comparados a outras áreas urbanas, compatível com a baixa massa de aerossóis encontrada anteriormente (BACKMAN et al., 2012).

Figura 4.9 - Série temporal dos coeficientes ópticos de espalhamento, em laranja, e absorção, em azul, de particulado fino em $637 \mathrm{~nm}$.

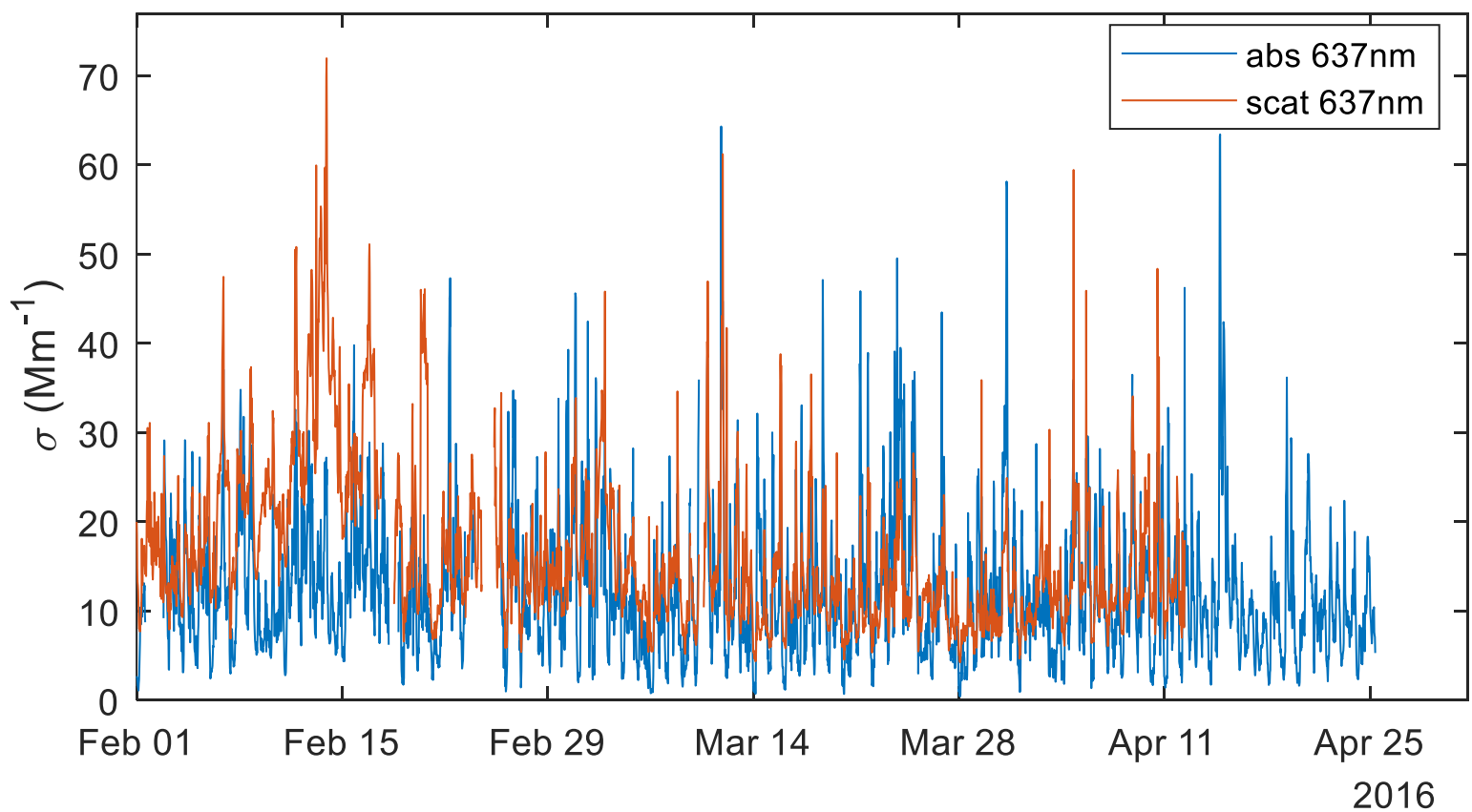

O coeficiente de albedo de espalhamento único, SSA, é uma variável crucial para entender o efeito climático direto de uma determinada população de partículas. Os valores característicos observados foram de SSA $637 \mathrm{~nm}=0.58(0.49-0.67)$, uma faixa de valores especialmente baixa em Manaus em comparação com outras cidades, como São Paulo, cidade do México e Pequim (PAREDES-MIRANDA et al., 2009; BACKMAN et al., 2012; 
GARLAND et al., 2009). Este SSA tão baixo concorda com o que foi observado na composição química do $\mathrm{PM}_{1}$, com uma grande fração relacionada ao $\mathrm{BC}$ e reduzida formação de componentes secundários em comparação a outras cidades, fatores que diminuem o espalhamento de radiação.

\subsubsection{Regressão do coeficiente de espalhamento aplicado à composição do $\mathrm{PM}_{1}$}

Para quantificar a responsabilidade de cada componente do particulado fino no espalhamento pode-se utilizar técnicas de regressão múltipla (HAND e MALM, 2007). Este ajuste resulta em coeficientes angulares de cada espécie que podem ser entendidas como eficiências de espalhamento, cuja unidade é expressa em unidades de espalhamento por unidade de massa: $\mathrm{Mm}^{-1}\left(\mu \mathrm{g} \mathrm{m}^{3}\right)^{-1}$, que simplificada gera a unidade $\mathrm{m}^{2} \mathrm{~g}^{-1}$. O comprimento de onda utilizado nesta regressão foi de $637 \mathrm{~nm}$, situando-se no meio da faixa do espectro de radiação solar no visível.

O modelo assume uma única eficiência de espalhamento por composto químico, embora essa eficiência dependa fortemente do tamanho e formato, que podem não ser uniformes durante a série temporal ou mesmo durante o dia (como sugere o perfil diurno das diferentes modas de tamanho de partícula). A comparação entre o coeficiente de espalhamento medido e o ajustado resultou em um coeficiente $\mathrm{R}^{2}$ de 0.59 e coeficiente $\mathrm{p}<0.01$, mostrando um ajuste estatisticamente significativo. Este ajuste resultou em um coeficiente linear de $5.4 \pm 0.2 \mathrm{Mm}^{-1}$ que não foi explicado pela variação das componentes e que pode ser causado (ao menos parcialmente) pelo limite superior de diâmetro de aerossol amostrado ser de $\sim 700 \mathrm{~nm}$ das lentes aerodinâmicas do ToF-ACSM, enquanto o nefelômetro amostrava partículas em um inlet com corte de partículas de $2.5 \mu \mathrm{m}$.

A região da primeira metade de fevereiro, do dia 01 até o dia 18 , não foi incluída na regressão pois apresentou uma estatística diferente do restante do período. Embora tenhamos observado maiores níveis de sulfato durante o período que possivelmente estão relacionadas ao maior espalhamento, não foi possível aplicar uma regressão múltipla apenas a este período com significância estatística. Entre as hipóteses para isso estão: características pouco homogêneas das partículas durante o período; amostra de tempo muito curta ou uma maior razão de $\mathrm{PM}_{2.5} / \mathrm{PM}_{1}$ durante este evento.

O cloreto e amônio não aumentaram a variância explicada de espalhamento pelo material particulado fino e não foram incluídos na análise. Enquanto o primeiro teve massa abaixo dos níveis de detecção, certamente não sendo um fator que contribuiu significativamente 
para o espalhamento, o segundo apresentou um ruído consideravelmente acima das outras espécies.

Figura 4.10 - O gráfico superior mostra o resultado da regressão multilinear da composição química do $\mathrm{PM}_{1}$ aplicada no coeficiente de espalhamento óptico para cada componente: orgânicos em verde, sulfato em vermelho, nitrato em azul e uma constante em preto. O gráfico inferior mostra a comparação entre o total de espalhamento dado pela regressão, em verde, e as medidas diretas de espalhamento óptico, em preto.
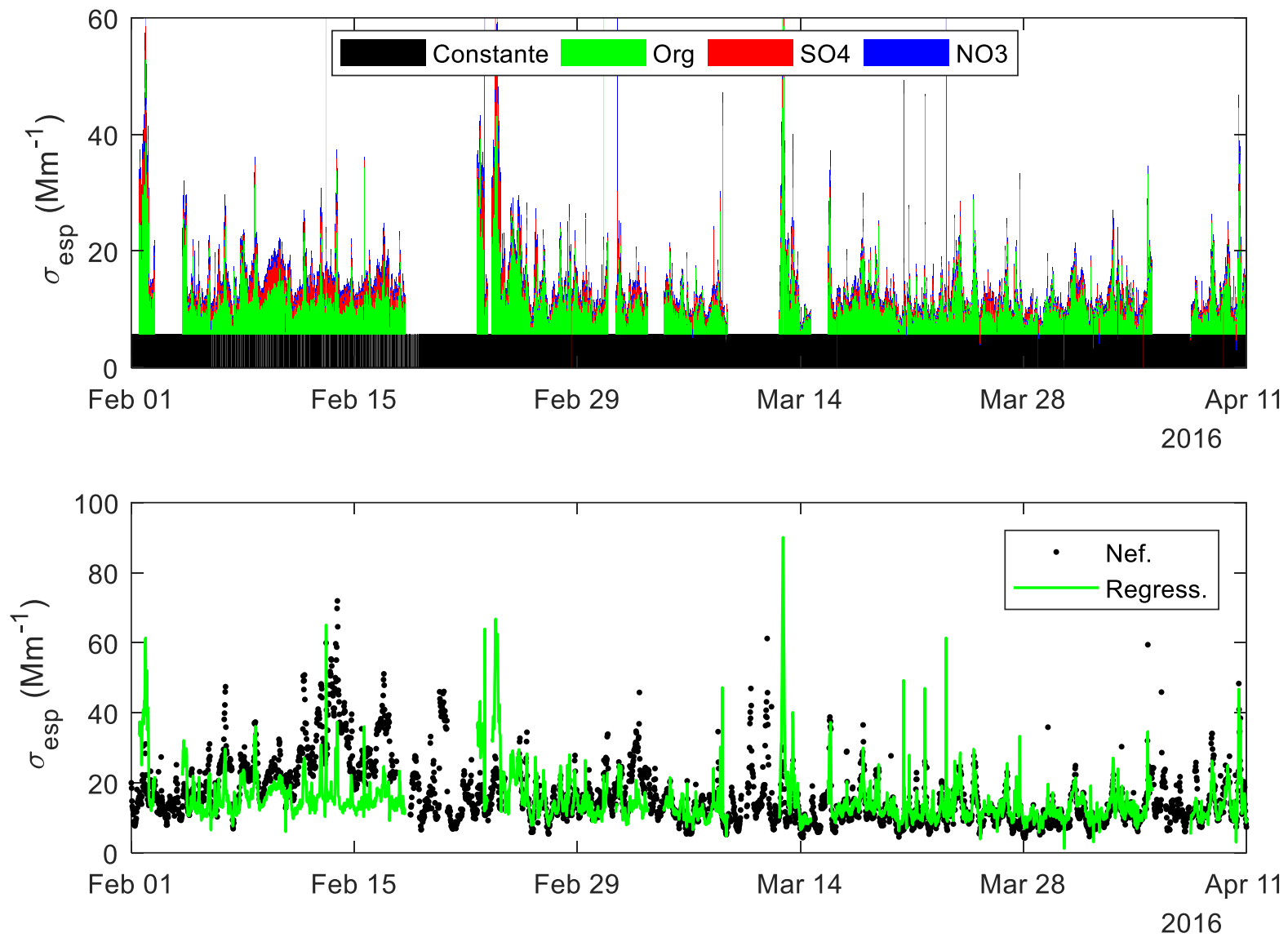

O gráfico superior da Figura 4.10 mostra a série temporal do coeficiente de espalhamento em $637 \mathrm{~nm}$ relacionado a cada componente química, mostrando uma dominância do espalhamento dos orgânicos, em verde, seguida do sulfato, em vermelho e do nitrato, em azul. Abaixo está a série temporal do espalhamento total dado pela regressão, em verde, e das medidas diretas do nefelômetro. Esta imagem inclui o período não utilizado na regressão e mostra a diferença entre a região ajustada, posterior ao dia 18 de fevereiro, e a não ajustada, anterior a este dia. Este período não ajustado mostraria espalhamento menor baseado nos mesmos coeficientes obtidos para o resto da série temporal.

De acordo com esta regressão, os orgânicos foram responsáveis por $47 \%$ do espalhamento, o sulfato $7 \%$ e o nitrato $3 \%$, de forma que juntas estas espécies explicaram quase $60 \%$ do espalhamento observado. Desta forma, a atribuição do espalhamento para cada espécie 
deve ser considerada como um limite inferior. As eficiências de espalhamento de cada espécies estão resumidas na Tabela 6 , abaixo.

Tabela 6 - Eficiências de espalhamento das espécies de particulado fino no sítio de Manaus (T1).

\begin{tabular}{|c|c|}
\hline & Coeficientes $\left(\mathrm{R}^{2}=0.59 \mathrm{e} \mathrm{p}<0.01\right)$ \\
\hline Constante $\left(\mathrm{Mm}^{-1}\right)$ & $5.4 \pm 0.2$ \\
\hline Org $\left(\mathrm{m}^{2} \mathrm{~g}^{-1}\right)$ & $1.94 \pm 0.07$ \\
\hline $\mathrm{SO}_{4}\left(\mathrm{~m}^{2} \mathrm{~g}^{-1}\right)$ & $5.9 \pm 0.7$ \\
\hline $\mathrm{NO}_{3}\left(\mathrm{~m}^{2} \mathrm{~g}^{-1}\right)$ & $3.4 \pm 1.3$ \\
\hline
\end{tabular}

A eficiência de espalhamento dos orgânicos obtida foi levemente menor do que a esperada para sítios urbanos de acordo com a revisão de HAND e MALM, (2007), fator que pode estar relacionado ao tamanho médio do aerossol ser menor do que encontrado em outros ambientes urbanos, já que o sítio T1 amostrar particulado fresco com pouco tempo de emissão e baixa oxidação. Já o sulfato apresentou uma eficiência de espalhamento de pouco menos do que o dobro de valores da literatura para sítios urbanos, de acordo com o mesmo estudo acima. Este fato pode indicar que a calibração relativa de sulfato aplicada neste estudo esteja subestimando a massa de sulfato, os autores afirmam que o sulfato pode apresentar eficiência de espalhamento superestimada com a aplicação da técnica de regressão linear múltipla devido a menores incertezas relativas. Desta forma, sugere-se que outros trabalhos com dados independentes calculem a eficiência de espalhamento das espécies da moda fina da região.

\subsubsection{Determinação do índice de refração dos aerossóis da moda fina de Manaus}

Uma outra forma de caracterizar as propriedades ópticas das partículas emitidas em Manaus é pelo índice de refração, uma quantidade complexa (com parte real e imaginária) que indica a capacidade dos aerossóis de espalhar e absorver luz. Esta quantidade é expressa da forma:

$$
m=n-i * k
$$

em que o termo real $n$ indica o espalhamento óptico e o termo imaginário, $k$, a absorção óptica

Utilizamos o sistema libRadtran para caracterizar o índice de refração médio das partículas de Manaus, uma informação que pode ser útil para introduzir nos modelos computacionais que envolvem as emissões da cidade de Manaus. A entrada no modelo radiativo 
é a distribuição de tamanho e o índice de refração complexo, enquanto a saída é o coeficiente de absorção e o de espalhamento.

Devido ao comportamento observado na última regressão realizada neste capítulo, decidimos excluir o período inicial de fevereiro, de forma que o índice de refração obtido nesta análise seja mais representativo das emissões da cidade.

Figura 4.11 - Resultado da qualidade das simulações utilizando a biblioteca libRadtran e a série temporal de distribuição de tamanho de partículas. A região mais escura é a que minimiza o resíduo entre o modelo e as observações.

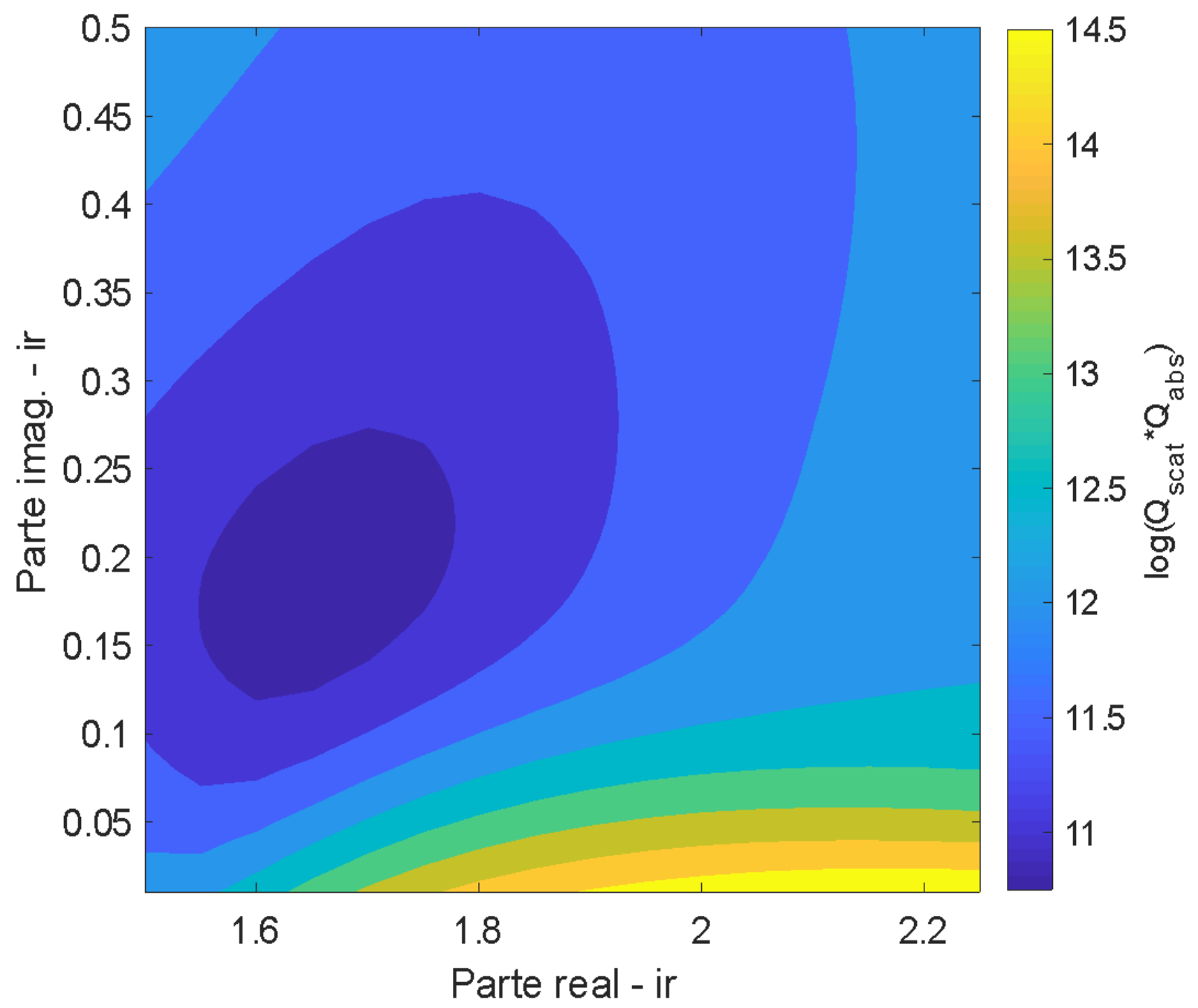

Simulamos as propriedades óticas para o comprimento de onda de $637 \mathrm{~nm}$ de distribuições de tamanho com uma matriz de índices de refração cuja variação vai de 0.01 até 0.5 para a parte imaginária e 1.4 até 2.3 para a parte real (baseados num limite superior de variação ao observado em ambientes urbanos) e comparamos com os coeficientes ópticos observados. Para determinar o melhor índice de refração, utilizamos a soma do erro quadrático (Q) entre a série temporal das observações e das simulações. Para minimizar o erro de ambas as propriedades ópticas (absorção e espalhamento), minimizamos o resultado da multiplicação 
entre os dois coeficientes $\mathrm{Q}_{\text {scat }}$ e $\mathrm{Q}_{\mathrm{abs}}$, como exposto na Figura 4.11. O coeficiente resultante foi de $m=1.65-i * 0.18$.

O termo real $n$ é compatível com valores altos observados na literatura para aerossóis urbanos enquanto o termo imaginário $k$ é por volta de 3 vezes maior que o encontrado usualmente para ambientes urbanos (EBERT et al., 2004). Este alto valor para o termo imaginário é compatível com a alta fração da massa atribuída à $\mathrm{BC}$ superior do que a medida normalmente em outras metrópoles. Este índice de refração pode ser introduzido em modelos regionais para melhorar a caracterização das emissões urbanas de Manaus e o cálculo da forçante radiativa dos aerossóis influenciados por emissões urbanas. 


\section{ESTUDO DA PLUMA URBANA VENTO ABAIXO DE MANAUS (SÍTIOS T2 E T3)}

Neste capítulo iremos estudar as características dos poluentes atmosféricos em sítios vento abaixo da cidade e impactados pela pluma de Manaus para comparar com as características medidas no centro da cidade. Em especial, iremos focar a comparação com o sítio T2, que amostra uma pluma urbana com pouco tempo de envelhecimento na atmosfera amazônica, com a finalidade de entender as mudanças de curto prazo assumidas pela pluma. As medidas no sítio T2 foram realizadas entre os meses de fevereiro e abril, durante a estação chuvosa da Amazônia Central, para eliminar contribuições de queimadas regionais que acontecem amplamente durante a estação seca.

Também farão parte das comparações resultados de estudos publicados com observações no sítio T3, que se localiza a $\sim 70 \mathrm{~km}$ vento abaixo de Manaus e recebe ocasionalmente plumas poluídas pela cidade com tempo de envelhecimento na ordem de $4 \mathrm{~h}$ (CIRINO et al., 2018) e sítios em regiões pristinas da floresta, como a torre ZF2 de 80m e a torre ATTO de 325m, que se situam 60 e $150 \mathrm{~km}$ vento acima de Manaus e servirão de referências naturais para comparação. Para consultar a descrição detalhada destes sítios, podese consultar MARTIN et al., (2016).

\subsection{POLUENTES GASOSOS EM REGIÕES INFLUENCIADAS PELA PLUMA URBANA DE MANAUS}

O sítio T2, foco principal da comparação deste capítulo, se situa na margem do Rio Negro oposta à Manaus, distando 14 km do sítio T1 e de 8 a $11 \mathrm{~km}$ (dependendo da direção média do vento) da fronteira da cidade na margem oposta do Rio Negro. Como indicado na metodologia deste presente trabalho, o sítio se situa na direção preferencial do vento vindo da área urbana. Porém, o transporte local está sujeito a outros efeitos além da direção média regional do vento, como a influência da dinâmica causada pela brisa do Rio Negro (DOS SANTOS et al., 2014), a intensidade dos processos turbulentos e pela e geografia do sítio de amostragem.

As concentrações de $\mathrm{CO}$ e $\mathrm{SO}_{2}$ características deste sítio dadas pela mediana e IIQ foram de 134 (116-163) ppb e 0.13 (0.04-0.34) ppb respectivamente, mostrando significativo processo de diluição, com concentrações de aproximadamente 2 e 3 vezes menores do que as medidas no centro da cidade. 
Ao mesmo tempo, mostra significativo impacto da poluição no local, já que os valores típicos amostrados no sítio são 40\% a 91\% acima da concentração de fundo de CO na Amazônia Central medida durante períodos limpos nos experimentos LBACLAIRE-2001 (KUHN et al., 2010) e cerca de 5 vezes maior do que as concentrações de fundo de $\mathrm{SO}_{2}$ (ANDREAE et al., 1990). Eventos de até 4 ppb de médias de 30min de razão de mistura de $\mathrm{SO}_{2}$ foram observados. Concentrações tão altas podem atuar como precursores de partículas de maneiras totalmente não esperadas na atmosfera amazônica muito limpa (EKMAN et al., 2008).

Apenas durante menos de $1 \%$ da série temporal de CO medido no sítio T2 as razões de mistura estiveram dentro dos valores sugeridos por Kuhn como concentração de fundo, de 70 a 90 ppb. Esta é uma evidência de que a região é constantemente impactada pelas emissões urbanas de Manaus em várias intensidades. Diferentemente das concentrações de CO que mostram impacto em praticamente todo o período de observações, durante pouco menos de $25 \%$ dos pontos observados a razão de mistura de $\mathrm{SO}_{2}$ estava tão baixa quanto a média mais um desvio padrão das observações de background de ANDREAE. Apesar desta comparação depender também da precisão das medidas de background realizadas por estudos e instrumentos diferentes, esta pode ser uma evidência o sítio $\mathrm{T} 2$ amostra pluma em que o $\mathrm{SO}_{2}$ já foi consumido e transformado em outras espécies, enquanto o mesmo não acontece para o $\mathrm{CO}$, já que o monóxido de carbono tem vida média na atmosfera muito maior do que o dióxido de enxofre, como mencionado no capítulo anterior.

O ciclo diurno do $\mathrm{CO}$ em T2, mostrado em azul e à esquerda da Figura 5.1, não apresenta variações tão intensas durante o dia como o observado na cidade. Às 7:30 este perfil apresenta um leve máximo local deslocado 30min em relação ao pico matutino observado no centro da cidade, sugerindo um atraso por transporte das emissões veiculares de Manaus até o sítio T2. Este máximo é seguido por um vale do período mais ensolarado do dia, que deve ser devido ao aumento da altura da camada limite, aumento da intensidade de processos turbulentos e menor emissão veicular fora dos horários de rush. As concentrações voltam a crescer a partir das $17 \mathrm{~h}$, que poderia ser causado pelo incremento no transporte do segundo pico de emissões veiculares, mas também pela diminuição dos processos turbulentos e condições menos favoráveis à dispersão dos poluentes. O perfil atinge um pico noturno entre $21 \mathrm{~h}$ e $22 \mathrm{~h}$.

Não há, neste sítio, o mesmo mínimo observado para o período do início da manhã no perfil diário de CO para Manaus, sugerindo que outras fontes podem ser importantes para manter as concentrações de $\mathrm{CO}$ no local durante o período noturno. Uma hipótese levantada por CIRINO et al., é que a brisa do Rio Negro pode ser responsável por mudar a direção do vento no T2 durante o período noturno, fazendo com que os ventos venham do sul e oeste do 
continente, em direção ao Rio Negro, na direção contrária a usual, e que eventualmente podem trazer emissões de fábricas de tijolos que se localizam ao nestas direções (MARTIN, 2016) que mantém seus fornos com queima de madeira. Apesar disso, não é simples diferenciar estas fontes de poluentes de transporte noturno de termelétricas ou outras fontes de queima de combustível atuando na cidade durante a noite.

Figura 5.1 - Perfil diários das razões de mistura de $\mathrm{CO}$ e $\mathrm{SO}_{2}$ para o sítio $\mathrm{T} 2$, mostrando a mediana das concentrações para cada horário em linhas sólidas e o intervalo interquartil representados pelas faixas semitransparentes.
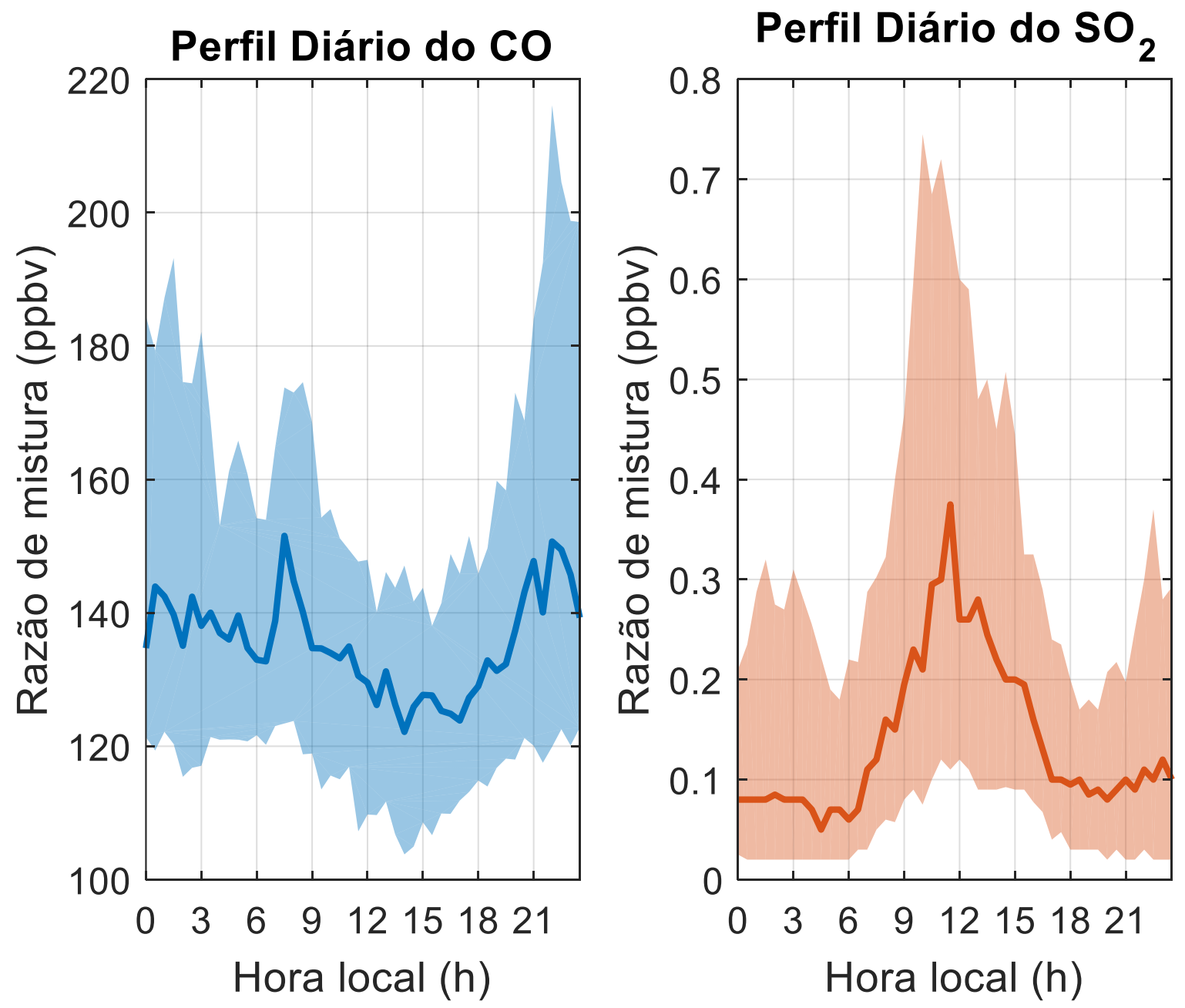

$\mathrm{O} \mathrm{SO}_{2}$ apresenta perfil diurno diferente para T2 do observado em T1. Este perfil está exposto na Figura 5.1 a direita, com linhas sólidas mostrando a mediana e IIQ em faixas semitransparentes. O perfil diurno mostra concentrações baixas durante a noite, na ordem de $0.09 \mathrm{ppbv}$ e aumento das concentrações durante o período diurno a até $12 \mathrm{~h}$, a partir de quando estas começam a diminuir. Apesar da grande diferença entre as concentrações de $\mathrm{SO}_{2}$ entre T1 e T2, no meio do dia as concentrações do percentil 0.75 chegam a superar o percentil 0.75 das medidas no sítio T1, no centro de Manaus. 
Este comportamento distinto entre os perfis diários de $\mathrm{CO}$ e de $\mathrm{SO}_{2}$ aliado a intensidade de $\mathrm{SO}_{2}$ amostrado em T2 no meio do dia são uma evidência de que as concentrações de $\mathrm{SO}_{2}$ são controladas por outras fontes, que não influenciam com a mesma intensidade e variabilidade as concentrações de CO. A hipótese é que compostos de enxofre emitidos por usinas termelétricas que se distribuem, em parte, ao longo do rio, estejam impactando o sítio T2 de forma mais significativa do que T1. Desta forma, o perfil diário de $\mathrm{SO}_{2}$ estaria indicando a intensidade de transporte da pluma urbana (incluindo as emissões de termelétricas) e este transporte estaria ligado a fatores meteorológicos, indicando que no meio do dia, com velocidades de vento mais altas, e o topo da camada de mistura mais alto (chega a cerca de 2.000 metros no meio do dia) o transporte da pluma de Manaus é mais eficiente.

Estes resultados indicam que o ambiente próximo a Manaus onde se localiza T2 é sempre impactado pelas emissões antrópicas, mas que fatores como a meteorologia local relacionada à dispersão de poluentes devem influenciar fortemente no transporte, envelhecimento e grau de oxidação com que a pluma chega neste sítio.

Uma transformação que acontece rapidamente entre os dois sítios separados por apenas $14 \mathrm{~km}$ é uma forte mudança nas razões de mistura de COVs, gases precursores de ozônio e de partículas. A concentração total de COVs medidos pelo PTR-MS (naturais e antrópicos) em partes por bilhão de carbono diminui de 60 ppbC em T1 para 21 ppbC em T2, mostrando significativa diminuição na razão de mistura total de compostos orgânicos voláteis gasosos amostrados no sítio fora de Manaus.

Esta mudança não pode ser totalmente explicada pela diluição dos COVs antrópicos, já que mesmo em uma região mais arborizada como o T2, a razão de mistura do isopreno, principal COV produzido pela floresta, diminuiu de 1874 (1336-2060) ppt para 689 (428-1142) ppt, enquanto concentrações típicas para regiões pristinas da floresta são de 1 a 5 ppb. COVs como benzeno e aromáticos $\mathrm{C}_{8}$ diminuíram por fatores de 4 e 5 vezes. Além de diluição dos COVs antrópicos, os COVs podem estar sofrendo reações na atmosfera e gerando produtos semivoláteis não medidos por este instrumento, radicais que podem alterar o equilíbrio de formação de ozônio e podem estar sofrendo reações de transformação gás-partícula, condensando para o estado de particulado.

Foi observada uma grande diferença nas razões de mistura de ozônio entre T2 e T1. Ao meio do dia, quando há a maior formação fotoquímica deste poluente, as concentrações observadas no sítio T2 foram de $21 \mathrm{ppb}$, quase o dobro da concentração de ozônio amostrada no centro da cidade, como mostra a Figura 5.2. A hipótese é a diluição das altas concentrações de NO vista em outros poluentes primários aliada a formação de radicais pela oxidação de 
COVs durante o transporte até o sítio T2 contribuam para um equilíbrio químico mais favorável para uma rápida produção líquida de ozônio. Estes radicais devem competir com o ozônio na oxidação do NO de forma que o ciclo descrito pelas reações R1 a R3 não esteja mais em equilíbrio.

Figura 5.2 - Perfil diário do $\mathrm{O}_{3}$ nos sítios do centro de Manaus (T1; azul) e margem do Rio Negro (T2; laranja). A linha cheia indica a mediana de cada 30min e a faixa semitransparente o IIQ. Observa-se uma grande diferença na concentração de ozônio conforme a pluma urbana deixa a cidade, chegando a produção rápida de $\sim 10 \mathrm{ppb}$ no pico.

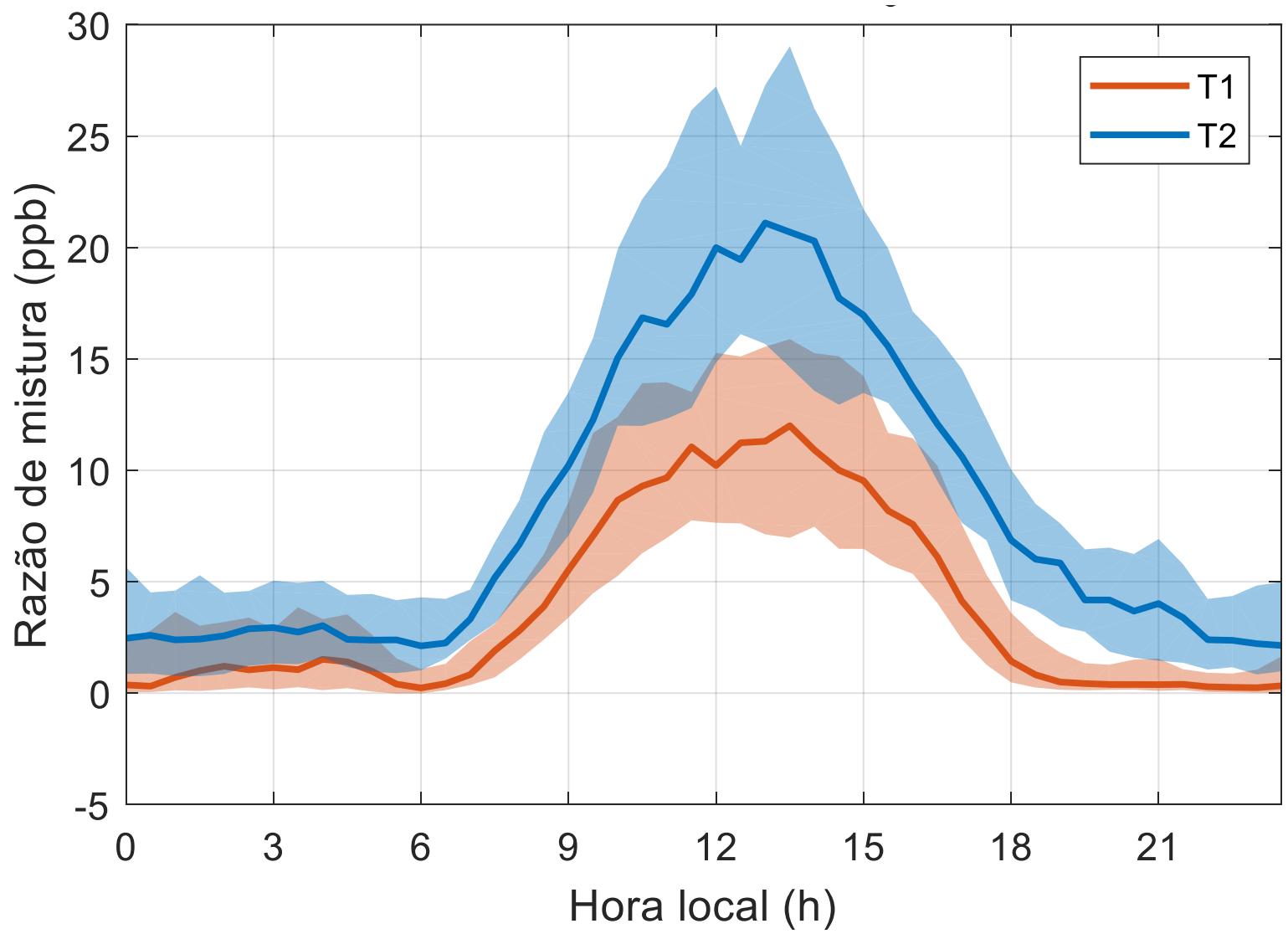

Valores típicos observados de razão de mistura de ozônio observados no sítio ZF2, localizado em região pristina da floresta foram de $\sim 7.5$ (5-10) ppb durante o pico diurno e $\sim 3$ ppb durante a noite (ARTAXO et al., 2013). Estas observações mostram concentrações naturais menores em regiões pristinas da floresta e uma rápida produção fotoquímica de ozônio causada pela poluição urbana. Esta pluma de ozônio proveniente dos compostos emitidos na cidade de Manaus já foi observada por diferentes estudos em regiões mais distantes de Manaus, e tem um alcance da ordem de centenas de quilômetros (KUHN et al., 2010).

A formação de ozônio vento abaixo de Manaus quanto a seus mecanismos, seu alcance e sua intensidade estão sendo estudados de forma mais ampla por NASCIMENTO et al. (2021), estudo que o aluno é coautor. Neste trabalho, o modelo regional WRF-Chem (GRELL et al., 
2005) foi utilizado para simular a atmosfera da região próxima a Manaus, incluindo a interação química entre as emissões antrópicas da cidade e as emissões biogênicas da floresta.

Figura 5.3 - Distribuição espacial das concentrações médias de ozônio durante o período diurno (7h-18h), obtida através de simulação no modelo regional WRF-Chem mostrando o impacto da pluma vento abaixo de Manaus (extraído de NASCIMENTO et al., 2021).

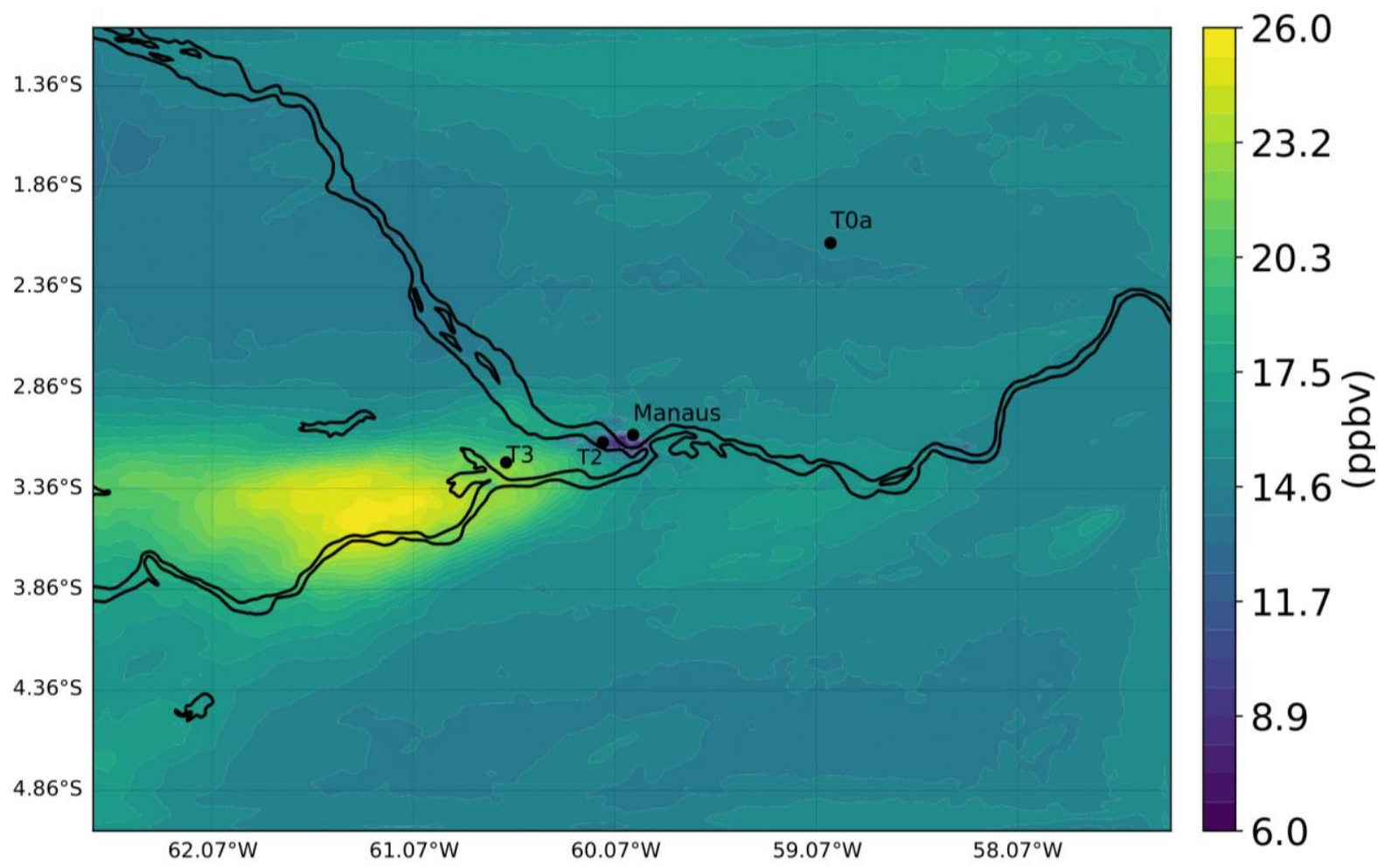

Na Figura 5.3 está a distribuição geográfica da média de concentrações de ozônio durante o período diurno ( $7 \mathrm{~h}$ a $18 \mathrm{~h}$ ) de 5 dias simulados ( 9 a 14 de março de 2014) na região simulada. Este mapa mostra que as maiores concentrações de ozônio estão a 120km da cidade, mais distantes do que o sítio T3, o mais afastado do Experimento GoAmazon. Também mostra que o efeito mais imediato da interação dos componentes de Manaus com a atmosfera amazônica é o consumo de $\mathrm{O}_{3}$ (indicado pelos valores azuis próximos a Manaus) seguido de um aumento nas concentrações desta variável em relação a áreas naturais.

Apesar de alguma falta de precisão espacial esperada na representação de um modelo regional das concentrações observadas em sítios pontuais, este resultado concorda com o presente trabalho quanto a baixas concentrações observadas na cidade e uma formação líquida de ozônio a partir da margem do Rio Negro oposta a Manaus. 


\subsection{CONCENTRAÇÃO E PROPRIEDADES DE PARTÍCULAS ATMOSFÉRICAS NO ENTORNO DE MANAUS}

Os gases podem ser co-emitidos com ou ainda influenciar a produção de partículas atmosféricas. No sítio T2 houve uma significativa diminuição do número de partículas em relação ao centro da cidade de $7.2(4.9-10) \mathrm{E}+03$ partículas $\mathrm{cm}^{-3}$ para $3,3(1.1-5,8) \mathrm{E}+03$ partículas $\mathrm{cm}^{-3}$, embora ainda mostre alto impacto urbano no sítio $\mathrm{T} 2$, com concentrações muito acima das 220 partículas $\mathrm{cm}^{-3}$ medidas em regiões não impactadas pela pluma urbana de Manaus como o ATTO. As medianas das distribuições de tamanho dos sítios T1, T2 e ATTO estão comparadas na Figura 5.4.

Figura 5.4 - Distribuição de tamanho de número de partículas para o sítio T1 (em laranja) e T2 (em azul) e ATTO (em verde). A mediana dos dados é indicada pela linha cheia, enquanto a linha pontilhada são ajustes de distribuições lognormais para cada moda, e as referências são indicadas por sequências de linhas e pontos.

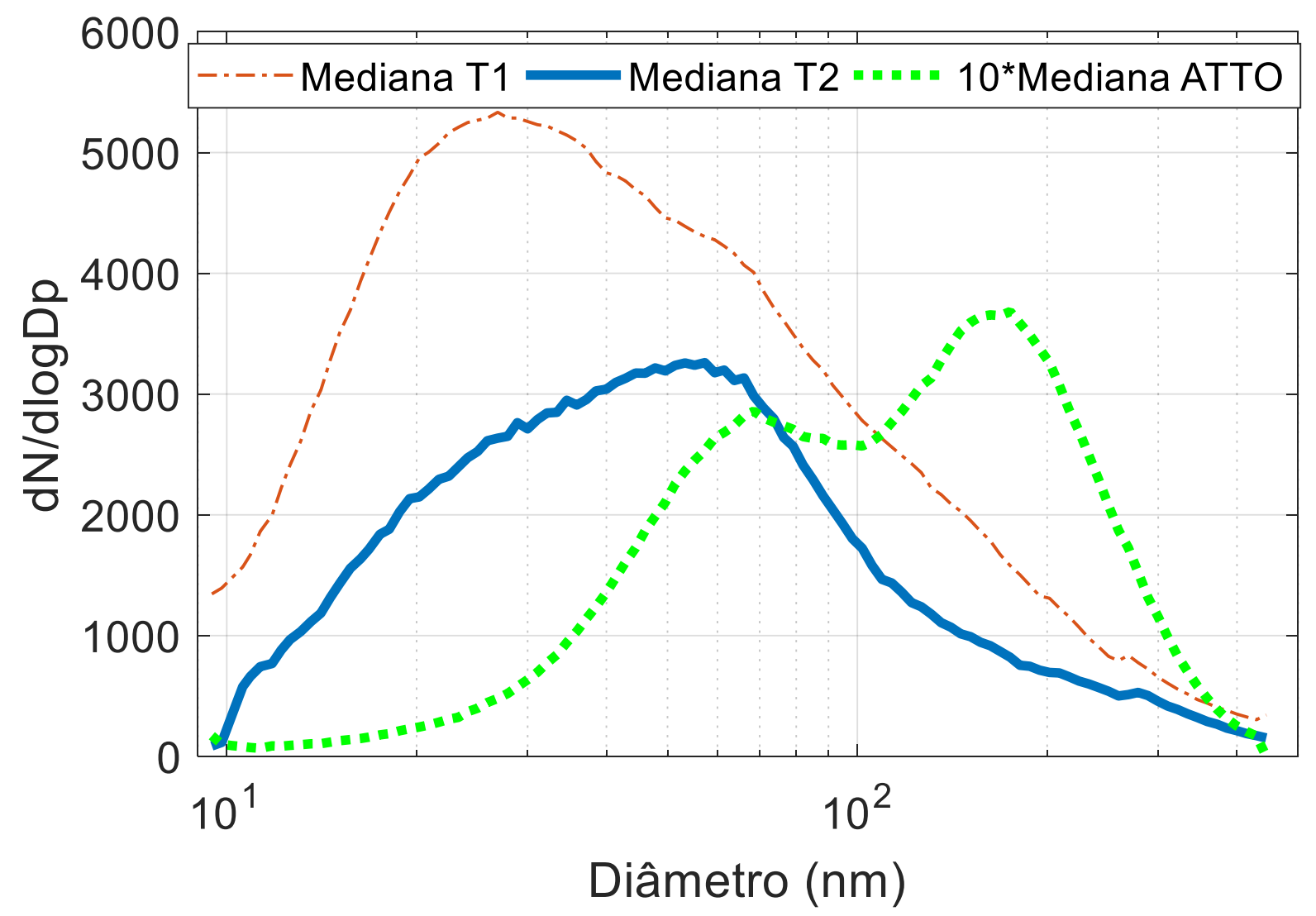

É notável a diferença entre a distribuição de tamanho natural do ATTO, em linha verde pontilhada, que precisou ser multiplicada por dez para ser visível no mesmo eixo, e as outras duas distribuições influenciadas pela cidade. Com pouquíssimas partículas ultrafinas $(<100$ 
nm), e apenas modas de Aitken e de acumulação notáveis, esta distribuição de tamanho tem característica bem distinta das distribuições urbanas, com número cerca de 10-50 vezes menor e a maior parte das partículas na moda de acumulação, atributo de grandes partículas biogênicas.

Além de uma diminuição para todos os tamanhos de partículas de T1 para T2, é possível notar uma rápida mudança na característica da distribuição de tamanho de partículas entre os sítios T1 e T2, em linhas laranja tracejada e azul sólida, respectivamente, distantes apenas 14 km entre si. Enquanto na primeira os valores máximos estão entre 20 e 30nm, na segunda estão entre 50 e $60 \mathrm{~nm}$. O diâmetro geométrico médio (DGM) observado em cada sítio reforçou esta diferença, de 44 (40-48) nm em T1 para 69 (56-91) nm no T2, mostrando partículas com DGM $25 \mathrm{~nm}$ maiores no sítio fora da cidade, além de apresentar limites de intervalo interquartil muito maiores do que os observados em T1.

Figura 5.5 - Distribuição de tamanho de número de partículas para cada moda no sítio T2. A moda de nucleação está exposta em verde, a moda de Aitken em azul, a moda de acumulação em vermelho e a mediana de toda a distribuição em preto. A mediana dos dados é indicada pela linha cheia, enquanto o IIQ é indicado pelas áreas semitransparentes.

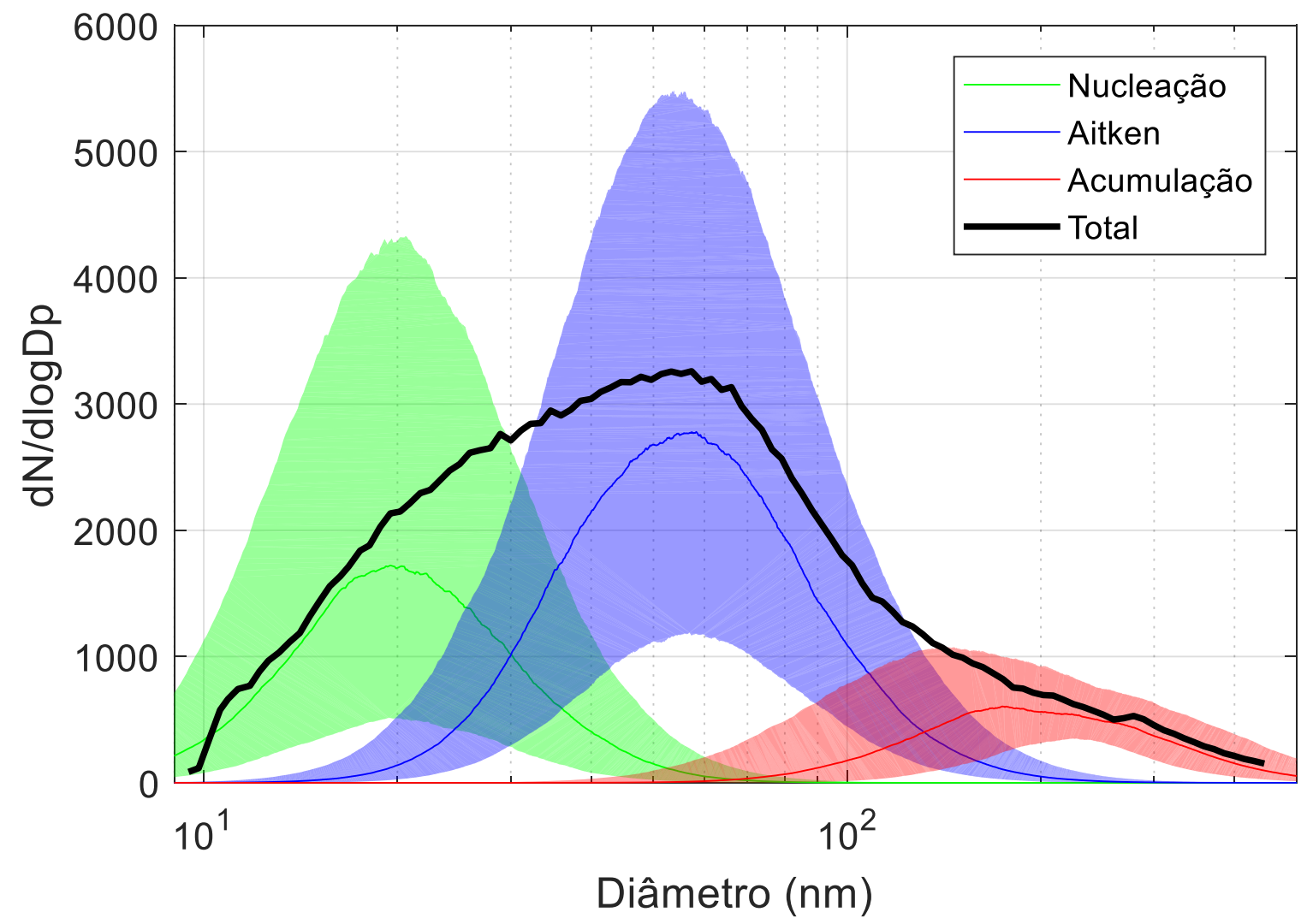

Para quantificar estas mudanças, aplicamos o mesmo algoritmo utilizado para ajustar 3 modas na distribuição de tamanho medida em T2 (RIZZO et al., 2018) e o resultado está exposto na Figura 5.5. No sítio T2, em média, 49\% das partículas observadas estão na moda de Aitken, 
centrada em 58 nm, e $37 \%$ estão na moda de nucleação, centrada em $20 \mathrm{~nm}$. Comparados com os $42 \%$ e $40 \%$ de partículas observadas na moda de nucleação e Aitken, o resultado em T2 representa uma significativa mudança na moda dominante entre os sítios, indicando um crescimento significativo da população de partículas. Essa mudança deve ser causada principalmente por efeitos de coagulação de precursores gasosos e pela coalescência de partículas menores, resultando em partículas com diâmetros maiores. Outros trabalhos mostram evidências de este crescimento das partículas ultrafinas emitidas em Manaus têm potencial para crescer até e além do sítio T3 por mecanismos de condensação de COVs biogênicos e antrópicos e coalescência de partículas ultrafinas (PALM et al., 2018; CIRINO et al., 2018; NASCIMENTO et al., 2021; DE SÁ et al., 2018; SHILLING et al., 2018).

Na Figura 5.6 está o perfil diurno das séries temporais de cada moda para o T2. Observase uma moda de acumulação quase constante, com concentrações levemente maiores durante o período ensolarado. Já as modas de Aitken e Nucleação tem perfil que claramente acompanha o ciclo diurno de $\mathrm{SO}_{2}$ que traz emissões urbanas mais frescas até o sítio. Importante observar também que o aumento de concentração no meio do dia indica um efeito da altura de camada de mistura que favorece o transporte de Manaus para o sítio T2. Além do aumento da altura da camada de mistura, as partículas sofrem efeitos de maiores velocidades do vento no meio do dia do que no período noturno, o que deve favorecer o transporte. 
Figura 5.6 - Ciclo diurno da concentração de número de partículas no T2 para cada moda, com estatística horária. A moda de nucleação está indicada em verde, a moda de Aitken em azul e a moda de acumulação em preto.

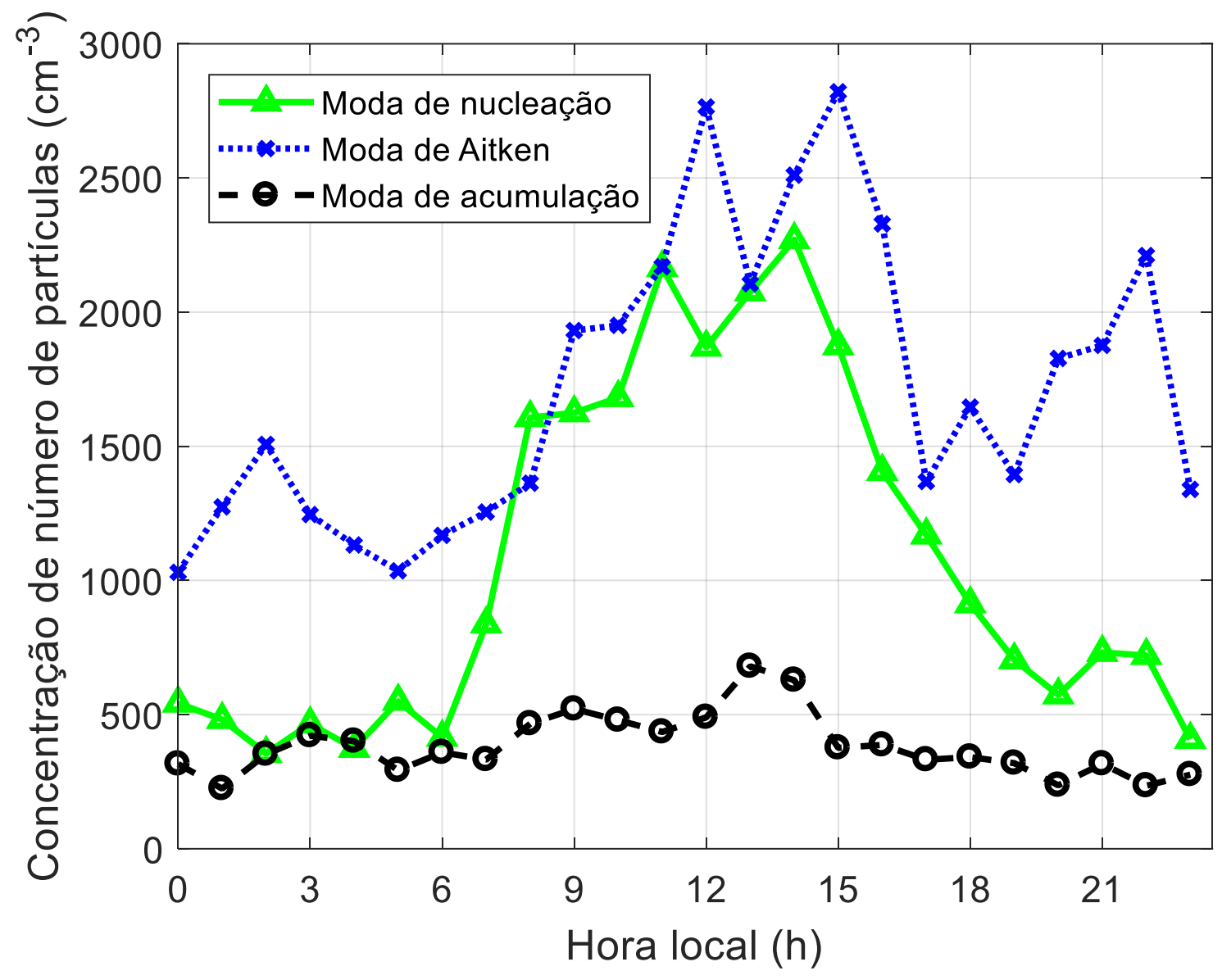

Embora não tenhamos identificado nenhum evento claro de formação de novas partículas (NPF) em Manaus, identificamos tais eventos no sítio T2. Neste trabalho, os eventos de NPF foram identificados por inspeção visual através do critério estabelecido por DAL MASO et al., (2005):

- Uma moda distinta de partículas deve aparecer na distribuição de tamanho;

- A moda deve iniciar em faixas de tamanho compatíveis com a moda de nucleação;

- A moda deve permanecer ao longo do período de algumas horas;

- Esta nova moda deve mostrar sinais de crescimento.

Apesar de que a geração de novas partículas deve acontecer na atmosfera da cidade pode ser uma importante fonte de partículas da moda de nucleação, as emissões locais pontuais confundem e misturam eventos de forma a não tornar possível a visualização de eventos duradouros de crescimento de partícula. 
Figura 5.7 - Distribuição de tamanho de aerossóis de alguns episódios de formação e crescimento de partículas durante o período da tarde com diferentes taxas de crescimento, partindo de tamanhos próximos a $10 \mathrm{~nm}$ a até $50 \mathrm{~nm}$.

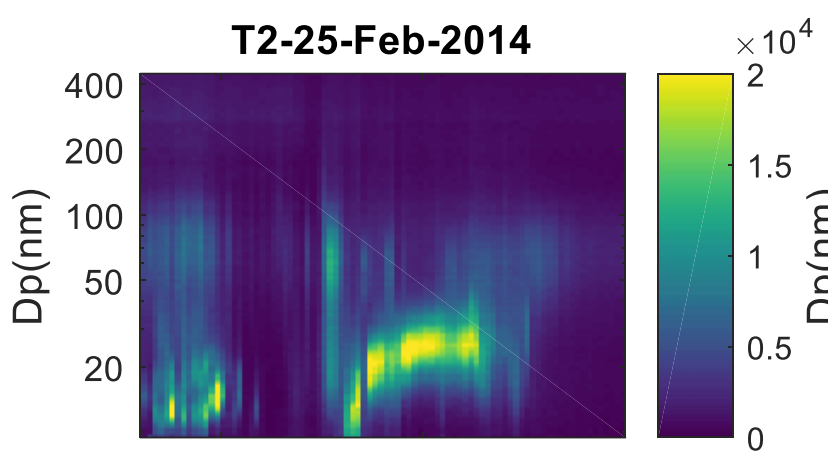

12

15
T2-10-Mar-2014

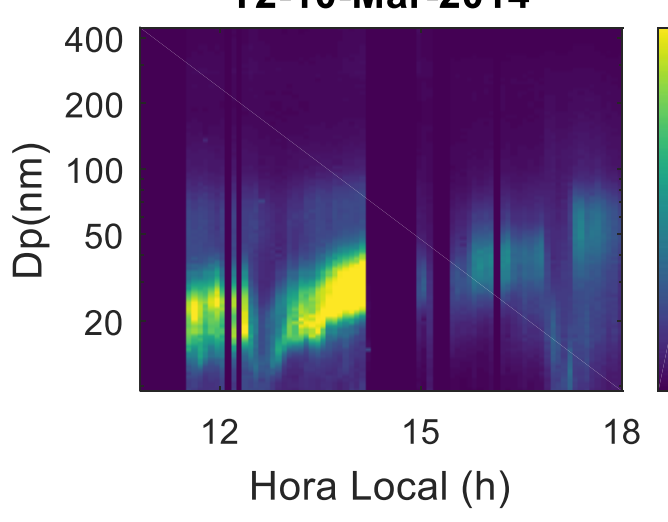

T2-04-Mar-2014

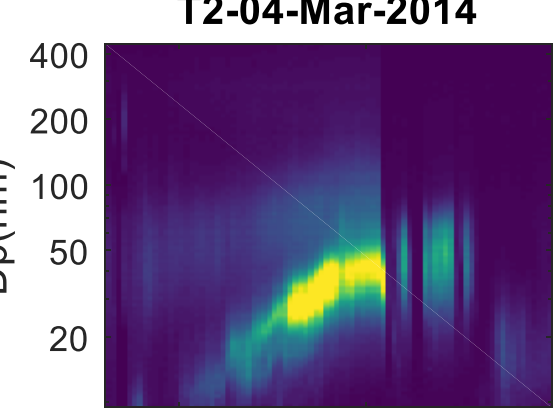

15

T2-19-Mar-2014

$\times 10^{4}$
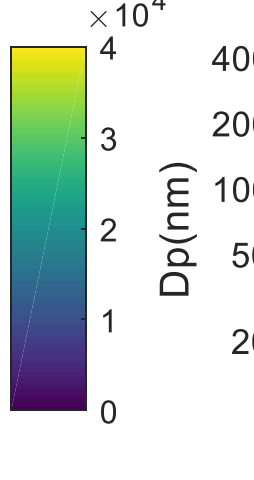

400
200
है 500
20

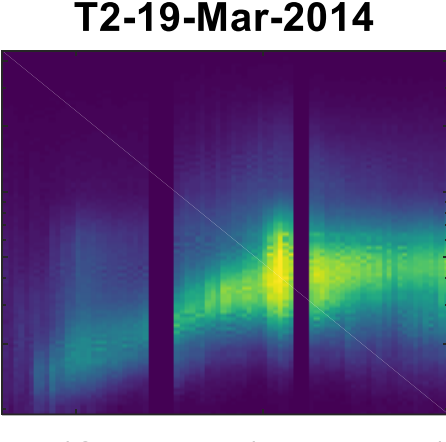

12

Hora Local (h)

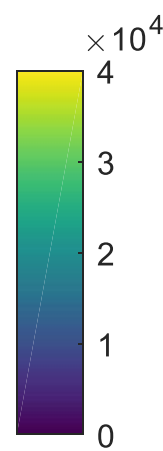

18

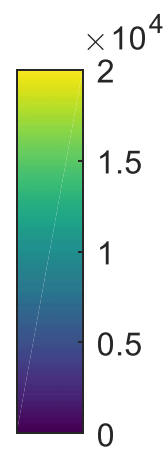

18

Curiosamente foram observados eventos de NPF com uma relativa alta frequência no sítio T2, às margens do Rio Negro. De 31 dias com amostragem de qualidade durante todo o dia, 6 apresentaram eventos de NPF, o que resulta em uma frequência de eventos de $~ 19 \%$, mais alta do que os 10\% observados na região metropolitana de São Paulo (BACKMAN et al., 2012) e são incomuns em regiões não perturbadas da camada limite da Floresta Amazônica, com frequência de 3\% observadas por RIZZO et al., (2018) e devem acontecer apenas em altas altitudes da troposfera (ANDREAE et al., 2018). Contudo, pelo caráter intensivo da campanha e por interrupções não planejadas das medições utilizadas neste estudo, nossa amostra total de dias é limitada e medidas de campanhas extensivas são indicadas para estudar e caracterizar com maior acurácia a frequência destes eventos de NPF na região influenciada pela pluma de Manaus na Amazônia.

Estes episódios apresentam taxas de crescimento e diâmetros máximos variáveis, como mostra a comparação entre o gráfico superior esquerdo e inferior direito na Figura 5.7. Enquanto a primeira mostra uma população de partículas que cresce lentamente das $11 \mathrm{~h} 30 \mathrm{~min}$ até às $18 \mathrm{~h}$ até diâmetros de $\sim 50 \mathrm{~nm}$, a segunda em pouco mais de uma hora saturou seu processo de 
crescimento para cerca de 30nm. Todos os episódios aconteceram durante o período da tarde, quando há radiação abundante e o transporte de poluentes da cidade é mais intenso. A formação de novas partículas observada no sítio T2 pode estar ligada ao consumo de isopreno observado anteriormente, já que este está ligado a supressão de SOA na atmosfera amazônica (KIENDLER-SCHARR et al., 2009).

A superfície de partículas compete com processos de NPF pois suas superfícies agem como sumidouro de gases precursores. A hipótese para explicar esta possível frequência de dias com NPF observada no T2 é que as baixas concentrações de partículas associadas com os radicais decorrentes do consumo de COVs e as altas concentrações de oxidantes como $\mathrm{SO}_{2}$ possam estar criando um ambiente favorável para a produção de novas partículas

Estes eventos demonstram o alto potencial de crescimento das nanopartículas observadas no centro de Manaus o que influencia fortemente seu impacto no clima, já que ao crescer a tamanhos típicos de 50nm, vistos na Figura 5.7, estas podem agir como núcleo de condensação de nuvens e alterar o ciclo hidrológico.

A série temporal da composição do particulado fino é mostrada na Figura 5.8, com as espécies de aerossol orgânico e sulfato, nitrato, amônio e cloreto inorgânicos medidos pelo QACSM, além de concentração de BCe medido por métodos ópticos através do MAAP. As concentrações de $\mathrm{PM}_{1}$ tiveram concentrações características de 3.1 (1.8-4.9) $\mu \mathrm{g} / \mathrm{m}^{3}$, cerca de $84 \%$ da massa média medida por filtros por (BURGUER, 2017) na mesma estação e ano e aproximadamente metade das concentrações medidas na cidade. O mesmo estudo compilou medidas de massa de BC através de filtros e foram observadas concentrações compatíveis: 0.7 $\pm 0.3 \mu \mathrm{g} / \mathrm{m}^{3}$ (média e desvio padrão) em comparação com $0.58(0.25-1.10) \mu \mathrm{g} / \mathrm{m}^{3}$ observados no presente estudo. 
Figura 5.8 - Acima, a série temporal da composição do $\mathrm{PM}_{1}$ em médias a cada 30 minutos para o sítio T2. Abaixo, a série temporal da fração em massa das componentes do $\mathrm{PM}_{1}$, mostrando a dominância dos orgânicos na composição química dos aerossóis e a presença mais relevante do sulfato neste sítio.
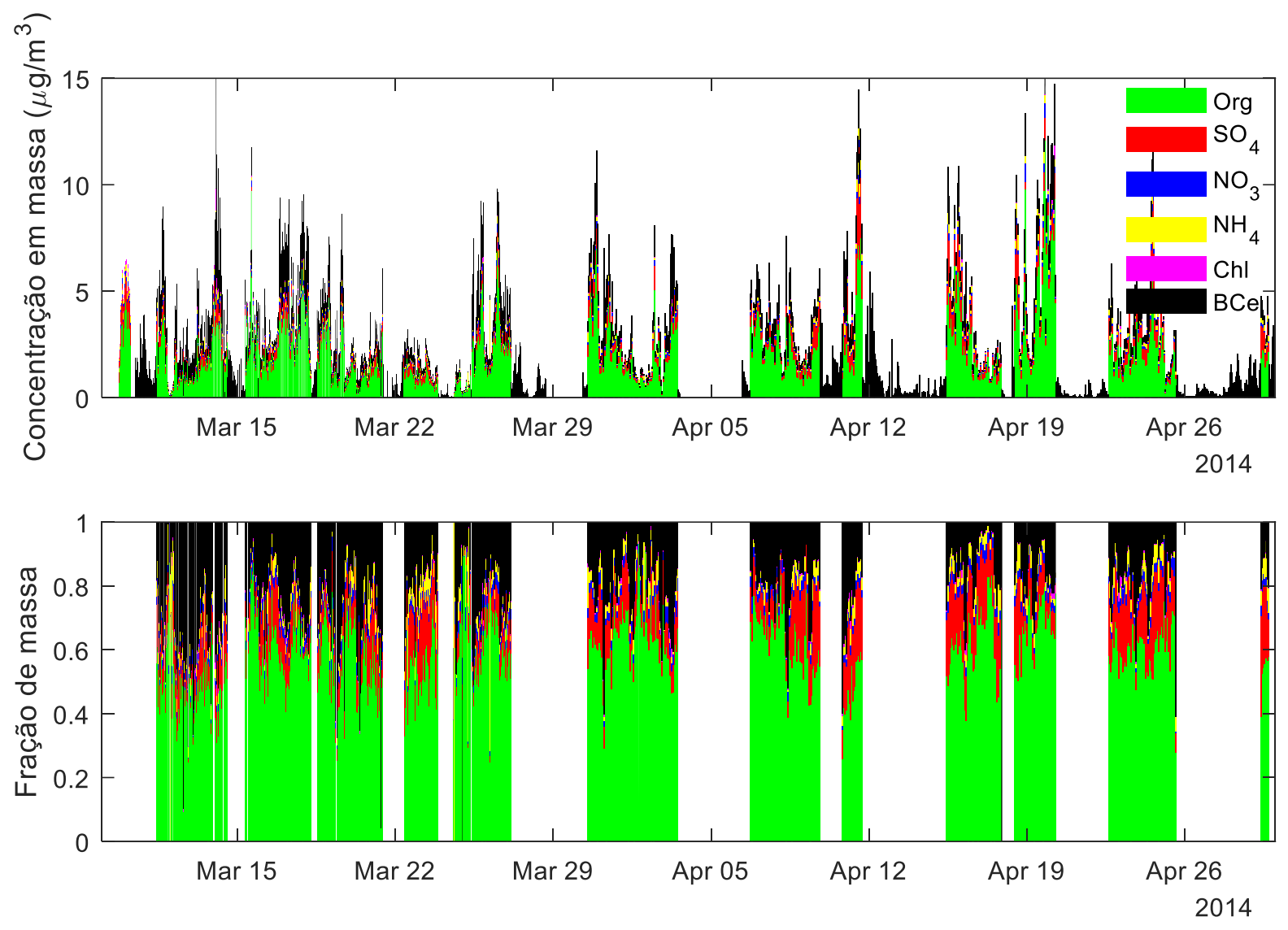

Foi observada uma diminuição na massa de particulado fino indicada pela mediana e IIQ de $5.3(3.8-7.2) \mu \mathrm{g} / \mathrm{m}^{3}$ no T1 para $3.1(1.8-4.9) \mu \mathrm{g} / \mathrm{m}^{3}$ no $\mathrm{T} 2$, como esperado devido a diluição e deposição entre os sítios. Quanto a composição fracionária, o BC foi responsável por uma fração consideravelmente menor da massa de $\mathrm{PM}_{1}$ em relação ao T1: 19\% comparado com $33 \%$ na cidade. Esta observação pode ser explicada pelo fato de que o BC é uma espécie unicamente primária que sofrerá efeitos de deposição e dispersão, enquanto os aerossóis orgânicos e o sulfato podem apresentar também formação secundária na atmosfera.

Como resumido na Figura 5.9, a fração média de aerossol orgânico é semelhante entre os sítios T1 e T2 e domina a massa de $\mathrm{PM}_{1}$ : é em torno de 59\% para T1 e 61\% para T2. Há um grande aumento entre a fração de sulfato medido em T1 e em T2. Como descrito no começo deste capítulo, foi mostrado que o sítio T2 sofre mais impacto de emissões de termelétricas que emitem $\mathrm{SO}_{2}$, um precursor de sulfato, cujas altas concentrações são responsáveis por uma grande produção secundária na atmosfera amostrada em T2. Nitrato e amônio permaneceram 
praticamente constantes, com $2 \%$ da composição em T1 e $3 \%$ em T2, e cloreto teve fração de massa menor do que $1 \%$ em ambos os sítios.

Figura 5.9 - Composição química das frações do $\mathrm{PM}_{1}$, nos dois sítios amostrados, T1 e T2, com orgânicos em verde, BC em preto, sulfato em vermelho, nitrato em azul, amônio em amarelo e cloreto em rosa. A comparação mostra um aumento relativo no sulfato e diminuição de black carbon.

Composição $\mathrm{PM}_{1}$ - T1

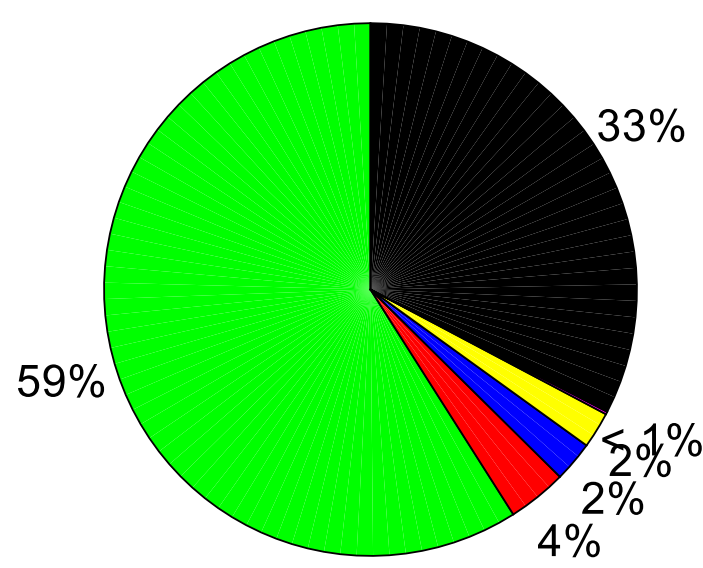

Composição $\mathrm{PM}_{1}$ - T2

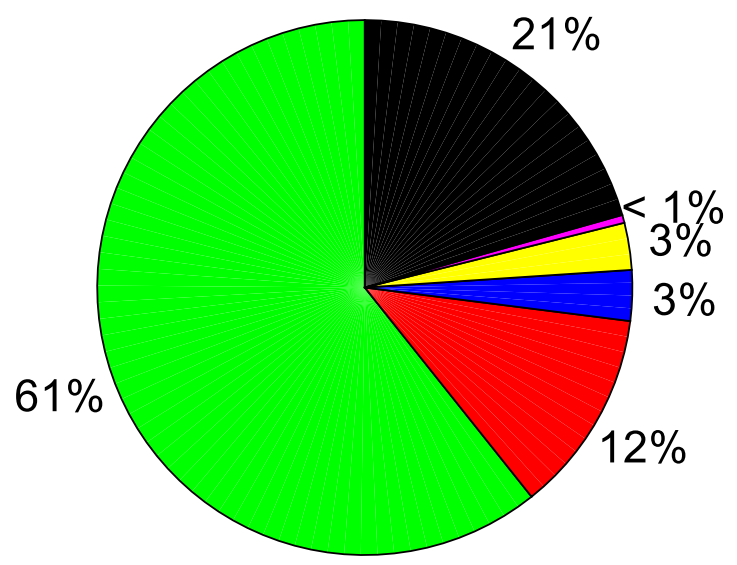

Apesar da fração semelhante de orgânicos entre ambos os sítios, uma diferença substancial foi observada quanto a oxigenação das partículas finas medidas pelo ACSM. O gráfico triangular que pode ser visto pela Figura 5.10 é uma maneira de caracterizar o envelhecimento da população de aerossóis orgânicos: a oxidação é maior quanto mais próximos os pontos estão da ponta superior deste triângulo, uma vez que a fração de íons com m/z 44 (f $\mathrm{f}_{44}$ ) é majoritariamente derivada do $\mathrm{CO}_{2}{ }^{+}$, enquanto que a fração de íons com m/z 43 é derivada dos compostos $\mathrm{C}_{2} \mathrm{H}_{3} \mathrm{O}^{+}$ou $\mathrm{C}_{3} \mathrm{H}_{7}{ }^{+}$, que apresentam fração de oxigênio muito menor. $\mathrm{O}_{44}$ indicado como mediana e IIQ foi de $8 \%(4-11 \%)$ para T1 e $15 \%(12-17 \%)$ para T2.

A razão de conteúdo de carbono para oxigênio do $\mathrm{PM}_{1}$ foi calculada a partir de ajuste caracterizado por Canagaratna et al., (2015), que utiliza o $\mathrm{f}_{44}$ como proxy para estimar a razão de massa de oxigênio para massa de carbono a partir da seguinte relação:

$$
O: C=0.079+4.31 \times f_{44}
$$

A razão obtida para as medidas em $\mathrm{T} 1$ foi de $0.42(0.27-0.56)$ e em T2 foi de $0.72(0.61-$ 0.80), uma diferença de $71 \%$ a mais de oxidação mostrando uma grande alteração em termos de oxidação dos compostos e, portanto, de processamento atmosférico entre os sítios. 
Figura 5.10 - Análise da oxidação do aerossol no sítio T2. À esquerda o gráfico triangular da fração relacionada ao íon 43 e da fração relacionada ao íon 44, mostrando que as partículas entre T1 e T2 sofreram significativo processo de envelhecimento. À direita o boxplot da razão entre o conteúdo de oxigênio e carbono da fração fina do aerossol para a série temporal dos dois sítios.
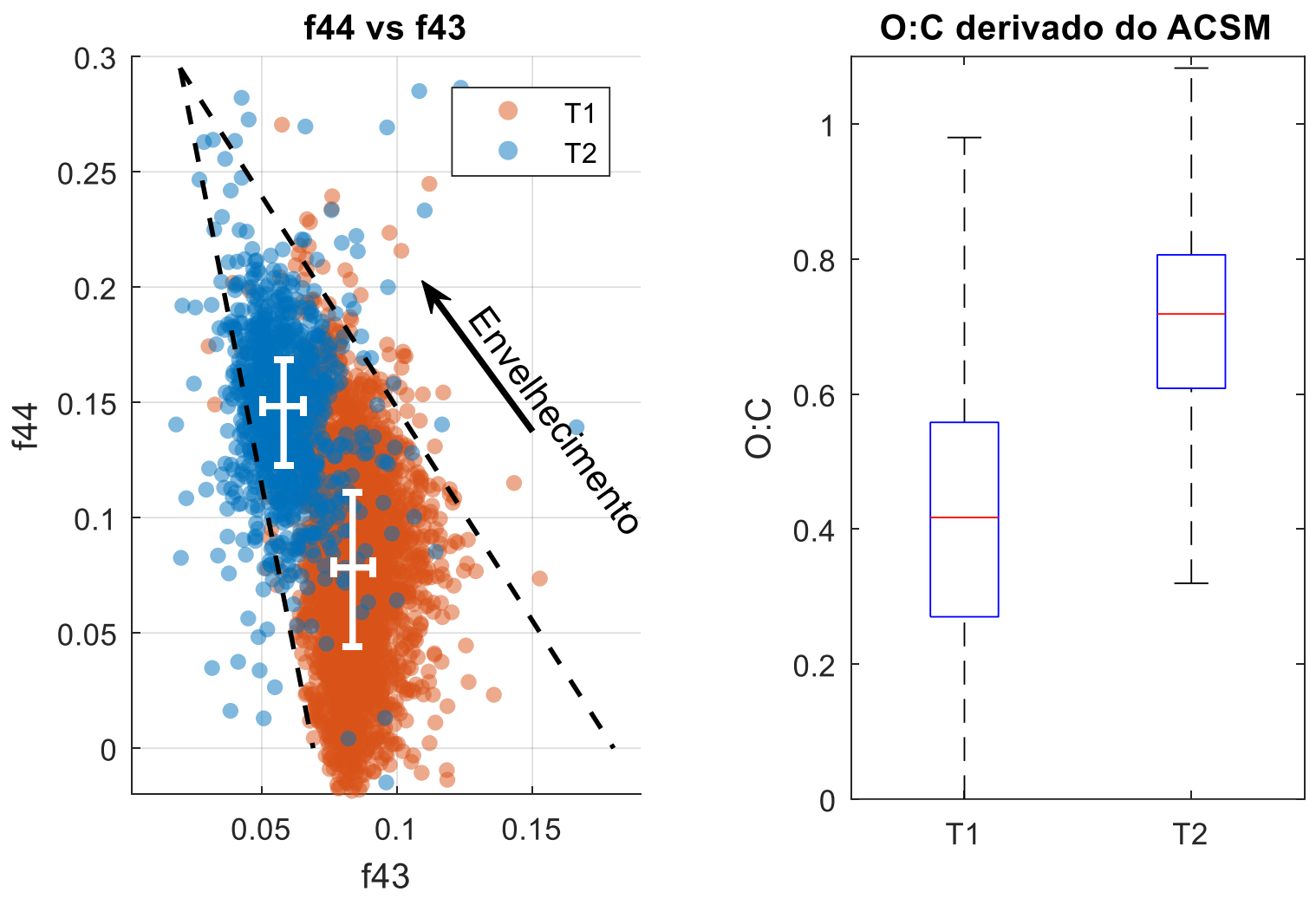

O nível de oxidação mensurado pela razão O:C no sítio T1 de 0.42 é comparável com as medidas numa torre $60 \mathrm{~km}$ vento acima de Manaus, em área florestada, caracterizadas por CHEN et al. (2009) de 0.42 em períodos dominados por partículas provenientes da bacia amazônica, e O:C de 0.49 provenientes de fora da bacia (CHEN et al., 2009). Esta razão medida no sítio T2 foi muito maior do que em ambos os sítios, de 0.72 , mostrando uma oxidação elevada das partículas que foi apenas possível pelo grande potencial oxidativo dos gases emitidos pela área urbana de Manaus.

Entretanto, uma intercomparação entre 13 diferentes ACSMs compilada por CRENN et al., (2015) mostrou que as frações de concentração do íon 44 podem apresentar diferenças sistemáticas em diferentes instrumentos medindo o mesmo ambiente, de forma que erros sistemáticos podem estar influenciando esta análise de maneira não caracterizada no presente trabalho. Apesar disso, pelos intervalos de variação apresentados na intercomparação é improvável que tamanha diferença seja puramente fruto de erros instrumentais. 
Um estudo recente (FRENEY et al., 2019) aplica uma correção para o artefato na variável f44 a partir de um procedimento de calibração com dependência do conteúdo de nitrato, e propõe uma calibração dependente da composição química para tratar este artefato. Sugerese para futuros trabalhos a aplicação desta correção para verificar com maior acurácia a diferença de oxigenação dos aerossóis no centro de Manaus para aerossóis de regiões próximas.

Em outro estudo utilizando os dados desta intercomparação, porém, foi observado que esta diferença instrumental não influencia de maneira significativa na massa dos componentes determinados pelo algoritmo PMF (FRÖHLICH et al., 2015). Desta forma, também exploramos a composição química dos aerossóis orgânicos da moda fina medidos em T2 pelo Q-ACSM.

\subsubsection{Análise de fatores dos aerossóis orgânicos - sítio T2}

No sítio T2 foram identificados outros 4 fatores através de procedimento semelhante ao realizado com a base de dados de espectrometria de massa do centro da cidade, pelo algoritmo PMF. Os perfis dos fragmentos de cada fatores estão expostos na Figura 5.11, ao lado do perfil diurno de sua intensidade. Na Figura 5.12 está exposto a fração da contribuição em massa de cada um dos fatores.

Houve, neste sítio, distinção menos clara do que o resultado obtido na cidade. Entre os motivos estão que o perfil diurno tem efeitos da meteorologia especialmente relevantes no local e que este sítio recebe uma pluma menos homogênea do que a pluma amostrada de aerossóis recém emitidos na cidade. Desta forma, um perfil fixo e único de fragmentos de aerossóis como o modelado pela técnica de PMF pode não representar tão bem o perfil químico das partículas sujeitas a tempo de envelhecimento na atmosfera variáveis.

O fator HOA 1 tem características de emissões antrópicas frescas como os íons f27, f29, f43, f55 e f91. Em especial, o alto sinal de f55 em relação ao f57 é uma evidência de que este fator pode estar relacionado às emissões de cozinha de Manaus. Além disso, o valor de f60 para este fator, de $0.4 \%$, é um pouco maior do que o background e da mesma forma que o COA obtido para o T1, este pode ser um segundo sinal de emissões de cozinha relacionadas a queima de lenha em Manaus. O ciclo diurno apresenta um leve máximo local próximo ao meio dia que pode ser um sinal de emissões de cozinha, embora com concentrações próximas dos outros horários. Entretanto não foi possível explicar o tão baixo f44, compatível com 0 , já que este deveria estar presente devido a oxidação dos componentes emitidos em Manaus.

$\mathrm{O}$ fator HOA 2 é o que melhor se relaciona com as concentrações de $\mathrm{CO}, \mathrm{BC}$ e $\mathrm{SO}_{2}$, e que deve estar relacionado às emissões de tráfego da cidade. Este tem maiores valores durante 
a manhã, que pode estar relacionado ao transporte da pluma do horário de rush matutino, relativo ao fator HOA no T1. Sua fração do fragmento 44 é maior, de $4 \%$ em comparação com a fração praticamente nula do HOA do sítio de Manaus, que pode indicar maior oxidação no T2 das partículas associadas a transporte do que a observada no centro da cidade.

Figura 5.11 - À esquerda, perfis dos 4 fatores de aerossóis orgânicos da moda fina encontrados na análise PMF no sítio T1. O eixo horizontal representa os fragmentos com determinado $\mathrm{m} / \mathrm{z}$, enquanto o vertical mostra a fração da contribuição relativa de cada íon em relação ao fator. À direita, perfis diurnos da concentração associada aos fatores à esquerda, com a mediana representada pela linha sólida e a amplitude interquartil representada pela região semitransparente.

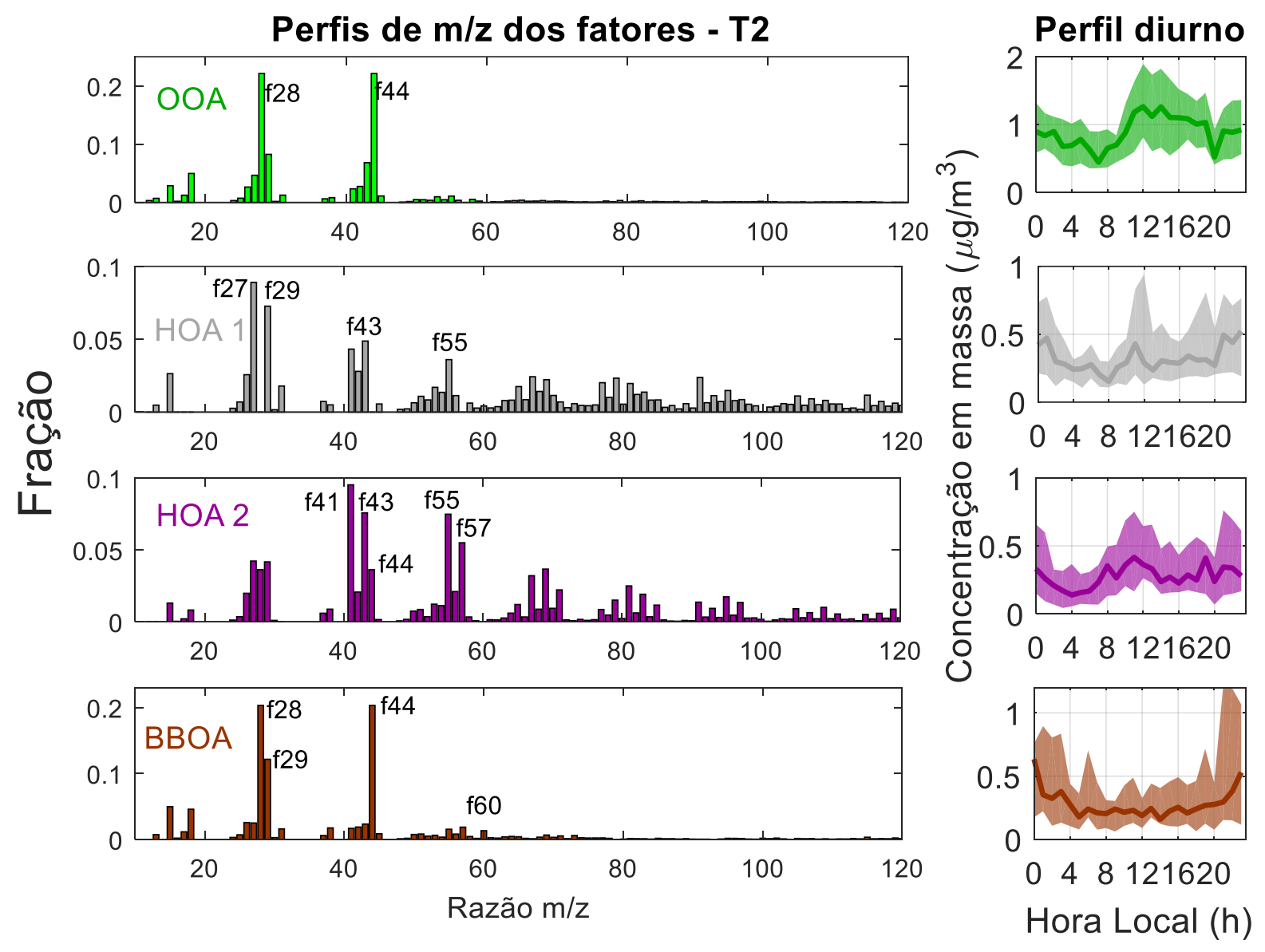

O fator BBOA do sítio T2 também foi identificado pelo sinal de f60, de 1.3\%, por este estar bem acima do limite de background determinado por Cubison et al. (2011) de 0.3\%. Porém, diferencia-se do BBOA observado em Manaus já que é dominado pelo f44, mostrando ser mais oxidado do que o BBOA da cidade. As hipóteses levantadas para explicar este fator, que é majoritariamente noturno, são de que estas partículas estejam relacionadas com transportes de plumas envelhecidas que foram emitidas no Sul/Leste por carvoarias e fábricas 
de tijolos que queimam madeira, ou que sejam provenientes de queimas de madeira na área urbana de Manaus.

Figura 5.12 - Fração de contribuição de cada fator para a massa de aerossóis orgânicos finos.

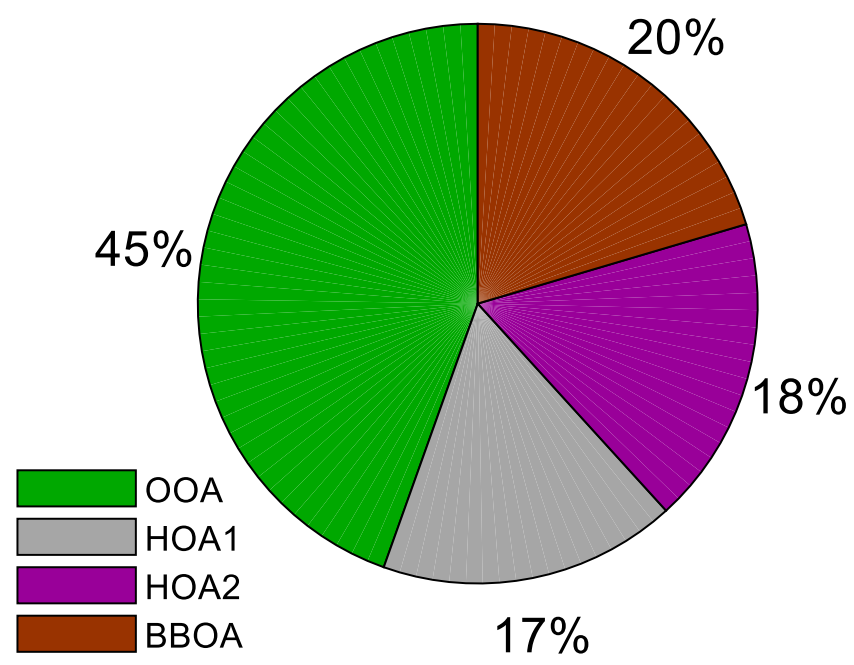

O fator OOA discriminado no sítio T2 tem seu espectro de massa semelhante ao OOA do T1 e este também é o fator que representa maior massa, com contribuição ainda maior para T2, de $45 \%$, mostrando um aumento de $10 \%$ em relação a componente muito oxidada do centro de Manaus, o que concorda com o maior nível de oxidação das partículas apresentado anteriormente neste capítulo.

Estes fatores mostram contribuições relativas semelhantes ao particulado medido no centro de Manaus e sinais de maior oxidação, como aumento de $10 \%$ na componente OOA e aumento notável do f44 nos perfis de todos os fatores, exceto o HOA 1.

\subsubsection{Comparação de razões de enriquecimento utilizando CO como traçador}

A razão de enriquecimento expressa a concentração extra (acima da concentração de fundo) de um poluente $\mathrm{X}$ na atmosfera normalizada pela quantidade extra de um poluente coemitido com o poluente $\mathrm{X}$, tal qual a expressão seguinte:

$$
E R(X)=\frac{\Delta[X]}{\Delta[C O]}
$$

Ao normalizar esta concentração do poluente X por um poluente estável, co-emitido junto a este poluente, e com formação secundária desprezível na atmosfera como o CO, pode- 
se analisar as concentrações do poluente descontando o fator de diluição, já que este efeito diminuiria a concentração extra do traçador - $\mathrm{CO}$ - na mesma taxa que reduziria a concentração extra do poluente $\mathrm{X}$.

A comparação desta quantidade para a mesma pluma medida em sítios distintos nos mostra as diferenças entre as concentrações de poluentes descontado o fator de diluição. Dessa forma seria possível atribuir o aumento deste coeficiente à produção secundária do poluente X, aumentando a concentração de X sem que o traçador de emissão CO aumente da mesma forma, e que a diminuição desse coeficiente significa consumo atmosférico ou deposição, já que a dispersão do traçador estável não foi suficiente para justificar o decréscimo nas concentrações do poluente.

Foi utilizada como concentração de background para composição química de $\mathrm{PM}_{1}$ os valores descritos por ARTAXO et al. (2021) foram de $0.33 \mu \mathrm{g} \mathrm{m}^{-3}, 0.03 \mu \mathrm{g} \mathrm{m}^{-3}$ e $0.02 \mu \mathrm{g} \mathrm{m}^{-3}$ para orgânicos, sulfato e nitrato, respectivamente, em que se descartam eventos regionais. Já a concentração background de número de partículas, identificada neste mesmo estudo, é de 220 $\mathrm{cm}^{-3}$. 
Figura 5.13 - Boxplots da série temporal de médias de $30 \mathrm{~min}$ das razões de enriquecimento (ER) com a comparação entre sítio T0a (ATTO), T1 e T2, mostrando em vermelho as medianas, nas caixas azuis o intervalo interquartil e entre as linhas tracejadas o intervalo de percentil 0.25 $-1.5 *$ IIQ e percentil $0.75+1.5 *$ IIQ, limite usado para outliers.

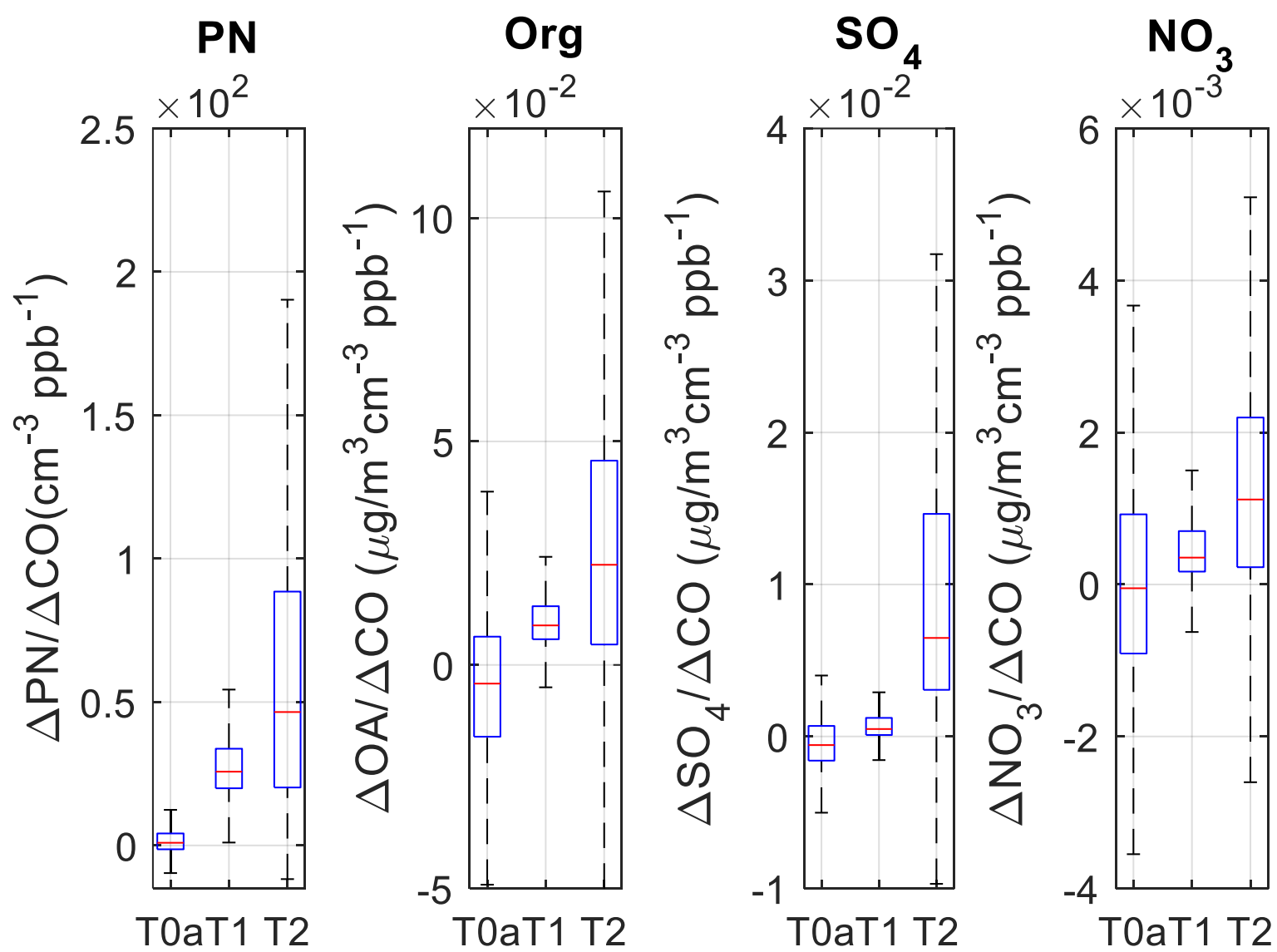

Embora em casos reais seja muito difícil obter a condição de diferentes sítios amostrando exatamente a mesma pluma e, portanto, este coeficiente estar sujeito a alterações não esperadas devido a fontes impactando sítios diferentes com intensidades distintas, nós obtivemos resultados consistentes de razões de enriquecimento progressivamente mais altas, como pode ser visto na estatística descritiva nos boxplots da Figura 5.13. Esta figura mostra em vermelho as medianas, nas caixas azuis o intervalo interquartil e entre as linhas tracejadas o intervalo de percentil $0.25-1.5^{*} \mathrm{IIQ}$ e percentil $0.75+1.5^{*} \mathrm{IIQ}$, limite usado para outliers.

Houve diminuição absoluta da componente de aerossol em número e massa de T1 para T2 (à exceção do sulfato), por efeito de dispersão e deposição. Porém, o parâmetro de razão de enriquecimento, indicado na Figura 5.13, mostra um significativo aumento nas razões de enriquecimento de aerossóis, usando o CO como indicador de diluição. Concordando com os eventos de formação de partículas identificados em T2, a comparação entre a mediana a razão de enriquecimento do número de partículas é mais de duas vezes maior em T2 do que em T1. 
Para a massa de OA, também concordando com o maior nível de oxidação mostrado na seção anterior que estaria relacionada a produção de SOA pela condensação de COVs entre os sítios, houve um aumento de quase 3 vezes entre as razões de enriquecimento de OA de T1 para T2. A razão de enriquecimento de nitrato, componente secundário relacionado a emissões veiculares, também mostrou aumento de quase 3 vezes. Já quanto ao sulfato, cuja concentração em massa (absoluta) observada já era 50\% maior em T2, vide Tabela 3, mostra razão de enriquecimento da ordem de 10 vezes maior neste sítio em relação ao T1. Este poluente de enxofre, como indicado no começo do capítulo, deve estar relacionado a emissões que não ocorrem em tanta intensidade em $\mathrm{T} 1$, como as termelétricas, dessa forma superestimando a razão de enriquecimento de sulfato.

\subsubsection{Comparação das propriedades ópticas de aerossóis observadas vento abaixo de Manaus}

Relacionado a estas partículas, em especial às diminuições em concentrações absolutas de T1 a T2, os coeficientes de absorção e de espalhamento também diminuem: $\sigma_{\mathrm{a}}(637)$ vai de 10.5 (6.7-15,6) $\mathrm{Mm}^{-1}$ em T1 para 3.8 (1.6-7.3) $\mathrm{Mm}^{-1}$ em T2 acompanhando a queda de BC, e $\sigma_{\mathrm{e}}$ (637) vai de 13.8 (10.4-20.3) $\mathrm{Mm}^{-1}$ em T1 para 7.6 (4.3-13) $\mathrm{Mm}^{-1}$ em T2, acompanhando a queda de concentrações de componentes espalhadores como orgânicos e sulfato. A Figura 5.14 contém a estatística das séries temporais de ambos os sítios descrita por um boxplot, mostrando na linha em vermelho a mediana, nas caixas azuis o intervalo interquartil e nos símbolos ' + ' vermelhos, outliers mostrando episódios locais de altos valores de coeficientes ópticos.

$\mathrm{Na}$ torre ZF2, vento acima da cidade e também parte do experimento GoAmazon2014/15, os valores para coeficientes ópticos durante a estação chuvosa são de $\sigma_{\text {esp }}$ $=6.3(3.4-11) \mathrm{Mm}^{-1}$ e $\sigma_{\mathrm{a}}=0.5(0.2-1.1) \mathrm{Mm}^{-1}$ (RIZZO et al, 2013). Considerando esses valores como relativos a condições pristinas do ambiente, vemos que o efeito de Manaus ser tão próxima ao sítio T2 é de aerossóis dez vezes mais absorvedores, diretamente ligado ao $\mathrm{BC}$ e $\mathrm{BrC}$ urbanos, e pouco mais espalhadores, relacionado ao fato de que as partículas frescas da cidade são pequenas em comparação com as biogênicas e, portanto, não representam efeito tão grande quanto na absorção. 
Figura 5.14 - Boxplots da série temporal de média de 30 min dos coeficientes de absorção e espalhamento com a comparação entre os sítios T1 e T2, mostrando em vermelho as medianas, nas caixas azuis o intervalo interquartil e entre as linhas tracejadas o intervalo de percentil 0.25 $-1.5^{*}$ IIQ e percentil $0.75+1.5^{*} \mathrm{IIQ}$, limites para outliers, e em vermelho os dados fora desses limites.
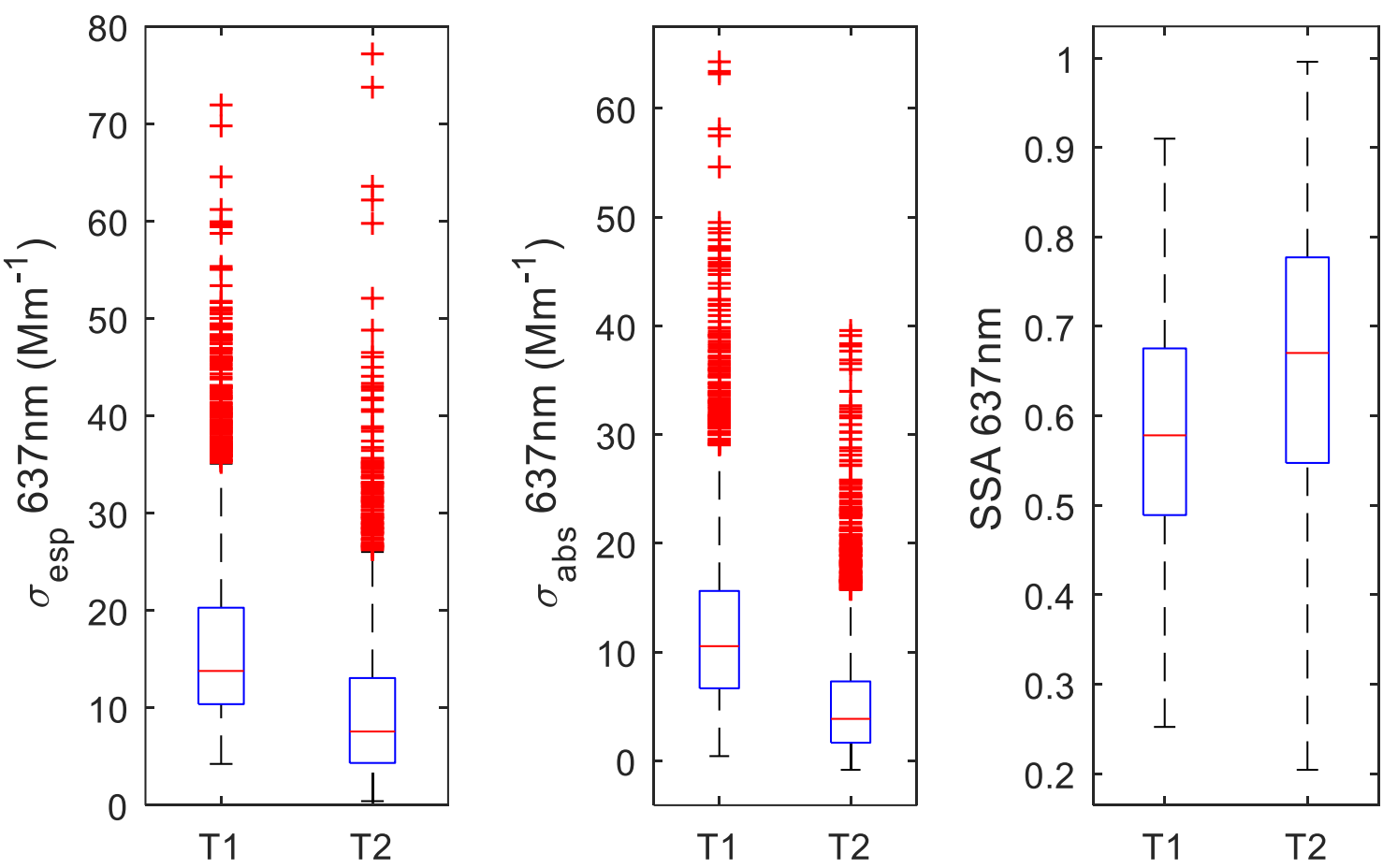

O SSA mostra que houve uma mudança importante na característica intrínseca das propriedades ópticas da população de partículas amostrada, já que este coeficiente não é influenciado pela quantidade de partículas. Os aerossóis neste sítio mantêm uma característica forte absorvedora, com $\mathrm{SSA}_{637 \mathrm{~nm}}=0.67$ (0.55-0.78). Observou-se, porém, uma grande diferença em relação às características medidas no centro de cidade, que apresentam valores de 0.58 (0.49-0.67). Como nota-se na série temporal da Figura 5.15, esta variável é mais estável em T1, onde as contribuições são mais homogêneas, em contraste com T2, cujo impacto momentâneo depende fortemente da meteorologia. Vento abaixo, essa característica fortemente absorvedora é modificada para 0.8 no T3, e simulações mostram que este SSA continua a crescer até 4-5h depois de ter sido emitido em Manaus (NASCIMENTO et al., 2020; CIRINO et al., 2018).

Esta tendência de aumento do SSA concorda com as observações de composição química de partículas mantidas em paralelo através dos espectrômetros de massa que revelam no T2 partículas significativamente mais oxidadas do que no sítio T1, consumo de COVs possivelmente para a fase de partícula e eventos de formação e crescimento de partículas entre os sítios mais próximos à cidade. 
Figura 5.15 - Série temporal do albedo de espalhamento único (SSA) nos sítios T1 e T2 mostrando aerossóis com capacidade alta de absorver luz em ambos os sítios, e variações maiores no $\mathrm{T} 2$.
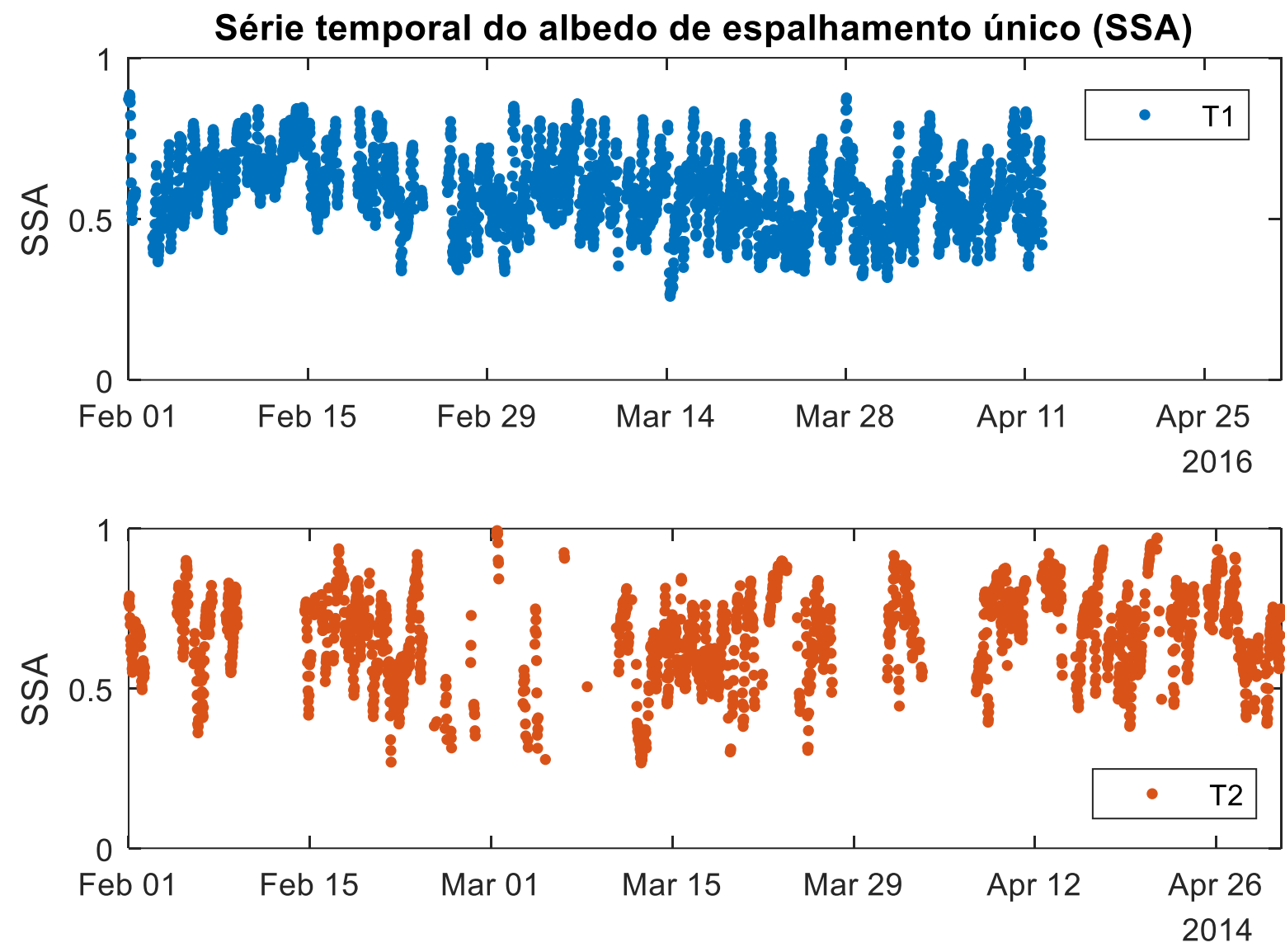


\section{CONCLUSÕES}

Este trabalho apresentou diversas abordagens buscando uma caracterização abrangente das propriedades físico-químicas dos poluentes urbanos de Manaus em meio a uma floresta tropical e das características do seu processamento químico em especial a curto prazo.

No centro da área urbana, as concentrações de grande parte dos poluentes antrópicos primários observados como $\mathrm{CO}, \mathrm{SO}_{2}, \mathrm{BC}$, benzeno, tolueno e $\mathrm{COV}$ s aromáticos $\mathrm{C}_{8}$ que estão ligados a emissões de tráfego foram pouco menores ou compatíveis com o observado em grandes metrópoles como São Paulo, Cidade do México e Beijing. As espécies secundárias como ozônio apresentaram concentrações de 12 ppbv no meio do dia, baixíssimas em comparação com outras metrópoles. O $\mathrm{PM}_{1}$ foi dominado em número de partículas pela moda de nucleação, de $42 \%$, e os principais componentes do particulado fino em massa foram primários, com alta fração de $\mathrm{BC}$ de $33 \%$ do $\mathrm{PM}_{1}$, acima de valores de referência para ambientes urbanos, e com aerossóis orgânicos (59\%) explicados na maior parte por fatores primários de tráfego (21\%), emissões de cozinha (22\%) e queima de biomassa local (22\%), além de um fator secundário de aerossóis oxidados (35\%). Dentre estes fatores, as emissões de cozinha e de biomassa local se destacam por sua contribuição em massa ser tão relevante quanto as emissões veiculares. Os aerossóis inorgânicos secundários representam uma fração menor do que $10 \%$ do $\mathrm{PM}_{1}$ na cidade. As propriedades ópticas de partículas refletem as demais propriedades identificadas do $\mathrm{PM}_{1}$ : o SSA de 0.58, baixo para ambientes urbanos, indica um particulado altamente absorvedor e concorda com a alta fração de BC, com a baixa massa de aerossóis secundários majoritariamente espalhadores e com o baixo tamanho de partículas.

Estas emissões da cidade criam um ambiente com grande potencial para produção secundária de poluentes e alteração no perfil dos poluentes. Grandes transformações nas características dos poluentes foram notadas entre o sítio situado no centro da cidade e o sítio situado na margem do Rio Negro mesmo com uma distância de apenas $14 \mathrm{~km}$ entre si. Diminuições de 2 a 3 vezes foram observados em poluentes como $\mathrm{CO}, \mathrm{SO}_{2}$ e $\mathrm{PM}_{1}$, enquanto as concentrações de COVs como o metanol diminuíram por fatores de até 8 vezes e como o isopreno diminuiu a níveis de 0.7 ppbv, abaixo de concentrações naturais da Floresta Amazônica, mostrando significativo consumo. Também se observou significativa formação secundária de poluentes como o ozônio, cujas concentrações quase dobraram durante o dia entre os sítios. Quanto às partículas da moda fina, foram notados: rápido crescimento no diâmetro geométrico médio de $25 \mathrm{~nm}$ entre os sítios; significativa oxidação representada pela diferença de razão O:C de 0.42 no T1 para 0.72 no T2 e grande aumento de sulfato, de $4 \%$ em T1 para 
$12 \%$ em T2. Foram identificados também eventos de formação de novas partículas no T2 em uma fração curiosamente alta dos dias, de $19 \%$ com crescimento a diâmetros de cerca de 50nm.

Embora não seja possível separar os efeitos de fontes diferentes com o efeito do envelhecimento na atmosfera, há diferentes evidências que apontam para significativo processamento da atmosfera entre os sítios. Também mostramos evidências de que as emissões de precursores da cidade induzem a formação de novas partículas e crescimento acelerado das partículas ultrafinas emitidas em Manaus, com o potencial de rapidamente atingir tamanhos de CCN, além de introduzir partículas altamente absorvedoras e destas formas influenciar o clima.

Este conjunto de observações mostram que os gases e partículas podem ter efeitos deletérios na vegetação e na saúde humana. Os aerossóis orgânicos formados têm o potencial de impactar o balanço radiativo, a razão entre radiação direta e difusa e, portanto, a fotossíntese vento abaixo da floresta.

Embora o estudo em dois sítios de amostragem tenha permitido uma ampla gama de análises, algumas sugestões são feitas para estudos e campanhas posteriores: a realização de medições simultâneas entre os sítios, que poderiam retirar a complexidade de eventos regionais potencialmente apenas observados durante um ano ou efeitos que atuam em um ano com intensidades diferentes de outro ano e podem permitir análises mais elaboradas de eventos regionais sob diferentes condições de interação da pluma urbana com a pristina; a manutenção de outros sítios espalhados pela cidade de forma que seja possível caracterizar as diferenças geográficas locais de emissão e de transformações da atmosfera da cidade; caracterização da eficiência relativa de sulfato durante a campanha para maior acurácia na determinação da massa desta componente; uso de inlets com mesmo corte superior do diâmetro de partícula para determinação mais acurada das eficiências de espalhamento de partículas.

Importante salientar que este estudo foi realizado durante a estação chuvosa, e suas conclusões não podem ser extrapolados para a estação seca, já que a química atmosférica é alterada pela presença maciça de emissões de queimadas transportadas a longa distância de agosto a novembro. 


\section{REFERÊNCIAS}

ABOU RAFEE, S. A. et al. Contributions of mobile, stationary and biogenic sources to air pollution in the Amazon rainforest: a numerical study with the WRF-Chem model. Atmospheric Chemistry \& Physics, v. 17, n. 12, 2017.

AIKEN, A. C.; DECARLO, P. F.; JIMENEZ, J. L. Elemental analysis of organic species with electron ionization high-resolution mass spectrometry. Analytical Chemistry, v. 79, n. 21, p. 8350-8358, 2007.

AIKEN, A. C. et al. O/C and OM/OC ratios of primary, secondary, and ambient organic aerosols with high-resolution time-of-flight aerosol mass spectrometry. Environmental science \& technology, v. 42, n. 12, p. 4478-4485, 2008.

AIKEN, A. C. et al. Mexico City aerosol analysis during MILAGRO using high resolution aerosol mass spectrometry at the urban supersite (T0)-Part 1: Fine particle composition and organic source apportionment. Atmospheric Chemistry and Physics, v. 9, n. 17, p. 66336653, 2009.

ALLAN, J. D. et al. Quantitative sampling using an Aerodyne aerosol mass spectrometer 1. Techniques of data interpretation and error analysis. Journal of Geophysical Research: Atmospheres, v. 108, n. D3, 2003.

ALLAN, J. D. et al. A generalized method for the extraction of chemically resolved mass spectra from Aerodyne aerosol mass spectrometer data. Journal of Aerosol Science, v. 35, n. 7, p. 909-922, 2004.

ALTARATZ, Orit et al. Lightning response to smoke from Amazonian fires. Geophysical Research Letters, v. 37, n. 7, 2010.

ANDERSON, J. O.; THUNDIYIL, J. G.; STOLBACH, A. Clearing the air: a review of the effects of particulate matter air pollution on human health. Journal of Medical Toxicology, v. 8, n. 2, p. 166-175, 2012.

ANDRADE, M. de F. et al. Vehicle emissions and PM 2.5 mass concentrations in six Brazilian cities. Air Quality, Atmosphere \& Health, v. 5, n. 1, p. 79-88, 2012.

ANDRADE, M. de F. et al. Ozone sounding in the Metropolitan Area of Sao Paulo, Brazil: Wet and dry season campaigns of 2006. Atmospheric environment (1994), v. 61, p. 627-640, 2012.

ANDREAE, M. O. et al. Smoking rain clouds over the Amazon. Science, v. 303, n. 5662, p. 1337-1342, 2004.

ANDREAE, M. O. et al. The Amazon Tall Tower Observatory (ATTO): overview of pilot measurements on ecosystem ecology, meteorology, trace gases, and aerosols. Atmospheric Chemistry and Physics, v. 15, n. 18, p. 10723-10776, 2015.

ANDREAE, M. O. et al. Aerosol characteristics and particle production in the upper troposphere over the Amazon Basin. Atmospheric Chemistry and Physics (Online), v. 18, n. BNL-203226-2018-JAAM, 2018.

ARTAXO, P. Modelos receptores aplicados à determinação da estrutura de fontes de aerossóis remotos. 1985. Tese de Doutorado. Universidade de São Paulo. 
ARTAXO, P. et al. Atmospheric aerosols in Amazonia and land use change: from natural biogenic to biomass burning conditions. Faraday discussions, v. 165, p. 203-235, 2013.

ARTAXO, P. Working together for Amazonia. Editorial Science Magazine, Vol. 363, Issue 6425, 2019.

ARTAXO, P., Hans-Christen H. et al., Tropical and Boreal Forest - Atmosphere Interactions: A Review. Período de revisão em Tellus-B, número do manuscrito ZELB-2020-0011R1. 2021.

ASR, Atmospheric System Research, U.S. Department of Energy, 12 September 2019, Disponível em: <https://asr.science.energy.gov/science>.

BACKMAN, J. et al. On the diurnal cycle of urban aerosols, black carbon and the occurrence of new particle formation events in springtime São Paulo, Brazil. Atmospheric Chemistry \& Physics, v. 12, n. 23, 2012.

BAKER, Angela K. et al. Measurements of nonmethane hydrocarbons in 28 United States cities. Atmospheric Environment, v. 42, n. 1, p. 170-182, 2008.

BARBOSA, C. G. G. Monitoramento de material particulado fino na cidade de Manaus para avaliação de potenciais riscos à saúde da população e caracterização de material particulado em ambiente de florestas (Atto-Amazonian tall tower observatory) Amazonas, Brasil. 2014.

BARTH, M. et al. Coupling between land ecosystems and the atmospheric hydrologic cycle through biogenic aerosol pathways. Bulletin of the American Meteorological Society, v. 86, n. 12 , p. $1738-1742,2005$.

BISCARO, Thiago S. et al. What drives daily precipitation over the central Amazon? Differences observed between wet and dry seasons. Atmospheric Chemistry and Physics, v. 21, n. 9, p. 6735-6754, 2021.

BON, D. M. et al. Measurements of volatile organic compounds at a suburban ground site (T1) in Mexico City during the MILAGRO 2006 campaign: measurement comparison, emission ratios, and source attribution. Atmospheric Chemistry and Physics, v. 11, n. 6, p. 2399-2421, 2011.

BOND, T. C. et al. Bounding the role of black carbon in the climate system: A scientific assessment. Journal of Geophysical Research: Atmospheres, v. 118, n. 11, p. 5380-5552, 2013.

BORBON, A. et al. Emission ratios of anthropogenic volatile organic compounds in northern mid-latitude megacities: Observations versus emission inventories in Los Angeles and Paris. Journal of Geophysical Research: Atmospheres, v. 118, n. 4, p. 2041-2057, 2013.

BOUCHER, Olivier et al. Clouds and aerosols. In: Climate change 2013: the physical science basis. Contribution of Working Group I to the Fifth Assessment Report of the Intergovernmental Panel on Climate Change. Cambridge University Press, 2013. p. 571657.

BRITO, J. et al. Vehicular emission ratios of VOCs in a megacity impacted by extensive ethanol use: results of ambient measurements in Sao Paulo, Brazil. Environmental science \& technology, v. 49, n. 19, p. 11381-11387, 2015. 
BRITO, J. et al. Disentangling vehicular emission impact on urban air pollution using ethanol as a tracer. Scientific reports, v. 8, n. 1, p. 1-10, 2018.

BÜRGER, A. A. Composição do aerossol atmosférico na Amazônia com influência antropogênica: estudo de caso no experimento GoAmazon. 2017. Tese de Doutorado. Universidade de São Paulo.

CANAGARATNA, M. R. et al. Chemical and microphysical characterization of ambient aerosols with the aerodyne aerosol mass spectrometer. Mass spectrometry reviews, v. 26, n. 2, p. 185-222, 2007.

CANAGARATNA, M. R. et al. Elemental ratio measurements of organic compounds using aerosol mass spectrometry: characterization, improved calibration, and implications. Atmospheric Chemistry and Physics, v. 15, n. 1, p. 253-272, 2015.

CANONACO, F. et al. SoFi, an IGOR-based interface for the efficient use of the generalized multilinear engine (ME-2) for the source apportionment: ME-2 application to aerosol mass spectrometer data. Atmospheric Measurement Techniques, v. 6, n. 12, p. 3649-3661, 2013.

CARVALHO, V. S. B. et al. Air quality status and trends over the Metropolitan Area of São Paulo, Brazil as a result of emission control policies. Environmental Science \& Policy, v. 47, p. 68-79, 2015.

CECCHINI, M. A. et al. Impacts of the Manaus pollution plume on the microphysical properties of Amazonian warm-phase clouds in the wet season. Atmospheric Chemistry and Physics (Online), v. 16, n. BNL-112537-2016-JA, 2016.

CIRINO, G. et al. Observations of Manaus urban plume evolution and interaction with biogenic emissions in GoAmazon 2014/5. Atmospheric environment, v. 191, p. 513-524, 2018.

CRENN, V. et al. ACTRIS ACSM intercomparison-Part 1: Reproducibility of concentration and fragment results from 13 individual Quadrupole Aerosol Chemical Speciation Monitors (Q-ACSM) and consistency with co-located instruments. Atmospheric Measurement Techniques, v. 8, n. 12, p. 5063-5087, 2015.

CUBISON, M. J. et al. Effects of aging on organic aerosol from open biomass burning smoke in aircraft and laboratory studies. Atmospheric Chemistry and Physics, v. 11, n. 23, p. 1204912064, 2011.

DAVIDSON, E. A. et al. The Amazon basin in transition. Nature, v. 481, n. 7381, p. 321-328, 2012.

DE MENDONÇA, M. J. C. et al. The economic cost of the use of fire in the Amazon. Ecological Economics, v. 49, n. 1, p. 89-105, 2004.

DE MIRANDA, R. M. et al. Urban air pollution: a representative survey of PM 2.5 mass concentrations in six Brazilian cities. Air Quality, Atmosphere \& Health, v. 5, n. 1, p. 63-77, 2012.

DE OLIVEIRA, G. et al. Smoke pollution's impacts in Amazonia. Science (New York, NY), v. 369, n. 6504, p. 634-635, 2020.

DE SÁ, S. et al. Influence of urban pollution on the production of organic particulate matter from isoprene epoxydiols in central Amazonia. Atmospheric Chemistry and Physics Discussions, v. 17, n. 11, p. 6611-6629, 2017. 
DE SÁ, S. et al. Urban influence on the concentration and composition of submicron particulate matter in central Amazonia. Atmospheric Chemistry and Physics, v. 18, n. 16, p. 1218512206, 2018.

DENATRAN. 2014. <Disponível em: http://www.denatran.gov.br/estatistica/253-frota-2014> Acesso em 2019 jan.

DECARLO, P. F. et al. Field-deployable, high-resolution, time-of-flight aerosol mass spectrometer. Analytical chemistry, v. 78, n. 24, p. 8281-8289, 2006.

DOS SANTOS, M. J.; SILVA DIAS, M. AF; FREITAS, E. D. Influence of local circulations on wind, moisture, and precipitation close to Manaus City, Amazon Region, Brazil. Journal of Geophysical Research: Atmospheres, v. 119, n. 23, p. 13,233-13,249, 2014.

DUTRA, J. M. Emissões de poluentes atmosféricos do sistema de transportes: inventários e predições. 2018.

EKMAN, A. ML. et al. Do organics contribute to small particle formation in the Amazonian upper troposphere? Geophysical Research Letters, v. 35, n. 17, 2008.

ELBERT, W. et al. Contribution of fungi to primary biogenic aerosols in the atmosphere: wet and dry discharged spores, carbohydrates, and inorganic ions. Atmospheric Chemistry and Physics, European Geosciences Union, 7 (17), p.4569-4588. 2007.

FAN, J. et al. Substantial convection and precipitation enhancements by ultrafine aerosol particles. Science, v. 359, n. 6374, p. 411-418, 2018.

FINLAYSON-PITTS, B. J.; PITTS JR, J. N. Atmospheric chemistry of tropospheric ozone formation: scientific and regulatory implications. Air \& Waste, v. 43, n. 8, p. 1091-1100, 1993.

FORELLO, A. C. et al. Exploiting multi-wavelength aerosol absorption coefficients in a multitime resolution source apportionment study to retrieve source-dependent absorption parameters. Atmospheric Chemistry and Physics, v. 19, n. 17, p. 11235-11252, 2019.

FRENEY, E. et al. The second ACTRIS inter-comparison (2016) for Aerosol Chemical Speciation Monitors (ACSM): Calibration protocols and instrument performance evaluations. Aerosol Science and Technology, v. 53, n. 7, p. 830-842, 2019.

FRÖHLICH, R. et al. The ToF-ACSM: a portable aerosol chemical speciation monitor with TOFMS detection. Atmospheric Measurement Techniques, v. 6, n. 11, 2013.

FRÖHLICH, R. et al. ACTRIS ACSM intercomparison-Part 2: Intercomparison of ME-2 organic source apportionment results from 15 individual, co-located aerosol mass spectrometers. Atmospheric Measurement Techniques, v. 8, n. 6, p. 2555-2576, 2015.

GARLAND, R. M. et al. Aerosol optical properties observed during Campaign of Air Quality Research in Beijing 2006 (CAREBeijing-2006): Characteristic differences between the inflow and outflow of Beijing city air. Journal of Geophysical Research: Atmospheres, v. 114, n. D2, 2009.

GIODA, Adriana; TONIETTO, Gisele Birman; LEON, Antonio Ponce de. Exposure to the use of firewood for cooking in Brazil and its relation with the health problems of the population.

Ciência \& saúde coletiva, v. 24, p. 3079-3088, 2019. 
GLOOR, M. R. J. W. et al. Intensification of the Amazon hydrological cycle over the last two decades. Geophysical Research Letters, v. 40, n. 9, p. 1729-1733, 2013.

GONÇALVES, W. A.; MACHADO, L. A. T.; KIRSTETTER, P.-E. Influence of biomass aerosol on precipitation over the Central Amazon: an observational study. Atmospheric Chemistry and Physics, v. 15, n. 12, p. 6789-6800, 2015.

GOULDING, M. et al. The Smithsonian atlas of the Amazon. Washington: Smithsonian Books. 2003.

GRELL, G. A. et al. Fully coupled "online" chemistry within the WRF model. Atmospheric Environment, v. 39, n. 37, p. 6957-6975, 2005.

GUENTHER, A. B. et al. The Model of Emissions of Gases and Aerosols from Nature version 2.1 (MEGAN2. 1): an extended and updated framework for modeling biogenic emissions. Geoscience Model Development, v.5, p. 1471-1492,2012.

HAND, J. L.; MALM, W. C. Review of aerosol mass scattering efficiencies from ground-based measurements since 1990. Journal of Geophysical Research: Atmospheres, v. 112, n. D16, 2007.

HANSEN, A. D. A.; ROSEN, H.; NOVAKOV, T. The aethalometer-an instrument for the real-time measurement of optical absorption by aerosol particles. Science of the Total Environment, v. 36, p. 191-196, 1984.

HOLLOWAY, T.; LEVY, H.; KASIBHATLA, P. Global distribution of carbon monoxide. Journal of Geophysical Research: Atmospheres, v. 105, n. D10, p. 12123-12147, 2000.

HONG, J. et al. Relating the hygroscopic properties of submicron aerosol to both gas-and particle-phase chemical composition in a boreal forest environment. Atmospheric Chemistry and Physics, v. 15, n. 20, p. 11999-12009, 2015.

HUSSEIN, T. et al. Particulate matter and number concentrations of particles larger than 0.25 $\mu \mathrm{m}$ in the urban atmosphere of Jeddah, Saudi Arabia. Aerosol and Air Quality Research, v. 14, n. 5, p. 1383-1391, 2014.

IBGE - Instituto Brasileiro de Geografia e Estatística. Sinopse do Censo Demográfico 2010. Rio de Janeiro. 2012. <Disponível em: https://biblioteca.ibge.gov.br/visualizacao/livros/liv49230.pdf >. Acesso em: 20 de dezembro de 2020 .

IBGE - Instituto Brasileiro de Geografia e Estatística. Estimativas da população residente no Brasil e unidades da federação com data de referência de $1^{\circ}$ de julho de 2020 . Rio de Janeiro. 2020. https://ftp.ibge.gov.br/Estimativas_de_Populacao/Estimativas_2020/estimativa_dou_2020.pdf >. Acesso em: 20 de dezembro de 2020.

INPE, 2020a. Portal do Monitoramento de Queimadas e Incêndios Florestais. Disponível em <http://www.inpe.br/queimadas>. Acesso em: 10 de janeiro de 2020.

INPE, 2020b. Taxas de desmatamento. Disponível em:

<http://terrabrasilis.dpi.inpe.br/app/dashboard/deforestation/biomes/legal_amazon/rates>. Acesso em: 15 de janeiro de 2021. 
IPBES, 2019: Global assessment report on biodiversity and ecosystem services of the Intergovernmental Science-Policy Platform on Biodiversity and Ecosystem Services. IPBES secretariat, Bonn, Germany. p. 1-1148, 2019.

IPCC, 2007: Climate Change 2007: The Physical Science Basis. Contribution of Working Group I to the Fourth Assessment Report of the Intergovernmental Panel on Climate Change Cambridge University Press, Cambridge, United Kingdom and New York, NY, USA. ISSN 978-0-521-88009-1, 2007

IPCC, 2013: Climate Change 2013: The Physical Science Basis. Contribution of Working Group I to the Fifth Assessment Report of the Intergovernmental Panel on Climate Change Cambridge University Press, Cambridge, United Kingdom and New York, NY, USA, p. 1535, 2013.

IPCC, 2019: Climate Change and Land: an IPCC special report on climate change, desertification, land degradation, sustainable land management, food security, and greenhouse gas fluxes in terrestrial ecosystems. Cambridge University Press, Cambridge, United Kingdom and New York, NY, USA, 2019.

JANDAGHIAN, Z.; AKBARI, H. Effects of increasing surface reflectivity on aerosol, radiation, and cloud interactions in the urban atmosphere. Theoretical and Applied Climatology, v. 139, n. 3-4, p. 873-892, 2020.

JOHANNESSON, S. et al. Exposure to fine particles (PM 2.5 and PM 1) and black smoke in the general population: personal, indoor, and outdoor levels. Journal of exposure science \& environmental epidemiology, v. 17, n. 7, p. 613-624, 2007.

KANAKIDOU, M. et al. Organic aerosol and global climate modelling: a review. Atmospheric Chemistry and Physics, v. 5, n. 4, p. 1053-1123, 2005.

KOREN, Ilan et al. Aerosol-induced intensification of rain from the tropics to the mid-latitudes. Nature Geoscience, v. 5, n. 2, p. 118-122, 2012.

KUHN, U. et al. Impact of Manaus City on the Amazon Green Ocean atmosphere: ozone production, precursor sensitivity and aerosol load. Atmospheric Chemistry and Physics, v. 10, n. 19, p. 9251-9282, 2010.

KUWATA, M.; ZORN, S. R.; MARTIN, S. T. Using elemental ratios to predict the density of organic material composed of carbon, hydrogen, and oxygen. Environmental Science \& Technology, v. 46, n. 2, p. 787-794, 2012.

LANG-YONA, N. et al. The chemical and microphysical properties of secondary organic aerosols from Holm Oak emissions. Atmospheric Chemistry and Physics, v. 10, n. 15, p. 7253, 2010.

LEE, C. et al. SO2 emissions and lifetimes: Estimates from inverse modeling using in situ and global, space-based (SCIAMACHY and OMI) observations. Journal of Geophysical Research: Atmospheres, v. 116, n. D6, 2011.

LEE, S. C. et al. PM1. 0 and PM2. 5 characteristics in the roadside environment of Hong Kong. Aerosol Science and Technology, v. 40, n. 3, p. 157-165, 2006.

LIU, Y.; DAUM, P. H. Indirect warming effect from dispersion forcing. Nature, v. 419, n. 6907, p. 580-581, 2002. 
LIU, Y. et al. Isoprene photochemistry over the Amazon rainforest. Proceedings of the National Academy of Sciences, v. 113, n. 22, p. 6125-6130, 2016.

LOVEJOY, T. E.; NOBRE, C. Amazon tipping point: Last chance for action. 2019.

MAHILANG, M.; DEB, M. K.; PERVEZ, S. Biogenic secondary organic aerosols: A review on formation mechanism, analytical challenges, and environmental impacts. Chemosphere, $p$. $127771,2020$.

MALHI, Y. et al. Climate change, deforestation, and the fate of the Amazon. Science, v. 319, n. 5860, p. 169-172, 2008.

MARTIN, S. T. et al. Sources and properties of Amazonian aerosol particles. Reviews of Geophysics, v. 48, n. 2, 2010.

MARTIN, S. T. et al. Introduction: observations and modeling of the Green Ocean Amazon (GoAmazon2014/5). Atmospheric Chemistry and Physics, v. 16, n. 8, 2016.

MARTIN, S. T. et al. The Green Ocean Amazon experiment (GoAmazon2014/5) observes pollution affecting gases, aerosols, clouds, and rainfall over the rain forest. Bulletin of the American Meteorological Society, v. 98, n. 5, p. 981-997, 2017.

MARTINS, J. A.; SILVA DIAS, M. A. F.; GONÇALVES, F. L. T. Impact of biomass burning aerosols on precipitation in the Amazon: A modeling case study. Journal of Geophysical Research: Atmospheres, v. 114, n. D2, 2009.

MIDDLEBROOK, A. M. et al. Evaluation of composition-dependent collection efficiencies for the aerodyne aerosol mass spectrometer using field data. Aerosol Science and Technology, v. 46, n. 3, p. 258-271, 2012.

MIRANDA, R. M. et al. Urban air pollution: a representative survey of PM 2.5 mass concentrations in six Brazilian cities. Air Quality, Atmosphere \& Health, v. 5, n. 1, p. 63-77, 2012.

MMA. $2^{\circ}$ Inventário Nacional de Emissões Atmosféricas por Veículos Automotores Rodoviários 2013-Ano-base 2012: Relatório final. MMA, Brasília, DF, Brasil, 2014.

MOHR, C. et al. Identification and quantification of organic aerosol from cooking and other sources in Barcelona using aerosol mass spectrometer data. Atmospheric Chemistry and Physics, v. 12, n. 4, p. 1649-1665, 2012.

NAKADA, L. Y. K.; URBAN, R. C. COVID-19 pandemic: Impacts on the air quality during the partial lockdown in São Paulo state, Brazil. Science of The Total Environment, p. 139087, 2020.

NASCIMENTO, J. P. et al. Aerosols from anthropogenic and biogenic sources and their interactions: modeling aerosol formation, optical properties and impacts over the central Amazon Basin. Atmospheric Chemistry and Physics Discussions, p. 1-34, 2020.

NASCIMENTO, J. P. et al. Estimation of isoprene and NOx interactions and their corresponding impact on ozone, secondary organic aerosols formation, and radiative forcing in the Amazonian region (GoAmazon2014/15 Experiment). Em processo de escrita. 2021

NETTO, F. D. et al. Formação de ozônio troposférico: uma revisão da literatura. XXV Simpósio Internacional de Engenharia Automotiva, v. 4, 2017. 
NG, N. L. et al. An Aerosol Chemical Speciation Monitor (ACSM) for routine monitoring of the composition and mass concentrations of ambient aerosol. Aerosol Science and Technology, v. 45, n. 7, p. 780-794, 2011.

PALM, B. B. et al. Secondary organic aerosol formation from ambient air in an oxidation flow reactor in central Amazonia. Atmospheric Chemistry and Physics, v. 18, n. 1, p. 467-467, 2018.

PAREDES-MIRANDA, G. et al. Primary and secondary contributions to aerosol light scattering and absorption in Mexico City during the MILAGRO 2006 campaign. Atmospheric Chemistry and Physics, v. 9, n. 11, p. 3721-3730, 2009.

PHILLIPS, O. L. et al. Drought sensitivity of the Amazon rainforest. Science, v. 323, n. 5919, p. 1344-1347, 2009.

RIZZO, L. V. et al. Long-term measurements of aerosol optical properties at a primary forest site in Amazonia. Atmospheric Chemistry and Physics, v. 13, n. 5, p. 2391-2413, 2013.

RIZZO, L. V. et al. Multi-year statistical and modeling analysis of submicrometer aerosol number size distributions at a rain forest site in Amazonia. Atmospheric Chemistry and Physics, 2018.

ROBINSON, N. H. et al. Evidence for a significant proportion of Secondary Organic Aerosol from isoprene above a maritime tropical forest. Atmospheric Chemistry and Physics, v. 11, n. 3, p. 1039-1050, 2011.

ROSENFELD, Daniel et al. Flood or drought: How do aerosols affect precipitation? Science, v. 321, n. 5894, p. 1309-1313, 2008.

ROSENFELD, Daniel et al. Global observations of aerosol-cloud-precipitation-climate interactions. Reviews of Geophysics, v. 52, n. 4, p. 750-808, 2014.

ROZANTE, J. R. et al. Variations of carbon monoxide concentrations in the megacity of São Paulo from 2000 to 2015 in different time scales. Atmosphere, v. 8, n. 5, p. 81, 2017.

SANTOS, T. V. dos. Metropolização e diferenciações regionais: estruturas intraurbanas e dinâmicas metropolitanas em Belém e Manaus. Cadernos Metrópole, v. 19, n. 40, p. 865-890, 2017.

SANTOS JUNIOR, D.A. M. dos. Emissões veiculares em São Paulo: quantificação de fontes com modelos receptores e caracterização do material carbonáceo. 2015. Dissertação (Mestrado em Física) - Instituto de Física, Universidade de São Paulo, São Paulo, 2015.

SANTOS JUNIOR, D. A. M. dos. et al. Ambient concentrations and insights on organic and elemental carbon dynamics in São Paulo, Brazil. Atmospheric Environment, v. 144, p. 226233, 2016.

SCHNEIDER, J. et al. Mass-spectrometric identification of primary biological particle markers and application to pristine submicron aerosol measurements in Amazonia. Atmospheric Chemistry and Physics, 2011.

SCHMALE, J. et al. Long-term cloud condensation nuclei number concentration, particle number size distribution and chemical composition measurements at regionally representative observatories. Atmospheric Chemistry and Physics, 18 (4), p.2853 - 2881, 2018. 
SCHROEDER, W.; CSISZAR, I.; MORISETTE, J. Quantifying the impact of cloud obscuration on remote sensing of active fires in the Brazilian Amazon. Remote Sensing of Environment, v. 112, n. 2, p. 456-470, 2008.

SEINFELD, J. H. et al. Improving our fundamental understanding of the role of aerosol- cloud interactions in the climate system. Proceedings of the National Academy of Sciences, v. 113, n. 21, p. 5781-5790, 2016.

SEINFELD, J. H. e PANDIS, S. N. Atmospheric chemistry and physics: From air pollution to climate change, John Willey \& Sons. Inc., New York, 2006.

SHRIVASTAVA, M. et al. Urban pollution greatly enhances formation of natural aerosols over the Amazon rainforest. Nature communications, v. 10, n. 1, p. 1-12, 2019.

SHILLING, J. E. et al. Aircraft observations of the chemical composition and aging of aerosol in the Manaus urban plume during GoAmazon 2014/5. Atmospheric Chemistry and Physics, v. 18, n. PNNL-SA-132487; BNL-211718-2019-JAAM, 2018.

SILVA, C. VJ et al. Estimating the multi-decadal carbon deficit of burned Amazonian forests. Environmental Research Letters, v. 15, n. 11, p. 114023, 2020.

SILVA JÚNIOR, R. S.; OLIVEIRA, M. G. L.; ANDRADE, M. F. Weekend/weekday differences in concentrations of ozone, NOx, and non-methane hydrocarbon in the metropolitan area of São Paulo. Revista Brasileira de Meteorologia, v. 24, n. 1, p. 100-110, 2009.

STARK, H. et al. Methods to extract molecular and bulk chemical information from series of complex mass spectra with limited mass resolution. International Journal of Mass Spectrometry, v. 389, p. 26-38, 2015.

STOCKER, T. F. et al. Climate change 2013: The physical science basis. 2013.

STREMME, W. et al. Top-down estimation of carbon monoxide emissions from the Mexico Megacity based on FTIR measurements from ground and space. Atmospheric Chemistry and Physics, v. 13, p. 1357-1376, 2013.

SWAMY, L. et al. The future of tropical forests under the United Nations Sustainable Development Goals. Journal of Sustainable Forestry, v. 37, n. 2, p. 221-256, 2018.

SWIETLICKI, E. et al. Hygroscopic properties of submicrometer atmospheric aerosol particles measured with H-TDMA instruments in various environments-a review. Tellus B: Chemical and Physical Meteorology, v. 60, n. 3, p. 432-469, 2008.

TÉ, Y. et al. Carbon monoxide urban emission monitoring: a ground-based FTIR case study. Journal of Atmospheric and Oceanic Technology, v. 29, n. 7, p. 911-921, 2012.

TÉ, Y. et al. Seasonal variability of surface and column carbon monoxide over the megacity Paris, high-altitude Jungfraujoch and Southern Hemispheric Wollongong stations. Atmos. Chem. Phys, v. 16, p. 10911-10925, 2016.

TIMONEN, H. et al. Applications and limitations of constrained high-resolution peak fitting on low resolving power mass spectra from the ToF-ACSM. Atmospheric Measurement Techniques, v. 9, p. 3263-3281, 2016. 
TREBS, I. et al. Impact of the Manaus urban plume on trace gas mixing ratios near the surface in the Amazon Basin: Implications for the NO-NO2-O3 photo stationary state and peroxy radical levels. Journal of Geophysical Research: Atmospheres, v. 117, n. D5, 2012.

TSI, Inc. Disponível em: <https://www.esrl.noaa.gov/gmd/aero/instrumentation/neph_desc.html>.

ULBRICH, I. M. et al. Interpretation of organic components from Positive Matrix Factorization of aerosol mass spectrometric data. Atmospheric Chemistry and Physics, v. 9, n. 9, p. 28912918, 2009.

VAN MARLE, M. J. et al. Fire and deforestation dynamics in Amazonia (1973-2014). Global biogeochemical cycles, v. 31, n. 1, p. 24-38, 2017.

VELASCO, E.; RETAMA, A. Ozone's threat hits back Mexico City. Sustainable Cities and Society, v. 31, p. 260-263, 2017.

YÁÑEZ-SERRANO, A. M. et al. Amazonian biogenic volatile organic compounds under global change. Global Change Biology, v. 26, n. 9, p. 4722-4751, 2020.

YERETZIAN, C. et al. From the green bean to the cup of coffee: investigating coffee roasting by on-line monitoring of volatiles. European Food Research and Technology, v. 214, n. 2, p. 92-104, 2002.

WU, Z. et al. Particle number size distribution in the urban atmosphere of Beijing, China. Atmospheric Environment, v. 42, n. 34, p. 7967-7980, 2008.

ZHANG, Y. et al. Chemical composition and sources of PM1 and PM2. 5 in Beijing in autumn. Science of the Total Environment, v. 630, p. 72-82, 2018. 


\section{APÊNDICE A - ARTIGOS PUBLICADOS OU EM DESENVOLVIMENTO}

1. NASCIMENTO, J. P., BELA, M. M., MELLER, B. B., BANDUCCI, A. L., RIZZO, L. V., VARA-VELA, A. L., ... \& ARTAXO, P. (2020). Aerosols from anthropogenic and biogenic sources and their interactions: modeling aerosol formation, optical properties and impacts over the central Amazon Basin. Atmospheric Chemistry and Physics, p. 1-34, aceito para publicação. https://doi.org/10.5194/acp-2020-1002

2. MELLER, B. B., CARBONE, S., NASCIMENTO, J. P., RIZZO, L. V., SOUZA, R., BRITO, J., \& ARTAXO, P. (2021). Rapid changes in atmospheric properties in a tropical urban environment - Manaus, Brazil, em desenvolvimento.

\section{APÊNDICE B - TRABALHOS APRESENTADOS EM CONGRESSOS}

3. NASCIMENTO, J. M. P.; BELA, M.; MELLER, B. B.; VELA, A. L. V.; RAFEE, S. A. A.; CARBONE, S.; RIZZO, L. V.; TRAINER, M.; ARTAXO, P. Manaus Urban Plume Influence on Aerosol Optical Properties. Em: International Workshop on Air Quality Forecasting Research. Manaus Urban Plume Influence on Aerosol Optical Properties, 2018

4. NASCIMENTO, J. M. P.; MELLER, B. B.; BELA, M.; RAFEE, S. A. A.; VELA, A. L. V.; RIZZO, L. V.; CARBONE, S.; BARBOSA, H. M. J.; TRAINER, M.; ARTAXO, P. Aerosols from Anthropogenic and Biogenic Sources: Optical Properties and their Interactions over the Amazon Rainforest [GoAmazon2014/15 Experiment]. Em: Gordon Research Conference on Atmospheric Chemistry, 2019.

5. MELLER, B. B., CARBONE, S., RIZZO, L. V. \& ARTAXO, P. Physical-chemical interaction of Manaus' urban emissions with Amazon forest biogenic emissions: the secondary formation in Central Amazon. Em: AGU Fall Meeting, 2020.

6. ARAUJO, A., PUGliESI, A., MELLER, B. B., SANTOS, D., NASCIMENTO, J. P., PONCZEK, M. Air Quality Assessment in São Paulo, Brazil during COVID-19 pandemic: links between isolation rates and pollutants. Em: AGU Fall Meeting, 2020. 
7. NASCIMENTO, J. P., BELA, M. M., MELLER, B. B., BANDUCCI, A. L., RIZZO, L. V., VARA-VELA, A. L., ... \& ARTAXO, P. (2020). Aerosols from anthropogenic and biogenic sources and their interactions: modeling aerosol formation, optical properties and impacts over the central Amazon Basin. Atmospheric Chemistry and Physics Discussions, 1-34. 


\title{
Aerosols from anthropogenic and biogenic sources and their interactions: modeling aerosol formation, optical properties and impacts over the central Amazon Basin
}

Janaína P. Nascimento ${ }^{1}$, Megan M. Bela ${ }^{5,6}$, Bruno Meller ${ }^{2}$, Alessandro L. Banducci ${ }^{8}$, Luciana V. Rizzo ${ }^{7}$, Angel Liduvino Vara-Vela ${ }^{4}$, Henrique M. J. Barbosa ${ }^{2}$, Helber Gomes ${ }^{9,10}$, Sameh A. A. Rafee ${ }^{3}$, Marco A. Franco ${ }^{2}$, Samara Carbone ${ }^{11,2}$, Glauber G. Cirino ${ }^{12}$, Rodrigo A. F. Souza ${ }^{1}$, Stuart A. McKeen ${ }^{5,6}$, and Paulo Artaxo ${ }^{2}$

${ }^{1}$ Post-graduate Program in Climate and Environment (CLIAMB), National Institute for Amazonian Research and Amazonas State University, Manaus, AM, Brazil

${ }^{2}$ Institute of Physics, University of Sao Paulo, Sao Paulo, SP, Brazil

${ }^{3}$ Department of Atmospheric Sciences, Institute of Astronomy, Geophysics and Atmospheric Sciences, University of São Paulo, SP, Brazil

${ }^{4}$ Center for Weather Forecasting and Climate Studies, National Institute for Space Research, Cachoeira Paulista, Sao Paulo, SP, Brazil

${ }^{5}$ Cooperative Institute for Research in Environmental Sciences, University of Colorado, Boulder, CO, USA

${ }^{6}$ NOAA Earth System Research Laboratory, Boulder, CO, USA

${ }^{7}$ Department of Environmental Sciences, Institute of Environmental, Chemical and Pharmaceutics Sciences, Federal University of Sao Paulo, Sao Paulo, SP, Brazil

${ }^{8}$ Department of Physics, Colorado State University, Fort Collins, CO, USA

${ }^{9}$ Institute of Atmospheric Sciences, Federal University of Alagoas, Maceió, AL, Brazil

${ }^{10}$ Department of Meteorology, Federal University of Campina Grande, Campina Grande, Brazil, PB, Brazil

${ }^{11}$ Federal University of Uberlândia, Uberlândia, MG, Brazil

${ }^{12}$ Department of Meteorology, Geosciences Institute, Federal University of Pará, PA, Brazil

Correspondence: J. M. P. Nascimento (janaina@if.usp.br)

\begin{abstract}
.
The Green Ocean Amazon experiment - GoAmazon2014/5 explored the interactions between natural biogenic forest emissions from Central Amazonia and urban air pollution from Manaus. Previous GoAmazon2014/5 studies showed that nitrogen oxides $\left(\mathrm{NO}_{x}=\mathrm{NO}+\mathrm{NO}_{2}\right)$ and sulfur oxides $\left(\mathrm{SO}_{x}\right)$ emissions from Manaus strongly interact with biogenic volatile organic compounds (BVOCs), affecting secondary organic aerosol (SOA) formation. In previous studies, ground based and aircraft measurements provided evidence of SOA formation and strong changes in aerosol composition and properties. Aerosol optical properties also evolve, and their impacts on the Amazonian ecosystem can be significant. As particles age, some processes such as SOA production, black carbon (BC) deposition, particle growth, and the BC lensing effect change the aerosol optical properties, affecting the solar radiation flux at the surface. This study analyzes data and models SOA formation using the Weather Research and Forecasting with Chemistry (WRF-Chem) model to assess the spatial variability of aerosol optical properties as the Manaus plumes interact with the natural atmosphere. The following aerosol optical properties are investigated: single scattering albedo (SSA), asymmetry parameter $\left(\mathrm{g}_{a e r}\right)$, absorption Ångström exponent (AAE), and scattering Ångström exponent
\end{abstract}


(SAE). These simulations were validated using ground based measurements at three experimental sites: Amazon Tall Tower Observatory - ATTO (T0a), downtown Manaus (T1), Tiwa Hotel (T2) and Manacapuru (T3), as well as the G1 aircraft flights. WRF-Chem simulations were performed over seven days during March 2014. Results show a mean biogenic SOA (BSOA) mass enrichment of 512\% at the T1 site, $450 \%$ in regions downwind of Manaus such as the T3 site and $850 \%$ in areas north of the T3 site in simulations with anthropogenic emissions. The SOA formation is rather fast, with about $80 \%$ of the SOA mass produced in 3-4 hours. Comparing the plume from simulations with and without anthropogenic emissions, SSA shows a downwind reduction of approximately $10 \%, 11 \%$ and $6 \%$ at the T1, T2 and T3 sites, respectively. Other regions, such as those further downwind of the T3 site, are also affected. $\mathrm{G}_{a e r}$ values increased from 0.62 to 0.74 at the T1 site and from 0.67 to 0.72 at the T3 site when anthropogenic emissions are active. During the Manaus plume aging process, a plume tracking analysis shows an increase in SSA from 0.91 close to Manaus to $0.98160 \mathrm{~km}$ downwind of Manaus as a result of SOA production and BC deposition.

\section{Introduction}

Aerosol particles are present in the atmosphere in highly variable types and concentrations, which contribute differently to climate forcing, cloud formation and development, as well as ecosystem impacts. Particles may have a cooling or heating effect on the atmosphere, and their climatic roles are defined by their interactions with solar and terrestrial radiation fluxes, which strongly depend on their optical properties (extinction coefficient, SSA, $\mathrm{g}_{a e r}$, etc.). Radiation attenuation by atmospheric constituents is described by the radiative transfer equation, which requires information on the intensive and extensive optical properties of particulates and gases (Boucher, 2015). The aerosol's effect on radiation can be direct, semi-direct, or indirect. Direct effects are related to scattering and absorption of solar radiation by aerosol particles. These effects tend to dominate under clear sky conditions. Indirect effects involve the aerosol influence on cloud formation and development through cloud droplet activation via cloud condensation nuclei (CCN) (Haywood and Boucher, 2000).

Recent studies in Amazonia that integrated data from ground-based sensors (e.g., Martin et al., 2016; Rizzo et al., 2013; Andreae et al., 2015; Artaxo et al., 2013) with regional numerical simulations (e.g., Rafee et al., 2017; Shrivastava et al., 2019; Medeiros et al., 2017) advanced our understanding of the interactions in Amazonia background aerosol urban anthropogenic emissions. However, none of these studies have quantified the impact of atmospheric aerosols on the Amazonian radiative forcing.

A previous study conducted over the Amazonian region during the GoAmazon2014/5 experiment found strong SOA production, with an enhancement of BSOA formation in both the Manaus plume and its outflow by a factor of 100-400\% on average during the afternoon of March 13, 2014 (Shrivastava et al., 2019). In Southeast Manaus, de Sá et al. (2018) showed an increase in SOA ranging from $25 \%$ to $200 \%$ under polluted conditions compared to background conditions, including contributions from both primary and secondary particulate matter (PM). All of these studies are related to an idea suggested in Palm et al. (2018), that anthropogenic emissions play a significant role in SOA production. Cirino et al. (2018) indicate that 
transport from Manaus to downwind sites (T2 and T3). Conversely, the same increase was not observed during wet season. The Manaus anthropogenic emissions are rather constant over the year, representing the major influence on the anthropogenic organic aerosol source and contributing to the OA increase downwind of Manaus (de Sá et al., 2018; Shrivastava et al., 2019; Martin et al., 2010).

A possible strategy to improve estimates of the urban plume impact on optical properties downwind of Manaus is to create modeling regional scenarios with and without anthropogenic emissions, and comparing them to analyze how the emissions affect aerosol properties. Other studies have used sensitivity scenarios to understand how aerosol optical properties and secondary formation can be affected by events such as biomass burning (Vara-Vela et al., 2018) or urban pollution (Shrivastava et al., 2019). Many studies have focused on improving the understanding of an urban plume's impact on aerosol optical properties by comparing measurements during background conditions with periods affected by the pollution plume (Palacios et al., 2020; de Sá et al., 2019; Brito et al., 2014; Rizzo et al., 2013, 2011). However, little work has been done to analyze the atmospheric chemistry in the regions typically within the plume but without the plume's effects. This is particularly critical during the wet season, when aerosol levels associated with biomass burning are low and biogenic aerosols become more sensitive to external disturbance. Numerical simulations with high-resolution regional models such as the Weather Research and Forecasting Model with Chemistry (WRF-Chem; Grell et al. (2005)) are necessary for this strategy to quantify the effects of urban areas on aerosol levels and ultimately on the ecosystem, especially in regions that lack ground based observations.

Different aerosol optical properties have been used to study aerosol impacts on ecosystems and the radiation balance, such as SSA (e.g., Dubovik and King, 2000; Lim et al., 2014; Russell et al., 2010; Rizzo et al., 2013), SAE and AAE (e.g., Romano et al., 2019; Palacios et al., 2020), and $\mathrm{g}_{a e r}$ (Korras-Carraca et al., 2015). The significant impacts of Manaus urban emissions on the characteristics of the aerosol population (size distribution, quantity, chemical and physical composition) in regions downwind of Manaus have been described by Rizzo et al. (2013). However, there are no results considering simulation scenarios when the Manaus pollution plume component is turned on and off.

The objective of this work is to model secondary aerosol formation in Central Amazonia, comparing modeled scenarios with and without anthropogenic emissions, examining the interactions between natural biogenic emissions urban air pollution from Manaus and investigating their impact on aerosol optical properties. We have extensively validated the model predictions with ground-based measurements, and estimate how the optical properties may be affected by the plume aging process (see Fig. 1a). This is the first study to our knowledge that focuses on aerosol optical properties such as SSA, $\mathrm{g}_{a e r}$, and absorption and scattering coefficients over a geographically extended area over Central Amazonia, using numerical simulations and ground based data.

\section{Model Description, Emissions and Observations}

\subsection{Study Region and Methodology}

The Amazonian region has an annual mean temperature of around $26^{\circ} \mathrm{C}$ due the intense solar radiation reaching the surface (Nobre et al., 2009), with an annual average precipitation of 2,300 $\mathrm{mm}_{\text {year }}{ }^{-1}$ (Fisch et al., 1998). In the wet season (between 

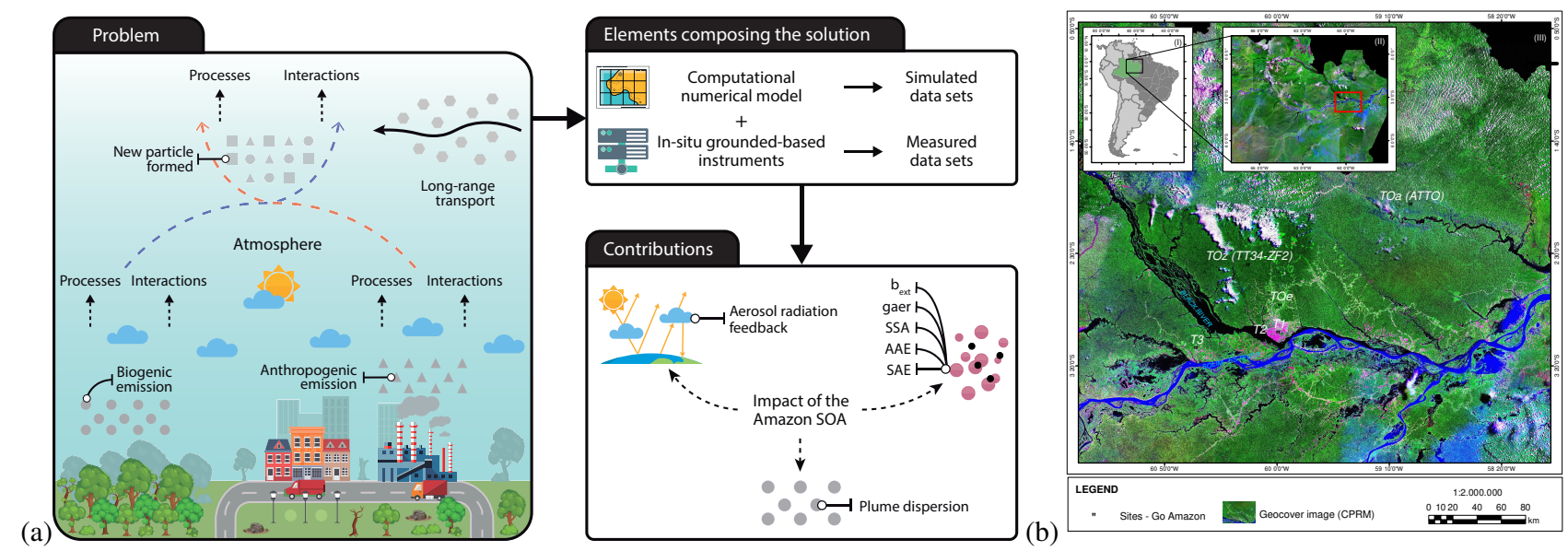

Figure 1. (a) Problem: The atmosphere with different pollution and natural sources and the interactions between them. Elements composing the solution: Computational numerical model and observational data sets. Contributions: Understanding the impact of the Manaus air pollution plume on aerosol optical property variability over the Amazon rainforest during the GoAmazon2014/5 experiment. (b) Sampling stations TT34-ZF2 (T0z) (ca. 60 km northwest) and ATTO (T0a) (ca. 150 km northeast), are both upwind of Manaus; Downtown Manaus (T1), Tiwa Hotel (T2) (ca. 8 km direction) and Manacapuru (T3) (ca. $70 \mathrm{~km}$ direction), are all downwind of Manaus. (I) South America and Brazil map. (II) Amazon region, the red rectangle indicates the area where the GoAmazon2014/5 experiment meteorology stations were located and the region used for the WRF-Chem simulations.

January and May), with the Inter-tropical Convergence Zone (ITCZ) extending south over Manaus, it is possible to find one of the lowest particle number concentrations over a continental area in the world (Andreae et al., 2015; Artaxo et al., 1994; Martin et al., 2016). In the wet season, the very high precipitation rate makes it virtually impossible for fires to occur, so the atmosphere is dominated by biogenic emissions, with a episodic component of Sahara desert dust and biomass burning emissions transported from Africa (Artaxo et al., 1990, 1993, 2013; Pöhlker et al., 2018, 2019)

Manaus is a city located in central Amazonia at latitude $3^{\circ} 06^{\prime} 07^{\prime \prime}$ and longitude $60^{\circ} 01^{\prime} 30^{\prime \prime}$. It currently has a population of about 1.8 million and an urban area of $377 \mathrm{~km}^{2}$. For this study we focus on a region centered on Manaus extending from latitudes $-5.3^{\circ} \mathrm{S}$ to $-0.76^{\circ} \mathrm{S}$ and longitudes $-63.07^{\circ} \mathrm{W}$ to $-56.90^{\circ} \mathrm{W}$ (see Fig. 1b). This $600 \mathrm{~km}$ by $450 \mathrm{~km}$ approximately rectangular area comprises the urban area of Manaus, its satellite cities and the surrounding Amazonian forests.

Our WRF-Chem simulation was performed over seven days between 7 and 14 March 2014. This period is part of the wet season in the region (Fisch et al., 1998; Martin et al., 2017). The first day were used as a spin-up period, as such they are discarded from any analysis. Corrections based on the methodology used in Cosgrove et al. (2003) were applied to the simulated temperature values aiming for better agreement between the topography height represented by the model and the one from the GoAmazon2014/5 experiment site.

The choice of the simulated days was made based upon ground-based data availability, which is necessary to evaluate the performance of the model, and the suggestions of Shilling et al. (2018), Shrivastava et al. (2019) and Martin et al. (2017) which 

Amazon tropical forest. Our investigation focuses on a detailed analysis of March 13, 2014, because on that day the plume reached regions downwind of Manaus such as the T2 and T3 sites. During this period mostly sunny skies were observed with little or no precipitation and the interference from biomass burning and cloud processing was negligible. We track the simulated Manaus plume as it ages in order to investigate the evolution of optical properties. Different analyses of atmospheric variables with and without anthropogenic emissions were used to characterize changes in aerosol properties downwind of Manaus due to anthropogenic activity.

To track the plume as it ages, its approximate location and extent over time were determined using the Hybrid Single-Particle Lagrangian Integrated Trajectory (HYSPLIT) model (Draxler, 2007; Stein et al., 2007). Forward trajectories were calculated starting from 8 points at 200 masl in a circle of radius $0.03^{\circ}(\sim 3.4 \mathrm{~km})$ centered on the plume's initial location at 6:00 LT. Winds and other forcing meteorological fields were taken from our WRF-Chem simulation. Average gas and aerosol concentrations and optical properties were calculated in the volume defined by the maximum and minimum latitude and longitude of the 8 points, and altitude range from 100 to $500 \mathrm{~m}$. The averaging region is shown in Figure S12 in the SI, and the altitude of the plume is shown in Figure S14 and S15 in the SI. $\Delta$ CO was determined by taking the difference in carbon monoxide (CO) between simulations with anthropogenic emissions turned on and off in the simulated region selected by HYSPLIT. The tracking plume approach was used to track the plume in other days (10 to 14 March 2014) in order to investigate the change in SOA formation due to different $\mathrm{NO}_{x}$ concentrations. The days other than the $13^{\text {th }}$ were not exemplary days for observing the evolution of the Manaus plume due to meteorological factors such as precipitation. Additionally, the plume did not appear until 8 LT. As such, our analysis focuses on March 13, 2014.

\subsection{WRF-Chem Model Description and Setup}

The study region was simulated with the WRF-Chem regional model, version 3.9.1.1 (Grell et al., 2005; Fast et al., 2006) using full coupled and online meteorology, gas-phase chemistry and aerosol feedback. The model grid covered the study region with a horizontal grid spacing of $3 \mathrm{~km}$ and $\mathrm{nx}=200$ and ny $=150$ grid points. Vertically, hybrid sigma coordinates were used to split the atmosphere into 51 levels, the bottom 10 within the planetary boundary layer (PBL). Data from the Global Model Data Assimilation System (GDAS), with a horizontal grid spacing of $1^{\circ}$ and 26 vertical levels was used for the initial and boundary conditions of the meteorological variables. Chemistry initial and boundary conditions were provided in 3 hour increments at a horizontal resolution of about $40 \mathrm{~km} \mathrm{x} 40 \mathrm{~km}$ with 60 vertical levels from the surface up to $60 \mathrm{~km}$ by the European Centre for Medium-Range Weather Forecasts (ECMWF) operational model.

The physics, chemistry and emission options used in this study, as well as their corresponding references, are listed in Table 1. The most significant ones for this application are: the Rapid Radiative Transfer Model for General Circulation Model applications (RRTMG) scheme for longwave and shortwave radiation (Iacono et al., 2008); the Revised Mesoscale Model version 5 Monin-Obukhov scheme for surface layer (Jiménez et al., 2012); the Unified Noah land-surface model for land surface (Tewari et al., 2004); land use provided by the Moderate-resolution Imaging Spectroradiometer (MODIS) with spatial resolution and 20 different classes; the Yonsei University scheme for the boundary layer (Hong et al., 2006); the Morrison 
2-moment scheme for microphysics (Morrison et al., 2009) and the Grell-Freitas ensemble convective scheme (Grell et al., 2014).

We simulated atmospheric chemistry using the Regional Atmospheric Chemistry Model (RACM) coupled with the Modal Aerosol Dynamics model for Europe/Volatility Basis Set (MADE/VBS) aerosol scheme, which treats the organic gas/particle partitioning within a spectrum of volatilities (Ahmadov et al., 2012). The RACM includes 21 stable inorganic species (4 being intermediates), 32 stable organic species (4 of which are primarily of biogenic origin). In addition, RACM includes 237 chemical reactions (23 of which are photolysis). MADE/VBS has an advanced SOA module based on VBS approach to simulate concentrations of the main organic and inorganic gas/particle partitions within a spectrum of volatilities using saturation vapor concentrations as surrogates for volatility. It also includes less complex aqueous reactions (sulfate - $\mathrm{SO}_{4}$ and nitrate - $\mathrm{NO}_{3}$ wet deposition) following CMAQ methodology (Sarwar et al., 2011). MADE/VBS has a four-bin VBS with the SOA precursor yields based on previous smog chamber studies under both high- and low- $\mathrm{NO}_{X}$ conditions (Murphy and Pandis, 2009; Ahmadov et al., 2012). Yields are for four volatility bins with saturation concentrations of 1, 10, 100, and 1000 $\mu \mathrm{g} \mathrm{m}^{-3}$, and represent aerosol modes - Aitken $(<0.1 \mu \mathrm{m})$, accumulation $(0.1-1 \mu \mathrm{m})$ and coarse $(>1 \mu \mathrm{m})$.

We used the approach by Fast et al. (2006), according to Mie theory (Mie, 1908), in order to account for aerosol radiative properties such as absorption and scattering coefficients, SSA and $\mathrm{g}_{a e r}$. These properties are then transferred to the RRTMG shortwave radiation scheme in order to calculate the corresponding radiative forcing. In addition, the feedback effects of clouds on aerosol size and composition via aqueous-phase chemistry (Sarwar et al., 2011) as well as wet scavenging processes (Easter et al., 2004) are considered.

Simulations were conducted in order to analyze how Manaus emissions affect SOA production and aerosol optical properties over the Amazon. We considered two scenarios: (i) Manaus on, which represents anthropogenic emissions and background emissions from initial and boundary conditions; (ii) Manaus off, which represents a background scenario, dominated by biogenic emissions, with anthropogenic contribution coming from the boundary conditions.

\subsubsection{Anthropogenic Emissions}

Anthropogenic emissions were calculated using the Rafee et al. (2017) inventory, which considers emissions of all classes of mobile (light-duty, heavy-duty vehicles and motorcycles) and stationary (thermal power plants (TPPs) and Refineries) sources. Both components were calculated according to emission factors estimates based on experiments conducted inside road traffic tunnels in São Paulo (Martins et al., 2006; Sánchez-Ccoyllo et al., 2009; Brito et al., 2013), providing the only vehicle emission factor measurements available in Brazil. Fine particle matter emission fractionation into size and chemical classes were based on studies developed for São Paulo (Ynoue and Andrade, 2004; Miranda and Andrade, 2005; Albuquerque et al., 2012).

\subsubsection{Biogenic Emissions}

Biogenic emissions were calculated online using the Model of Emissions of Gases and Aerosols from Nature (MEGAN) version 2 (Guenther et al., 2006). Based on driving variables such as ambient temperature, solar radiation, leaf area index, and 
Table 1. WRF-Chem simulations configuration used in this study

\begin{tabular}{|c|c|}
\hline & Simulation time: $2014-3-800$ UTC to $2014-3-1500$ UTC \\
\hline Attributes & Model configurations \\
\hline Grid resolution & $\mathrm{dx}=\mathrm{dy}=3 \mathrm{~km}$ \\
\hline $\mathrm{nx}, \mathrm{ny}, \mathrm{nz}$ & $200 \times 150 \times 51$ \\
\hline Time step & $10 \mathrm{~s}$ \\
\hline Vertical resolution & 51 layers from surface to $100 \mathrm{hPa}(\sim 16 \mathrm{~km})$ \\
\hline \multicolumn{2}{|l|}{ Physical options } \\
\hline Radiation & Long/shortwave RRTMG scheme (Iacono et al., 2008) \\
\hline Land surface & Unified Noah land-surface model (Tewari et al., 2004) \\
\hline Surface layer & Revised Mesoscale Model version 5 Monin-Obukhov scheme (Jiménez et al., 2012) \\
\hline Boundary layer & Yonsei University scheme (Hong et al., 2006) \\
\hline Cloud microphysics & Morrison 2-moment (Morrison et al., 2009) \\
\hline Cumulus clouds & Grell-Freitas ensemble scheme (Grell et al., 2014) \\
\hline \multicolumn{2}{|l|}{ Chemical options } \\
\hline Gas-phase chemistry & Updated RACM version with chemical reactions for sesquiterpenes (Papiez et al., 2009) \\
\hline Aerosol module & MADE/VBS (Ahmadov et al., 2012) \\
\hline Aerosol activation & Abdul-Razzak and Ghan scheme (Abdul-Razzak and Ghan, 2000) \\
\hline Photolysis & TUV (Madronich, 1987) \\
\hline Meteorological IC and BC & National Center for Environmental Prediction Final Analysis (NCEP-FNL) \\
\hline Chemical IC and BC & European Centre for Medium-Range Weather Forecasts (ECMWF) \\
\hline \multicolumn{2}{|l|}{ Emissions sources } \\
\hline Biogenic & Model of Emissions of Gases and Aerosols from Nature (Guenther et al., 2006) \\
\hline Anthropogenic & Emission inventory developed by Rafee et al. (2017) \\
\hline
\end{tabular}

plant functional types, this model estimates the net terrestrial biosphere emission rates for different trace gases and aerosols with a global coverage of $\approx 1 \mathrm{~km}^{2}$ spatial resolution.

\subsection{Observed Data}

We used in situ real-time measurement at several GoAmazon2014/5 surface sites (see Fig. 1b). The particle scattering coefficient $\left(\sigma_{s}\right)$ was measured using a 3-wavelength Nephelometer (450, 550 and 700nm; TSI 3563 Integrating Nephelometer). Particle absorption coefficient $\left(\sigma_{a}\right)$ was measured at the T3 site with a 7-wavelength Magee AE31 Aethalometer that operates at $\lambda=370,430,470,520,565,700$ and $880 \mathrm{~nm}$ and was subjected to the correction scheme outlined by Rizzo et al. (2011). The observed $\left(\sigma_{a}\right)$ values have been interpolated to the nephelometer's wavelengths to allow a proper comparison and calculation of the intensive parameters, such as SSA. The BC mass concentration at the T3 site was estimated using AE31 measurements of 
the absorption coefficient at $880 \mathrm{~nm}$ and a mass absorption cross section (MAC) section of $7.77 \mathrm{~m}^{2} \mathrm{~g}^{-1}$ (Drinovec et al., 2015). At ATTO, the BC concentration was measured using a Thermo Environment MAAP 5012 (Thermo) using a $\sigma_{a}$ at $637 \mathrm{~nm}$ and a MAC of $6.6 \mathrm{~m}^{2} \mathrm{~g}^{-1}$, the absorption data was corrected according to Müller et al. (2011). Organic and inorganic submicron aerosol mass loadings were measured with a Time of Flight Aerosol Mass Spectrometer (ToF-AMS) (de Sá et al., 2018). Mixing rations of ozone $\left(\mathrm{O}_{3}\right)$ and $\mathrm{CO}$ were obtained with a $49 \mathrm{i} \mathrm{O}_{3}$ Analyzer (Thermo Environment) and a $\mathrm{N}_{2} \mathrm{O} / \mathrm{CO}$ Analyzer (Los Gatos Research - LGR). Meteorological observations was measured by a Vaisala WXT520. Observed data was averaged at 1-hour intervals for comparison it with the WRF. Standard temperature and pressure (STP) corrections were also applied to all measurements. We also used aircraft measurements of $\sigma_{a}$ from the DoE Gulfstream 1 (G-1), as part of the GoAmazon2014/5 experiment (Shilling et al., 2018; Martin et al., 2016), measured using a 3-wavelength (461, 522 and 648nm) Particle/Soot Absorption Photometer (PSAP) from Radiance Research.

\subsubsection{GoAmazon2014/5 Experiment}

The Observations and Modeling of the Green Ocean Amazon experiment GoAmazon2014/5 was designed to understand how aerosol and cloud life cycles are influenced by the pollutant outflow from Manaus into the tropical rain forest (Martin et al., 2016). The experiment used a set of detailed aerosol, trace gas and cloud measurements at six different sites (see Fig. 1b) in order to better understand the atmospheric processes caused by the interaction between urban pollution emissions with volatile organic compounds (VOCs) emitted from the forest, and the environmental impacts on the natural microphysical properties of clouds and aerosols, such as optical properties and particle size distributions (Gu et al., 2017; Fraund et al., 2017).

\section{Results and Discussion}

\subsection{Meteorological Analysis}

To study the impact that Manaus pollution plume has on SOA production aerosol optical properties in the area downwind of Manaus, meteorological conditions, especially temperature, humidity and PBL height, must be properly characterized and represented in the WRF-Chem model. Comparisons at the T3 site between observed and simulated hourly variations of accumulated total precipitation, $2 \mathrm{~m}$ temperature, $2 \mathrm{~m}$ relative humidity, $10 \mathrm{~m}$ wind speed, and PBL height (SI Figs. S1 and S2) show that the model performs well in terms of diurnal representation and trends. Simulated temperature and humidity tend to be underestimated (mean bias $(\mathrm{MB})=-0.5$ and -1.6 , respectively), with a short delay between peak observed (11:00 LT) and simulated (15:00 LT) values. The simulation has difficulties in obtaining the observed maximum temperature (see SI Fig. S1a). According to statistical indices (SI Table 1), the correlation coefficient $(r)$ and Root Mean Square Error (RMSE) show consistent results for relative humidity $(r=0.7$ and RMSE $=1.8)$, temperature $(r=0.8$ and RMSE $=0.4)$ and wind speed $(r=0.7$ and RMSE $=0.2$ ). The relative humidity profile agrees well with ground base measurements, but the simulated values exhibit the diurnal minimum with a 3 hour delay. Individual calculations of performance statistics are presented in Supplementary Table S1. 
The Central Amazon region has unique topographic characteristics including the Amazon, Negro and Solimões rivers (Marinho et al., 2020), resulting in meteorological systems such as local circulations and the so called friagem events, which occur when a frontal system reaches the Central Amazon basin (Marengo et al., 1997; Lu et al., 2005), that have important influences on the local and mesoscale circulations (dos Santos et al., 2014; Pereira Oliveira and Fitzjarrald, 1993; Silva Dias et al., 2004). That may affect the wind direction and air subsidence patterns. Figure S3 in the SI compares the simulated vertical wind component during night time at the T3 site. In the early morning hours (05 - 11 LT), downdraft movement is not sufficient at the T3 site to inhibit pollutant dispersion. However, during the night time (20 - 22 LT), the simulation captured an organic aerosol concentration peak (see Fig. 5a) consistent with the presence of downdraft movement and a temperature inversion at low levels (see SI Fig. S4) observed at the T3 site.

\subsubsection{Background Conditions}

Generally, global and regional models contain uncertainties associated with the wet/dry deposition scheme (Wang et al., 2015). For example, the $\mathrm{BC}$ residence time in the atmosphere is typically larger in global models than in the real atmosphere. During the wet season, the T0a site is upwind of Manaus and so has low anthropogenic influence. However, the T0a site receives sporadic air masses loaded with marine aerosol transported from the Atlantic Ocean, and dust outflows from the Sahara desert, in general together with smoke from fires in West Africa (Ben-Ami et al., 2010; Andreae et al., 2012, 2015; Rizzolo et al., 2017; Pöhlker et al., 2018). Those air masses transported from Africa during the wet season occur when the ITCZ is shifted to the south of the central Amazonian Basin, allowing air masses from the Northern Hemisphere to reach the central portion of the Basin.

Looking at Figure 2, it is possible to observe that on March $201410^{\text {th }}$ and $11^{\text {th }}$, BC (both simulated and observed) were above expected levels $\left(0.1 \mu \mathrm{gm}^{-3}\right)$, consistent with coherent BC long range transport from west Africa (Moran-Zuloaga et al., 2018). During the $10^{\text {th }}$ and the $11^{\text {th }}$, the simulation also follows the BC variability shown in the observed data. The simulation appears to do a reasonable job of representing the BC transport from West Africa. Figure 2 shows that the global model BC concentrations are also representative of the hours with the largest values during the $10^{\text {th }}$ and $11^{t h}$.

March $13^{\text {th }}$ shows good agreement between simulated and observed data at T3. We can assess the simulations ability to represent Amazonian background conditions comparing observed and simulated data from the region with very little anthropogenic influence during the wet season, as is the case for the T0a site. Given that, the simulation calculates background BC and $\mathrm{O}_{3}$ with RMSE and MB consistent with observations, it is possible to determine the aerosol enrichment at the T3 site due to the Manaus plume. The background BC in the Amazon near the T0a site is representative of almost pristine continental regions. The average observed $\mathrm{BC}$ values are influenced by biogenic aerosol absorption, the global $\mathrm{BC}$ background as well as by $\mathrm{BC}$ that is long range transported from Saharan dust and African biomass burning. The $\mathrm{BC}$ transported from Africa is episodic, depending on the ITCZ positioning, as well as the air mass trajectories from Africa to the Central Amazon. As we have several years of BC background measurements at the ATTO tower, it is possible to separate African episodic events from the rather constant regional $\mathrm{BC}$ concentrations that are relevant to compare with the modeled values under no anthropogenic influences (Artaxo et al., 2020). 


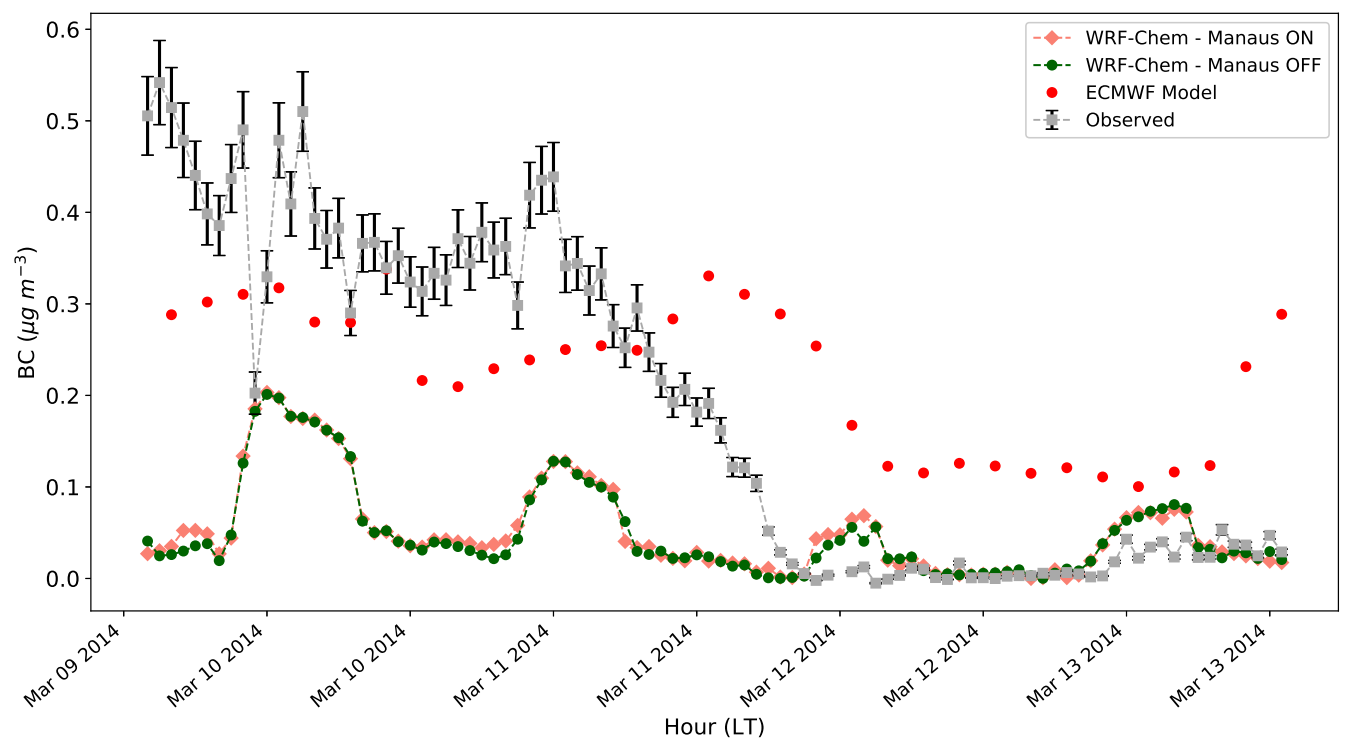

Figure 2. Observed and simulated surface BC concentration from March 10 to March 13, 2014 at the T0a site. Standard deviation bars are shown for each set of measurements. Events due to long range transport of Saharan dust and biomass burning emissions from West Africa are visible on the $10^{\text {th }}$ and $11^{\text {th }}$ (Moran-Zuloaga et al., 2018). The Manaus OFF (green) and Manaus ON (orange) simulations show $\mathrm{BC}$ concentrations simulated at a height of ca. $8 \mathrm{~m}$ above the surface. During BC transport event days, we can see that the simulation had the largest peaks, trying to represent the black carbon transport coming from west Africa. The global model contribution (red dots) also represents BC transport event days, showing the largest values during days $10^{\text {th }}$ and $11^{\text {th }}$.

\subsection{Chemical Analyses}

To better understand the impact of the Manaus urban plume on SOA formation and mixing ratios at the T3 site during March 13, 2014 we must be able to separate time periods representing clean and polluted episodes, and compare observed and simulated values. Previous studies have developed methods to separate these episodes in the Amazon region (Palm et al., 2017; de Sá et al., 2018; Cirino et al., 2018).

In our analysis, with observed data from the GoAmazon2014/5 experiment (T3 site), adjusted cluster centroids were used to analyze clean and polluted conditions, during two months in the wet season (February and March 2014). We define three different clusters (i) low pollution (Low Pol), (ii) middle pollution (Mid Pol) and (iii) high pollution (High Pol) (see Table 2). We chose three different clusters at the $T 3$ site because the pollution conditions arriving are heterogeneous. Our cluster analysis (see Fig. 3) was made with a fuzzy c-means (FCM) clustering algorithm (Bezdek et al., 1984). On March 13, 2014, our analysis shows a day with mostly polluted conditions (at 10-17 LT). Previous work (Palm et al., 2017; de Sá et al., 2018) reported the same polluted conditions during this day. 

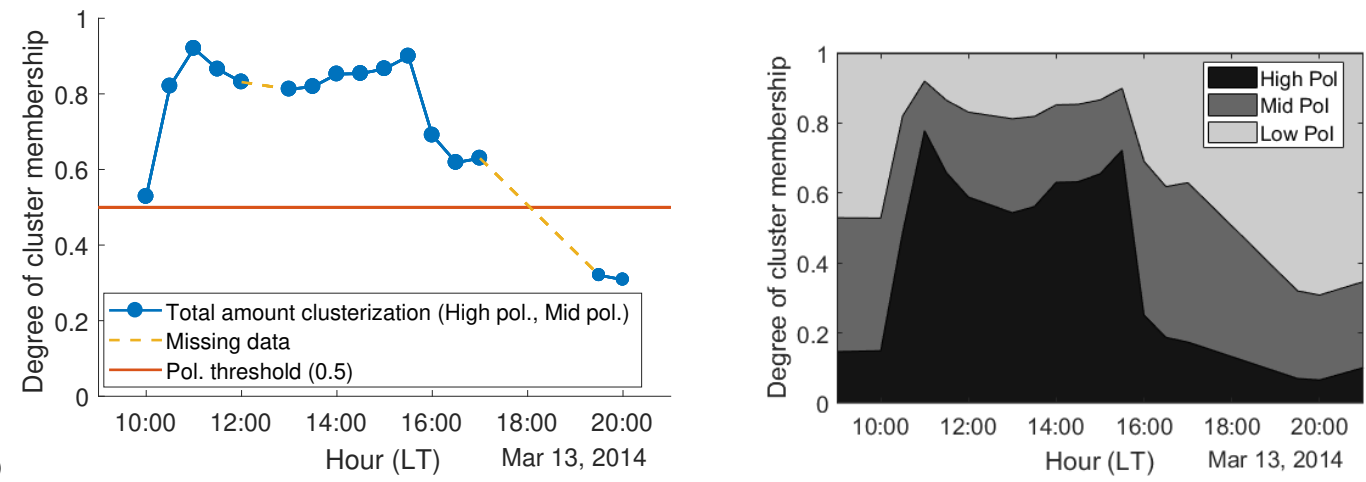

(b)

Figure 3. Results of FCM clusters analysis during March 13, 2014 from 10:00 to 20:00 LT. (a) Total clusterization considering polluted conditions with degree of cluster membership > 0.5. (b) Degree of membership in each of the three clusters. The sum of degrees of membership across all clusters is unity. Background conditions are abbreviated as "Low Pol", intermediate conditions as "Mid Pol" and polluted conditions are abbreviated as "High Pol".

Table 2. Cluster centroids used to analyze clean and polluted conditions.

\begin{tabular}{lllllll}
\hline \hline \multicolumn{7}{c}{ Cluster Centroids for March Day 13th } \\
\hline \hline Clusters & $\mathrm{PM}_{2.5}$ conc. num. $\left(\mathrm{cm}^{-3}\right)$ & $\mathrm{CO}(\mathrm{ppbv})$ & $\mathrm{O}_{3}(\mathrm{ppbv})$ & $\mathrm{BC}\left(\mathrm{ng} / \mathrm{m}^{-3}\right)$ & $\mathrm{NO}_{y}(\mathrm{ppbv})$ & $\mathrm{SO}_{4}\left(\mu \mathrm{g} / \mathrm{m}^{-3}\right)$ \\
Low Pol. & 1304 & 117 & 11 & 43 & 0.71 & 0.16 \\
Mid. Pol. & 2566 & 123 & 15 & 99 & 1.39 & 0.29 \\
High Pol. & 5329 & 124 & 26 & 144 & 2.28 & 0.43 \\
\hline
\end{tabular}

Because the concentration values of High Pol and Mid Pol, episodes are substantially larger than those at Low Pol we distinguish time periods representing clean episodes as Low Pol and polluted episodes as High Pol and Mid Pol. Quantitatively we separate clean from polluted episodes with the degree of cluster membership. When membership for Low Pol is $>0.5$, we consider this a clean episode. When the sum of Mid Pol and High Pol membership is $>0.5$ we consider this a polluted episode. Initially, we attempted clustering with only two clusters (one for clean and one for polluted episodes), but were unable to separate polluted from background conditions. In this case the nominally background cluster had high black carbon (BC) and $\mathrm{NO}_{y}$ concentrations.

Given the abundance of BVOCs in the Amazon region (Alves et al., 2016; Yáñez-Serrano et al., 2020), we expect $\mathrm{O}_{3}$ to be especially sensitive to changes in $\mathrm{NO}_{x}$ emission. This can be seen in Figure $4 \mathrm{a}$; 4e, which shows high $\mathrm{O}_{3}$ and low $\mathrm{NO}_{x}$ values downwind of Manaus. According to the WRF-Chem chemical mechanism, isoprene is rapidly oxidized by hydroxyl radicals $(\mathrm{OH})$ to form peroxy radicals $\left(\mathrm{HO}_{2}\right)$ in a few hours (Ahmadov et al., 2012). The $\mathrm{T} 1$ site has a low isoprene concentration, since as the Manaus plume passes through forest regions with high isoprene production, the high plume $\mathrm{NO}_{x}$ concentration oxidizes the isoprene. This can be seen in Figure 4, where the Manaus plume consumes the isoprene around the $\mathrm{T} 3$ site, producing $\mathrm{O}_{3}$ 
and $\mathrm{HO}_{2}$. Because the enhancement of $\mathrm{HO}_{2}$ radicals occurs downwind of Manaus (such as at the $\mathrm{T} 3$ site), the concentrations of $\mathrm{NO}_{x}$ are significantly lower (higher) than the values in Manaus (downwind in the forest), leading to a significant enhancement of $\mathrm{O}_{3}$ (ca. 8 - 30 pppv (Fig. 4a). Because $\mathrm{NO}_{x}$ and isoprene emissions vary in different regions, our results suggest that $\mathrm{NO}_{x}$ in southeastern Manaus (Rafee et al., 2017) has important impacts on the $\mathrm{O}_{3}$ concentration in the Manaus urban area. This is primarily due to the rapid reactions of radicals with $\mathrm{NO}_{x}$, which deplete the radicals.

The $\mathrm{O}_{3}$ values are highest during the day as VOC production peaks and solar radiation is available for the photo-chemical processes that produce $\mathrm{O}_{3}$ (Graham et al., 2003a, b; Chen et al., 2015; Schultz et al., 2017). The $\mathrm{O}_{3}$ enhancement 8 to $300 \mathrm{~km}$ downwind of Manaus suggests that the interaction between forest biogenic emissions and the pollution from Manaus could have an important impact on the chemical production of $\mathrm{O}_{3}$ (Fig. 4a). The interaction between anthropogenic and biogenic trace gases has strong regional characteristics, such the ones found near Manaus. They also depend on the distributions of BVOCs and anthropogenic $\mathrm{NO}_{x} . \mathrm{O}_{3}$ mixing ratios downwind of Manaus under the influence of anthropogenic pollution were also reported by Trebs et al. (2012) and were on average $31 \pm 14 \mathrm{ppbv}$, with peak values of $60 \mathrm{ppbv}$ at a distance of $19 \mathrm{~km}$ downwind of Manaus. Our simulations showed an $\mathrm{O}_{3}$ average of $30 \pm 11 \mathrm{ppbv}$ at the $\mathrm{T} 3$ site (70 km downwind of Manaus) with high peak values of $148 \mathrm{ppbv}$ in regions northwest of Manaus (Fig. 4a). Manaus pollution plume influence on $\mathrm{O}_{3}$ production is clearly observed in the surrounding area, predominantly to the west and northwest of Manaus.

In regions downwind of Manaus, the simulations showed $\mathrm{O}_{3}$ concentrations extending more than $300 \mathrm{~km}$ downwind. It is also interesting to note the lower $\mathrm{O}_{3}$ values around $\mathrm{T}$, which are represented in both observed (ca. 8 ppbv on average) and simulated (ca. $12 \mathrm{ppbv}$ on average) data (Fig. 4a). $\mathrm{O}_{3}$ with ca. 8 ppbv on average is uncommonly low for a metropolis of nearly 1.8 million people. The agreement between observed and simulated $\mathrm{O}_{3}$ values around $\mathrm{T} 1$ indicates that the chemistry there is being successfully reproduced by the simulation. Our explanation for this anomaly is that VOCs are abundant all around Manaus (Kuhn et al., 2010; Alves et al., 2016) and $\mathrm{HO}_{x}$ and $\mathrm{O}_{3}$ are low despite having high $\mathrm{NO}_{x}$ in a typically VOC limited regime. We hypothesize that in areas with very high $\mathrm{NO}_{x}$ emissions (averaging $129.02 \mathrm{ppbv}$ ), such as the power plant cluster surrounding $\mathrm{T} 1$ (Fig. 4e), radicals react quickly with $\mathrm{NO}_{x}\left(\mathrm{NO}_{x}+\mathrm{OH} \rightarrow \mathrm{HNO}_{3}\right.$ ). This depletes the $\mathrm{O}_{3}$, creating radicals, causing a decrease in $\mathrm{O}_{3}$ formation. Conversely, downwind of Manaus, the radicals last long enough to form $\mathrm{O}_{3}$ and we observe an increase in $\mathrm{O}_{3}$ formation, as well as an increase in $\mathrm{HO}_{2}$ radicals (Fig. 4c).

Our results imply that the high $\mathrm{NO}_{x}$ conditions within Manaus affect the $\mathrm{O}_{3}$ formation around Manaus, decreasing $\mathrm{O}_{3}$ production with in the city and providing a great enhancement downwind of Manaus (Fig. 4a). The wind direction is predominantly from the northeast, which allows the plume be transported to the T2 and T3 sites and allowing the pollution plume to have a great impact on the surrounding areas (Martin et al., 2017). Interestingly, our results show that when $\mathrm{O}_{3}$ concentrations change by a factor of between 2 and 4, oxidation and $\mathrm{NO}_{x}$ levels may be affected, and consequently, the rate and SOA production efficiency may be impacted, by decreasing the reacted BVOCs and SOA formation downwind of Manaus.

According to Figure 5a, the simulated organic $\mathrm{PM}_{2.5}$ at the $\mathrm{T} 3$ site has one of the highest values during the first hours of March 13, 2014 (2 to 4, LT), with the largest contribution coming from primary anthropogenic organic aerosol (POA). We suggest that the large contributions of $\mathrm{BC}$ and $\mathrm{CO}$ emissions, coming from Manaus (Fig. S7 in the SI) together with a prevailing northeast wind direction, are the most plausible explanations why simulated total organics present high values 
(a)

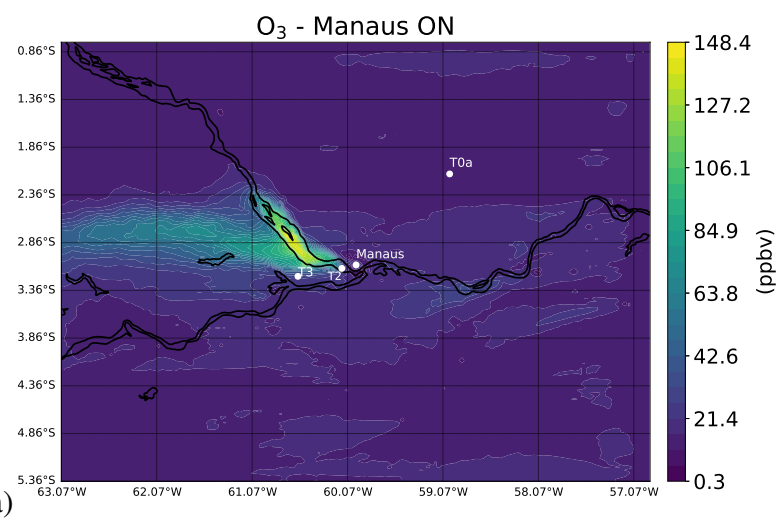

(c)

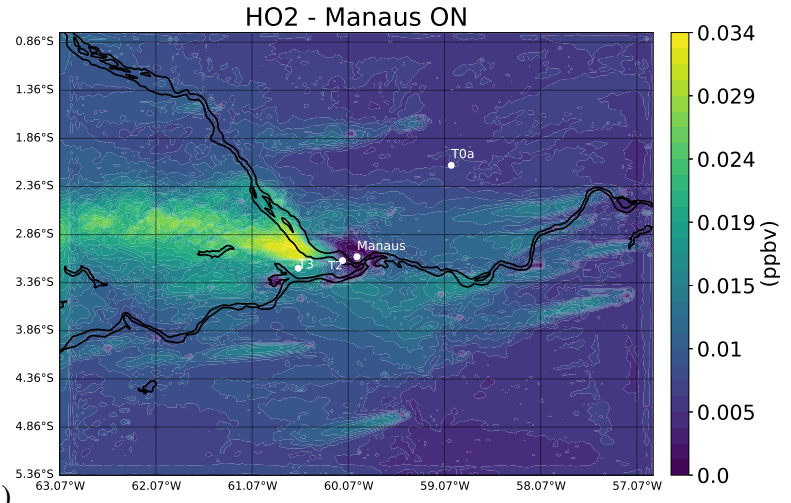

(e)

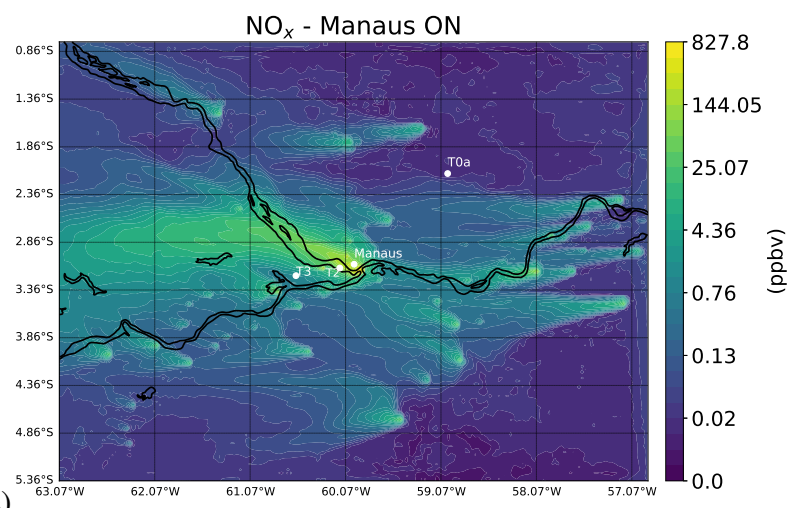

(b)

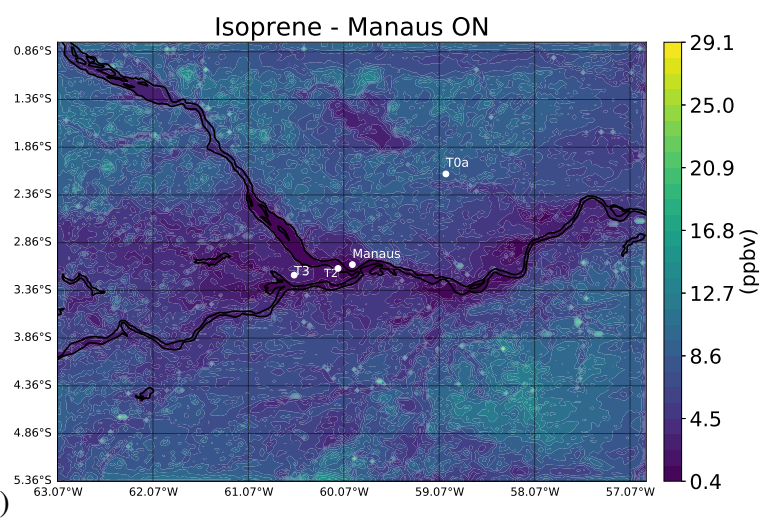

(d)
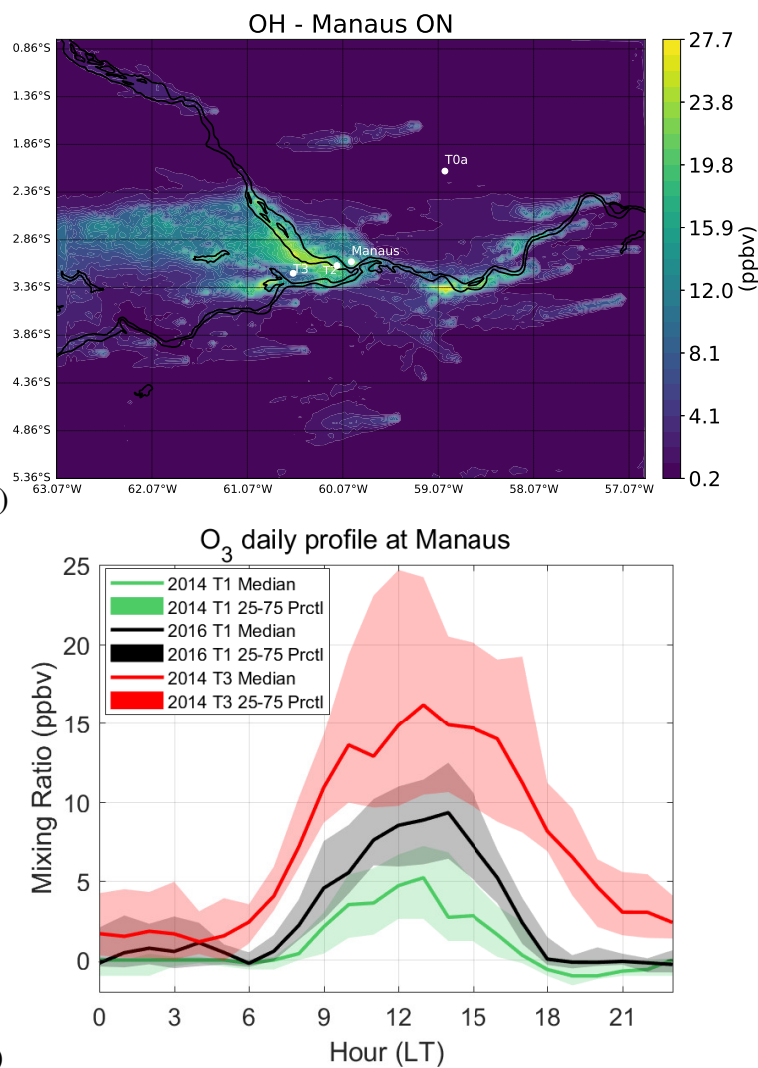

Figure 4. Temporal mean (06 to 15 LT March 13th) spatial distribution of simulated surface level concentrations of (a) $\mathrm{O}_{3}$, (b) Isoprene, (c) $\mathrm{HO}_{2}$, (d) $\mathrm{OH}$, (e) $\mathrm{NO}_{x}$ and (f) daily median $\mathrm{O}_{3}$ profile for the month of March (wet season) at T1 during 2014 (green line), 2016 (black line) and at the T3 site during 2014 (red line). The red, gray and green shaded areas show the $25_{t h}$ to $75_{t h}$ percentiles of the respective median line. 

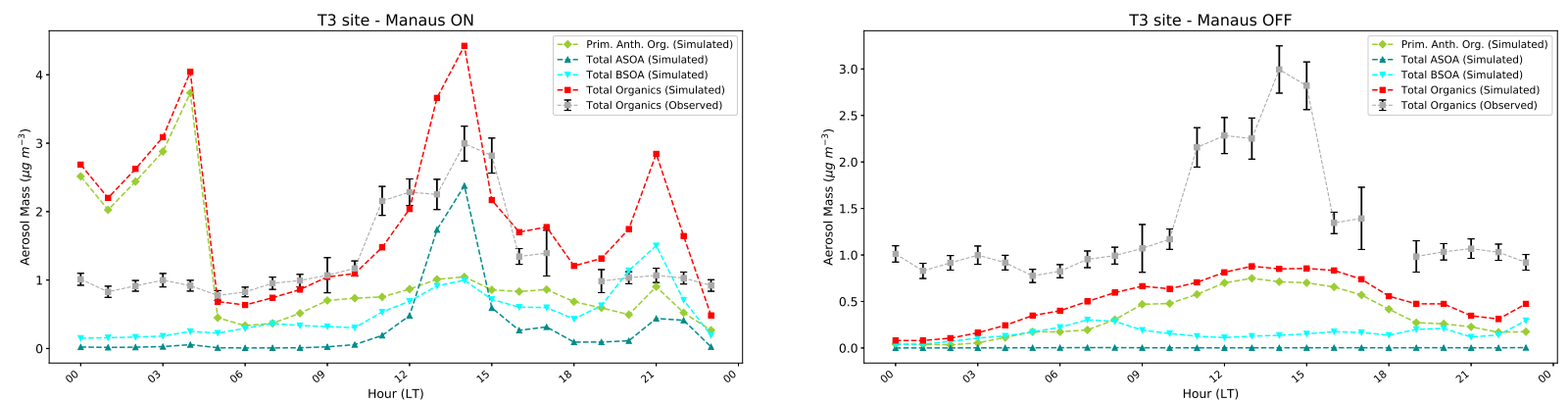

(a)

(c)

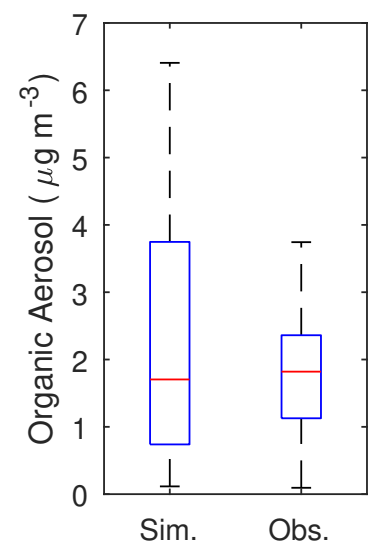

(b)

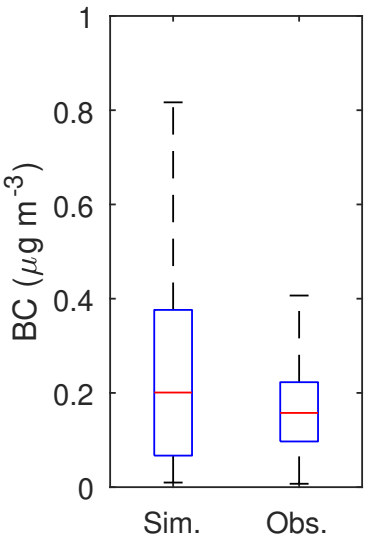

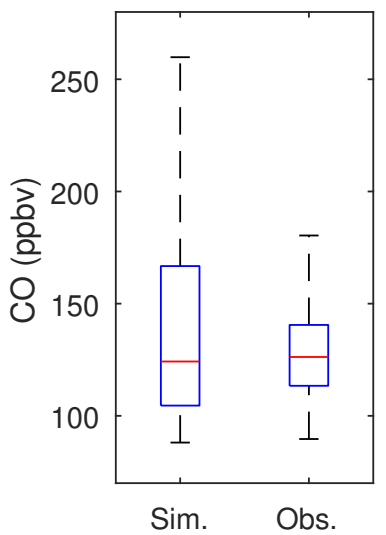

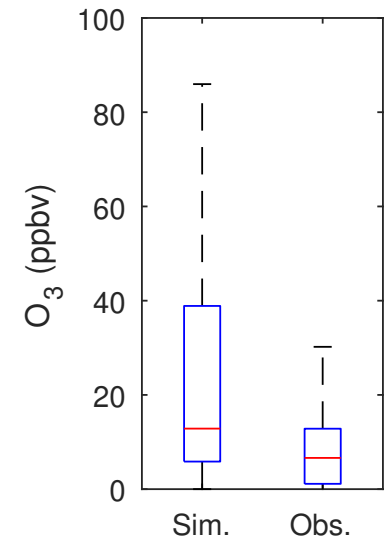

Figure 5. Times series and box plot comparison of measured and WRF-Chem-simulated surface level gases and aerosols at the T3 site. Contributions from simulated primary anthropogenic organic, BSOA and ASOA to total OA as simulated by WRF-Chem in the case (a) with and (b) without anthropogenic emissions on March 13, 2014 at the T3 site. (c) Comparison between observed and simulated surface level gases and aerosols. Box plot of simulated and observed organics, BC, $\mathrm{CO}$ and $\mathrm{O}_{3}$ from March 9 to 13, 2014 at the T3 site. Median values are shown in red lines and the blue box indicates data between the $25^{\text {th }}$ and $75^{\text {th }}$ percentiles.

during the first hours of the day with an high POA peak during the first hours of March 13, 2014 (2 to 4, LT). The BC and CO contributions can end up reaching the $\mathrm{T} 3$ site, increasing the POA amount. In addition, the simulated $\mathrm{BC}$ concentration also showed simultaneously high values during the first hours of March 13, 2014 (2 to 4, LT) (Fig. S5 in the SI).

Between 10 and 16 LT there is an increase in the total organic aerosol concentration, which was successfully reproduced by our simulation. This evolution of the organic aerosol concentration was expected on that day due to the Manaus plume arriving at the T3 site (Shilling et al., 2018). This increase is mostly due to a sharp increase in anthropogenic SOA (ASOA) peaking at 15 LT, as well as the BSOA and POA at the same time. The highest value $\left(4.4 \mu \mathrm{g} \mathrm{m}^{-3}\right)$ of simulated total organics occurred at 14 LT (Fig. 5a), and is comprised of mostly the SOA component, with increases in BSOA contributing $1.0 \mu \mathrm{g} \mathrm{m}^{-3}$ (22.6\%), ASOA $2.4 \mathrm{\mu g} \mathrm{m}^{-3}$ (53.9\%) and POA $1.04 \mu \mathrm{g} \mathrm{m}^{-3}$ (23.5\%). Conversely, when the simulation is run with anthropogenic emissions turned off, the total organic aerosol simulated at $14 \mathrm{LT}$ is $0.9 \mu \mathrm{g} \mathrm{m}^{-3}$, with BSOA contributing $0.14 \mu \mathrm{g} \mathrm{m}-3$ (16.3\%), ASOA 
$0.02 \mu \mathrm{g} \mathrm{m} \mathrm{m}^{-3}$ (2.3\%) and POA $0.7 \mu \mathrm{g} \mathrm{m} \mathrm{m}^{-3}$ (81.4\%). We attribute most of the difference in total organic aerosol between simulations with and without anthropogenic emissions to the ASOA amount, related the Manaus plume contributions. The same analysis, now considering the entire day of March 13th, shows a contribution coming mostly from POA of $26.4 \mu \mathrm{g} \mathrm{m}^{-3}$ (57.1\%), BSOA $12.4 \mu \mathrm{g} \mathrm{m}^{-3}$ (26.8\%) and ASOA $7.4 \mu \mathrm{g} \mathrm{m}^{-3}$ (16\%). Considering the immensely complex mixture of organic aerosol particle and gas phase, VOCs and other species in continuous evolution in the atmosphere, and the large number of chemical reactions with oxidant species such as $\mathrm{OH}$ (day-time) and $\mathrm{NO}_{3}$ (nighttime) (Kuhn et al., 2010), we emphasize that there may be a relationship between BSOA and ASOA simulated peaks (see Fig. 5a)) and the $\mathrm{O}_{3}$ peak at 15 LT (Fig. S6 in the SI), since those chemical reactions are associated with the production of tropospheric $\mathrm{O}_{3}$ and also oxygenated VOCs (Bela et al., 2016).

A third total organic aerosol simulated peak is observed between 20 and 21 LT (see Fig. 5a). The simulated peak may be explained by the transport of air pollutants from the regions south of the T3 site (Fig. S8 in the SI). We propose two possible explanations for this phenomenon. Our first explanation involves the Negro River breeze effect. Since most thermal power plants and the Issac Sabbá refiner REMAN are located near the banks of the Negro and Solimões rivers (Rafee et al., 2017), the plume transport could be influenced by the river breeze circulation, which defines the trajectory of pollutants. It may be that, between 19 to 21 LT (Fig. S8 in the SI), the wind direction was affected by the Negro River breeze effect due the horizontal thermal gradient caused by the different energy partitioning of the water and land surfaces. Consistent with dos Santos et al. (2014), the water surface temperature of the Negro River starts to increase in the afternoon (13 LT), affecting the vertical heat and mass transport. Our second explanation is that there is an air subsidence pattern at the T3 site between 19 and 22 LT (see SI Fig. S3). At 20 LT T3 site presents a saturation trend from $850 \mathrm{~m}$ to $900 \mathrm{~m}$ and also from $520 \mathrm{~m}$ to $600 \mathrm{~m}$ with temperature and dew-point temperature close to each other, creating a dry air region (see Fig. S4 in the SI), and consequently, air subsidence (see Fig. S4b in the SI). This causes upward movement inhibition, which confines the atmospheric pollutants to low levels, impeding their spread.

An example of the differences between the measured and modeled concentration distributions is shown for organics, BC, $\mathrm{CO}$ and $\mathrm{O}_{3}$ in Fig. 5c. Both simulated and observed BC show a median value of $0.2 \mu \mathrm{g} \mathrm{m}^{-3}$, demonstrating that our simulation represents $\mathrm{BC}$ well. The same behavior is shown for $\mathrm{OA}$ and $\mathrm{CO}$ with simulated and observed median values of $1.8 \mu \mathrm{g} \mathrm{m}^{-3}$ and $122 \mathrm{ppbv}$, respectively. However, the simulation presets a larger range of values compared with observations. The simulations present some high peaks not seen in the observed data, such as the ones in BC (see Fig. S5 in the SI) and OA, with a high contribution coming from POA emission factor (see Fig. 5a). Both have peaks in the early morning on March 13, 2014. In addition, the simulation shows a median $\mathrm{O}_{3}$ value of ca. $12 \mathrm{ppbv}$ (observed 7 ppbv). Conversely, looking at just 10 to 17 LT on March 2014, which represents an exemplary day with pollution contributions at the T3 site coming from Manaus (Shilling et al., 2018), both simulated and observed $\mathrm{O}_{3}$ present high median values, $38 \mathrm{ppbv}$ and $30 \mathrm{ppbv}$, respectively. This agreement of the observed and simulated median values during a day with polluted conditions, particularly noting the uncertainties in emissions (speciation, spatial and temporal distribution), measurements, boundary conditions, meteorological component and other input parameterization of the model are low on the $13^{\text {th }}$. Overall, the comparisons of the median measured and predicted 

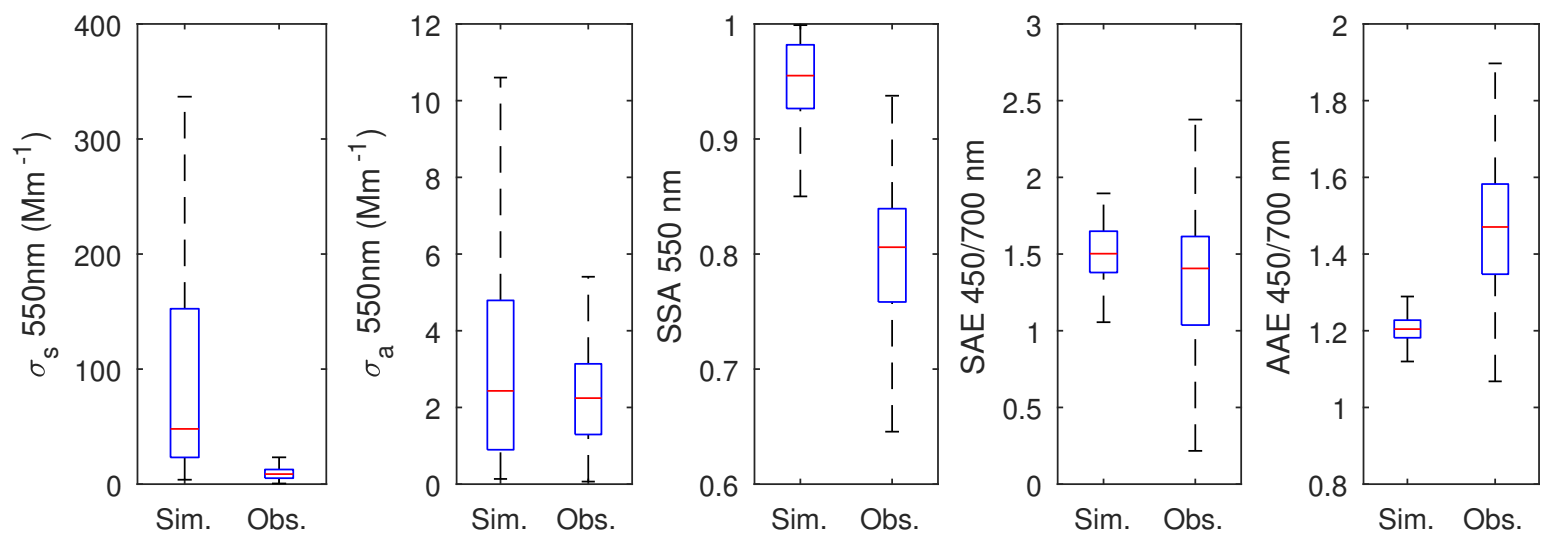

Figure 6. Comparisons between observed and simulated aerosol optical properties. Box plot of simulated and observed SSA, SAE, AAE, scattering and absorption coefficients from 9 to 13 March 2014 at the T3 site. Median values are shown in red lines and the blue box indicates data between the $25^{\text {th }}$ and $75^{\text {th }}$ percentiles.

chemical concentrations are satisfactory, with the best match obtained in OA (observed $1.8 \mu \mathrm{g} \mathrm{m}^{-3}$; simulated $1.7 \mu \mathrm{g} \mathrm{m}^{-3}$ ), CO (observed 124 ppbv; simulated $126 \mathrm{ppbv}$ ) and BC (observed $0.201 \mu \mathrm{g} \mathrm{m}^{-3}$; simulated $0.203 \mu \mathrm{g} \mathrm{m}^{-3}$ ).

\subsection{Variability of Amazonian Aerosol Optical Properties}

Understanding how optical properties such as SSA and $\mathrm{g}_{a e r}$ vary downwind of Manaus is key to understanding the impact of the pollution plume on radiative forcing, its contributions to the local radiative budget, its impacts on the hydrological cycle and unknown indirect consequences on photosynthesis rates. These effects suggest the possibility of investigating aerosol direct radiative effects (DREs) by examining $\mathrm{g}_{a e r}$, which presents, in general, higher values associated with stronger forward scattering of radiation by atmospheric aerosols (Korras-Carraca et al., 2015).

Figure 6 shows that the simulation overestimates the observed scattering coefficient by a factor 6 . The overestimate in the observed scattering coefficient is due the fact that our WRF-Chem simulations are producing more $\mathrm{SO}_{4}$ than in the real atmosphere, with $30 \%$ of the observed PM1 attributed to $\mathrm{SO}_{4}$ in the accumulation mode (Fig. S11 in the SI). Observed scattering coefficient values are significantly lower than simulated likely due to decreases in the aerosol loading during the transect, modulated by the effects of dilution of gases and particles in the air. On the other hand, the median simulated absorption coefficient of $2.2 \mathrm{Mm}^{-1}$ is in good agreement with the observed median value of $2.4 \mathrm{Mm}^{-1}$. We observe the simulated SSA being affected by the simulated scattering coefficient overestimation. Comparing simulated and observed SAE values, we again have good agreement between the simulation and observations, with the simulation representing the mean size of the aerosol population $70 \mathrm{~km}$ downwind of Manaus quite well. These results are important for the plume aging mechanism discussed in Section 3.4. Additionally, the observed AAE is considerably higher than in our simulation. This suggests that the brown carbon component, 
(a)

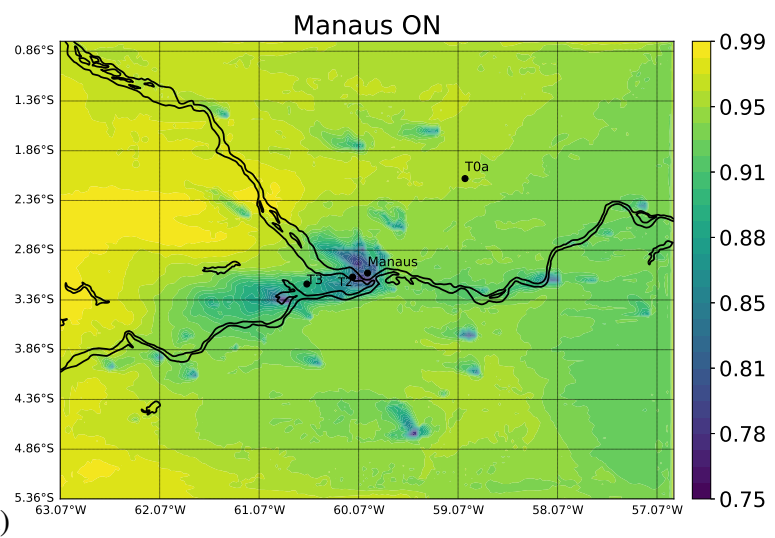

(c)

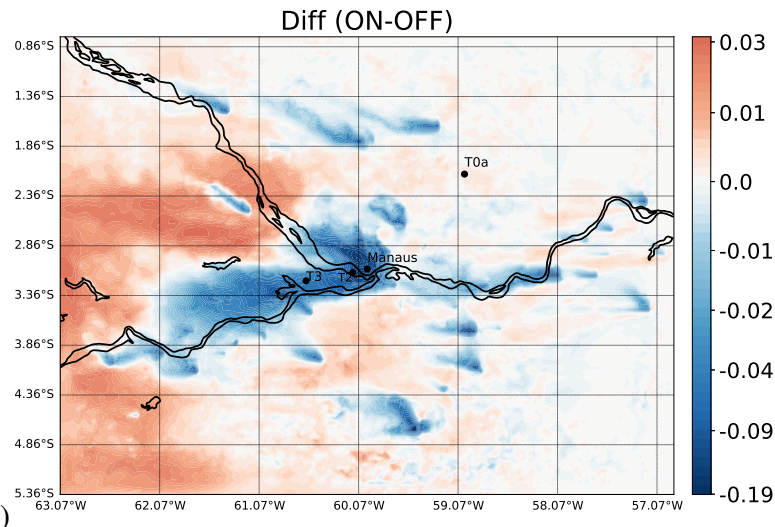

(b)
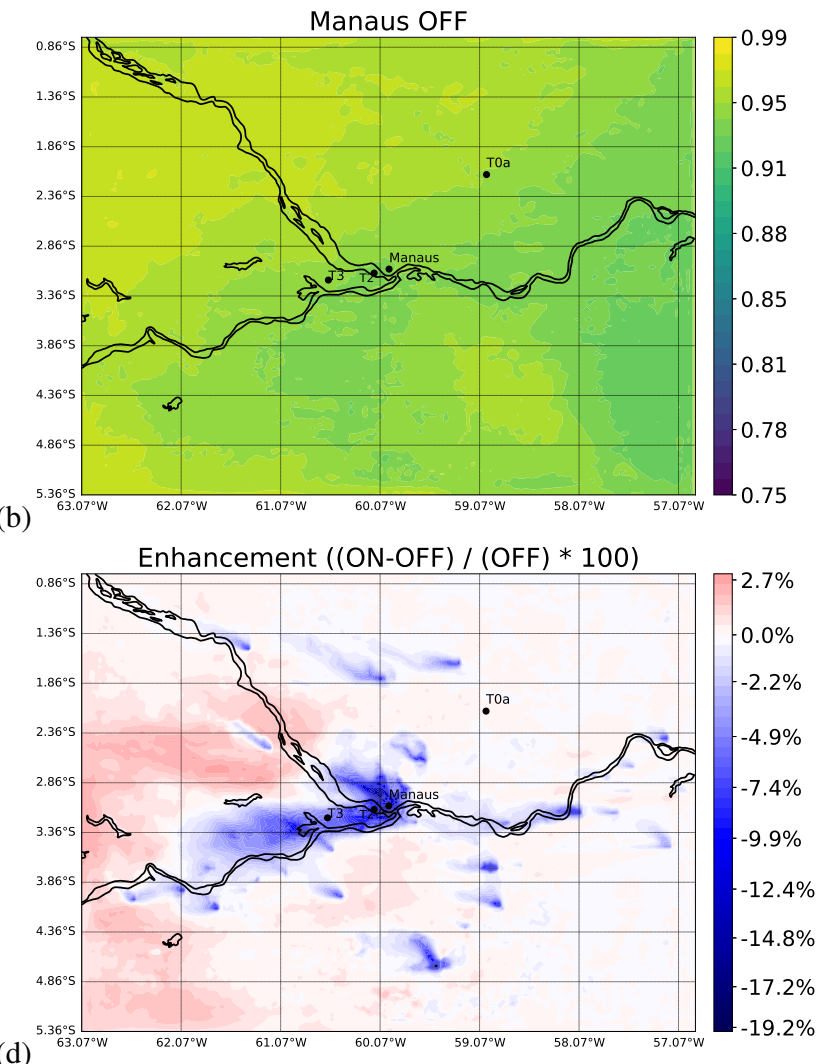

Figure 7. WRF-Chem simulated values of SSA in the presence or absence of Manaus emissions. (a) SSA when all emissions are ON. (b) SSA when just biogenic emissions are ON and anthropogenic emissions are OFF. (c) SSA difference between the two simulations with anthropogenic emissions turned ON and OFF i.e. (ON-OFF). (d) SSA enhancement (\%) calculated from the two simulations with anthropogenic emissions turned ON/OFF i.e. $((\mathrm{ON}-\mathrm{OFF}) / \mathrm{OFF}) \times 100$. WRF-Chem predictions are at ca. $8 \mathrm{~m}$ altitude, averaged over March 13, 2014 (00:00 - 23:00 LT.))

not accounted for our simulations, could have an critical effect on the AAE value, contributing to the lower median simulated AAE (1.2) compared with the median observed value (1.5).

\subsubsection{Calculations and measurements of SSA}

According to our simulation results, the Manaus plume interferes with the amount of radiation absorbed by the atmosphere, being responsible for an SSA reduction of approximately 10\% at Manaus, $12 \%$ at the T2 site and 5.3\% at the T3 site (see Fig. 7d). This indicates a large fraction of absorbing material present in the Manaus plume, potentially warming the local atmosphere. These regions are associated with thermal power plants (Medeiros et al., 2017), indicating that the vehicular emissions and stationary sources (refineries) are dominated by small absorbing particles like BC, while biogenic particles are mostly found in the coarse mode and efficiently scatter radiation due to their organic carbon-dominated composition. 

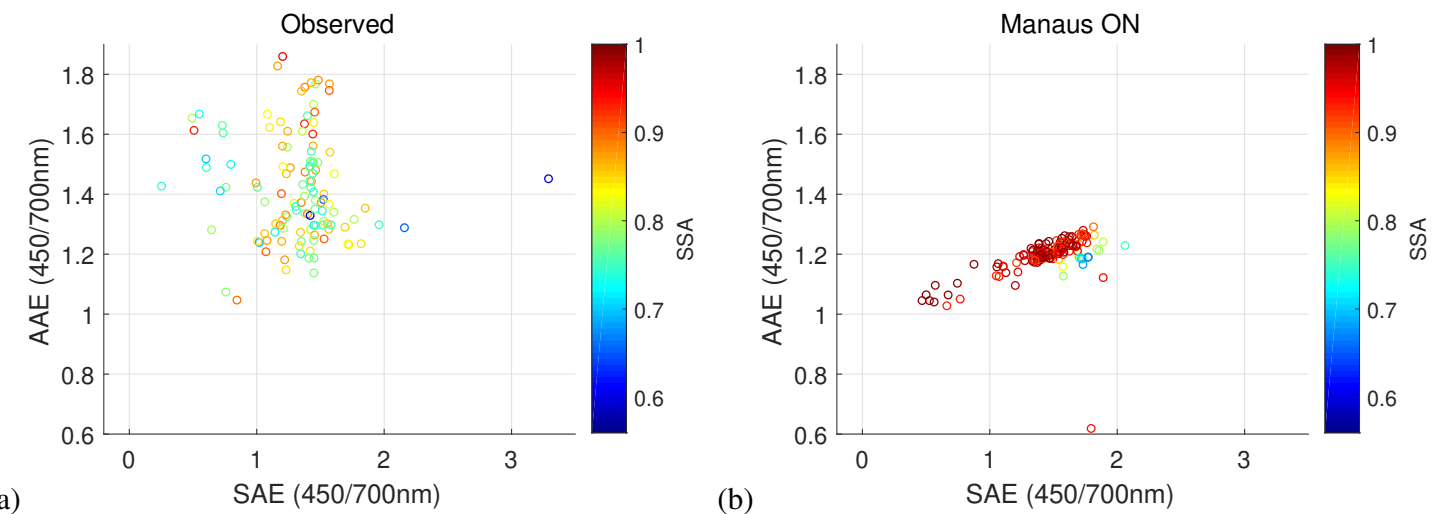

(b)

Manaus OFF

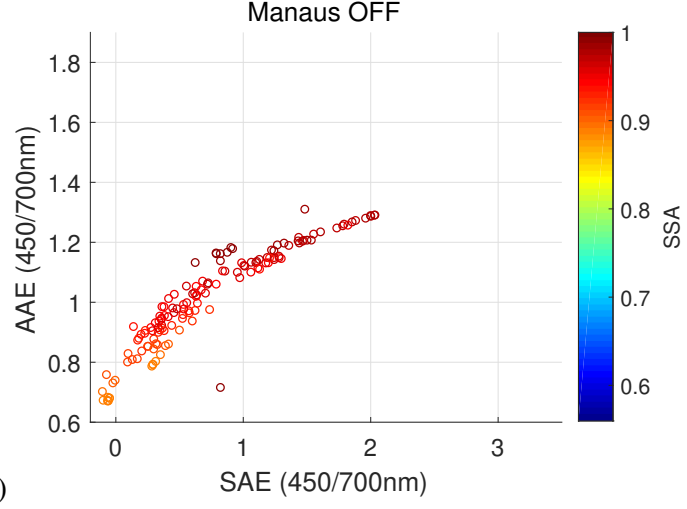

Figure 8. AAEs at the wavelength pair $470 \mathrm{~nm}$ and $660 \mathrm{~nm}$ as a function of the corresponding SAEs at the wavelength pair $470 \mathrm{~nm}$ and 660 $\mathrm{nm}$ ), color-coded using the related SSA at the wavelength pair $470 \mathrm{~nm}$ and $660 \mathrm{~nm} .1 \mathrm{~h}$ averaged instantaneous observed data values (a) from simultaneous nephelometer and aethalometer measurements from 9 to 14 March 2014. (b) $1 \mathrm{~h}$ averaged simulated values when all emissions are on. (b) $1 \mathrm{~h}$ average simulated values when just biogenic emissions are on and anthropogenic emissions are off.

During simulations with the Manaus pollution plume component turned on, average SSA values vary between 0.75 and 0.90 in regions downwind of Manaus. This represents the contribution from the interaction of urban aerosols with biogenic components of the forest. Similar results were found by Cirino et al. (2018) at the T3 site (0.80) and Ramachandran and Rajesh (2007) in western India (0.88), He et al. in China (0.80), Backman et al. (2012) in São Paulo, Brazil (0.76). These SSA values are associated with the formation of SOA aerosols which scatter radiation efficiently (Fig. S10 in the SI). The decrease in the SSA is associated with a significant fraction of aerosol loading from small particles of anthropogenic origin, e.g., BC. The average simulated and observed SSA on $550 \mathrm{~nm}$ values during March 13, 2014 at the T3 site were $0.86 \pm 0.09$ and $0.78 \pm$ 0.09 , respectively. 


\subsubsection{Calculations of AAE and SAE}

Figure 8 shows the simulated and observed SAE and AAE distributions from 9 to 14 March 2014. The simulation with anthropogenic emissions is mostly characterized by $1.0<\mathrm{AAE}<1.3$ and $1.0<\mathrm{SAE}<2.0$, corresponding to a large OC particle contribution, including primary and secondary components (POC and SOC, respectively) (Cazorla et al., 2013). Additionally, the simulated SAE (Manaus on) when variability ranges between 1 to 1.8 , indicates a contribution of fine and absorbing particles, which increases the SAE (see Fig. 8).

In general, these SAE and AAE values show that the values in simulation with anthropogenic emissions are, on average, associated with the fine fraction of $\mathrm{PM}_{2.5}$ sampled particles. In contrast, some values are mostly associated with large-size $\mathrm{PM}_{2.5}$ particles ( $\mathrm{SAE}<1$ ), consistent with the Manaus plume not having a strong influence on the T3 site during those days. Conversely, the SAE with anthropogenic emissions (see Fig. 8b) shows a range between 0.5 and 2.1, values associated with the presence of fine aerosols originating from industrial activities in Manaus and the thermal power plants (TTPs) located in the surrounding area. The simulation with the Manaus plume turned off (see Fig. 8c) shows a coarse mode predominance, with SAE values varying mainly between 0.0 and 1.5 . Thus, we can assume those values have a large OC contribution because of the predominance of aerosol coming from coarse mode biogenic sources.

The observed AAE values in the simulation without anthropogenic emissions express a large variability (1.1 to 1.8) compared with the ones from simulation with anthropogenic emissions (1 to 1.3). This behavior is assumed being caused by the lack of a brown carbon component in the aerosol population in our simulation. When the anthropogenic emissions are off, the SAE variability is mostly related with the significant contribution from large aerosol, as already mentioned (Cazorla et al., 2013; Seinfeld and Pandis, 2016; Romano et al., 2019).

\subsubsection{Asymmetry Parameter}

$\mathrm{G}_{a e r}$ is an important optical property in radiative transfer, climate and general circulation models (Korras-Carraca et al. (2015).

The, $\mathrm{g}_{a e r}$ describes the angular distribution of scattered radiation and determines whether the particles scatter radiation preferentially forwards or backwards (Boucher (2015)).

Figure 9 (a) shows low $600 \mathrm{~nm} \mathrm{~g}_{\text {aer }}$ values (0.64) that could be associated with industrial activities such as TTPs as well as biomass burning in nearby areas. A region of special interest is between Manaus and T3, since it hosts a large variety of mixing interactions between anthropogenic, biogenic and dust aerosols (e.g., Artaxo et al., 2002; Saturno et al., 2018; Martin et al., 2016; Rizzo et al., 2013). In this region it can be seen that $\mathrm{g}_{a e r}$ decreases by $8 \%$ compared when there is no anthropogenic emissions (see Fig. 9d). This is associated with the presence of fine anthropogenic aerosols transported from adjacent urban and industrial areas in the northwest, especially from central Manaus (Medeiros et al., 2017; Rafee et al., 2017; Shrivastava et al., 2019). Those smaller $\mathrm{g}_{a e r}$ values are seen in places where a significant fraction of the aerosol loading comes from small size particles of anthropogenic origin, with the smallest values appearing over the regions containing industrial activities. Previous studies (Cirino et al., 2018) have shown a period in the late afternoon around T3 in which particles with the smallest geometric diameter (ca. $50 \mathrm{~nm}$ ) were observed, and the same period coincides with smaller $\mathrm{g}_{a e r}$ found in simulations for the 
(a)
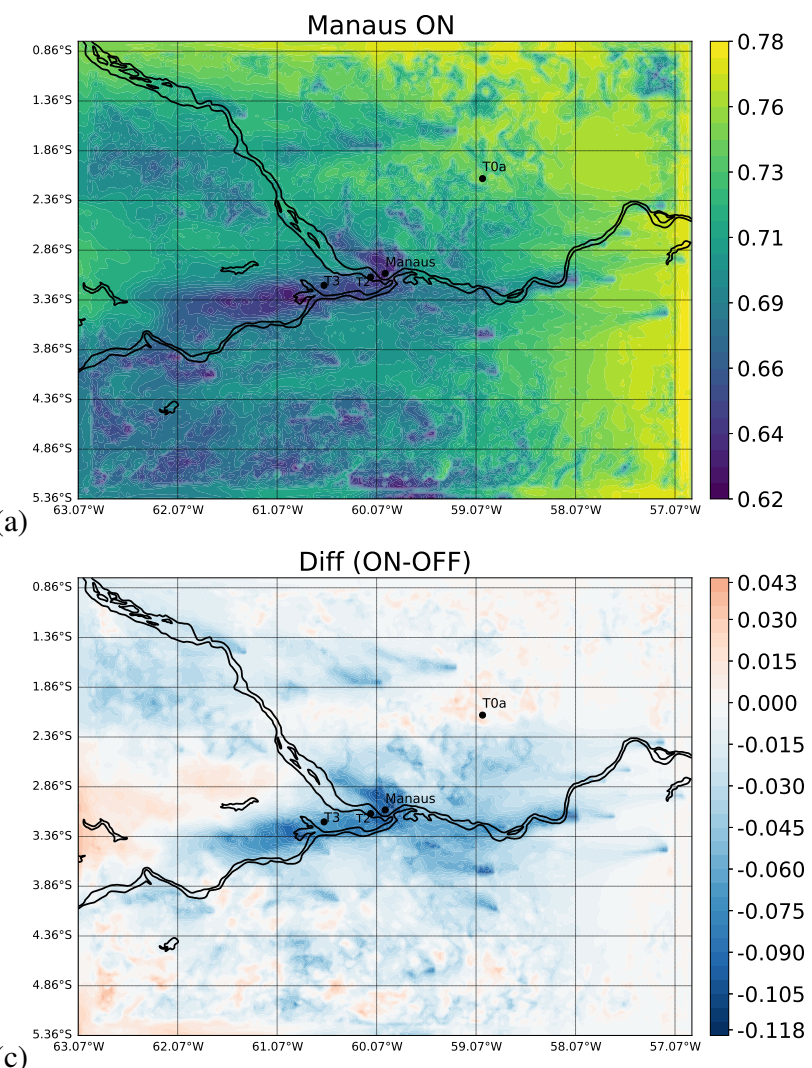

(b)
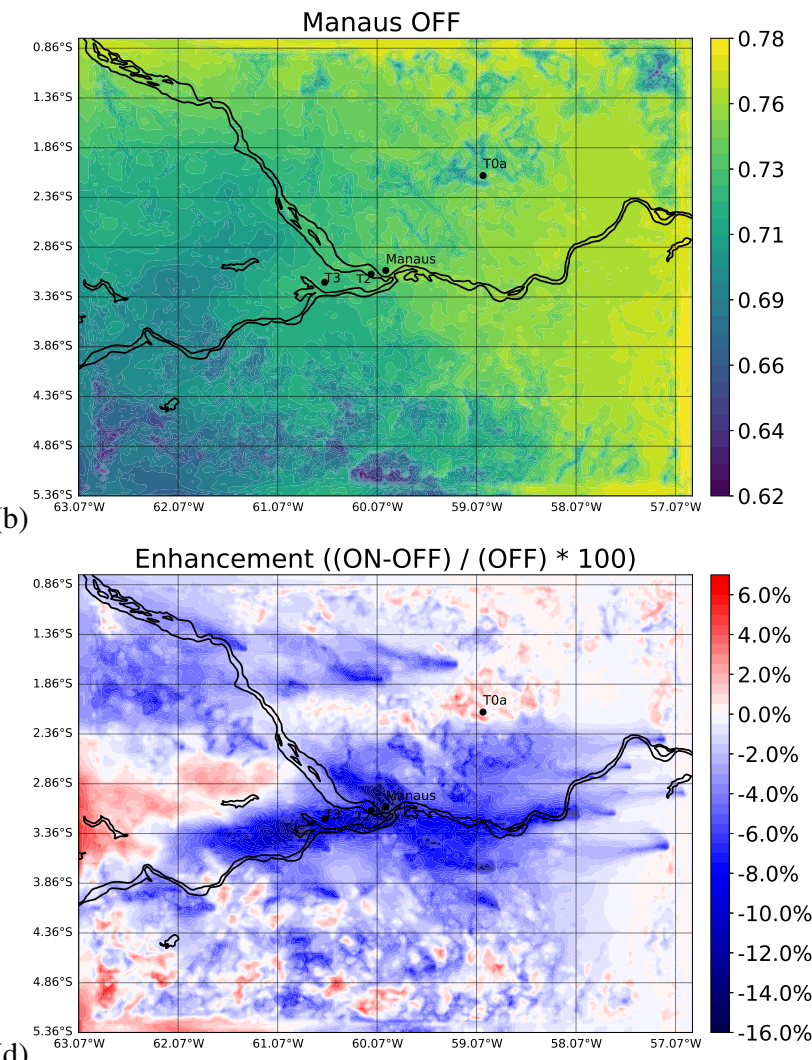

Figure 9. WRF-Chem simulated values of $600 \mathrm{~nm} \mathrm{~g}_{a e r}$ in the presence or absence of Manaus emissions. (a) gaer when all emissions are on. (b) $g_{a e r}$ when just biogenic emissions are on and anthropogenic emissions are off. (c) $g_{a e r}$ difference between the two simulations with anthropogenic emissions turned on and off i.e. (ON-OFF). (d) $g_{a e r}(\%)$ enhancement calculated from the two simulations when anthropogenic emissions turned on and off i.e. $((\mathrm{ON}-\mathrm{OFF}) / \mathrm{OFF}) \times 100$. WRF-Chem predictions are at ca. $8 \mathrm{~m}$ altitude, averaged over March $13,2014(0$ to 23 LT).

same station (see Fig. 9a). On the other hand, $\mathrm{g}_{a e r}$ when anthropogenic emissions are off, $\mathrm{g}_{a e r}$ has predominately large values varying between 0.75 and 0.76 at $300 \mathrm{~nm}, 0.73$ and 0.75 at $400 \mathrm{~nm}, 0.71$ and 0.74 at $600 \mathrm{~nm}$ and 0.63 and 0.71 at $1000 \mathrm{~nm}$. These values indicate strong forward scattering of radiation by atmospheric aerosols and are related with the presence of coarse biogenic particles. According to the obtained results, anthropogenic emissions decrease $\mathrm{g}_{a e r}$ values by between $2 \%$ and $16 \%$, especially in regions with large mobile and stationary anthropogenic activities. Those smaller values can induce modifications of the DREs.

\subsubsection{Irradiance}

In regions like the Amazon with sufficiently high levels of $\mathrm{NO}_{x}$, and VOCs such as isoprene and monoterpene, an enhanced formation of near surface $\mathrm{O}_{3}$ is expected. Solar radiation is another element that contributes to photochemical activity and, 


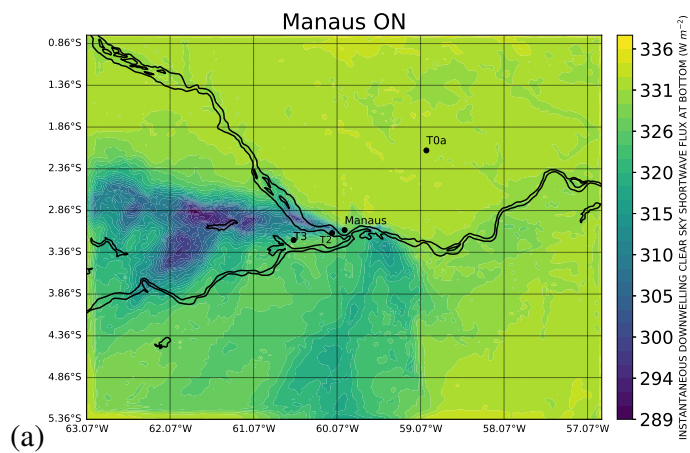

(b)
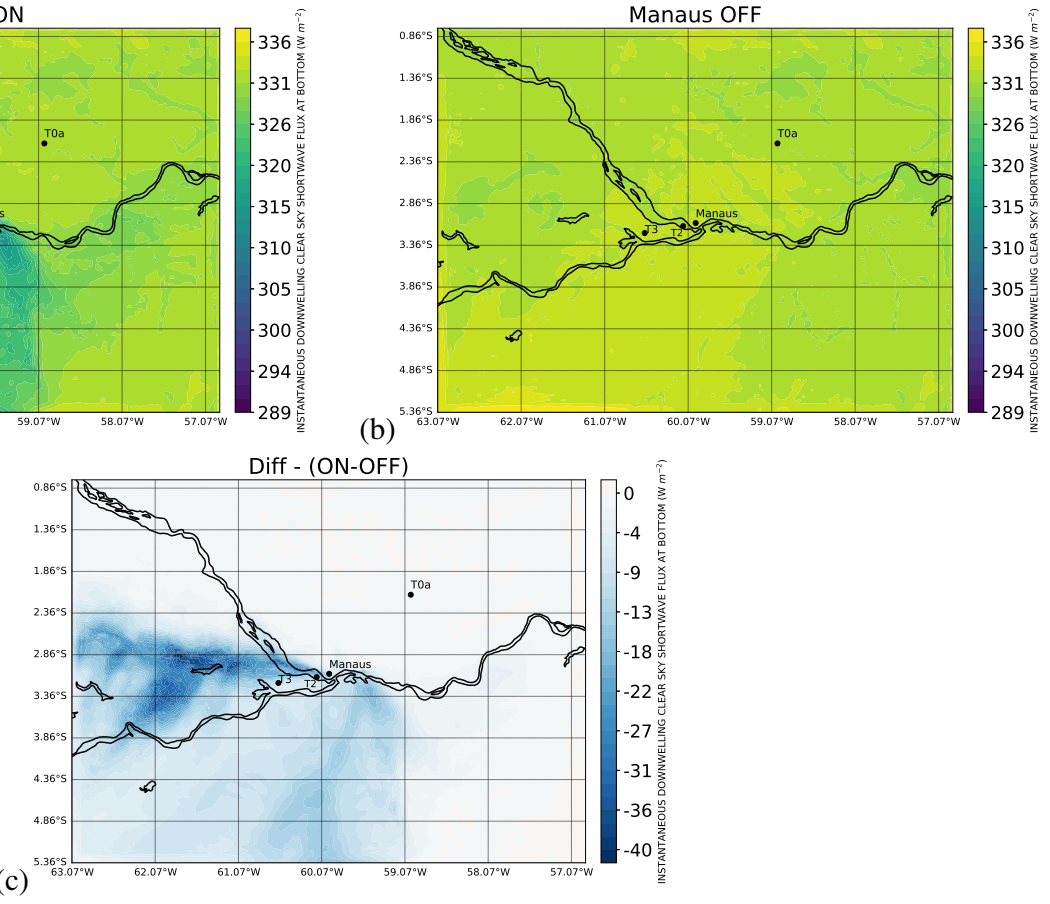

Figure 10. WRF-Chem simulated mean incoming solar radiation (instantaneous downwelling clear sky shortwave flux at bottom: SWDNBC) in $\mathrm{Wm}^{-2}$ in the presence and absence of Manaus emissions. (a) SWDNBC when all emissions are on. (b) SWDNBC when biogenic emissions are on and anthropogenic emissions are off. (c) SWDNBC difference between the simulations with and without anthropogenic emissions, i.e. ON-OFF.

consequently, the formation of $\mathrm{O}_{3}$. According to Figure 10c, it is possible to notice that even in regions presenting average decreased surface downward shortwave flux values of ca. $20 \mathrm{~W} \mathrm{~m}^{-2}$ due to the presence of anthropogenic emissions near $\mathrm{T} 2$ and T3, not enough to reduce the enhanced formation of near surface $\mathrm{O}_{3}$ (see Fig. 4a), which more than compensates for the effect of the comparatively reduced solar radiation there. The lower solar radiation over the west side of Manaus seen in simulations with anthropogenic emissions (see Fig. 10a) is accompanied by a general increase in mean $\mathrm{O}_{3}$ values (see Fig. 4a). Studies of regional direct and indirect aerosol effects are important and still challenging due to their complexity making an accurate determination of the direct and indirect effects difficult (Forkel et al., 2012; Wang et al., 2015; Zhang et al., 2010).

In our simulations, we considered both direct and indirect aerosol effects during the wet season in the Amazon region. Incoming shortwave radiation at the surface is predicted to drop by up to ca. $-40 \mathrm{~W} \mathrm{~m}^{-2}$ due the direct aerosol effect. In regions within and up to ca. $100 \mathrm{~km}$ south-west of Manaus, Figure 10c shows an aerosol cooling effect with maximum SWDNBC values ca. $-40 \mathrm{~W} \mathrm{~m}^{-2}$. The same behavior can also be seen in the region north-west of the $\mathrm{T} 3$ site. The aerosol cooling effect is mostly related with SOA production caused by the interaction between VOCs and $\mathrm{NO}_{x}$. When the Manaus plume reaches regions downwind of the city, as seen on March 13, 2014, with few clouds, low precipitation and biomass burning, the plume has a cooling effect on the region as the plume evolves. The SWDNBC (clear sky) variable was used in this study to investigate the 
aerosol radiative effect on the surface due limitations for simulate the cloud coverage on Amazonian region. Also, the results founded in this paper have to be investigated deeply in order to better understand the effects on the diffuse and direct radiation.

\subsection{Aging Plume Impact on the Optical Properties}

In this section, we examine how aging of the Manaus plume may affect its optical properties. SSA initially has low values of ca. 0.91, then increases after plume age 1 (7 LT). Some processes which affect SSA values as the plume ages are dilution, BC deposition, SOA formation and the lensing effect (Holanda et al., 2020; Shrivastava et al., 2019; Cirino et al., 2018). The SSA values in the plume continue to increase during the plume aging process, consistent with SOA (ASOA + BSOA) production in the aging plume (see Fig. 11d). Our simulations show that, on March 13, 2014, the increase of SSA as the plume ages is mostly related to a combination of an increase in SOA formation and BC dilution. Figure 11f shows that $\mathrm{BC}$ and $\mathrm{CO}$ diluted in similar proportions, suggesting that, at this time scale, dilution is more important than deposition. When the plume is 3 hours old, total organics reach ca. $11 \mathrm{\mu g} \mathrm{m}^{-3}$ and at that time the plume is north of the T3 site (see Fig. S12d in the SI). Similar results were found by de Sá et al. (2018) at the T3 site.

During plume aging, a decrease of anthropogenic primary organic aerosol and a increase in SOA was observed, similar to results reported by Shilling et al. (2018). The biggest contribution to total SOA during the plume aging comes from anthropogenic emissions, ca. $70 \%$ of the total SOA. SOA production increases rapidly and saturates at plume age 4 , indicating that it is a challenge to represent these processes in tropical regions with global models, especially without correct treatments of sub-grid effects, such as the production of SOA. The simulated plume used in the tracking analysis traveled $160 \mathrm{~km}$ from Manaus (Fig. S13 in the SI). The distance between T1 and T3 is around $70 \mathrm{~km}$, so when the plume reaches that distance from Manaus, it is ca. 3 hours old.

Figure 11b shows instantaneous downwelling clear sky shortwave flux at bottom with the Manaus plume turned on and off. After 3 hours of plume aging, incoming solar radiation is reduced by ca. $-15 \mathrm{~W} \mathrm{~m}^{-2}$ and is further reduced by about $-30 \mathrm{~W}$ $\mathrm{m}^{-2}$ after the plume is 7 hours old. This reduction by $3 \%$ of solar flux and the resulting increase in diffuse radiation results in a significant increase in net primary productivity (Cirino et al., 2014; Rap et al., 2015). As the plume ages and dilutes, its impact on the solar radiation remains constant. Between hours 7 and 9, although the plume's attenuation of incoming solar radiation decreases in absolute terms, from ca. $-32 \mathrm{~W} \mathrm{~m}^{-2}$ to $-27 \mathrm{~W} \mathrm{~m}^{-2}$, as a percentage, the plume's attenuation remains constant at ca. $3 \%$.

$\mathrm{BC}$ simulations at an altitude of ca. $500 \mathrm{~m}$ above the ground were evaluated using aircraft measurements from the Manaus plume on March 13, 2014. For the most part, our simulation shows good agreement with the G1 measurements (SI Fig. S16, in the SI), particularly for background conditions. The offset in the third and fourth peaks is due to differences between the meteorological conditions of the simulation and reality. Similar offsets between simulations and observations were found by Shrivastava et al. (2019).

As the plume ages SAE, begins to increase at 8 LT (after 2 hours of plume aging) and remains constant with values of ca. 1.17 until 13 LT (after 7 hours of plume aging). During this period, AAE is mostly close to 1, which can be explained by increased concentrations of fine ( $\mathrm{SOA}>15 \mu \mathrm{g} \mathrm{m}^{-3}$ ) and absorbing $\left(\mathrm{BC}>0.4 \mu \mathrm{g} \mathrm{m}^{-3}\right.$ ) particles near Manaus. Similar results 

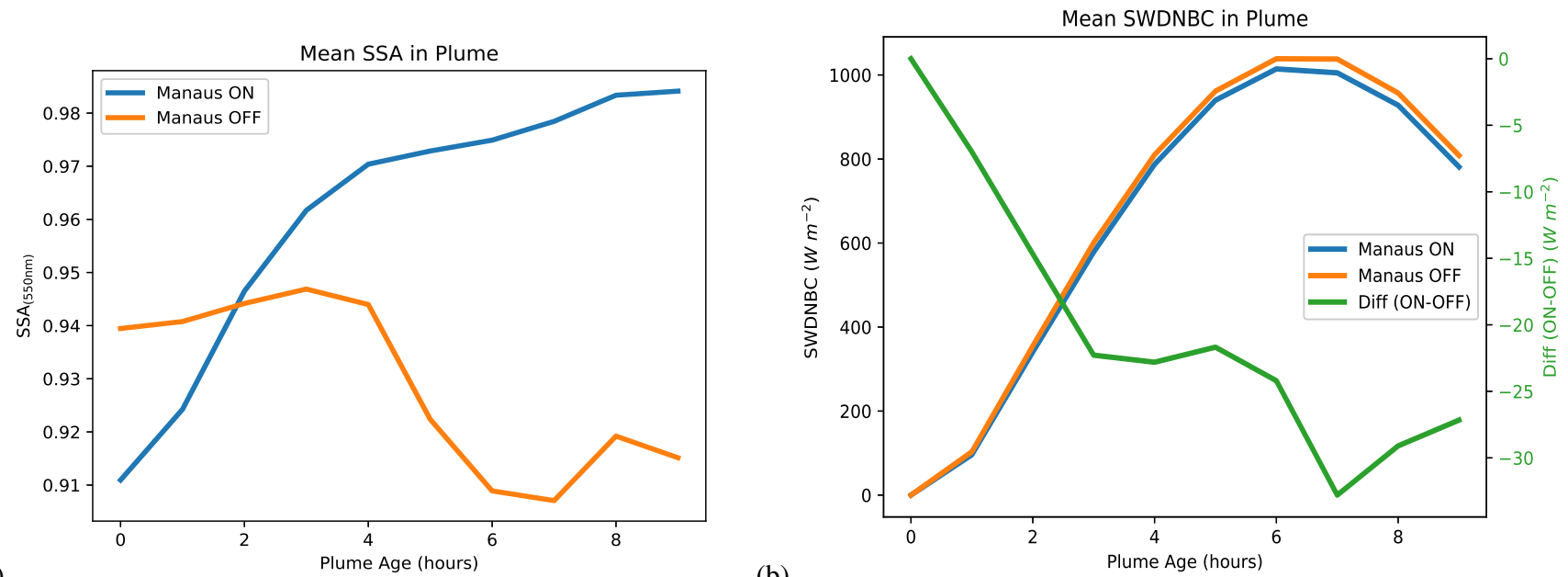

(a)

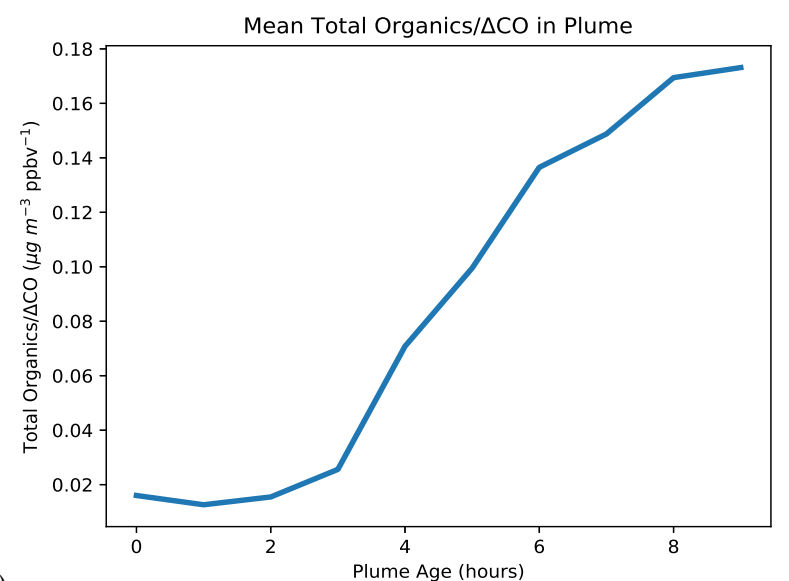

(c)

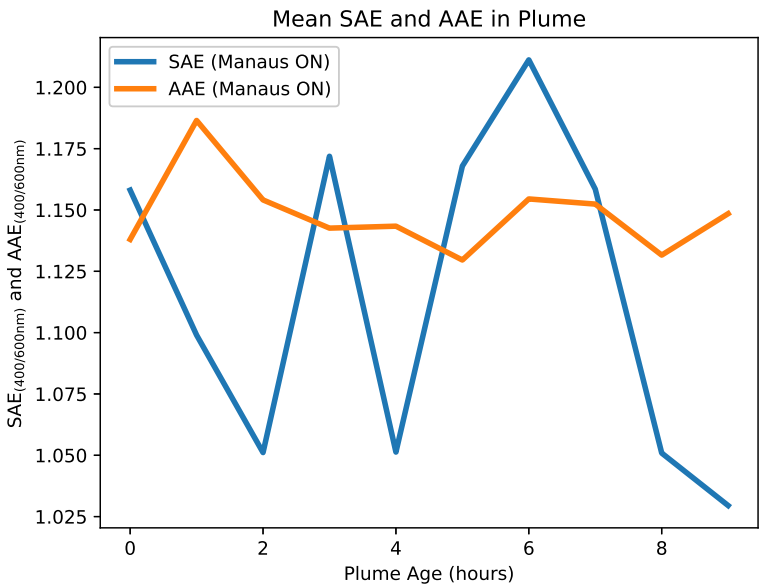

(b)

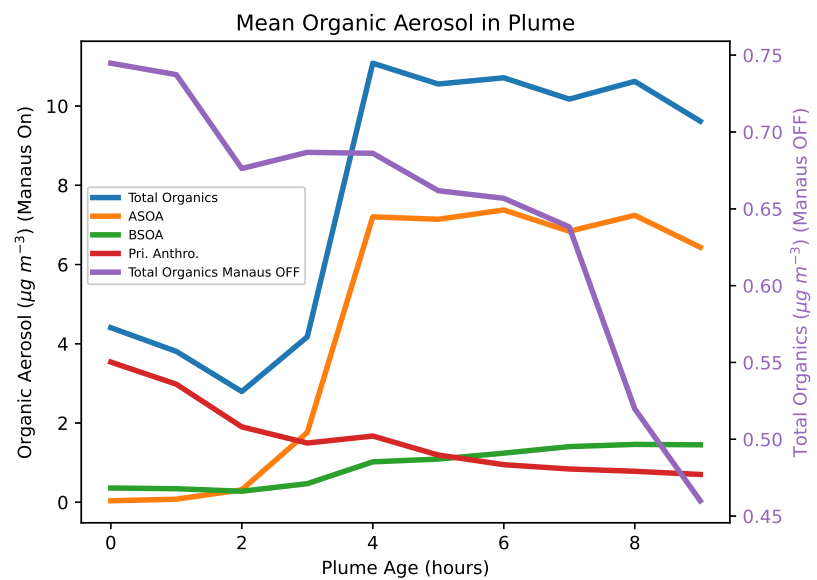

(d)

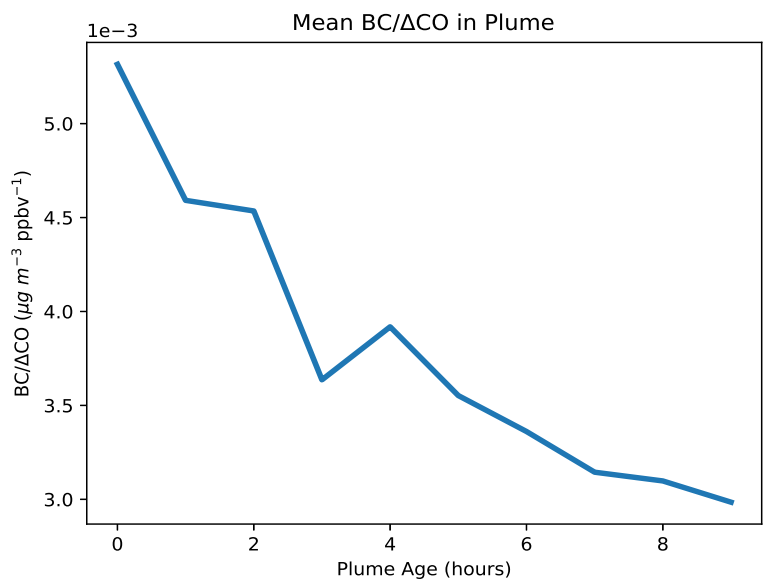

(e)

Figure 11. Simulated plume 100-500 m starting at Manaus 6 to 15 LT on March 13, 2014 in order to calculate the mean (a) SSA at 550nm, (b) Instantaneous downwelling clear sky shortwave flux at bottom $\left(\mathrm{W} \mathrm{m}^{-2}\right)$, (c) Total organics $\left(\mu g \mathrm{~m}^{-3}\right)$ normalized by $\Delta \mathrm{CO}$, (d) Organic aerosol $\left(\mu \mathrm{g} \mathrm{m}^{-3}\right)$, (e) SAE and AAE and (f) BC $\left(\mu \mathrm{g} \mathrm{m}^{-3}\right)$ normalized by $\Delta \mathrm{CO}$. The plume age represents the time the plume tracking started. 
were found by Romano et al. (2019) in southeastern Italy from December 22, 2015 to March 30, 2016, with $1<$ AAE $<1.5$ and SAE > 1 using the classification defined by Cappa et al. (2016).

\section{Summary and conclusions}

Numerical simulations with the WRF-Chem model were performed in order to investigate the impact of the Manaus plume on aerosol optical properties downwind of Manaus and how the plume aging process can affect those optical properties. We use the simulations to investigate the impact of anthropogenic emissions on SOA formation over the Amazon region during the wet season and the effect of anthropogenic $\mathrm{NO}_{x}$ on $\mathrm{O}_{3}$ production from $\mathrm{O}_{3}$ precursors emitted by the forest. Aerosol characteristics have many impacts that could influence ecosystems on a regional scale. We selected March 13 ${ }^{\text {th }}, 2014$ as a "golden day" (Shilling et al., 2018), to analyze the Manaus plume's influence at the T3 site and regions further downwind. During this day, the transport event brought elevated gas and aerosol concentrations from Manaus, associated with favorable meteorological conditions. According to our results, downwind of Manaus at the T3 site, the total organic aerosol mass increased by ca. 75\% (0.5 - $2.0 \mu \mathrm{g} \mathrm{m}^{-3}$ ) when anthropogenic emissions were turned on. This increase in organic aerosol mass suggests the Manaus plume is primarily responsible for the changes in the physical and chemical aerosol population characteristics in those regions.

From model experiments, we conclude that the influence of the Manaus plume can reach areas up to $300 \mathrm{~km}$ downwind of Manaus, and provide a quantitative assessment of the effects urban pollution could cause to Amazonian forests surrounding urban centers. Overall, our simulations indicate that the aerosol impact of the Manaus plume increases irradiance values by $20 \%$ near the T3 site. We also separated the contributions of the different aerosol chemical components that contribute to our estimate of the total aerosol mass concentration and their impact on optical properties. Especially striking is the impact on $\mathrm{O}_{3}$ formation. Due to the high $\mathrm{NO}_{x}$ concentrations present in Manaus, the simulations showed that increased $\mathrm{O}_{3}$ production mostly occurs in the regions to the south-west of Manaus, where an atmosphere conducive to $\mathrm{O}_{3}$ enhancement can be found.

According to our results, the lowest $\mathrm{g}_{a e r}$ values were generally found in regions with a significant fraction of the aerosol load coming from small size particles of anthropogenic origin, e.g., from TPPs and refineries in the Manaus region. Conversely, the largest $\mathrm{g}_{a e r}$ values were observed over regions with aerosol dominated by large particles of biogenic origin (T0a site). Further investigations are necessary to determine if different sulfate amounts from anthropogenic emissions may change the strong direct effect for high aerosol particle concentrations. More ground-based aerosol and trace gas observations over the western Amazon region could help to evaluate the magnitude of the aerosol effect in this area.

This study contributes to the investigation of the optical properties of $\mathrm{PM}_{2.5}$ over the Amazon region during the wet season. To assess the impact of Manaus emissions on SOA production, and consequently, on aerosol optical properties, WRF-Chem model runs were conducted with and without anthropogenic emissions. Assuming only biogenic emissions with boundary conditions from the global model, OA production decreased by 75\% at the T3 site. This study also shows that on March 13, 2014, the aerosol aging process caused a gradual increase in SSA. Additionally, due to the deposition process, significantly decreasing concentrations of $\mathrm{BC}$ are found during plume evolution. This process, combined with SOA formation, contributes to the increase in SSA as the plume ages. The results of this study demonstrate that uncertainties in coating processes of organic 
aerosols involving BC particles also warrant additional study to better account for a possible decrease in SSA during the plume aging process. The results here also demonstrate that in order to precisely calculate the radiative forcing impact, it is important to take into account all SOA formation mechanisms, including VOC oxidation, especially for tropical forest regions like the Amazon. One action that may improve SOA model accuracy is to update some of the MEGAN model inputs when new data such as emission factors and vegetation coverage data becomes available. In addition, there are very few long term aircraft based ASOA and BSOA observations data and more observations could help validate the models and improve their accuracy.

Data availability. The GoAmazon2014/5 experiment data are available from the ARM website: https:/www.arm.gov/research/campaigns/ amf2014goamazon and from the Laboratory of Atmospheric Physics - LFA website: http://lfa.if.usp.br/ftp/public/LFA_Processed_Data/. The simulations and analysis code generated for this study are available upon request from JPN.

Author contributions. JPN, MMB and PA conceptualized and defined the methodology. JPN carried out the formal analysis and investigation of the model results with support from BM, MMB, ALB, HG, LVR, SC, HJB, MAF, MT, SAM and PA. ALVV, SAAR, HG and MMB supported the design and running of simulations. GGC, PA, LVR, MLB, BM and RAFS collected and curated the experimental data. JPN wrote the original draft and all authors discussed the results and commented on the paper.

Acknowledgements. We acknowledge support from the Central Office of the Large-Scale Biosphere Atmosphere Experiment in Amazonia (LBA), coordinated by the National Institute of Amazonian Research (INPA) and the Amazonas State University (UEA), Amazonas, Brazil. JPN thanks the Brazilian Federal Agency for Support and Evaluation of Graduate Education (CAPES) for a graduate fellowship, linked to the doctoral program in Climate and Environment (CLIAMB) and for supporting 7 months of a visiting graduate student program at the NOAA

515 Earth System Research Laboratory. JPN also thanks the Institute of Physics of the University of São Paulo (IFUSP) for student mobility and logistical support, and CIRES and NOAA ESRL for financial and logistical support. We thank Michael Trainer for providing support and knowledge during the research. We thank Manish Shrivastava for providing WRF-Chem simulation output for comparison with this work. We thank Steven Jefferts, Stefania Romisch and Samuel Brewer for facilitating communication between members of this collaboration. We are grateful to Bruno Takeshi, Luiz Cândido, Renata Teixeira and Delano Campos for instrument operation and data analysis. Finally, we thank Richard Tisinai for IT support. MAF acknowledges a scholarship from CNPq, Project 169842/2017-7, for supporting his PhD studies at the IFUSP, São Paulo, Brazil, and CAPES, Project 88887.368025/2019-00, for supporting 6 months of a visiting graduate student program at the Max Planck Institute for Chemisty, Mainz, Germany. BM acknowledges a scholarship from CNPq, Project 133393/2019-4, for supporting his Masters studies at the IFUSP, São Paulo, Brazil. HG acknowledges funding from CAPES through grant 1757/2017. PA acknowledges funding from FAPESP through grant 2017/17047-0. 
https://doi.org/10.5194/acp-2020-1002

Preprint. Discussion started: 19 November 2020

(C) Author(s) 2020. CC BY 4.0 License.

(c) (i)

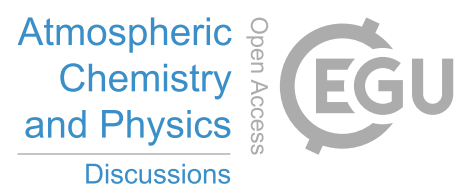

525 Financial support. JPN has been supported by the Brazilian Federal Agency for Support and Evaluation of Graduate Education (CAPES) Project Code 88882.444345/2018-01 and 88881.190103/2018-01. 


\section{References}

Abdul-Razzak, H. and Ghan, S. J.: A parameterization of aerosol activation: 2. multiple aerosol types, J. Geophys. Res., 105, 6837-6844, https://doi.org/10.1029/1999JD901161, 2000.

Ahmadov, R., McKeen, S., Robinson, A., Bahreini, R., Middlebrook, A., De Gouw, J., Meagher, J., Hsie, E.-Y., Edgerton, Shaw, S., and Trainer, M.: A volatility basis set model for summertime secondary organic aerosols over the eastern United States in 2006, J. Geophys. Res., 117, D06301, https://doi.org/10.1029/2011JD016831, 2012.

Albuquerque, T. T. A., Andrade, M. F., and Ynoue, R. Y.: Characterization of atmospheric aerosols in the city of São Paulo, Brazil: comparisons between polluted and unpolluted periods, Environ. Monit. Assess., 184(2), 969-984, 2012.

Alves, E. G., Jardine, K., Tota, J., Jardine, A., Yãnez-Serrano, A. M., Karl, T., Tavares, J., Nelson, B., Gu, D., Stavrakou, T., Martin, S., Artaxo, P., Manzi, A., and Guenther, A.: Seasonality of isoprenoid emissions from a primary rainforest in central Amazonia, Atmos. Chem. Phys., 16, 3903-3925, https://doi.org/10.5194/acp-16-3903-2016, 2016.

Andreae, M., Artaxo, P., Beck, V., Bela, M., Freitas, S., Gerbig, C., Longo, K., Munger, J., Wiedemann, K., and Wofsy, S.: Carbon monoxide and related trace gases and aerosols over the Amazon Basin during the wet and dry seasons, Atmos. Chem. Phys., 12, 6041-6065, https://doi.org/10.5194/acp-12-6041-2012, 2012.

Andreae, M. O., Acevedo, O. C., Araùjo, A., Artaxo, P., Barbosa, C. G. G., Barbosa, H. M., Joel, B., Carbone, S., Chi, X., Cintra, B. B. L., da Silva, N. F., Dias, N. L., Dias-Júnior, C. Q., Ditas, F., Ditz, R., Godoi, A. F. L., Godoi, R. H. M., Heimann, M., Hoffmann, T., Kesselmeier, J., Könemann, T., Krüger, M. L., Lavric, J. V., Manzi, A. O., Lopes, A. P., Martins, D. L., Mikhailov, E. F., MoranZuloaga, D., Nelson, B. W., Nölscher, A. C., Santos Nogueira, D., Piedade, M. T. F., Pöhlker, C., Pöschl, U., Quesada, C. A., Rizzo, L. V., Ro, C.-U., Ruckteschler, N., Sá, L. D. A., de Oliveira Sá, M., Sales, C. B., dos Santos, R. M. N., Saturno, J., Schöngart, J., Sörgel, M., de Souza, C. M., de Souza, R. A. F., Su, H., Targhetta, N., Tóta, J., Trebs, I., Trumbore, S., van Eijck, A., Walter, D., Wang, Z., Weber, B., Williams, J., Winderlich, J., Wittmann, F., Wolff, S., and Yáñez-Serrano, A. M.: The Amazon Tall Tower Observatory (ATTO): overview of pilot measurements on ecosystem ecology, meteorology, trace gases, and aerosols, Atmos. Chem. Phys., 15, 10 723-10 776, https://doi.org/10.5194/acp-15-10723-2015, 2015.

Artaxo, P., Maenhaut, W., Storms, H., and Van Grieken, R.: Aerosol characteristics and sources for the Amazon Basin during the wet season, J. Geophys. Res.-Atmos., 95(D10), 16 971-16 985, https://doi.org/10.1029/JD095iD10p16971, 1990.

Artaxo, P., Yamasoe, M., Martins, J., Kocinas, S., Car-Vallo, S., and Maenhaut, W.: Case study of atmospheric measurements in Brazil : aerosol emissions from Amazon Basin fires, in: Environmental Sciences Research Report, edited by Crutzen, P. J. and Goldammer, J., vol. 13, pp. 139-158, Wiley, 1993.

Artaxo, P., Gerab, F., Yamasoe, M. A., and Martins, J. V.: Fine mode aerosol composition at three long-term atmospheric monitoring sites in the Amazon Basin, J. Geophys. Res.-Atmos., 99, 22 857-22 868, https://doi.org/10.1029/94JD01023, 1994.

Artaxo, P., Martins, J. V., Yamasoe, M. A., Procópio, A. S., Pauliquevis, T. M., Andreae, M. O., Guyon, P., Gatti, L. V., and Leal, A. M. C.: Physical and chemical properties of aerosols in the wet and dry seasons in Rondônia, Amazonia, J. Geophys. Res., 107, 8081, https://doi.org/10.1029/2001JD000666, 2002.

Artaxo, P., Rizzo, L. V., Brito, J. F., Barbosa, H. M., Arana, A., Sena, E. T., Cirino, G. G., Bastos, W., Martin, S. T., and Andreae, M. O.: Atmospheric aerosols in Amazonia and land use change: from natural biogenic to biomass burning conditions, Faraday discussions, 165, 203-235, https://doi.org/10.1039/C3FD00052D, 2013. 
Artaxo, P., Hansson, H.-C., Andreae, M. O., Bäck, J., Alves, E. G., Barbosa, H. M. J., Bender, F., Bourtsoukidis, E., Carbone, S., Chi, J., Decesari, S., Després, V. R., Ditas, F., Ezhova, E., Fuzzi, S., Hasselquist, N. J., Heintzenberg, J., Holanda, B. A., Guenther, A., Hakola, H., Heikkinen, L., Kerminen, V.-M., Kontkanen, J., Krejci, R., Kulmala, M., Lavric, J., de Leeuw, G., Lehtipalo, K., Machado, L. A. T., McFiggans, G., Franco, M. A. M., Mohr, C., Morgan, W., Nilsson, M. B., Peichl, M., Petäjä, T., Praß, M., Pöhlker, C., Pöhlker, M. L., Pöschl, U., Randow, C. V., Riipinen, I., Rinne, J., Rizzo, L. V., Rosenfeld, D., Dias, M. A. F. S., Sogacheva, L., Stier, P., Swietlicki, E., Sörgel, M., Tunved, P., Virkkula, A., Wang, J., Weber, B., Yáñez-Serrano, A. M., Zieger, P., Mikhailov, E., Smith, J., and Kesselmeier, J.: Tropical and Boreal Forest - Atmosphere Interactions: A Review, Tellus B: Chemical and Physical Meteorology, 2020.

Backman, J., Rizzo, L. V., Hakala, J., Nieminen, T., Manninen, H. E., Morais, F., Aalto, P. P., Siivola, E., Carbone, S., Hillamo, R., Artaxo, P., Virkkula, A., Petaj” a, T., and Kulmala, M.: On the diurnal cycle of urban aerosols, black carbon and the occurrence of new particle formation events in springtime São Paulo, Brazil, Atmos. Chem. Phys., 12, 11 733-11 751, https://doi.org/10.5194/acp-12-11733-2012, 2012.

Bela, M. M., Barth, M. C., Toon, O. B., Fried, A., Homeyer, C. R., Morrison, H., Cummings, K. A., Li, Y., Pickering, K. E., Allen, D. J., Yang, Q., Wennberg, P. O., Crounse, J. D., St. Clair, J. M., Teng, A. P., O’Sullivan, D., Huey, L. G., Chen, D., Liu, X., Blake, D. R., Blake, N. J., Apel, E. C., Hornbrook, R. S., Flocke, F., Campos, T., and Diskin, G.: Wet scavenging of soluble gases in DC3 deep convective storms using WRF-Chem simulations and aircraft observations, J. Geophys. Res.-Atmos., 121, 4233-4257, https://doi.org/10.1002/2015JD024623, 2016.

Ben-Ami, Y., Koren, I., Rudich, Y., Artaxo, P., Martin, S., and Andreae, M.: Transport of Saharan dust from the Bodele Depression to the Amazon Basin: a case study, Atmos. Chem. Phys. Discuss, 10, 4345, https://doi.org/10.5194/acp-10-7533-2010, 2010.

Bezdek, J. C., Ehrlich, R., and Full, W.: FCM: The fuzzy c-means clustering algorithm, Computers \& Geosciences, 10, 191-203, https://doi.org/10.1016/0098-3004(84)90020-7, 1984.

Boucher, O.: Atmospheric Aerosols: Properties and Climate Impacts, Springer Netherlands, https://doi.org/10.1007/978-94-017-9649-1, 2015.

Brito, J., Rizzo, L. V., Herckes, P., Vasconcellos, P., Caumo, S. E. S., Fornaro, A., Ynoue, R. Y., Artaxo, P., and Andrade, M. F.: Physicalchemical characterisation of the particulate matter inside two road tunnels in the São Paulo Metropolitan Area, Atmos. Chem. Phys., 13, 12 199-12 213, https://doi.org/10.5194/acp-13-12199-2013, 2013.

Brito, J., Rizzo, L., Morgan, W., Coe, H., Johnson, B., Haywood, J., Longo, K., Freitas, S., Andreae, M., and Artaxo, P.: Ground-based aerosol characterization during the South American Biomass Burning Analysis (SAMBBA) field experiment, Atmos. Chem. Phys., 14, 12 069-12 083, https://doi.org/10.5194/acp-14-12069-2014, 2014.

Cappa, C. D., Kolesar, K. R., Zhang, X., Atkinson, D. B., Pekour, M. S., Zaveri, R. A., Zelenyuk, A., and Zhang, Q.: Understanding the optical properties of ambient sub-and supermicron particulate matter: results from the CARES 2010 field study in northern California, Atmos. Chem. Phys., 16, 6511-6535, https://doi.org/10.5194/acp-16-6511-2016, 2016, 2016.

Cazorla, A., Bahadur, R., Suski, K., Cahill, J. F., Chand, D., Schmid, B., Ramanathan, V., and Prather, K.: Relating aerosol absorption due to soot, organic carbon, and dust to emission sources determined from in-situ chemical measurements., Atmos. Chem. Phys., 13, https://doi.org/10.5194/acpd-13-3451-2013, 2013.

Chen, Q., Farmer, D., Rizzo, L. V., Pauliquevis, T., Kuwata, M., Karl, T. G., Guenther, A., Allan, J. D., Coe, H., Andreae, M. O., Pöschl, U., Jimenez, J. L., Artaxo, P., and Martin, S. T.: Submicron particle mass concentrations and sources in the Amazonian wet season (AMAZE-08), Atmos. Chem. Phys., 15, 3687-3701, https://doi.org/10.5194/acp-15-3687-2015, 2015. 

A. F., Wolff, S., Walter, D., Tota, J., Oliveira, M. B. L., Martin, S. T., and Artaxo, P.: Observations of Manaus urban plume evolution and interaction with biogenic emissions in GoAmazon 2014/5, Atmos. Environ., 191, 513-524, https://doi.org/10.1016/j.atmosenv.2018.08.031, 2018.

Cirino, G. G., Souza, R. A. F., Adams, D. K., and Artaxo, P.: The effect of atmospheric aerosol particles and clouds on net ecosystem exchange in the Amazon, Atmos. Chem. Phys., 14, 6523-6543, https://doi.org/10.5194/acp-14-6523-2014, 2014.

Cosgrove, B. A., Lohmann, D., Kenneth, M. E., Houser, P. R., Wood, E. F., Schaake, J. C., Robock, A., Marshall, C., Sheffield, J., Duan, Q., Lifeng, L., Higgins, W. R., Pinker, R. T., Tarpley, D. J., and J., M.: Real-time and retrospective forcing in the North American Land Data Assimilation System (NLDAS) project, J. Geophys. Res.-Atmos., 108, https://doi.org/10.1029/2002JD003118, 2003.

de Sá, S. S., Palm, B. B., Campuzano-Jost, P., Day, D. A., Hu, W., Isaacman-VanWertz, G., Yee, L. D., Brito, J., Carbone, S., Ribeiro, I. O., Cirino, G. G., Liu, Y. J., Thalman, R., Sedlacek, A., Funk, A., Schumacher, C., Shilling, J. E., Schneider, J., Artaxo, P., Goldstein, A. H., Souza, R. A. F., Wang, J., McKinney, K. A., Barbosa, H., Alexander, M. L., Jimenez, J. L., and Martin, S. T.: Urban influence on the concentration and composition of submicron particulate matter in central Amazonia, Atmos. Chem. Phys., 18, 12 185-12 206, https://doi.org/10.5194/acp-18-12185-2018, 2018.

de Sá, S. S., Rizzo, L. V., Palm, B. B., Campuzano-Jost, P., Day, D. A., Yee, L. D., Wernis, R., Isaacman-VanWertz, G., Brito, J., Carbone, S., Liu, Y. J., Sedlacek, A., Springston, S., Goldstein, A. H., Barbosa, H. M. J., Alexander, M. L., Artaxo, P., Jimenez, J. L., and Martin, S. T.: Contributions of biomass-burning, urban, and biogenic emissions to the concentrations and light-absorbing properties of particulate matter in central Amazonia during the dry season, Atmos. Chem. Phys., 19, 7973-8001, https://doi.org/10.5194/acp-19-7973-2019, 2019. dos Santos, M. J., Silva Dias, M. A. F., and Freitas, E. D.: Influence of local circulations on wind, moisture, and precipitation close to Manaus City, Amazon Region, Brazil, J. Geophys. Res.-Atmos., 119, 13 233-13 249, https://doi.org/10.1002/2014JD021969, 2014.

Draxler, R. R.: Demonstration of a global modeling methodology to determine the relative importance of local and long-distance sources, Atmos. Environ., 41, 776-789, https://doi.org/10.1016/j.atmosenv.2006.08.052, 2007.

Drinovec, L., Močnik, G., Zotter, P., Prévôt, A. S. H., Ruckstuhl, C., Coz, E., Rupakheti, M., Sciare, J., Müller, T., Wiedensohler, A., and Hansen, A. D. A.: The "dual-spot" Aethalometer: an improved measurement of aerosol black carbon with real-time loading compensation, Atmos. Meas. Tech., 8, 1965-1979, https://doi.org/10.5194/amt-8-1965-2015, 2015.

Dubovik, O. and King, M. D.: A flexible inversion algorithm for retrieval of aerosol optical properties from Sun and sky radiance measurements, J. Geophys. Res.-Atmos., 105, 20 673-20 696, 2000.

Easter, R. C., Ghan, S. J., Zhang, Y., Saylor, R. D., Chapman, E. G., Laulainen, N. S., Abdul-Razzak, H., Leung, L. R., Bian, X., and Zaveri, R. A.: MIRAGE: Model description and evaluation of aerosols and trace gases, J. Geophys. Res.-Atmos., 109, https://doi.org/10.1029/2004JD004571, 2004.

Fast, J. D., Gustafson, W. I., Easter, R. C., Zaveri, R. A., Barnard, J. C., Chapman, E. G., Grell, G. A., and Peckham, S. E.: Evolution of ozone, particulates, and aerosol direct radiative forcing in the vicinity of Houston using a fully coupled meteorology-chemistry-aerosol model, J. Geophys. Res.-Atmos., 111, D21305, https://doi.org/10.1029/2005JD006721, 2006.

Fisch, G., Marengo, J. A., and Nobre, C. A.: Uma revisão geral sobre o clima da Amazônia, Acta amazônica, 28, 101-101, 1998.

Forkel, R., Werhahn, J., Hansen, A. B., McKeen, S., Peckham, S., Grell, G., and Suppan, P.: Effect of aerosol-radiation feedback on regional air quality-A case study with WRF/Chem, Atmos. Environ., 53, 202-211, https://doi.org/10.1016/j.atmosenv.2011.10.009, 2012. 
Fraund, M., Pham, D. Q., Bonanno, D., Harder, T., Wang, B., Brito, J., de Sá, S. S., Carbone, S., China, S., Artaxo, P., Martin, S., Pöhlker, C., Andreae, M., Laskin, A., Gilles, M., and Moffet, R.: Elemental mixing state of aerosol particles collected in Central Amazonia during GoAmazon2014/15, Atmosphere, 8, 173, https://doi.org/10.3390/atmos8090173, 2017.

Graham, B., Guyon, P., Maenhaut, W., Taylor, P. E., Ebert, M., Matthias-Maser, S., Mayol-Bracero, O. L., Godoi, R. H. M., Artaxo, P., Meixner, F. X., Lima Moura, M. A., Eça D’Almeida Rocha, C. H., Van Grieken, R., Glovsky, M. M., Flagan, R. C., and Andreae, M. O.: Composition and diurnal variability of the natural Amazonian aerosol, J. Geophys. Res.-Atmos., 108 (D24), 4765, https://doi.org/10.1029/2003JD004049, 2003a.

Graham, B., Guyon, P., Taylor, P. E., Artaxo, P., Maenhaut, W., Glovsky, M. M., Flagan, R. C., and Andreae, M. O.: Organic compounds present in the natural Amazonian aerosol: Characterization by gas chromatography-mass spectrometry, J. Geophys. Res.-Atmos., 108 (D24), 4766, https://doi.org/10.1029/2003JD003990, 2003b.

Grell, G. A., Peckham, S. E., Schmitz, R., McKeen, S., Frost, G., Skamarock, W. C., and Eder, B.: Fully coupled "online” chemistry within the WRF model, Atmos. Environ., 39, 6957-6975, https://doi.org/10.1016/j.atmosenv.2005.04.027, http://dx.doi.org/10.1016/j.atmosenv. 2005.04.027, 2005.

Grell, G. A., Freitas, S. R., et al.: A scale and aerosol aware stochastic convective parameterization for weather and air quality modeling, Atmos. Chem. Phys, 14, 5233-5250, https://doi.org/10.5194/acp-14-5233-2014, 2014.

Gu, D., Guenther, A. B., Shilling, J. E., Yu, H., Huang, M., Zhao, C., Yang, Q., Martin, S. T., Artaxo, P., Kim, S., Seco, R., Stavrakou, T., Longo, K. M., Tóta, J., de Souza, R. A. F., Vega, O., Liu, Y., Shrivastava, M., Alves, E. G., Santos, F. C., Leng, G., and $\mathrm{Hu}, \mathrm{Z}$ : : Airborne observations reveal elevational gradient in tropical forest isoprene emissions, Nature communications, 8, 1-7, https://doi.org/10.1038/ncomms15541, 2017.

Guenther, A., Karl, T., Harley, P., Wiedinmyer, C., Palmer, P., and Geron, C.: Estimates of global terrestrial isoprene emissions using MEGAN (Model of Emissions of Gases and Aerosols from Nature), Atmos. Chem. Phys., 6, 3181-3210, https://doi.org/10.5194/acp-6-3181-2006, 2006.

Haywood, J. and Boucher, O.: Estimates of the direct and indirect radiative forcing due to tropospheric aerosols: A review, Rev. Geophys., 38 (4), 513-543, https://doi.org/10.1029/1999RG000078, 2000.

He, X., Li, C. C., Lau, A. K. H., Deng, Z. Z., Mao, J. T., Wang, M. H., and Liu, X. Y.: An intensive study of aerosol optical properties in Beijing urban area., Atmos. Chem. Phys., 9, 8903-8915.

Holanda, B. A., Pöhlker, M. L., Saturno, J., Sörgel, M., Ditas, J., Ditas, F., Wang, Q., Donth, T., Artaxo, P., Barbosa, H. M. J., Borrmann, S., Braga, R., Brito, J., Cheng, Y., Dollner, M., Kaiser, J. W., Klimach, T., Knote, C., Krüger, O. O., Fütterer, D., Lavrič, V. J., Ma, N., Machado, L. A. T., Ming, J., Morais, F. G., Paulsen, H., D., S., Schlager, H., Schneider, J., Su, H., Weinzierl, B., Walser, A., Wendisch, M., Ziereis, H., Zöger, M., Pöschl, U., Andreae, M. O., and Pöhlker, C.: Influx of African biomass burning aerosol during the Amazonian dry season through layered transatlantic transport of black carbon-rich smoke, Atmos. Chem. Phys., 20, 4757-4785, 2020.

Hong, S.-Y., Noh, Y., and Dudhia, J.: A new vertical diffusion package with an explicit treatment of entrainment processes, Monthly weather review, 134, 2318-2341, https://doi.org/10.1175/MWR3199.1, 2006.

Iacono, M. J., Delamere, J. S., Mlawer, E. J., Shephard, M. W., Clough, S. A., and Collins, W. D.: Radiative forcing by long-lived greenhouse gases: Calculations with the AER radiative transfer models, J. Geophys. Res.-Atmos., 113, D13103, https://doi.org/10.1029/2008JD009944, 2008.

Jiménez, P. A., Dudhia, J., González-Rouco, J. F., Navarro, J., Montávez, J. P., and García-Bustamante, E.: A revised scheme for the WRF surface layer formulation, Mon. Weather Rev., 140, 898-918, https://doi.org/10.1175/MWR-D-11-00056.1, 2012. 
Korras-Carraca, M., Hatzianastassiou, N., Matsoukas, C., Gkikas, A., and Papadimas, C.: The regime of aerosol asymmetry parameter over Atmos. Chem. Phys., 15, 13 113, 2015.

Kuhn, U., Ganzeveld, L., Thielmann, A., Dindorf, T., Schebeske, G., Welling, M., Sciare, J., Roberts, G., Meixner, F., Kesselmeier, J., et al.: Impact of Manaus City on the Amazon Green Ocean atmosphere: ozone production, precursor sensitivity and aerosol load, Atmos. Chem. Phys., 10, 9251-9282, https://doi.org/10.5194/acp-10-9251-2010, 2010.

Lim, S., Lee, M., Kim, S.-W., Yoon, S.-C., Lee, G., and Lee, Y. J.: Absorption and scattering properties of organic carbon versus sulfate dominant aerosols at Gosan climate observatory in Northeast Asia., Atmos. Chem. Phys., 14, https://doi.org/10.5194/acp-14-7781-2014, 2014.

Lu, L., Denning, A. S., da Silva-Dias, M. A., da Silva-Dias, P., Longo, M., Freitas, S. R., and Saatchi, S.: Mesoscale circulations and atmospheric CO2 variations in the Tapajós Region, Pará, Brazil, J. Geophys. Res.-Atmos., 110, 1-17, https://doi.org/10.1029/2004JD005757, 2005.

Madronich, S.: Photodissociation in the atmosphere: 1. Actinic flux and the effects of ground reflections and clouds, J. Geophys. Res.-Atmos., 92, 9740-9752, https://doi.org/10.1029/JD092iD08p09740, 1987.

Marengo, J. A., Nobre, C. A., and Culf, A. D.: Climatic impacts of "friagens" in forested and deforested areas of the Amazon basin, Journal of Applied Meteorology, 36, 1553-1566, https://doi.org/10.1175/1520-0450(1997)036<1553:CIOFIF>2.0.CO;2, 1997.

Marinho, R. R., Filizola Junior, N. P., and Cremon, É. H.: Analysis of Suspended Sediment in the Anavilhanas Archipelago, Rio Negro, Amazon Basin, Water, 12, 1073, https://doi.org/10.3390/w12041073, 2020.

Martin, S., Artaxo, P., Machado, L., Manzi, A., Souza, R., Schumacher, C., Wang, J., Andreae, M., Barbosa, H., Fan, J., et al.: Introduction: observations and modeling of the Green Ocean Amazon (GoAmazon2014/5), Atmos. Chem. Phys., 16, https://doi.org/10.5194/acp-164785-2016, 2016.

Martin, S. T., Andreae, M. O., Althausen, D., Artaxo, P., Baars, H., Borrmann, S. H., Chen, Q., Farmer, D. K., Guenther, A. B., Gunthe, S. S., et al.: An overview of the Amazonian aerosol characterization experiment 2008 (AMAZE-08), Volume 10, Número 23, Pags. 11415-11438, https://doi.org/10.5194/acp-10-11415-2010, 2010.

Martin, S. T., Artaxo, P., Machado, L., Manzi, A. O., Souza, R., Schumacher, C., Wang, J., Biscaro, T., Brito, J., Calheiros, A., et al.: The Green Ocean Amazon experiment (GoAmazon2014/5) observes pollution affecting gases, aerosols, clouds, and rainfall over the rain forest, Bulletin of the American Meteorological Society, 98, 981-997, https://doi.org/10.1175/BAMS-D-15-00221.1, 2017.

Martins, L. D., Andrade, M. F., Freitas, E. D., Pretto, A., Gatti, L. V., Albuquerque, É. L., Tomaz, E., Guardani, M. L., Martins, M. H., and Junior, O. M.: Emission factors for gas-powered vehicles traveling through road tunnels in São Paulo, Brazil, Environmental science \& technology, 40, 6722-6729, 2006.

Medeiros, A. S., Calderaro, G., Guimarães, P. C., Magalhaes, M. R., Morais, M. V., Rafee, S. A., Ribeiro, I. O., Andreoli, R. V., Martins, J. A., Martins, L. D., et al.: Power plant fuel switching and air quality in a tropical, forested environment, Atmos. Chem. Phys. (Online), 17, https://doi.org/10.5194/acp-2016-1113, 2017.

Mie, G.: Beiträge zur Optik trüber Medien, speziell kolloidaler Metallösungen, Annalen der physik, 330, 377-445, 1908.

Miranda, R. M. and Andrade, M. F.: Physicochemical characteristics of atmospheric aerosol during winter in the São Paulo Metropolitan area in Brazil, Atmos. Environ, 39, 6188-6193, 2005. 

term study on coarse mode aerosols in the Amazon rain forest with the frequent intrusion of Saharan dust plumes, Atmos. Chem. Phys., 18, 10055-10088, 2018.

Morrison, H., Thompson, G., and Tatarskii, V.: Impact of cloud microphysics on the development of trailing stratiform precipitation in a simulated squall line: Comparison of one-and two-moment schemes, Monthly weather review, 137, 991-1007, https://doi.org/10.1175/2008MWR2556.1, 2009.

Müller, T., Henzing, J., Leeuw, G. d., Wiedensohler, A., Alastuey, A., Angelov, H., Bizjak, M., Collaud Coen, M., Engström, J., Gruening, C., et al.: Characterization and intercomparison of aerosol absorption photometers: result of two intercomparison workshops, https://doi.org/10.5194/amt-4-245-2011, 2011.

Murphy, B. N. and Pandis, S. N.: Simulating the formation of semivolatile primary and secondary organic aerosol in a regional chemical transport model, Environmental science \& technology, 43, 4722-4728, https://doi.org/10.1021/es803168a, 2009.

Nobre, C. A., Obregón, G. O., , J. A., Fu, R., and Poveda, G.: Characteristics of Amazonian climate: Main features, Amazonia and Global Change, edited by: Keller, M., Bustamante, M., Gash, J., Silva Dias, P., Geophys. Mon. Ser, 186, 149-162, https://doi.org/10.1029/2002JD002911, 2009.

Palacios, R. d. S., Romera, K. S., Curado, L. F., Banga, N. M., Rothmund, L. D., Sallo, F. d. S., Morais, D., Santos, A. C., Moraes, T. J., Morais, F. G., et al.: Long term analysis of optical and radiative properties of aerosols in the Amazon Basin, Aerosol and Air Quality Research, https://doi.org/10.4209/aaqr.2019.04.0189, 2020.

Palm, B. B., Day, D. A., Jimenez, J. L., et al.: CCN activity and organic hygroscopicity of aerosols downwind of an urban region in central Amazonia: seasonal and diel variations and impact of anthropogenic emissions, Atmos. Chem. Phys., 17, https://doi.org/10.5194/acp-1711779-2017, 2017.

Palm, B. B., de Sá, S. S., Day, D. A., Campuzano-Jost, P., Hu, W., Seco, R., Sjostedt, S. J., Park, J.-H., Guenther, A. B., Kim, S., et al.: Secondary organic aerosol formation from ambient air in an oxidation flow reactor in central Amazonia, Atmos. Chem. Phys. Discussions (Online), 18, https://doi.org/10.5194/acp-18-467-2018, 2018.

Papiez, M. R., Potosnak, M. J., Goliff, W. S., Guenther, A. B., Matsunaga, S. N., and Stockwell, W. R.: The impacts of reactive terpene emissions from plants on air quality in Las Vegas, Nevada, Atmos. Environ, 43, 4109-4123, https://doi.org/10.1016/j.atmosenv.2009.05.048, 2009.

Pereira Oliveira, A. and Fitzjarrald, D. R.: The Amazon river breeze and the local boundary layer: I. Observations, Boundary-Layer Meteorology, 63, 141-162, https://doi.org/10.1007/BF00705380, 1993.

Pöhlker, C., Walter, D., Paulsen, H., Könemann, T., Rodriguez-Caballero, E., Moran-Zuloaga, D., Brito, J., Carbone, S., Degrendele, C., Després, V. R., Ditas, F., Holanda, B. A., Kaiser, J. W., Lammel, G., Lavrič, J. V., Ming, J., Pickersgill, D., Pöhlker, M. L., Saturno, J., Sörgel, M., Wang, Q., Weber, B., Wolff, S., Artaxo, P., Pöschl, U., and Andreae, M. O.: Land cover and its transformation in the backward trajectory footprint region of the Amazon Tall Tower Observatory, Atmos. Chem. Phys., 19, 8425-8470, https://doi.org/10.5194/acp-198425-2019, 2019.

Pöhlker, M. L., Ditas, F., Saturno, J., Klimach, T., Hrabe de Angelis, I., Araùjo, A., Brito, J., Carbone, S., Cheng, Y., Chi, X., Ditz, R., Gunthe, S. S., Kandler, K., Kesselmeier, J., Könemann, T., Lavrič, J. V., Martin, S. T., Mikhailov, E., Moran-Zuloaga, D., Rizzo, L. V., Rose, D., Su, H., Thalman, R., Walter, D., Wang, J., Wolff, S., Barbosa, H. M. J., Artaxo, P., Andreae, M. O., Pöschl, U., and Pöhlker, C.: Long-term observations of cloud condensation nuclei in the Amazon rain forest-Part 2: Variability and characteristic differences under 
https://doi.org/10.5194/acp-2020-1002

Preprint. Discussion started: 19 November 2020

(c) Author(s) 2020. CC BY 4.0 License.
Atmospheric

Chemistry

and Physics

Discussions

near-pristine, biomass burning, and long-range transport conditions, Atmos. Chem. Phys. Discuss., https://doi.org/10.5194/acp-2017-847, 2018.

Rafee, S. A. A., Martins, L. D., Kawashima, A. B., Almeida, D. S., Morais, M. V., Souza, R. V., Oliveira, M. B., Souza, R. A., Medeiros,

A. S., Urbina, V., et al.: Contributions of mobile, stationary and biogenic sources to air pollution in the Amazon rainforest: a numerical study with the WRF-Chem model, Atmos. Chem. Phys., 17, 7977, https://doi.org/10.5194/acp-17-7977-2017, 2017.

Ramachandran, S. and Rajesh, T.: Black carbon aerosol mass concentrations over Ahmedabad, an urban location in western India: comparison with urban sites in Asia, Europe, Canada, and the United States, J. Geophys. Res.-Atmos., 112, https://doi.org/10.1029/2006JD007488, 2007.

Rap, A., Spracklen, D., Mercado, L., Reddington, C., Haywood, J., Ellis, R., Phillips, O., Artaxo, P., Bonal, D., Restrepo Coupe, N., et al.: Fires increase Amazon forest productivity through increases in diffuse radiation, Geophysical Research Letters, 42, 4654-4662, https://doi.org/10.1002/2015GL063719, 2015.

Rizzo, L. V., Correia, A. L., Artaxo, P., Procópio, A. S., and Andreae, M. O.: Spectral dependence of aerosol light absorption over the Amazon Basin, Atmos. Chem. Phys., 11, 8899, https://doi.org/10.5194/acp-11-8899-2011, 2011.

Rizzo, L. V., Artaxo, P., Mueller, T., Wiedensohler, A., Paixao, M., Cirino, G. G., Arana, A., Swietlicki, E., Roldin, P., Fors, E. O., et al.: Long term measurements of aerosol optical properties at a primary forest site in Amazonia, https://doi.org/10.5194/acp-13-2391-2013, 2013.

Rizzolo, J. A., Barbosa, C. G., Borillo, G. C., Godoi, A. F., Souza, R. A., Andreoli, R. V., Manzi, A. O., Sá, M. O., Alves, E. G., Pöhlker, C., et al.: Soluble iron nutrients in Saharan dust over the central Amazon rainforest, Atmos. Chem. Phys., 17, 2673-2687, https://doi.org/10.5194/acp-17-2673-2017, 2017.

Romano, S., Perrone, M. R., Pavese, G., Esposito, F., and Calvello, M.: Optical properties of PM2. 5 particles: Results from a monitoring campaign in southeastern Italy, Atmos. Environ, 203, 35-47, https://doi.org/10.1016/j.atmosenv.2019.01.037, 2019.

Russell, P., Bergstrom, R., Shinozuka, Y., Clarke, A., DeCarlo, P., Jimenez, J., Livingston, J., Redemann, J., Dubovik, O., and Strawa, A.: Absorption Angstrom Exponent in AERONET and related data as an indicator of aerosol composition, Atmos. Chem. Phys., 10, 11551169, https://doi.org/10.5194/acp-10-1155, 2010.

Sánchez-Ccoyllo, O. R., Ynoue, R. Y., Martins, L. D., Astolfo, R., Miranda, R. M., Freitas, E. D., Borges, A. S., Fornaro, A., Freitas, H., Moreira, A., et al.: Vehicular particulate matter emissions in road tunnels in Sao Paulo, Brazil, Environmental monitoring and assessment, 149, 241-249, https://doi.org/10.1007/s10661- 008-0198-5, 2009.

Sarwar, G., Fahey, K., Napelenok, S., Roselle, S., and Mathur, R.: Examining the impact of CMAQ model updates on aerosol sulfate predictions, in: The 10th Annual CMAS Models-3 User's Conference, October, Chapel Hill, NC, 2011.

Saturno, J., Holanda, B. A., Pöhlker, C., Ditas, F., Wang, Q., Moran-Zuloaga, D., Brito, J., Carbone, S., Cheng, Y., Chi, X., et al.: Black and brown carbon over central Amazonia: Long-term aerosol measurements at the ATTO site, Atmos. Chem. Phys., 18, 12 817-12 843, https://doi.org/10.5194/acp-18-12817-2018, 2018.

Schultz, M. G., Schröder, S., Lyapina, O., Cooper, O. R., Galbally, I., Petropavlovskikh, I., Von Schneidemesser, E., Tanimoto, H., Elshorbany, Y., Naja, M., et al.: Tropospheric Ozone Assessment Report: Database and metrics data of global surface ozone observations, Elementa: Science of the Anthropocene, 5, https://doi.org/10.1525/elementa.244, 2017.

Seinfeld, J. H. and Pandis, S. N.: Atmos. Chem. Phys.: from air pollution to climate change, John Wiley \& Sons, 2016. 
https://doi.org/10.5194/acp-2020-1002

Preprint. Discussion started: 19 November 2020

(C) Author(s) 2020. CC BY 4.0 License.
Atmospheric

Chemistry

and Physics

Discussions

Shilling, J. E., Pekour, M. S., Fortner, E. C., Artaxo, P., Sá, S. d., Hubbe, J. M., Longo, K. M., Machado, L. A., Martin, S. T., Springston, S. R., et al.: Aircraft observations of the chemical composition and aging of aerosol in the Manaus urban plume during GoAmazon 2014/5, Atmos. Chem. Phys., 18, 10 773-10 797, https://doi.org/10.5194/acp-18-10773-2018, 2018.

Shrivastava, M., Andreae, M. O., Artaxo, P., Barbosa, H. M., Berg, L. K., Brito, J., Ching, J., Easter, R. C., Fan, J., Fast, J. D., et al: Urban pollution greatly enhances formation of natural aerosols over the Amazon rainforest, Nature communications, 10, 1-12, https://doi.org/10.5194/acp-17-7977-2017, 2019.

Silva Dias, M. A. F., Silva Dias, P. L., Longo, M., Fitzjarrald, D. R., and Denning, A. S.: River breeze circulation in eastern Amazonia: observations and modelling results, Theor. Appl. Climatol., 78, 111-121, https://doi.org/10.1007/s00704-004-0047-6, 2004.

Stein, A. F., Isakov, V., Godowitch, J., and Draxler, R. R.: A hybrid modeling approach to resolve pollutant concentrations in an urban area, Atmos. Environ., 41, 9410-9426, https://doi.org/10.1016/j.atmosenv.2007.09.004, 2007.

Tewari, M., Chen, F., Wang, W., Dudhia, J., LeMone, M., Mitchell, K., Ek, M., Gayno, G., Wegiel, J., and Cuenca, R.: Implementation and verification of the unified NOAH land surface model in the WRF model, in: 20th conference on weather analysis and forecasting/16th conference on numerical weather prediction, vol. 1115, pp. 2165-2170, American Meteorological Society Seattle, WA, 2004.

Trebs, I., Mayol-Bracero, O. L., Pauliquevis, T., Kuhn, U., Sander, R., Ganzeveld, L., Meixner, F. X., Kesselmeier, J., Artaxo, P., and Andreae, M. O.: Impact of the Manaus urban plume on trace gas mixing ratios near the surface in the Amazon Basin: Implications for the NO-NO2-O3 photostationary state and peroxy radical levels, J. Geophys. Res.-Atmos., 117, https://doi.org/10.1029/2011JD016386, 2012.

Vara-Vela, A., de Fátima Andrade, M., Zhang, Y., Kumar, P., Ynoue, R. Y., Souto-Oliveira, C. E., da Silva Lopes, F. J., and Landulfo, E.: Modeling of Atmospheric Aerosol Properties in the São Paulo Metropolitan Area: Impact of Biomass Burning, J. Geophys. Res.-Atmos., 123, 9935-9956, https://doi.org/10.1029/2018JD028768, 2018.

Wang, K., Zhang, Y., Yahya, K., Wu, S.-Y., and Grell, G.: Implementation and initial application of new chemistry-aerosol options in WRF/Chem for simulating secondary organic aerosols and aerosol indirect effects for regional air quality, Atmos. Environ, 115, 716-732, 2015.

Yáñez-Serrano, A. M., Bourtsoukidis, E., Alves, E. G., Bauwens, M., Stavrakou, T., Llusià, J., Filella, I., Guenther, A., Williams, J., Artaxo, P., et al.: Amazonian biogenic volatile organic compounds under global change, Global Change Biology, https://doi.org/10.1111/gcb.15185, 2020.

Ynoue, R. Y. and Andrade, M. F.: Size-resolved mass balance of aerosol particles over the São Paulo metropolitan area of Brazil, Aerosol Science and Technology, 38, 52-62, 2004.

Zhang, Y., Wen, X.-Y., and Jang, C.: Simulating chemistry-aerosol-cloud-radiation-climate feedbacks over the continental US using the online-coupled Weather Research Forecasting Model with chemistry (WRF/Chem), Atmos. Environ, 44, 3568-3582, 2010. 